INTEGRATING WATER RESOURCES MODELLING AND REMOTE SENSING IN KARKHEH RIVER BASIN, IRAN 
Examining committee

Prof.dr. Z. Su

Prof.dr.ir. A.Y. Hoekstra

Prof.dr.ir. R. Uijlenhoet

Prof.dr.ir. P. Reggiani
University of Twente, ITC University of Twente, CTW Wageningen UR

University of Siegen

ITC dissertation number 261

ITC, P.O. Box 217, 7500 AA Enschede, The Netherlands

ISBN 978-90-365-3794-0

DOI $10.3990 / 9789036537940$

Cover designed by Job Duim

Printed by ITC Printing Department

Copyright (c) 2014 by Lal P. Muthuwatta

\section{UNIVERSITY OF TWENTE.}

DU FACULTY OF GEO-INFORMATION SCIENCE AND EARTH OBSERVATION 


\title{
INTEGRATING WATER RESOURCES MODELLING AND REMOTE SENSING IN KARKHEH RIVER \\ BASIN, IRAN
}

\author{
DISSERTATION
}

to obtain

the degree of doctor at the University of Twente, on the authority of the rector magnificus, prof.dr. H. Brinksma, on account of the decision of the graduation committee,

to be publicly defended

on Wednesday 26 November 2014 at $14.45 \mathrm{hrs}$

by

Lal Perakum Muthuwatta

Borne on 18 March 1965

In Kandy, Sri Lanka 
This thesis is approved by

Prof.dr.ing. W. Verhoef, promoter

Prof.dr.ir. M.G. Bos, co-promoter

Dr.ing. T.H.M. Rientjes, co-promoter 
This work is dedicated to my wife Ishika 



\section{Acknowledgements}

This thesis work was made possible with the support of many people and institutions.

I would like to thank my promoter Prof. M.G. Bos for his guidance and support. He rigorously reviewed the content of the thesis. Without his critical readings and suggestions there could not have been any guarantee to the academic qualification of this thesis.

I'm greatly indebted to Dr. T.H.M. Rientjes for his guidance and encouragement throughout the period of this $\mathrm{PhD}$. I appreciate his constructive criticism, advice and all that he has taught me. I exceedingly benefited from his understanding of hydrological modeling and uncertainty assessment, critical thinking and technical writing ability.

I gratefully acknowledge the financial support I received from the International Water Management Institute (IWMI) and the Faculty of GeoInformation Science and Earth Observation, University of Twente (ITC). I also thank IWMI for granting me study leave to enable me to pursue this research.

Thankful acknowledgements go to the administrative staff of education affairs, research coordination, financial and economic affairs divisions at ITC, particularly Theresa, Bettine Geerdink, Marie Chantal, Loes, Carla, Marion for the help provided in administrative matters. Many thanks are due to Tina and Anke in the secretarial section of the water resources department. I also greatly acknowledge the support of the computer support staff, especially Gerrit, Aiko and Harold from the ICT center.

Many thanks go to the staff in the division of water resources at ITC for the great assistance I received from them. Of special mention are Dr. R. Becht, Dr. A.S. M. Gieske, MSc. G.N. Parodi and Dr. C.M.M. Mannaerts. My appreciation is incomplete if I do not mention the support and help extended to me by Prof. A.M.J. Meijerink during this work.

Insights and support from Dr. Mobin-ud-Din Ahmad and Dr. M.J. Booij during the writing of articles are greatly appreciated.

I am extremely grateful to Mala for setting aside her valuable time to read endless draft chapters of my thesis and correcting language errors. I also want to thank Aditya and Mahen for their support during the writing phase of this thesis. 
I would like to express my sincere gratitude to Palitha, Yann and SMB for their endless cooperation during this study. The support provided by David Van Eyck, Capacity Building Officer at IWMI, is also gratefully acknowledged.

Finally, I would like to express my deepest appreciation to my family members. Among them my most profound gratitude goes to my wife Ishika for patiently taking care of the homefront and looking after our two children throughout my long absences. 


\section{Abstract}

Muthuwatta, L.P., 2014. Integrating Water Resources Modelling and Remote Sensing in Karkheh River Basin, Iran. Doctoral thesis, University of Twente, Enschede, the Netherlands.

In many river basins lack of data often hampers the judicious management of water resources. In this study remote sensing images and a hydrological model were used concurrently to help fill this gap. The Surface Energy Balance System (SEBS) was used to estimate spatial and temporal variability of actual evapotranspiration ( $E T_{a}$ ) for the various land covers in the basin. $A$ semi-distributed Hydrologiska Byråns Vattenbalansavdeling (HBV) rainfallrunoff model is selected to simulate streamflow at sub-basin outlets. This study was conducted in the Karkheh River Basin, located in southwestern Iran.

For the estimation of $E T_{a}, 19$ Moderate Resolution Imaging Spectroradiometer (MODIS) images covering the basin from November 2002 to October 2003 were used. The results show that about $16,680 \times 10^{6} \mathrm{~m}^{3}$ of water evapotranspired. A geo-statistical approach was used to estimate precipitation for the same period and accumulatedto $18,507 \times 10^{6} \mathrm{~m}^{3}$. As such, these estimations showed that about $90 \%$ of the water received from precipitation evapotranspired, annual outflow from the basin is less than $8 \%$ of the total precipitation and about $2 \%$ could flow to the sink where it is unaccounted for. This indicates that the basin is water scarce. The water consumed by various land covers shows marked variations. Rainfed areas consume about $3,720 \times 10^{6} \mathrm{~m}^{3} \mathrm{y}^{-1}$ of water whereas irrigated areas consume about $2,680 \times 10^{6} \mathrm{~m}^{3} \mathrm{y}^{-1}$. Total water consumption by forest areas is about $2,070 \times 10^{6} \mathrm{~m}^{3} \mathrm{y}^{-1}$, which is mainly in the middle of the basin. Rangelands, which are scattered mainly over the Upper Karkheh, consume about 3,360 $\times$ $10^{6} \mathrm{~m}^{3} \mathrm{y}^{-1}$.

A method is presented in this study to estimate daily $E T_{a}$ time series by using gap filling procedure for the missing satellite data. Comparison of daily $E T_{a}$ values of SEBS and the new method shows that Root-Mean-Square Error (RMSE) ranges from $0.31-0.53 \mathrm{~mm} \mathrm{~d}^{-1}$. Further, comparison of total $E T_{a}$ at sub-catchment scale using two methods for the one-year period shows less than $10 \%$ difference for all sub-catchments.

The HBV model serves for multi-variable calibration using streamflow data and $E T_{a}$ time series estimates based on remote sensing data. Single variable calibration showed that the model simulates the streamflow well but fails to simulate satellite based $E T_{a}$. Results by multi-variable calibration showed that 
a relatively small deterioration in performance in simulation streamflow significantly improves the simulation of the $E T_{a}$ and vice versa.

Due to the significant role of the basin in the wheat production for the country, strategies were proposed to sustainably increase wheat production in the Karkheh Basin, without impacting the basin water balance, in order to match the 2025 production targets. Indicators such as crop water productivity (CWP) and relative evapotranspiration $\left(E T_{a} / E T_{p}\right)$ were used to analyze water stress and productivity. CWP for wheat ranges from $0.5-1.63$ $\mathrm{kg} \mathrm{m}^{-3}$ in irrigated areas to $0.37-0.62 \mathrm{~kg} \mathrm{~m}^{-3}$ in rainfed areas. Results suggest that irrigated wheat is most efficiently produced when $E T_{a} / E T_{p}$ ranges between 0.67 and 1.0. Land suitability by topographic analysis and the current level of water consumption revealed that the rainfed wheat area can be expanded by 71,000 ha. This can be achieved without increasing water stress in the basin if this increase comes from converting the rangeland. Results from this study indicate that, even if managed properly, available surface water resources are only sufficient to meet about $85 \%$ of the wheat production target in the year 2025.

Keywords: Satellite remote sensing, rainfall-runoff modelling HBV, Karkheh, multi-variable model calibration, evapotranspiration SEBS, crop water productivity, relative evapotranspiration. 


\section{Contents}

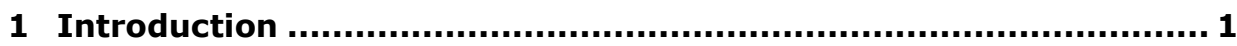

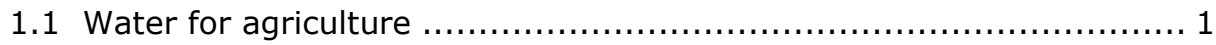

1.2 Crop production and water resources ..................................... 3

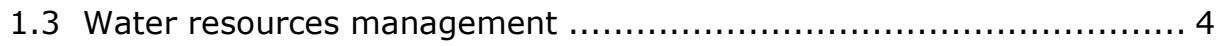

1.4 Freshwater resources and demands in Iran............................... 5

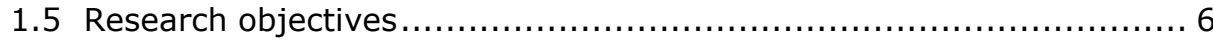

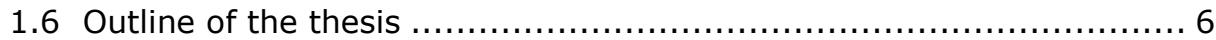

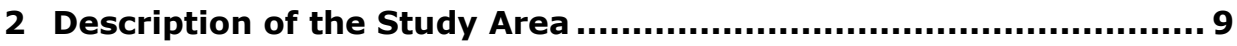

2.1 Geographic and climatic settings ......................................... 9

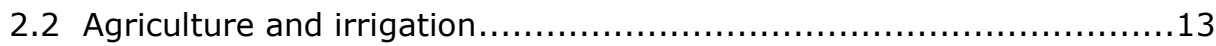

2.3 Water resources and demands ........................................... 16

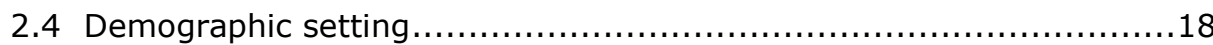

2.5 Water management ........................................................ 19

2.6 Data availability ......................................................... 19

3 Remote Sensing and Hydrological Modelling in Water Resources

Management: A Literature Review ................................................ 21

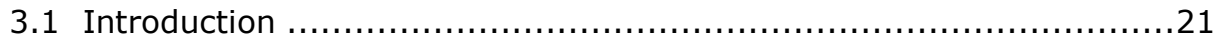

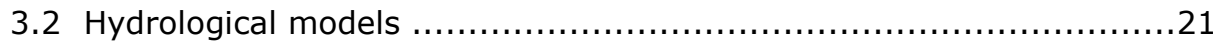

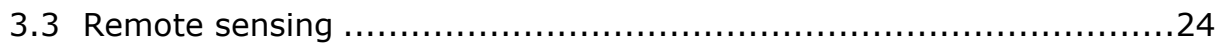

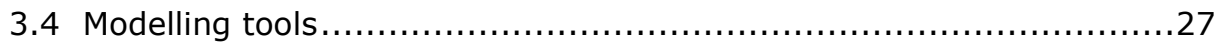

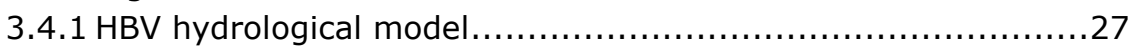

3.4.2 Surface Energy Balance System (SEBS) .......................... 31

4 Assessment of Water Availability and Consumption ..................... 37

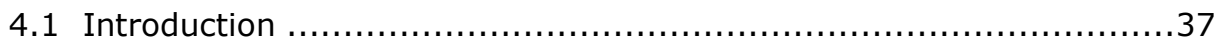

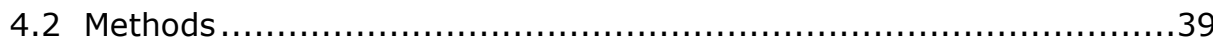

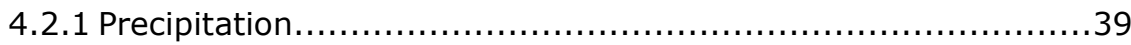

4.2.2 Actual evapotranspiration ........................................40

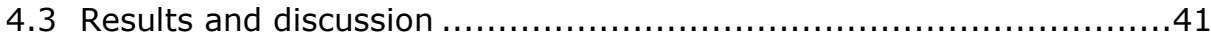

4.3.1 Precipitation............................................................ 41

4.3.2 Satellite based actual evapotranspiration............................45

4.3.3 Actual evapotranspiration for specific land uses .....................48

4.4 Comparison of different methods to estimate actual

evapotranspiration ........................................................... 51

4.5 Water Balance ................................................................ 54

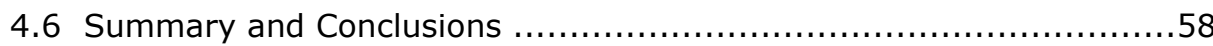

5 Multi-variable Calibration of a Semi-distributed Hydrological Model Using streamflow Data and Satellite-Based Evapotranspiration....... 61

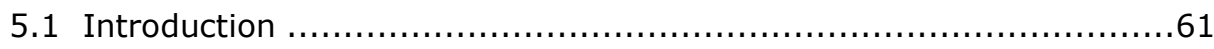

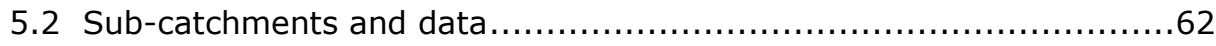

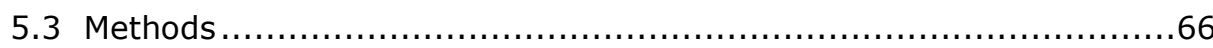

5.3.1 Time series of SEBS-based actual evapotranspiration.............66

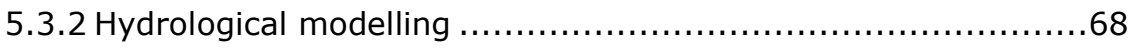




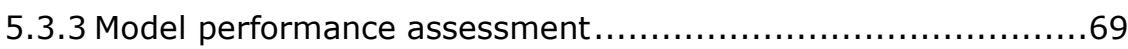

5.3.4 Parameter estimation ................................................ 70

5.4 Results and Discussion...................................................... 73

5.4.1 Time series of actual evapotranspiration............................73

5.4.2 Calibration on Qs (Case 1) ............................................. 74

5.4.3 Calibration on actual evapotranspiration (Case 2) .................76

5.4.4 Calibration on straemflow and actual evapotranspiration

(Case 3) ........................................................... 78

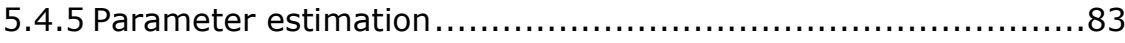

5.4.6 Impact of weights on model performance ........................... 85

5.4 .7 Uncertainty of measurement data................................... 86

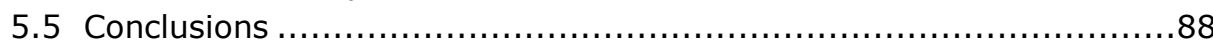

6 Strategies to increase wheat production in the water-scarce

Karkheh River Basin, Iran ........................................................... 91

6.1 Introduction ............................................................... 91

6.2 Land use soils and water consumption of the Karkheh River Basin.....92

6.2.1 Land use and soils .....................................................92

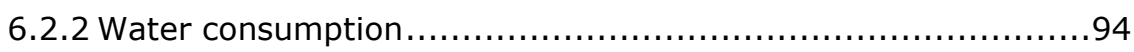

6.3 Crop water productivity and relative evapotranspiration .................95

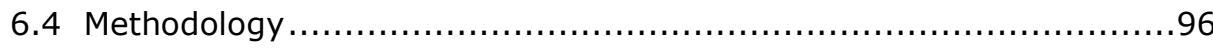

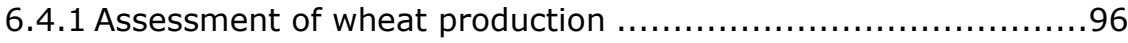

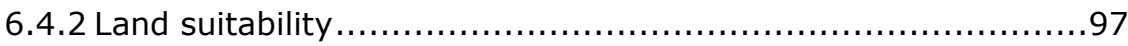

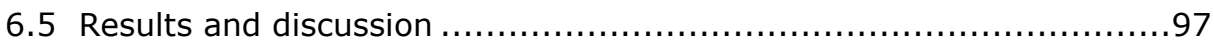

6.5.1 Production of irrigated wheat ...................................... 97

6.5.2 Production of rainfed wheat ....................................... 101

6.5.3 Fertilizer application \& seed rates for irrigated wheat areas in different sub-basins ................................................ 102

6.5.4 Crop production function ........................................ 102

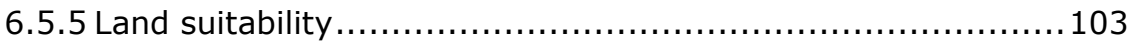

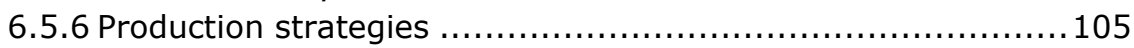

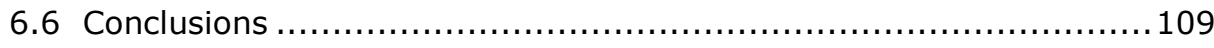

7 Conclusions ........................................................................... 111

7.1 Estimation of Actual Evapotranspiration .................................. 111

7.2 Quantification of water availability ....................................... 111

7.3 Calibration and parameterization of a hydrological model ...............112

7.4 Increasing wheat production and ensuring downstream water availability ................................................................. 112

7.5 Implications for Iran's agriculture policy ................................ 113

7.6 Recommendations and future directions ............................... 114

References ........................................................................... 117

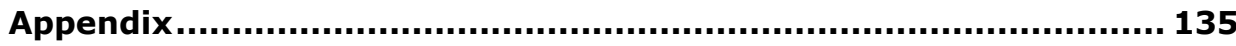




\section{List of Figures}

Figure 1.1 Trends in global water consumption by sector (Chartres and Sood, 2013).

Figure 2.1. Karkheh River Basin showing Upper and Lower Karkheh and their respective sub-catchments.

Figure 2.2 Digital elevation model with the river network, flow gauges and meteorological stations of the Karkheh River Basin

(meteorological station names are given in Table 2.1). (Acquired from http://srtm.csi.cgiar.org/) ..............................11

Figure 2.3 Average annual precipitation at Kermanshah in the Upper

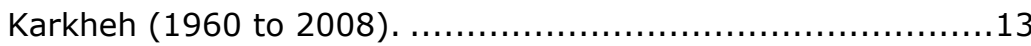

Figure 2.4 Monthly precipitation and maximum temperature from two stations: Kermanshah (Latitude: $34^{\circ} 21^{\prime} \mathrm{N}$, Longitude: $47^{\circ} 9^{\prime} \mathrm{E}$ ) in Upper Karkheh and Bostan (Latitude: $31^{\circ} 43^{\prime} \mathrm{N}$, Longitude: $48^{\circ} 0^{\prime} \mathrm{E}$ ) in Lower Karkheh.

Figure 2.5 Land use in the Karkheh River Basin. ..........................14

Figure 2.6 Extent of agricultural land in the Karkheh River Basin (1983 to 2004) (Source: Marjanizadeh, 2008)...........................15

Figure 2.7 Drainage ratios for different sub-basins in the Upper Karkheh

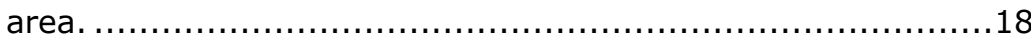

Figure 3.1 Flow chart showing the procedure to manual model calibration (adapted from Rientjes, 2004) .............................23

Figure 3.2 Schematization of the HBV-96 model structure (based on Lindström et al., 1997)........................................28

Figure 3.3 Runoff response to the increment of rainfall. ....................29

Figure 3.4 Relationship between actual and potential evapotranspiration..30

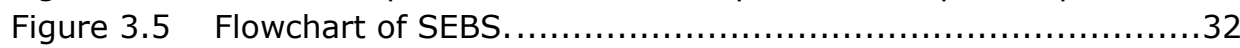

Figure 4.1 Scatter plot of annual precipitation over elevation..............41

Figure 4.2 Spatial distribution of annual precipitation in the Karkheh River Basin from November 2002 to October 2003...................43

Figure 4.3 Spatial distribution of annual actual evapotranspiration $\left(E T_{a}\right)$ in the Karkheh Basin, November 2002 to October $2003 \ldots \ldots \ldots \ldots . . . .46$

Figure 4.4 Frequency distribution of the annual actual evapotranspiration $\left(E T_{a}\right)$ for the Upper and Lower Karkheh. .........................48

Figure 4.5 Actual evapotranspiration for specific land uses in the Karkheh

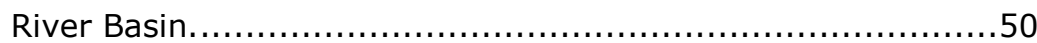

Figure 4.6 Comparison of $E T_{a}$ estimated by SEBS at the swamp with the Priestley \& Taylor $E T_{0}$ calculated from the meteorological data collected at the Bostan station (Latitude: $31^{\circ} 43^{\prime} \mathrm{N}$, Longitude: $48^{\circ} 0^{\prime} \mathrm{E}$ ) in the Lower Karkheh Basin.

Figure 4.7 Comparison of $E T_{a}$ estimated by SEBS with $E T_{p}$ calculated from meteorological data collected at Kangavar station (Latitude: $34^{\circ}$ 
30 'N, Longitude: $47^{\circ} 59^{\prime} \mathrm{E}$ ), and literature-based $K_{c}$ values for a

wheat site in the Upper Karkheh Basin. .......................52

Figure 4.8 Comparison of $E T_{a}$ estimated by SEBS with $E T_{p}$ calculated from meteorological data collected at Ahvaz station (Latitude: $31^{\circ}$ $20^{\prime} \mathrm{N}$, Longitude: $48^{\circ} 41^{\prime} \mathrm{E}$ ), and literature-based $\mathrm{K}_{\mathrm{c}}$ values for a wheat site in the Lower Karkheh Basin.

Figure 5.1 Location of sub-catchments and the streamflow gauging stations

used for modeling.

Figure 5.2 Evolution of $Y$ against run number for Qs and $E T_{a}$ (Doab subcatchment).

Figure 5.3 Constructed time series of SEBS-ET for Doab sub-catchment. Estimates used for validation are indicated by the $\Delta$-symbol....73

Figure 5.4 Comparison of observed and simulated daily Qs for Doab subcatchment for all three cases................................... 75

Figure 5.5 Comparison of HBV-ETa to satellite-based $E T_{a}$ for Doab subcatchment for all three cases....................................76

Figure 5.6 Cumulative distribution of HBV-based $E T_{a}$ and SEBS-based $E T_{a}$ from for Doab sub-catchment for all three cases. .81

Figure 5.7 Cumulative distribution of Qs for Doab sub-catchment for all three cases.

Figure 5.8 Cumulative distributions of daily Qs and $E T_{a}$ for Doab subcatchment for all three cases.

Figure 5.9 Box-whisker plots of parameters standardized by the prior range used for Monte Carlo Simulations (Doab sub-catchment). 85

Figure 5.10 Variation of model performances $\left(Y_{\text {TOT }}\right)$ for different weights in Doab sub-catchment.

Figure 6.1 Monthly variation of $E T_{a}$ for two pixels, where single pixels exclusively represent production areas of irrigated or rainfed wheat (adapted from Muthuwatta et al., 2010).

Figure 6.2 Relationships between yield and actual evapotranspiration/potential evapotranspiration $\left(E T_{a} / E T_{p}\right)$ for irrigated wheat in the Gamasiab sub-basin.

Figure 6.3 Relationship between crop water productivity (CWP) and actual crop evapotranspiration/potential evapotranspiration $\left(E T_{a} / E T_{p}\right)$ for irrigated wheat in the Gamasiab sub-basin.

Figure 6.4 Rangeland area with $E T_{a} / E T_{p}$ greater than 0.5 for respective slope classes. 


\section{List of Tables}

Table 2.1 Names of the meteorological stations presented in Figure 2.2...12

Table 2.2 Growing periods for different crops in the Upper and Lower

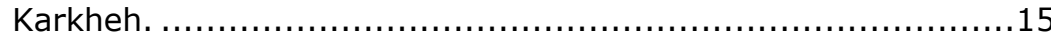

Table 2.3 Mean annual streamflow data (1961 to 2001) for respective sub-

basins $\left(10^{6} \times \mathrm{m}^{3}\right)$ (Source: Masih et al., 2009)....................16

Table 2.4 Estimated annual groundwater abstraction $\left(10^{6} \times \mathrm{m}^{3}\right)$ from the major sub-basins in 2004 (Source: Iranian Energy Ministry).....17

Table 2.5 Current and planned water allocations for different sectors in the basin (Source: Masih et al., 2009)..................................17

Table 2.6 Population trends in sub-basins of the Karkheh River Basin (Source: Marjanizadeh, 2008)......................................19

Table 2.7 Meteorological and streamflow data used in this study............20

Table 2.8 Acquisition dates of MODIS-TERRA images for the study period (Source: http://ladsweb.nascom.nasa.gov/).....................20

Table 4.1 Variation of monthly precipitation volumes $\left(10^{6} \times \mathrm{m}^{3}\right)$ for respective sub-catchments for the period November 2002 to October 2003.

Table 4.2 Variation of actual monthly evapotranspiration $\left(10^{6} \times \mathrm{m}^{3}\right)$ in the Karkheh sub-catchments for the period November 2002-October

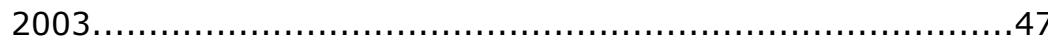

Table 4.3 Accumulated $E T_{a}$ and $E T_{p}$ for two wheat pixels in the Upper and Lower Karkheh....................................................... 53

Table 4.4 Water balance for the entire basin and major sub-basins $\left(10^{6} \times\right.$ $\mathrm{m}^{3}$ ) from November 2002-October 2003. ..........................55

Table 4.5 Monthly variations of the water balance terms $\left(10^{6} \times \mathrm{m}^{3}\right)$ in Holilan sub-catchment from November 2002-October 2003.....56

Table 4.6 Monthly variations of the water balance terms $\left(10^{6} \times \mathrm{m}^{3}\right)$ in Pole Dokhtar sub-catchment from November 2002-October 2003....56

Table 4.7 Monthly variations of the water balance terms $\left(10^{6} \times \mathrm{m}^{3}\right)$ in Lower Karkheh sub-basin (surface outflow is not measured from November 2002-October 2003...................................5

Table 5.1 Details of the sub-catchments......................................63

Table 5.2 Thiessen weights and annual precipitation for Doab subcatchment (2000 to 2003)..............................................65

Table 5.3 Annual water balance of the seven sub-catchments (2001 to

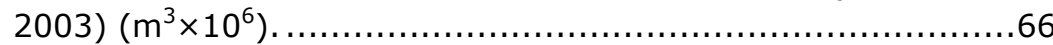

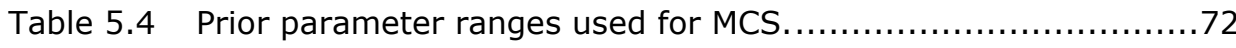

Table 5.5 Statistics of SEBS_daily estimates versus SEBS estimates (RMSE

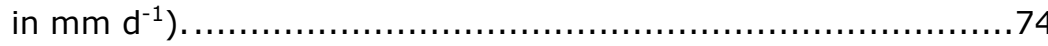

Table 5.6 Model efficiency for $Q s$ for respective periods when calibration

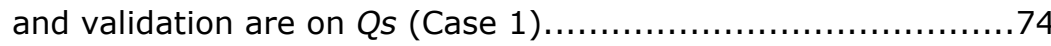


Table 5.7 Model efficiency for $E T_{a}$ for respective periods when calibration

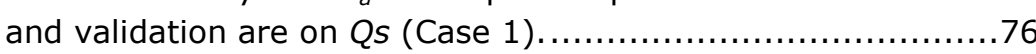

Table 5.8 Model efficiency for $E T_{a}$ when calibration and validation are on $E T_{a}$ (Case 2).

Table 5.9 Model efficiency for Qs when calibration and validation are on $E T_{a}$

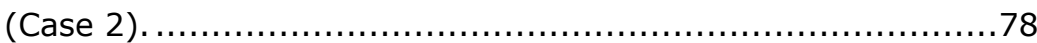

Table 5.10 Weights used in multi-variable calibration (Case 3 ) ..............78

Table 5.11 Model efficiency for all three cases. Hatched values indicate values for optimized parameters by calibration. All other values result from simple application of the objective functions.

Table 5.12 Averaged parameter values of the best performing 25 parameter sets for all three cases for Doab sub-catchment.

Table 5.13 Change of parameter values and the model performance with respect to the change of precipitation.

Table 6.1 Land use (in hectares) in the sub-basins of the Karkheh River Basin.

Table 6.2 Average yield $\left(\mathrm{kg} \mathrm{ha}^{-1}\right)$ for irrigated and rainfed wheat for subbasins of the Karkheh River Basin (adapted from Ahmad et al. 2009)

Table 6.3 Water consumption $\left(E T_{a}\right)$, actual evapotranspiration/potential evapotranspiration $\left(E T_{a} / E T_{p}\right)$, average and highest irrigated wheat yield, crop water productivity $(C W P)$, fertilizer application and seed rate for the $E T_{a}$ classes in Gamasiab sub-basin

Table 6.4 Water consumption $\left(E T_{a}\right)$, average and highest rainfed wheat yield, crop water productivity (CWP), fertilizer application rate and seed rate in different $E T_{a}$ classes in Gamasiab sub-basin. 101

Table 6.5 Coefficients of the crop production functions 102

Table 6.6 Size of the area for the respective slope classes having $E T_{a} / E T_{p}>0.5$

Table 6.7 Projected production values in existing irrigated wheat areas when yield is increased by $25 \%$ of the yield gap................ 106

Table 6.8 Projected production values in existing rainfed wheat areas...107

Table 6.9 Projected increase in rainfed wheat production as a result of expanding the land area. 108

Table 6.10 Projected wheat production $\left(\mathrm{kg} \times 10^{6}\right)$ values for the two strategies. 


\section{List of Symbols}

\begin{tabular}{|c|c|c|c|}
\hline Symbol & Representation & Dimensions & $\begin{array}{l}\text { SI } \\
\text { units }\end{array}$ \\
\hline$A L F A$ & $\begin{array}{l}\text { Measure for the nonlinearity of the } \\
\text { flow in the quick runoff reservoir }\end{array}$ & - & - \\
\hline BETA & $\begin{array}{l}\text { Parameter in soil moisture routine of } \\
\text { HBV model }\end{array}$ & - & - \\
\hline$C_{f}$ & Capillary flow & $\mathrm{LT}^{-1}$ & $\mathrm{~ms}^{-1}$ \\
\hline CFLUX & Maximum value for capillary flow & $\mathrm{LT}^{-1}$ & $\mathrm{~ms}^{-1}$ \\
\hline$c_{p}$ & Air specific heat at constant pressure & $\mathrm{L}^{-1} \mathrm{~T}^{2} \Theta$ & $j k g^{-1} K^{-1}$ \\
\hline$d$ & Zero displacement height & $\mathrm{L}$ & $\mathrm{m}$ \\
\hline$E T_{0}$ & $\begin{array}{l}\text { Reference crop evapotranspiration } \\
\text { rate }\end{array}$ & $\mathrm{LT}^{-1}$ & $\mathrm{~ms}^{-1}$ \\
\hline$E T_{a}$ & Actual evapotranspiration rate & $\mathrm{LT}^{-1}$ & $\mathrm{~ms}^{-1}$ \\
\hline$E T_{p}$ & Potential evapotranspiration & $\mathrm{LT}^{-1}$ & $\mathrm{~ms}^{-1}$ \\
\hline$e_{s}$ & Saturated vapor pressure & $M^{-1} \mathrm{~T}^{-2}$ & $\mathrm{~Pa}$ \\
\hline$e_{a}$ & Actual vapor pressure & $M^{-1} \mathrm{~T}^{-2}$ & $\mathrm{~Pa}$ \\
\hline FC & $\begin{array}{l}\text { Soil water-holding capacity in HBV } \\
\text { model }\end{array}$ & $\mathrm{L}$ & $\mathrm{m}$ \\
\hline$f_{c}$ & Fractional canopy coverage & - & - \\
\hline$G_{0}$ & Soil heat flux density & $\mathrm{MT}^{-3}$ & $\mathrm{Wm}^{-2}$ \\
\hline$H$ & Sensible heat flux density & $\mathrm{MT}^{-3}$ & $W^{-2}$ \\
\hline$H_{\text {standard }}$ & Standard elevation & $\mathrm{L}$ & $\mathrm{m}$ \\
\hline$H_{i}$ & Elevation at station i & $\mathrm{L}$ & $\mathrm{m}$ \\
\hline$k$ & Von Karman's constant & - & - \\
\hline$K^{\downarrow}$ & $\begin{array}{l}\text { Global shortwave radiation at the } \\
\text { surface }\end{array}$ & $\mathrm{MT}^{-3}$ & $W m^{-2}$ \\
\hline$K_{\text {exo }}^{\downarrow}$ & Extraterrestrial solar radiation & $\mathrm{MT}^{-3}$ & $\mathrm{Wm}^{-2}$ \\
\hline$K_{f}$ & $\begin{array}{l}\text { Recession coefficient of fast reservoir } \\
\text { in HBV model }\end{array}$ & $\mathrm{T}^{-1}$ & $d^{-1}$ \\
\hline$K_{s}$ & $\begin{array}{l}\text { Recession coefficient of slow } \\
\text { reservoir in HBV model }\end{array}$ & $\mathrm{T}^{-1}$ & $d^{-1}$ \\
\hline$L P$ & $\begin{array}{l}\text { Fraction between } 0 \text { and } 1 \text { in soil } \\
\text { moisture routine in HBV model }\end{array}$ & - & - \\
\hline$L Z$ & Storage in the base flow reservoir & $\mathrm{L}$ & $\mathrm{m}$ \\
\hline NS & Nash-Sutcliffe efficiency coefficient & - & - \\
\hline$N$ & $\begin{array}{l}\text { Theoretical maximum hours of } \\
\text { sunshine }\end{array}$ & $\mathrm{T}$ & $\mathrm{s}$ \\
\hline$N$ & Actual sunshine hours measured & $\mathrm{T}$ & $\mathrm{s}$ \\
\hline PERC & $\begin{array}{l}\text { Constant percolation rate that occurs } \\
\text { when water is available in the quick } \\
\text { runoff reservoir }\end{array}$ & $\mathrm{LT}^{-1}$ & $\mathrm{~ms}^{-1}$ \\
\hline
\end{tabular}




\begin{tabular}{|c|c|c|c|}
\hline Symbol & Representation & Dimensions & $\begin{array}{l}\text { SI } \\
\text { units }\end{array}$ \\
\hline$P_{i, \text { standard }}$ & $\begin{array}{l}\text { Precipitation at the standard } \\
\text { elevation for station } \mathrm{i}\end{array}$ & $\mathrm{L}$ & $\mathrm{m}$ \\
\hline$P_{i}$ & Measured precipitation at station $\mathrm{i}$ & L & $\mathrm{m}$ \\
\hline$P$ & Precipitation & L & $\mathrm{m}$ \\
\hline$Q_{d}$ & $\begin{array}{l}\text { Direct discharge over land in HBV } \\
\text { model }\end{array}$ & $\mathrm{LT}^{-1}$ & $\mathrm{~ms}^{-1}$ \\
\hline$Q_{\text {in }}$ & $\begin{array}{l}\text { Indirect discharge through the soil } \\
\text { layer in HBV model }\end{array}$ & $\mathrm{LT}^{-1}$ & $\mathrm{~ms}^{-1}$ \\
\hline$R_{n}$ & Net radiation flux density & $\mathrm{MT}^{-3}$ & $\mathrm{Wm}^{-2}$ \\
\hline$r_{0}$ & Surface albedo & - & - \\
\hline RVE & Relative volume error & - & - \\
\hline$r_{s}$ & Surface resistances & $\mathrm{L}^{-1} \mathrm{~T}$ & $\mathrm{~s} \mathrm{~m}^{-1}$ \\
\hline$r_{a}$ & Aerodynamic resistances & $\mathrm{L}^{-1} \mathrm{~T}$ & $\mathrm{~s} \mathrm{~m}^{-1}$ \\
\hline SM & Soil moisture depth & $\mathrm{L}$ & $\mathrm{m}$ \\
\hline$T_{a}$ & Air temperature & $\Theta$ & $\mathrm{K}$ \\
\hline$T_{s}$ & Surface temperature & $\Theta$ & $\mathrm{K}$ \\
\hline$U Z$ & Storage in the quick runoff reservoir & L & $\mathrm{m}$ \\
\hline$u_{z}$ & Wind speed at height $z$ & $\mathrm{LT}^{-1}$ & $\mathrm{~ms}^{-1}$ \\
\hline$w_{Q}$ & $\begin{array}{l}\text { Weight for Qs in the objective } \\
\text { function }\end{array}$ & - & - \\
\hline$w_{E T a}$ & $\begin{array}{l}\text { Weight for } E T_{a} \text { in the objective } \\
\text { function }\end{array}$ & - & - \\
\hline Y & Combined objective function & - & - \\
\hline$z_{m}$ & Height of wind speed measurement & L & $\mathrm{m}$ \\
\hline$z_{h}$ & Height of humidity measurements & L & $\mathrm{m}$ \\
\hline$z_{o m}$ & $\begin{array}{l}\text { Roughness length governing } \\
\text { momentum transfer }\end{array}$ & L & $\mathrm{m}$ \\
\hline$z_{o h}$ & $\begin{array}{l}\text { Roughness length governing transfer } \\
\text { of heat and vapor }\end{array}$ & L & $\mathrm{m}$ \\
\hline Y & Psychometric constant & $L^{-1} M T^{-2} \Theta^{-1}$ & $\mathrm{~Pa} \mathrm{k}^{-1}$ \\
\hline$\Lambda$ & Evaporative fraction & - & - \\
\hline$\Delta$ & $\begin{array}{l}\text { Slope of the saturated vapor } \\
\text { pressure curve }\end{array}$ & - & $\mathrm{Pa} \mathrm{K}^{-1}$ \\
\hline$\Delta s$ & $\begin{array}{l}\text { Storage change during the time } \\
\text { interval considered }\end{array}$ & $L^{3}$ & $\mathrm{~m}^{3}$ \\
\hline$\varepsilon_{s}$ & Surface emissivity & - & - \\
\hline$\varepsilon_{a}$ & Emissivity of air & - & - \\
\hline$\lambda$ & Latent heat of vaporization & $L^{2} T^{-2}$ & $\mathrm{~J} \mathrm{~kg}^{-1}$ \\
\hline$\lambda E$ & Latent heat flux density & $\mathrm{MT}^{-3}$ & $W m^{-2}$ \\
\hline$\rho_{a}$ & Air density & $\mathrm{ML}^{-3}$ & $\mathrm{~kg} \mathrm{~m}^{-3}$ \\
\hline$\rho_{w}$ & Density of water & $L^{-3} M$ & \\
\hline
\end{tabular}




\begin{tabular}{llll}
\hline Symbol & Representation & Dimensions & $\begin{array}{l}\text { SI } \\
\text { units }\end{array}$ \\
\hline$\sigma$ & $\begin{array}{l}\text { Stefan-Bolzmann constant } \\
\psi_{m}\end{array}$ & $\begin{array}{l}\text { Stability correction functions for } \\
\text { momentum transport }\end{array}$ & - \\
$\psi_{h}$ & $\begin{array}{l}\text { Stability correction functions for heat } \\
\text { transport }\end{array}$ & - & - \\
$\Lambda_{r}$ & Relative evaporation & - & - \\
$\xi$ & Precipitation lapse rate & $\mathrm{LL}^{-1}$ & $\mathrm{~mm}^{-1}$ \\
$\Gamma_{c}$ & $\begin{array}{l}\text { Ratio of soil heat flux to net radiation } \\
\text { for full vegetation canopy }\end{array}$ & - \\
$\Gamma_{s}$ & $\begin{array}{l}\text { Ratio of soil heat flux to net radiation } \\
\text { for bare soil }\end{array}$ & - \\
\hline
\end{tabular}




\section{Introduction}

\subsection{Water for agriculture}

Water is a vital resource that is needed for all forms of life on this Earth. Humans use water for agriculture, domestic use, industries, transport and recreation. In addition, water is essential for the nature to provide ecosystem services. Growing water demands from agriculture, industries, the domestic sector and ecosystems impose more pressure on available water resources in different areas of the world (Wallace, 2000; Rockström et al., 2009). For instance, world population will grow past eight billion by 2025 , with the contribution of a growth rate of about 3\% from some developing countries (UN, 2011), and is expected to reach 9.3 billion by 2050 (Pimentel and Burgess, 2013). Such an increase in population implies an increased demand for freshwater for agriculture. This increasing demand, combined with rising water pollution is a major constraint on development and agricultural activities in many parts of the world.

Global renewable freshwater resources, as estimated by different studies, range from 42,700 to $44,540 \times 10^{9} \mathrm{~m}^{3}$ (Shiklomanov, 2000; Gleick, 2003; FAO, 2003; Balonishnikova et al., 2006). The major water withdrawals come from the agriculture, domestic and industrial sectors. In 2000, an estimated amount of $3,784 \times 10^{9} \mathrm{~m}^{3}$ of water was withdrawn for these three sectors. The agricultural withdrawals are estimated at 2,675 $\times 10^{9} \mathrm{~m}^{3}$, which is about $70 \%$ of total water withdrawals and about $6 \%$ of total renewable freshwater resources (FAO, 2009). However, according to global assessments water withdrawals far exceed consumption in these major sectors. About half of the total water withdrawn for agriculture is consumed as evaporation and transpiration by plants. In the industrial and municipal sectors, water consumption fluctuates between 9 to $15 \%$ and 12 to $20 \%$ of withdrawals, respectively (e.g. Shiklomanov 1999). As such, only part of the withdrawn water is consumed, and a considerable part is discharged downstream or to groundwater and consumed by downstream users (Bos, 2005; Garizábal and Causapé, 2010). Figure 1.1 shows the water consumption in 2010 and future projections till 2050 for irrigated agriculture, industries, and domestic use (Chartres and Sood, 2013). As shown, water consumption for irrigated agriculture between 2010 and 2050 has increased from $1,563 \times 10^{9} \mathrm{~m}^{3}$ to $1,662 \times 10^{9} \mathrm{~m}^{3}$. This is based on the assumption that there will not be further increase in the agriclure land area. For the same period, the increase in the industrial and domestic sectors is from $434 \times 10^{9} \mathrm{~m}^{3}$ to $1,807 \times 10^{9} \mathrm{~m}^{3}$ and $212 \times 10^{9} \mathrm{~m}^{3}$ to $1,497 \times 10^{9} \mathrm{~m}^{3}$, respectively. This shows that, in 2050 , consumptions from the irrigation sector will be $6 \%$ higher compared to levels in 2010, whereas increases in consumptions from the industrial and domestic sectors will be fourfold and more than sevenfold, respectively. 
Figure 1.1: Trends in global water consumption by sector (Chartres and Sood, 2013).

Lannerstad, (2009) estimated global water use for both irrigated and rainfed agriculture at about $6,800 \times 10^{9} \mathrm{~m}^{3} \mathrm{y}^{-1}$. Based on the data from 92 developing countries, Rockström et al. (2005) estimated consumption of water for both rainfed and irrigated agriculture to be $4,500 \times 10^{9} \mathrm{~m}^{3} \mathrm{y}^{-1}$ in 2002. In the same report, it is stated that, to supply food for half of the malnourished people in the world by 2015, an additional 2,200 $\times 10^{9} \mathrm{~m}^{3} \mathrm{y}^{-1}$ of consumptive water use in agriculture is required. Further, to eradicate hunger in developing countries by 2030, an additional $4,160 \times 10^{9} \mathrm{~m}^{3} \mathrm{y}^{-1}$ of consumptive water use will be required for agriculture. Whereas demands are increasing, overexploitation and poor management of water resources threaten the resource base on which agriculture depends. In addition, the protection of ecosystems becomes even more important and urgent (Falkenmark et al., 2009). In this situation, as freshwater resources are limited, the question of whether there will be sufficient water to fulfill the increasing demand generated by agriculture and other sectors arises.

However, according to some global-scale studies on water resources management (Molden et al., 2007; de Fraiture and Wichelns, 2010), there is sufficient water available to satisfy global food demands for the next 50 years, but only if water is managed more effectively in agriculture. Despite the optimism in this statement, selecting the best management option for increasing agricultural production depends on local conditions. The amount of water required to produce crops varies by climate, mode of cultivation, crop variety and length of the growing season. For instance, every kilogram of wheat depletes between 0.4 to $5.0 \mathrm{~m}^{3}$ of water, depending on the location 
(e.g., Sakthivadivel et al., 1999; Tuong and Bouman, 2003; Zwart and Bastiaanssen, 2004). Therefore, whereas it is clear that agricultural production must increase, it is less clear which management option is most effective under which condition to achieve the required production increases.

\subsection{Crop production and water resources}

Traditionally, agricultural production is increased by expanding the size of its production area through the transformation of land use and land cover to agriculture (Guo et al., 2005; Rockström et al., 2007; Masih, 2011). Nature can be converted into agricultural land, if conditions that relate to soils, topography and accessibility are suitable. The premise is that water availability is not a constraint. Water evaporated by natural land can then be used for agricultural production (Falkenmark et al., 2009). In addition, field practices such as improving tillage, fertilizer strategies and the use of better seeds can increase agricultural production. By doing this, crop yields increase and water is used more effectively in terms of yield per cubic meter of water consumed. Such practices are of particular importance in areas where available water resources are limited.

In areas where all available water resources have already been allocated for various other uses, increasing crop water productivity (CWP) has often been suggested as being one of the alternative strategies for increasing food production (Amarasinghe et al., 2010). CWP expresses productivity in terms of kilograms per unit of water consumed (Kijne et al., 2003; Bos et al., 2005; Molden et al., 2007). A higher CWP results in, either the same production from the use of less water or a higher production from the use of the same amount of water, and is a direct benefit to other water users (Zwart and Bastiaanssen, 2004). Dehghanisanij et al. (2006) showed that, agricultural production can be maintained to its current level by using $20 \%$ to $40 \%$ less water s, if new water management practices are adopted.

Zwart et al. (2010) found that, on a global scale, CWP for irrigated wheat varies from 0.2 to $1.8 \mathrm{~kg} \mathrm{~m}^{-3}$ between and within countries. They also concluded that water availability and soil fertility are probably the most dominant factors that affect crop yields and CWP. Sadras and Angus (2006) showed that CWP for wheat in Australia, USA, China and Mediterranean countries is $32 \%$ to $44 \%$ lower than the maximum potential attainable values. Several studies have stated that there are significant opportunities to save water by improving CWP (Cai and Rosegrant, 2003; Zwart and Bastiaanssen, 2004). These improvements can be achieved by increasing yields through better water management practices and non-water inputs such as better fertilizer application and land preparation, and using better seeds (Breman et al., 2001; Nangia et al., 2008). 


\subsection{Water resources management}

Sound water management should be based on a quantitative understanding of the state of the resources. Good policy design, research, monitoring and decision making always require that sufficient and reliable data is available (Oyebande, 2001; Awad et al., 2009). Lack of such data compromises the validity of information used for assessments and subsequent decision making (UNESCO, 2009). Internationally, integrated water resources management (IWRM) is increasingly considered as a means to ensure equitable, economically sound and environmentally sustainable development of water resources within a river basin. IWRM starts with the gathering of comprehensive data (physical and socio-economic) on river basins and developing models of the physical systems (hydrology, hydrogeology and hydraulics) (Ako et al., 2010).

For instance, to allocate freshwater for agriculture and other uses, in order to acquire the best possible outcomes, a variety of information is needed. Some of this essential information are streamflow and water availability, water consumption patterns by crops and other vegetation, and related crop productions (Albek, et al., 2004; Young, 2006; Awad et al., 2009). However, in many areas, finding this information is challenging. For example, worldwide, water observation networks, in most cases, provide incomplete and incompatible data on water quantity and quality for managing water resources (UNESCO, 2009). Further, these networks are in jeopardy of future decline. Due to deterioration of gauging stations, measured streamflow data is not available anymore in several river basins around the world. Out of 7,782 streamflow gauging stations in the Mediterranean region, only $24 \%$ have more than 30 years of time series data (FAO, 2003). Milliman and Farnsworth (2011) cited a $25 \%$ reduction in the number of river gauging stations in Canada between 1990 and 2001. There were about 50 streamflow gauging stations installed in the Karkheh River Basin in Iran after 1950 and only half of them are used continuously (Masih, 2011).

When sufficient observed data are lacking, models can be used to generate information for decision-making, provided they have a baseline from which the models are calibrated (UNESCO, 2009). In these circumstances, hydrological models are among the available tools used to simulate streamflow. Some of these models could also predict the impacts of natural and anthropogenic changes on water resources, and quantify the spatial and temporal availability of the resource. However, simulating streamflow is challenging in hydrology, as it has to consider issues such as changing land use and unavailability of in-situ streamflow data as in un-gauged basins. Standard hydrological approaches often have to be adapted for use in such cases (Croke et al., 2006). Further, in addition to the inherent errors and 
uncertainty in hydrological modelling, model calibration is also challenging since observed data for model calibration increasingly is becoming unavailable in many areas of the world. Therefore, much attention is on exploring new ways to derive data for model calibration (Seibert and McDonnell, 2002; Parajka and Blöschl, 2008). Improved calibration procedures would provide an accurate estimate of hydrological variables that helps informed decision making on water resources management.

In this context, researchers have identified the importance of the use of geoinformation, such as satellite remote sensing, in the field of water resources management. This is very important in areas where the required data are not available or the availability of data is low. In this regard, the development of satellite sensors and techniques during the last four decades have complemented water resources management by supplying spatially and temporally distributed biophysical and hydrological parameters at different scales. For instance, data on water consumed by crops provides valuable information to plan water allocations. Water consumption by different crops can be estimated by assessing the $E T_{a}$ of each crop. To estimate water consumption over large spatial domains, satellite-based methods can be useful, since conventional methods of estimating $E T_{a}$ are generally based on in-situ measurements at point scale. Further, studies have already been conducted to check the feasibility of using water balance terms, estimated based on data for model calibration, especially over data-scarce areas (Immerzeel and Droogers 2008).

\subsection{Freshwater resources and demands in Iran}

Iran is one of the countries where fresh water resources are limited but demands for water increases rapidly. Iran comprises $1.1 \%$ of the world's land area, nearly $1 \%$ of the world's population, and only $0.38 \%$ of the world's freshwater resources. Approximately $10 \%$ of the land in Iran is used for agriculture. In 2005 agricultural production was $11.8 \%$ of the Gross Domestic Product (GDP) (Marjanizadeh, 2008). The population of Iran was about 69 million in 2003. There are different estimates of the future population of Iran (e.g., Zehtabian et al., 2010). According to the most recent revision of the United Nations world population prospects (UN, 2011), the projected population of Iran will be about 87 million by 2025 . Food self-sufficiency for the growing population is a key concern in Iran, and its agricultural policy is focused towards achieving this goal. To achieve food self-sufficiency, the production of crops, such as wheat, maize, oilseed crops, sugar beet and rice, is high on the agenda of Iran's agricultural policymakers (Bansouleh, 2009). Between 1975 and 2004, Iran's water withdrawals have increased from $45 \times$ $10^{9} \mathrm{~m}^{3} \mathrm{y}^{-1}$ to $93.3 \times 10^{9} \mathrm{~m}^{3} \mathrm{y}^{-1}$, and about $90 \%$ of this water was allocated to the agriculture sector (FAO, 2009). It is estimated that $55 \%$ of the water 
comes from groundwater and $45 \%$ is exploited from surface water (Zehtabian et al., 2010). The projected withdrawals for irrigated agriculture by 2025 are $124 \times 10^{9} \mathrm{~m}^{3} \mathrm{y}^{-1}$. Because of the continuous rise in population, water demand for non-agricultural uses will also increase and is expected to reach $9 \%$ of the total available water resources by the year 2025 (Seckler et al., 1998). Per capita availability of water is decreasing. For instance, in 1961 , the availability of water was about $6,057 \mathrm{~m}^{3}$ per person per year. This has reduced to $1,820 \mathrm{~m}^{3}$ per person per year in 2009 (Masih, 2011). The estimated per capita water availability in 2020 is about $1,300 \mathrm{~m}^{3}$ per year per person (Mohammadian and Zehtabian, 2006). Projections of future water demand and supply (Seckler et al., 1998; Wallace, 2000) suggested that Iran would face serious water scarcity problems in the first quarter of the $21^{\text {st }}$ century.

These figures show an increasing trend in the water demand for agriculture, municipalities and industries whereas per capita water availability is decreasing through the years. Despite the shortage of water in the country, the emphasis has been more on water resources development rather than on water resources management (Zehtabian et al., 2010). As such, considering the situation in Iran, a well-balanced allocation of freshwater resources to different uses, e.g., agriculture, municipalities, industries and natural ecosystems, is required. This would contribute to increasing food production while also ensuring water availability for other uses. However, well-balanced water allocation requires accurate information on water availability and consumption, which is not very commonly available in Iran.

\subsection{Research objectives}

The main objective of this study is to quantify the spatial and temporal distribution of water availability for agriculture in the Karkheh River Basin in Iran by integrating satellite remote sensing and hydrological modeling. This analysis was further used to evaluate the possible increase of wheat production in the basin within the constraints of existing water resources. The specific objectives of this study are as shown below:

1. To estimate water availability in the basin for agricultural development using remote sensing and geo-statistical techniques.

2. To test effectiveness of satellite based actual evapotranspiration and streamflow in the HBV rainfall-runoff model to represent and to close the catchment water balance.

3. To estimate how much wheat can be produced by 2025 using available water resources in the Karkheh River Basin, by introducing various agricultural development strategies.

\subsection{Outline of the thesis}


Chapter 2 provides a brief description of the Karkheh River Basin, including geography, climate, agriculture, hydrology, demography, water management and the data used in this study.

Chapter 3 presents a literature review on satellite remote sensing and hydrological models applied in water resources management. This chapter also includes descriptions of the HBV rainfall-runoff model and Surface Energy Balance System (SEBS) algorithm that used in this study to estimate satellite-based actual evapotranspiration.

Chapter 4 presents the estimation of water availability and water consumption by the different vegetation classes in the Karkheh River Basin. Actual evapotranspiration is estimated by a satellite based procedure Precipitation is estimated by geo-statistical techniques.

In Chapter 5, preference-based multi-variable calibration using streamflow and actual evapotranspiration is described. To assess HBV model performance, multiple objective functions were used. Representation and closure of the water balance is assesses and discussed.

In Chapter 6, strategies to improve wheat production in the basin to meet the production targets of 2025 are evaluated.

Chapter 7 provides a summary and concludes on this study. 


\section{Description of the Study Area}

\subsection{Geographic and climatic settings}

The Karkheh River Basin $\left(51,000 \mathrm{~km}^{2}\right)$ is located in the southwest of Iran between $30^{\circ}$ to $35^{\circ}$ North and $46^{\circ}$ to $49^{\circ}$ East (Figure 2.1).

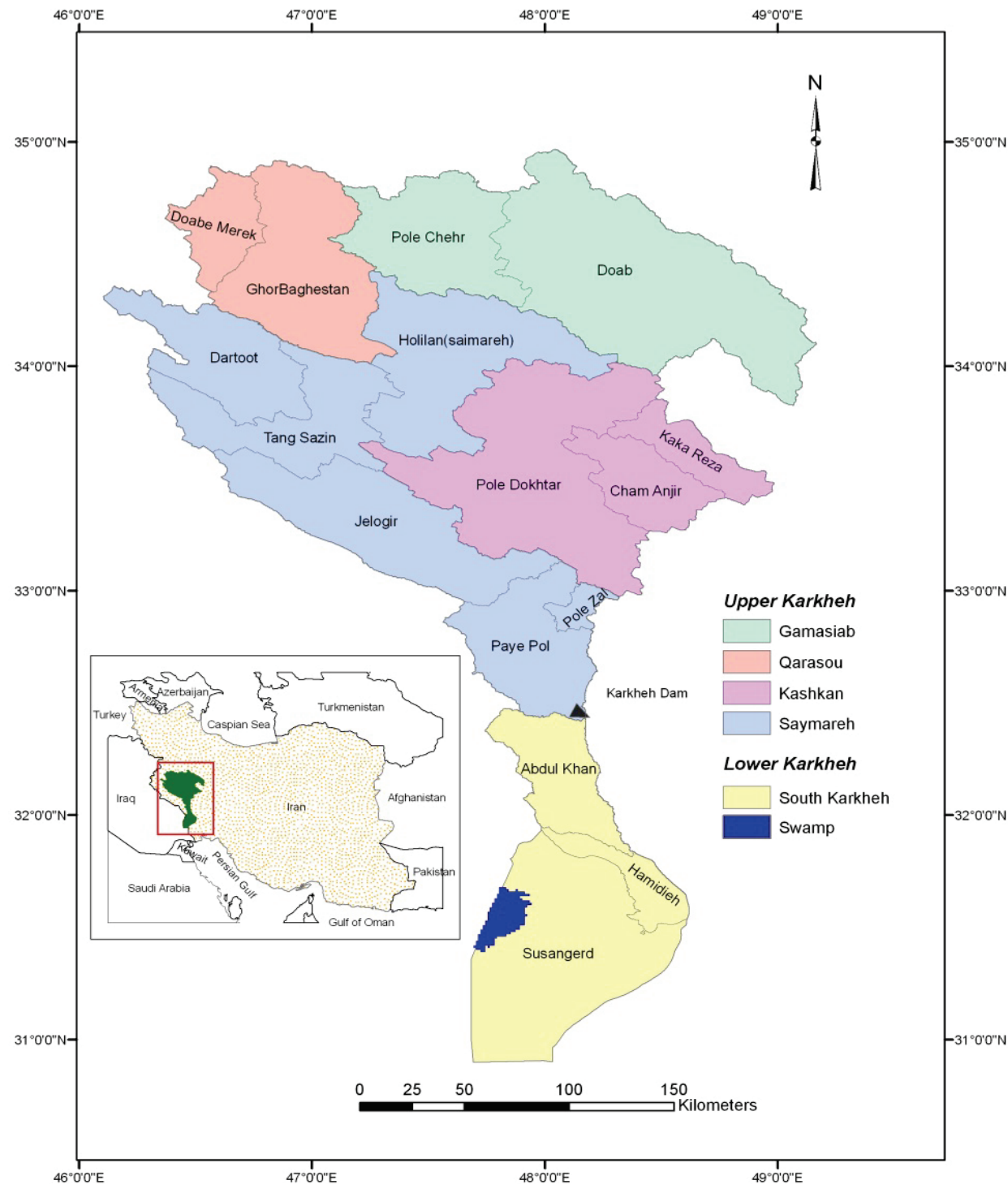

Figure 2.1: Karkheh River Basin showing Upper and Lower Karkheh and their respective sub-catchments. 
It is one of the most productive river basins in Iran and has $9 \%$ of the total irrigated area of the country. Approximately $11 \%$ of the country's wheat production comes from the basin (Marjanizadeh, 2008). Hereafter, in this thesis, sub-basins is referred to the five major areas as shown in Figure 2.1 while the smaller spatial units inside those five sub-basins are termed subcatchments.

Water from the basin is mainly used for agricultural production, domestic supplies, fish farming but it also serves to sustain the environment. For the latter, a major concern is the sustainability of the Hoor-Al-Azim swamp, which is considered as a site of international importance by the Ramsar Convention on Wetlands and located at the Iran-Iraq border. The elevation of the basin (Figure 2.2) ranges from less than $10 \mathrm{~m}$ above mean sea level (amsl) in the south to more than 3,500 amsl in the north. About $60 \%$ of the basin ranges between 1,000 and 2,000 amsl. Agriculture and human settlements are mainly in the valleys of the Upper Basin and in the arid plains in the Lower Basin. 


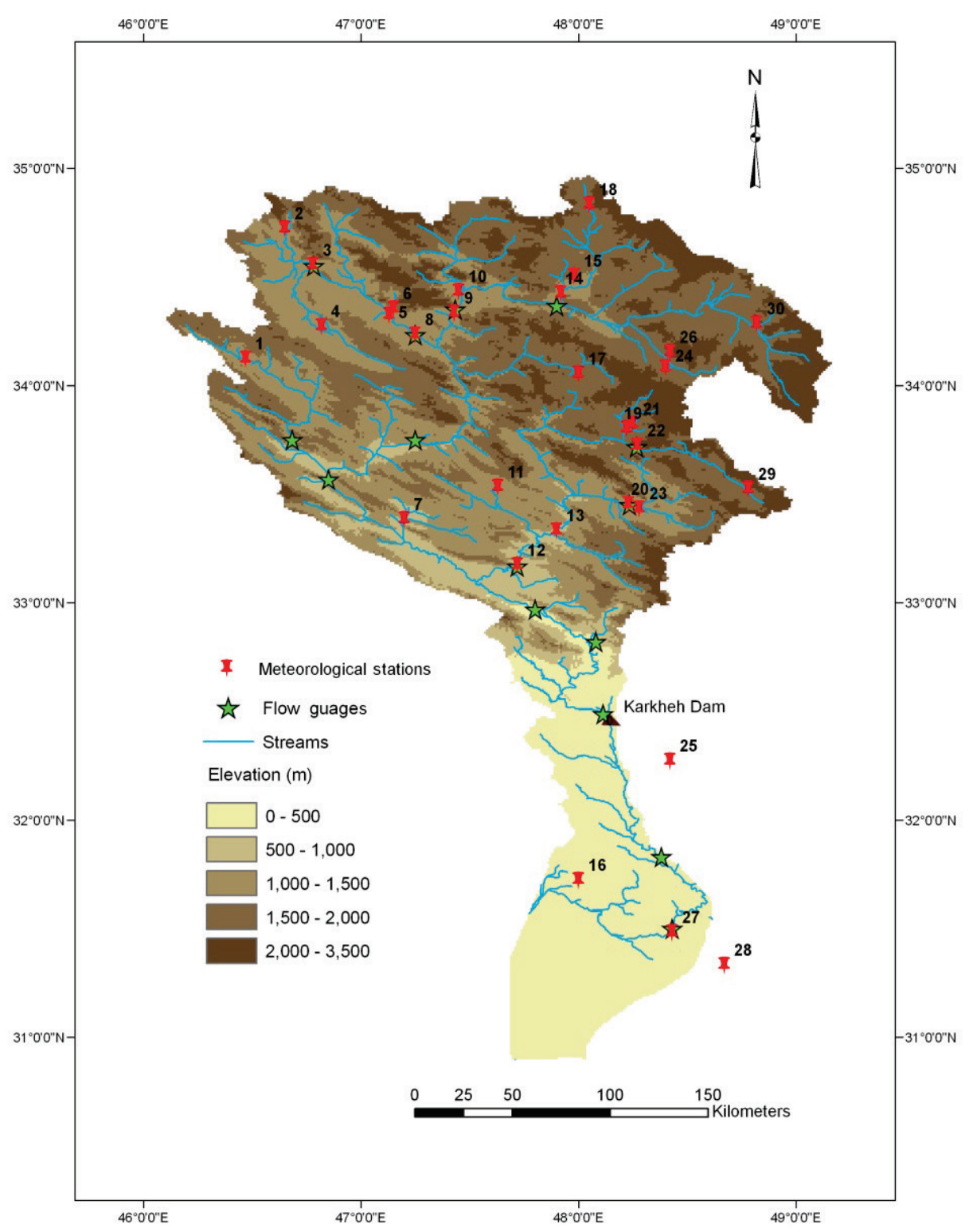

Figure 2.2: Digital elevation model with the river network, flow gauges and meteorological stations of the Karkheh River Basin (meteorological station names are given in Table 2.1). (Acquired from http://srtm.csi.cgiar.org/) 
Table 2.1: Names of the meteorological stations presented in Figure 2.2.

\begin{tabular}{llll}
\hline Stationnumber & Station name & Station number & Station name \\
& & & \\
\hline 1 & Eslamabad Gha & 16 & Bostan \\
2 & Ravansar & 17 & Norabade \\
3 & Doabe Mer & 18 & Aghajanbo \\
4 & Mahidasht & 19 & Sarab sei \\
5 & Pole Kohn & 20 & Cham Anji \\
6 & Kermanshah & 21 & Aleshtar \\
7 & Tang Siab & 22 & Kaka Reza \\
8 & Ghor Baghestan & 23 & Khorram \\
9 & Pole Chehr & 24 & Varayneh \\
10 & Bistoon & 25 & Safiabad \\
11 & Kouhdasht & 26 & Nahavand \\
12 & Pole Dokh & 27 & Hamidiyeh \\
13 & Afarineh & 28 & Ahwaz \\
14 & Aran & 29 & Dehno \\
15 & Kangavar & 30 & Malayer \\
\hline
\end{tabular}

The Lower Karkheh receives an annual average precipitation of about 150 $\mathrm{mm}$ while it can reach up to $750 \mathrm{~mm}$ in the northern part. Figure 2.3 presents the average annual precipitation for the Kermanshah station in Upper Karkheh from 1960 to 2008. In the Lower Karkheh and Upper Karkheh, maximum summer temperatures go up to $45{ }^{\circ} \mathrm{C}$ and $35{ }^{\circ} \mathrm{C}$, respectively (Figure 2.4). Class A pan evaporation, which is the available evaporation data from the basin, ranges from 2,000 to $3,600 \mathrm{~mm} \mathrm{y}^{-1}$ from the north to the south. Precipitation in the Lower Karkheh area is insufficient to meet crop water requirements, and irrigated agriculture largely depends on water from the Karkheh Dam and on groundwater. 


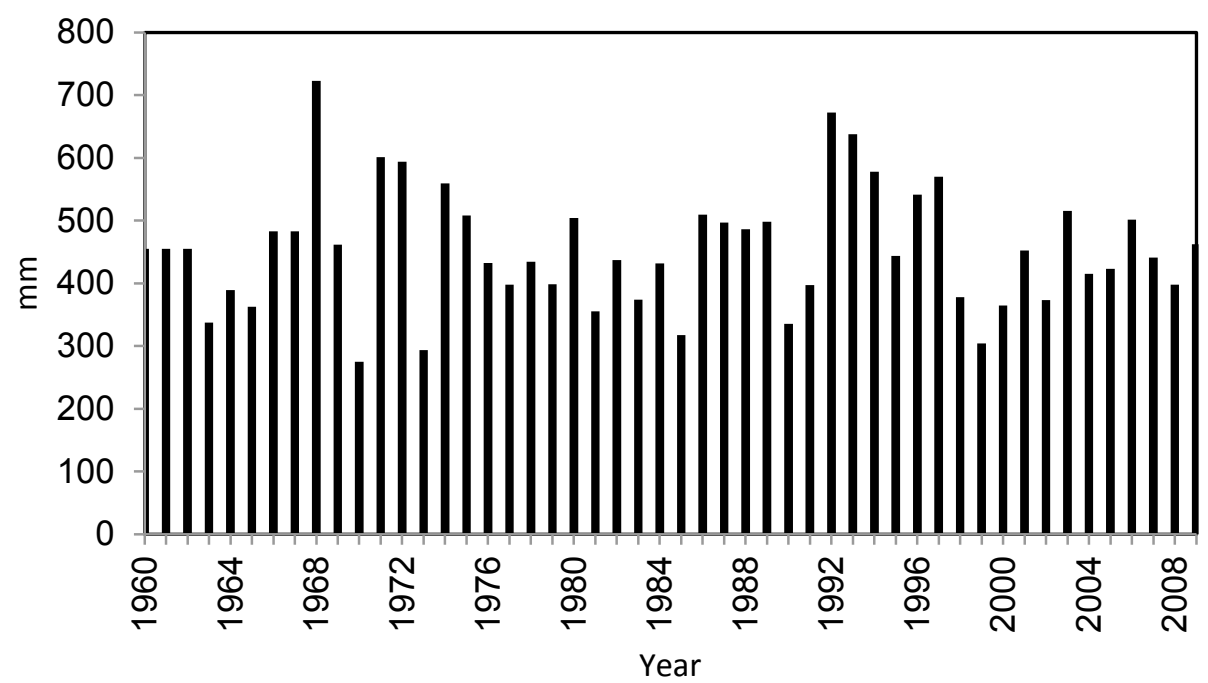

Figure 2.3: Average annual precipitation at Kermanshah in the Upper Karkheh (1960 to 2008).

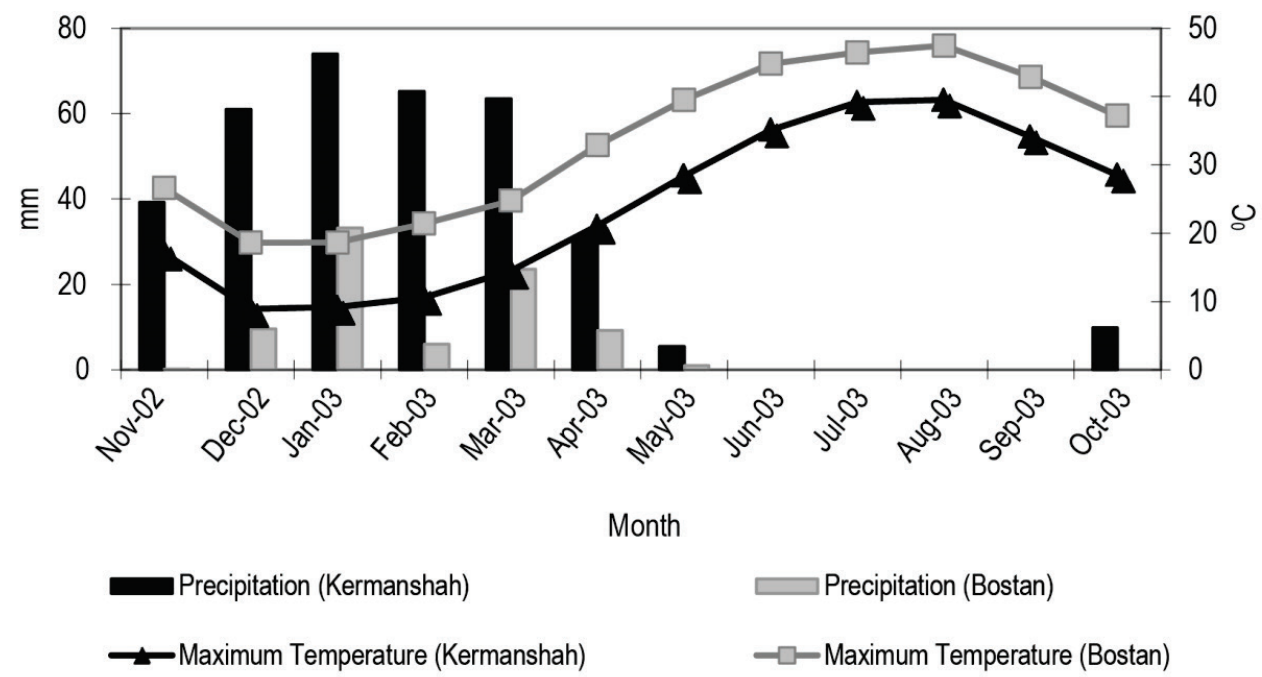

Figure 2.4: Monthly precipitation and maximum temperature from two stations: Kermanshah (Latitude: $34^{\circ} 21^{\prime} \mathrm{N}$, Longitude: $47^{\circ} 9^{\prime} \mathrm{E}$ ) in Upper Karkheh and Bostan (Latitude: $31^{\circ} 43^{\prime} \mathrm{N}$, Longitude: $48^{\circ} 0^{\prime} \mathrm{E}$ ) in Lower Karkheh.

\subsection{Agriculture and irrigation}

Rangelands, rainfed agriculture, forest and irrigated agriculture are the main land uses in the basin (Figure 2.5). In the Upper Karkheh, both rainfed and irrigated agriculture are practiced whereas only irrigated agriculture is practiced in the lower Karkheh. In the Upper Karkheh, irrigation water is 
traditionally supplied by springs, but also by diversion and pumping of river water, more recently.

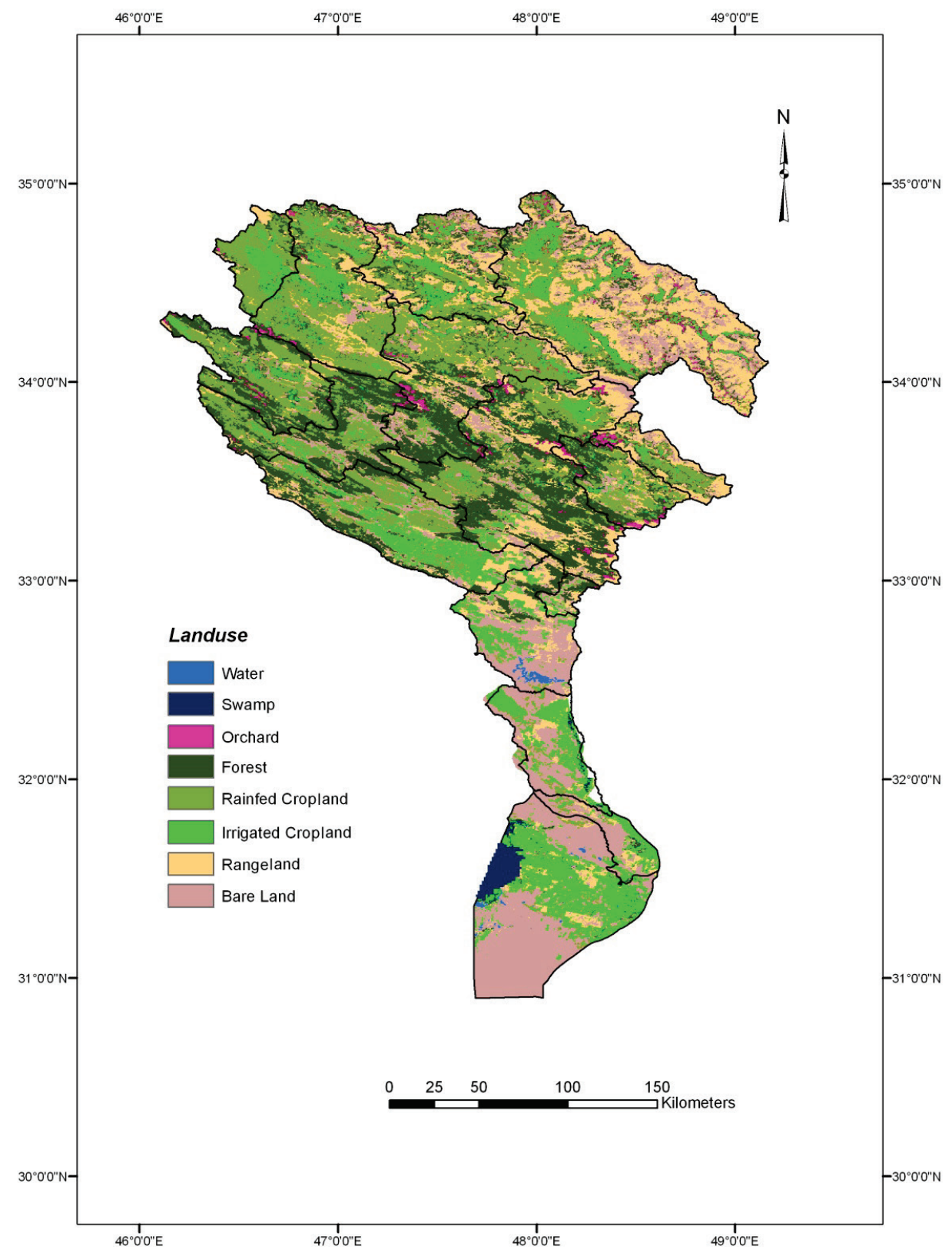

Figure 2.5: Land use in the Karkheh River Basin. 
The Karkheh reservoir has a storage capacity of $7,500 \times 10^{6} \mathrm{~m}^{3}$ with a live storage capacity of about $4,700 \times 10^{6} \mathrm{~m}^{3}$, and has been in operation since 2002. The reservoir is designed to irrigate 320,000 ha of agricultural land in Lower Karkheh. Wheat, barley and maize are the main crops in both Lower and Upper Karkheh whereas also chickpea, under rainfed conditions, is grown in the Upper Karkheh. Growing periods of these crops in Upper and Lower Karkheh are given in Table 2.2.

Table 2.2: Growing periods for different crops in the Upper and Lower Karkheh.

\begin{tabular}{lll|l}
\hline \multirow{2}{*}{ Crop } & \multicolumn{2}{c|}{ Upper Karkheh } & \multicolumn{1}{c}{ Lower Karkheh } \\
\cline { 2 - 4 } & Irrigated & Rainfed & Irrigated \\
\hline Wheat & November - July & November - June & December - May \\
Barley & November - July & November - June & December - May \\
Maize & May - October & - & June - October \\
Chickpea & - & April - July & - \\
\hline
\end{tabular}

Agricultural areas in the Karkheh Basin have increased from 786,000 ha in 1983 to $1,867,000$ ha in 2004 (Figure 2.6).

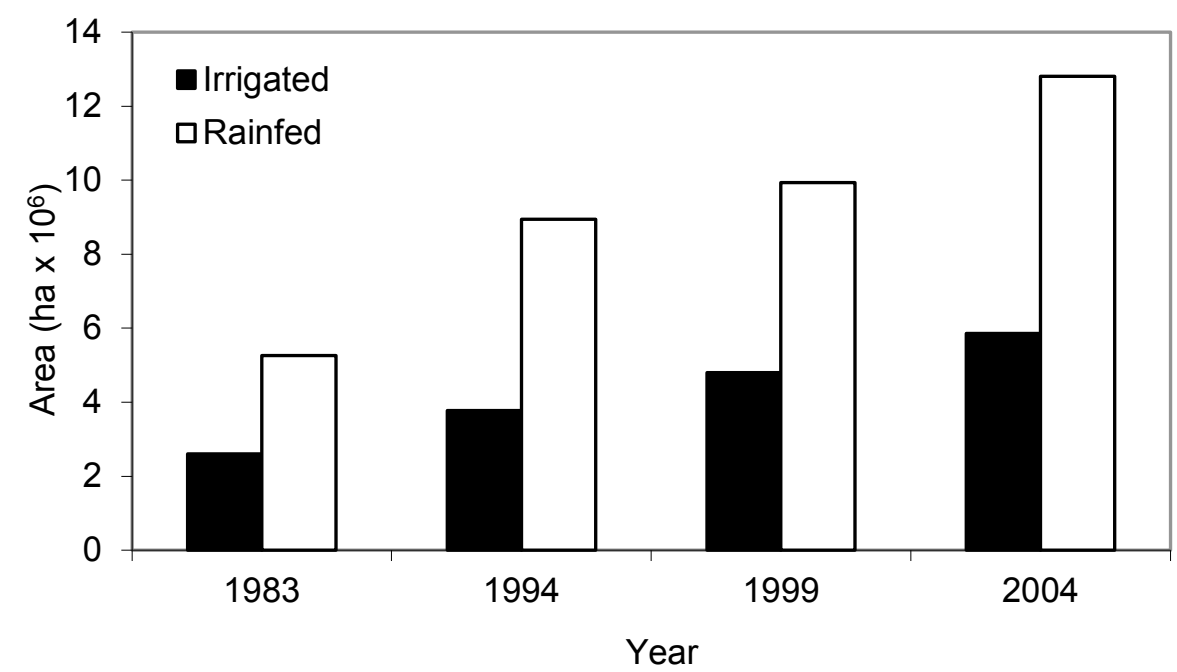

Figure 2.6: Extent of agricultural land in the Karkheh River Basin (1983 to 2004) (Source: Marjanizadeh, 2008).

Throughout this period, rainfed agriculture remained dominant and approximately $30 \%$ of the agricultural lands were under irrigation. Rainfed farming is scattered in almost all parts of the basin with varying degrees of coverage whereas most of the irrigated farming is concentrated in the upstream Gamasiab sub-basin and in the downstream South Karkheh subbasin. Secondary statistics on irrigated and rainfed wheat production indicate 
that there is a significant difference between irrigated and rainfed areas in terms of production (Ahmad et al., 2009).

\subsection{Water resources and demands}

Hydrologically, the basin is divided into five sub-basins, Gamasiab, Qarasou, Kashkan, Saymareh and South Karkheh (Figure 2.1). The first four subbasins are major tributaries to the main stream of the Karkheh River. The South Karkheh is the area south of the Karkheh Dam. These major subbasins are divided into 16 smaller catchments (Figure 2.1) based on the locations of the streamflow gauging stations. Hereafter the sub-basins are referred to as the five major areas as shown in Figure 2.1, whereas the smaller spatial units inside the five sub-basins are referred to as subcatchments. Table 2.3 presents the mean, minimum and maximum streamflow measured at the outlets of the five major sub-basins based on streamflow data from 1961 to 2001.

Table 2.3: Mean annual streamflow data (1961 to 2001) for respective sub-basins $\left(10^{6} \times \mathrm{m}^{3}\right)$ (Source: Masih et al., 2009).

\begin{tabular}{lcccc}
\hline Sub-basin & Drainage area & Mean & Minimum & Maximum \\
\hline Gamasiab & 10,888 & 1,080 & 198 & 2,815 \\
Qarasou & 5,358 & 722 & 104 & 1,914 \\
Kashkan & 9,541 & 1,639 & 645 & 3,206 \\
Saymareh & 42,818 & 5,827 & 1,916 & 12,524 \\
South Karkheh & 45,716 & 5,153 & 1,068 & 11,324 \\
\hline
\end{tabular}

${ }^{*}$ For South Karkheh, the streamflow figures reported are measured at the outlet of the Hamediah and do not represent the total streamflow figure from the sub-basin.

In recent years, scarcity of water has prompted farmers to pump groundwater to meet their irrigation needs. The groundwater system consists of confined and unconfined aquifers lying in hard rocks and alluvial sediments. Tube wells, qanats and springs are the main sources of groundwater in the basin. Table 2.4 shows the estimated groundwater abstraction from the major sub-basins in 2004. It is noted, however, that these figures could significantly underestimate the true volume of abstraction, since there are many unregistered wells in the area. 
Table 2.4: Estimated annual groundwater abstraction $\left(10^{6} \times \mathrm{m}^{3}\right)$ from the major subbasins in 2004 (Source: Iranian Energy Ministry).

\begin{tabular}{llllll}
\hline Sub-basin & Deep well & Semi-deep well & Qanat $^{*}$ & Spring & Total \\
\hline Upper Karkheh & & & & & \\
Qarasou & 353 & 227 & 131 & 546 & 1,615 \\
Saymareh & 88 & 91 & 33 & 142 & 761 \\
Kashkan & 167 & 40 & 5 & 459 & 643 \\
Lower Karkheh & 242 & 3 & 0 & 524 & 731 \\
\hline Total & 1,561 & 594 & 0 & 0 & 245 \\
\hline
\end{tabular}

* Qanat - a gently sloping underground tunnel for irrigation purposes, especially in ancient Persia; also called kanat.

In the Karkheh River Basin, the highest water extraction comes from irrigation. Table 2.5 presents the current and planned water allocations to different sectors in the basin. Total water demand for different sectors will increase by $80 \%$ in 2025 whereas demands for irrigation will be $82 \%$ of the total demand.

Table 2.5: Current and planned water allocations for different sectors in the basin (Source: Masih et al., 2009).

\begin{tabular}{lllllll}
\hline Sector & \multicolumn{6}{l}{ Water allocations in different years $\left(10^{6} \times \mathrm{m}^{3}\right)$} \\
\cline { 2 - 7 } & 2001 & 2006 & 2011 & 2016 & 2021 & 2025 \\
\hline Rural areas & 59 & 62 & 66 & 69 & 70 & 67 \\
Urban areas & 203 & 231 & 242 & 259 & 278 & 295 \\
Mining & 0 & 1 & 1 & 1 & 2 & 2 \\
Industry & 23 & 30 & 57 & 76 & 93 & 113 \\
Irrigated agriculture & 4,149 & 6,879 & 6,814 & 7,135 & 7,476 & 7,416 \\
Fish farming & 14 & 119 & 249 & 379 & 477 & 510 \\
Environment & 500 & 500 & 500 & 500 & 500 & 500 \\
\hline Total & 4,948 & 7,822 & 7,929 & 8,419 & 8,896 & 8,903 \\
\hline
\end{tabular}

The basin's water resources are subject to growing water demands that further increases water scarcity. To classify water scarcity, Bos (2005) introduced the drainage ratio, which stands for "the volume of water drained from an area over the volume of water that enters the area". According to this definition, the volume of water that enters the area includes precipitation and the inflows from upstream sub-basins. Small values $(<0.1)$ indicate that water is very scarce while high values ( $>0.33$ ) indicate that water is abundantly available. 
As shown in Figure 2.7, the average drainage ratio for the period from 2000 to 2003 for the four major sub-basins in the Upper Karkheh area show a reduction relative to the period from 1990 to 1995 .

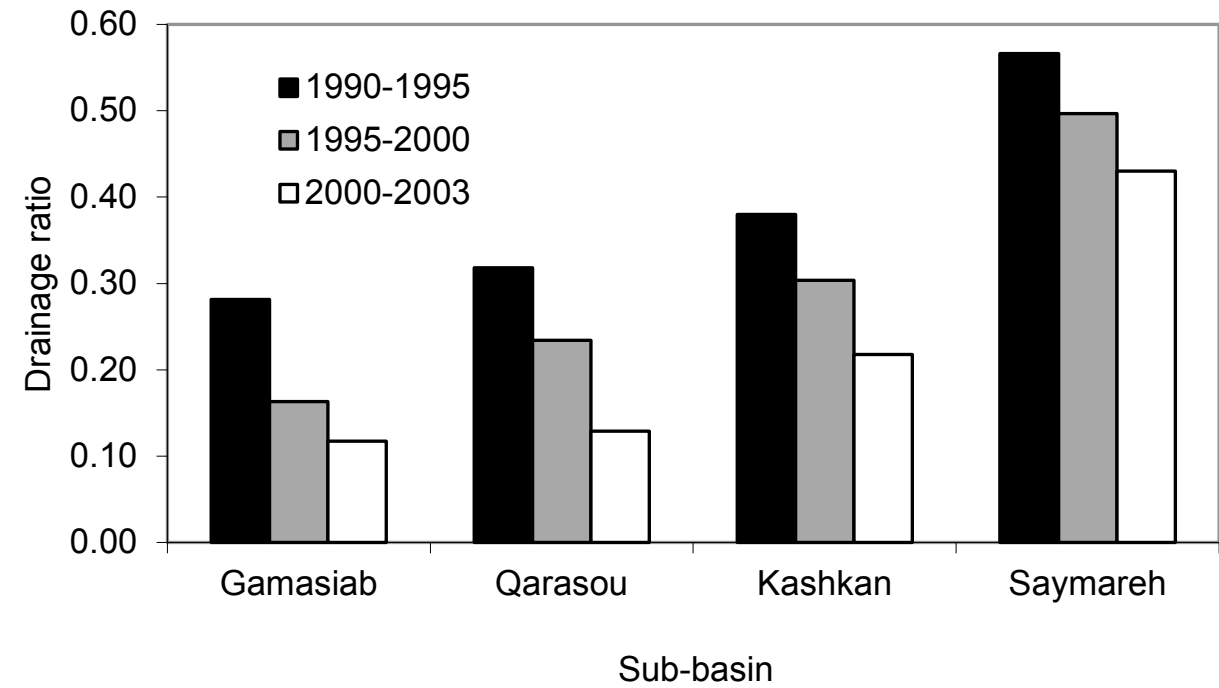

Figure 2.7: Drainage ratios for different sub-basins in the Upper Karkheh area.

As shown in Figure 2.7, the drainage ratio for the four major sub-basins in the Upper Karkheh has decreased over the past decades. Two sub-basins in the Upper Karkheh already are water scarce by the low 18rainage ratio. The pronounced decreases of ratios for the period 1995-2000 and 2000-2003 indicate that water uses from these sub-basins have increased.

\subsection{Demographic setting}

In 1996, the estimated population of the Karkheh River Basin was 3,057,000 (Table 2.6). Rural population growth is significantly lower when compared with the urban growth rate in the Karkheh Basin. The major reason for the low population growth in the rural areas is the trend towards smaller families, and migration of people to larger cities to find employment and better living conditions. From 1976 to 1994, about $10 \%$ of the rural population shifted their activities from agriculture and most of them migrated to cities (Ashrafi et al., 2004). 
Table 2.6: Population trends in sub-basins of the Karkheh River Basin (Source: Marjanizadeh, 2008).

\begin{tabular}{lcccc}
\hline & \multicolumn{4}{c}{ Population (1,000s) } \\
\cline { 2 - 5 } Sub-basin & 1976 & 1996 & 2006 & 2025 \\
\hline Gamasiab & 605 & 984 & 1,063 & 1,225 \\
Qarasou & 473 & 904 & 1,017 & 1,258 \\
Saymareh & 326 & 378 & 450 & 612 \\
Kashkan & 362 & 637 & 734 & 946 \\
Lower Karkheh & 146 & 154 & 187 & 263 \\
\hline Total & 1,912 & 3,057 & 3,451 & 4,304 \\
\hline
\end{tabular}

Kermanshah and Khoramabad are two major cities located in the Qarasou and Kashkan sub-basins, respectively. The relatively high population growth rates in these two cities indicate high migration rates from rural areas.

\subsection{Water management}

The growing competition among the various uses of water is a major concern in the basin. In the Lower Basin, the sustainability of irrigated agriculture and wetland ecosystems has been marred by low water productivity, increasing salinity and reduced surface water supplies. In the Karkheh River Basin, large-scale irrigation development is on its way, but the knowledge and understanding of basin hydrology (including water balance variations in space and time) and the impact of these developments on other users and water use across the basin are not well known (Masih et al., 2009). Under these circumstances, the sustainable management of water resources is a complicated issue. The methods developed in this study may contribute to improving the understanding of basin hydrological processes. The insights and recommendations by this study may improve the management of water resources in the Karkheh River Basin, similar regions of Iran and some other areas of the world.

\subsection{Data availability}

Meteorological and streamflow data for period March 2000 to December 2003 have been collected from respective organizations and authorities (Table 2.7). Figure 2.2 shows the location of 30 precipitation stations within and near the study area. Time series of daily streamflow is available from 15 gauging stations (Figure 2.2). Data on inflow and outflow volumes of the Karkheh Dam were only available from July 2002 onwards. Using the locations of the river gauging stations and a Shuttle Radar Topography Mission (SRTM) digital elevation model (DEM) (acquired from http://srtm.csi.cgiar.org/), the upstream contributing area for each river gauging station was estimated. 
Table 2.7: Meteorological and streamflow data used in this study.

\begin{tabular}{lcccc}
\hline \multicolumn{1}{c}{ Parameter } & Units & Frequency & Source & Time period \\
\hline Temperature & Celsius & daily & IRIMO $^{*}$ & $2000-2004$ \\
Relative humidity & $\%$ & three hourly & IRIMO & $2000-2004$ \\
Wind speed & $\mathrm{m} \mathrm{s}^{-1}$ & three hourly & IRIMO & $2000-2004$ \\
Sunshine hours & hours & daily & IRIMO & $2000-2004$ \\
Precipitation & $\mathrm{mm}$ & daily & IRIMO & $2000-2004$ \\
streamflow & $\mathrm{m}^{3} \mathrm{~s}^{-1}$ & daily & IPM $^{*}$ & $2000-2004$
\end{tabular}

${ }^{*}$ IRIMO - Islamic Republic of Iran Meteorological Organization. IPM - Iranian Power Ministry.

For the estimation of ETa, 87 cloud-free MODIS-TERRA images covering the study area were acquired for the period, March 2000 to December 2003 (Table 2.8). Land use was classified using the time series of MODIS-TERRA with bands in the visible, near infrared and thermal infrared areas of the electromagnetic spectrum. Images served to identify irrigated and rainfed areas.

Table 2.8: Acquisition dates of MODIS-TERRA images for the study period (Source: http://ladsweb.nascom.nasa.gov/).

\begin{tabular}{lllll}
\hline & \multicolumn{1}{c}{2000} & \multicolumn{1}{c}{2002} & \multicolumn{2}{c}{2003} \\
\hline January & & 02,15 & 20 & 12 \\
February & & 07,24 & 6,27 & 06 \\
March & $05,06,16$ & 11,29 & 19,31 & 15 \\
April & $04,11,22$ & 10,25 & 21,28 & 29 \\
May & 18,25 & 06,24 & 8,26 & 24 \\
June & 03,19 & 11,26 & $2,28,17$ & 05,19 \\
July & $05,12,28$ & 6,13 & $7,16,23$ & 02 \\
August & $04,22,29$ & 30 & $7,19,30$ & $02,10,22$ \\
September & $08,23,27$ & 12,30 & 14,27 & $07,16,25$ \\
October & 13,29 & 14 & 9,21 & $06,11,25$ \\
November & 21 & 01,22 & 03 & 17 \\
December & 06 & 13 & 08 & 21 \\
\hline
\end{tabular}




\section{Remote Sensing and Hydrological Modelling in Water Resources Management: A Literature Review}

\subsection{Introduction}

The availability of hydrological data is critical for water resources planning and management. Increasing anthropogenic pressure on water resources requires accurate knowledge of water resources dynamics However, in many river basins in developing countries, due to limited financial, human and technical resources, in-situ data is lacking while, moreover, hydrological networks are poorly designed (Wolski, 1999). In-situ data collection relies on sensors that can only measure at point scale. Such information cannot be assumed to be representative for large areas. Hydrological processes exist over a wide range of scales in space and time. In such situations, satellite remote sensing $(R S)$ is useful to monitor and acquire spatiotemporal variations of land surface characteristics over large areas (e.g., Heilman et al., 1982; Moran et al., 1997; Gallego, 2004; Xie et al., 2007). Satellite RS is now closely monitoring the state of the Earth surface, including water fluxes (i.e. precipitation, evapotranspiration) and hydrological variables (i.e. soil moisture and water levels). Over the years, the usefulness of satellite remote sensing data to provide spatial information on water resources has been demonstrated by several studies (e.g., Meijerink et al., 2005; Khan et al., 2008; Chowdary et al., 2009; Casa et al., 2009).

In literature it is often claimed that accurate measurements from satellite RS can improve the performace of hydrological models that simulate spatial and temporal variations of variables such as streamflow and groundwater levels. Also model-based information is used more and more frequently for the decision making in water resources management (e.g., Andersson and Moody, 2004; Olsson and Andersson, 2007).

The following section presents short descriptions on hydrological model applications and the use of remote sensing in water resources management.

\subsection{Hydrological models}

For simulation of the complex relation between rainfall and runoff, a wide range of model approaches are suggested in literature. Models can be very complex and may rely on physically based flow equations with distributed (Abbott et al., 1986) or semi-distributed (Reggiani and Rientjes, 2005) model domains. Models may also be relatively simple according to their flow equations and data requirements, which apply to lumped models. The most 
popular class of hydrological models is the conceptual models, which are based on the principles of mass conservation and simplified forms to conserve momentum and energy (De Vos and Rientjes, 2007). In such approaches, it is common to apply lumped or semi-distributed model domains with relatively low data requirements. Popular examples include the Sacramento soil moisture accounting model (Burnash, 1995), the HBV model (Bergström, 1976; Lindström et al., 1997) or, parsimoniously, very simple storage-based models such as NAM (Madsen, 2003), GR4J (Perrin et al., 2003) and FLEX (Fenicia et al., 2007). Probably the most common use of these models is for simulation of the rainfall-runoff relation for flow simulation and forecasting.

In the lumped model approach, the model domain is considered a homogeneous unit ignoring spatial variability of model parameters and forcing data such as precipitation and evapotranspiration. In contrast, the distributed models can incorporate the spatial variations, forcing data and parameters by partitioning the river basin into computational units such as sub-basins or grids. The major hydrological processes described by these models commonly include canopy interception, evapotranspiration, snowmelt, interflow, overland flow, channel flow, unsaturated subsurface flow and saturated subsurface flow. These processes are subjected to change over space and time domains. Some models describe part of the processes by differential equations based on simplified hydraulic laws, whereas other processes are expressed by empirical algebraic equations (Arnold, et al., 1998).

Model parameters used in conceptual models serve to represent catchment properties and characteristics. In modelling, parameters act as a descriptor of a single or a number of catchment characteristics that relate to land use, soils and topography, but also on geometrical aspects to consider the effect of catchment shape and elevation on runoff generation. Since parameters are not directly measurable, they require estimation and optimization through calibration with the objective to have good agreement between observed and simulated counterparts of some hydrologic variables of interest (Madsen, 2000). In rainfall-runoff modelling, such a variable is usually the streamflow that must be considered as an integrated response variable in which all aspects and effects of upstream processes are lumped. In the protocol of modelling, the (accumulated) deviation between observations and simulated counterparts is termed the 'residual error' that may arise from a large number of causes. Already, in the early work of Carrera and Neuman (1986), a number of causes have been identified such as 1) deficiencies in the structure of the model, 2) incorrectness of parameter values, 3) errors by incomplete representations of forcing data such as precipitation and evapotranspiration, and 4) observation errors of variables. Other sources of 
error relate to the initialization of a model and also to applied boundary fluxes to allow transfer of mass across the model domain.

\section{Hydrological model calibration}

General methodologies related to hydrological model calibration and validation have been subject to considerable discussion in scientific literature (Beven, 1989; Bergström, 1991; Refsgaard, 1997; Seibert and McDonnell 2002; Fenicia et al., 2007). In runoff hydrology and basin-scale water resources management, it is common to calibrate models by using streamflow time series observed at one or few locations in the river basin. Beven (1989) stated that comparison of predicted and observed hydrographs is a necessary test, but cannot be considered a sufficient test of models that purport to simulate the internal responses of a catchment. Figure 3.1 shows a flowchart model calibration procedure.

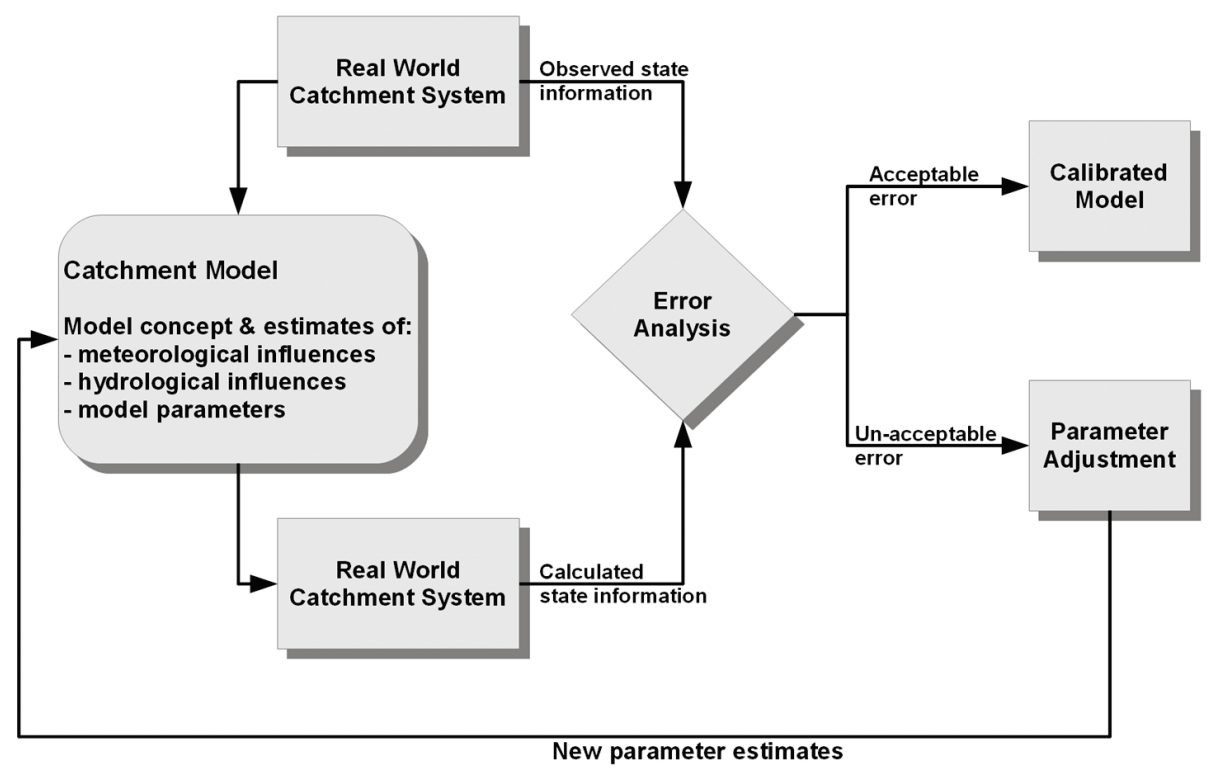

Figure 3.1: Flow chart showing the procedure to manual model calibration (adapted from Rientjes, 2004).

Furthermore, a large range of models with different complexities are available and all require parameterization to reflect real-world basin settings. Also, calibration can be through different procedures that may include a single objective or multiple objectives (Gupta et al., 1998; Vrugt et al., 2003; De Vos and Rientjes 2007, 2008), single variable or multi-variable (Bergström et al., 2002; Cao et al., 2006) or time-variant parameters (de Vos et al., 2010).

Simulation of one variable, such as streamflow, as close as possible to the gauge observations, does not guarantee the satisfactory simulation of a 
second variable of model output, such as actual evapotranspiration (Mroczkowski et al., 1997; Seibert and McDonnell, 2002). As such, several studies (Madsen, 2000; Gupta et al., 2008; Khu et al., 2008; among others) have stated that, for evaluation of rainfall-runoff models, a second model output variable such as groundwater hydraulic heads or soil moisture should be considered. Seibert (1997), Fenicia et al. (2005) and Khu et al. (2008) report on multi-variable calibration by using groundwater piezometer graphs next to streamflow. Downer and Ogden (2003) report on the use of a simple soil moisture storage indicator or soil wetness index whereas Campo et al. (2006) used satellite-based soil moisture estimates as a second variable. Gupta et al. (1999) calibrated Biosphere-Atmosphere Transfer Scheme (BATS) using measured values of sensible heat, latent heat, ground temperature and soil moisture, and have stated that calibrating for one model output variable is not sufficient to simulate other variables accurately. Bergström, et al. (2002) used snow and groundwater depths to calibrate a conceptual hydrological model over a $0.5 \mathrm{~km}^{2}$ small catchment in northern Sweden. Cao et al. (2006) used measured streamflow and soil moisture to calibrate the SWAT model over a 2,075 $\mathrm{km}^{2}$ Motueka River Basin situated at the north of the South Island of New Zealand.

Despite the suggestion by several studies about multi-variable calibration, finding data for such calibration is not alwayspossible. Measurements such as groundwater levels, soil moisture or fluxes measured at ground stations are not commonly available or representative. This makes the general applicability of the multi-variable calibration is restricted to catchments where data on variables other than streamflow is available. However, recent development of satellite sensors and algorithms to derive hydrological information based on satellite data can be used as an alternative way of obtaining calibration data. In recent hydrological literature, calibration attempts by using satellite remote sensing data is presented. The following section describes the use of $R S$ data for hydrological modelling and water resources management.

\subsection{Remote sensing}

A major focus of satellite RS research in hydrology and water resources management has been the development of approaches for estimating hydrometeorological states and fluxes (Schmugge et al., 2002). Advances in satellite sensors during the past decade have made it an ideal tool for monitoring certain environmental processes of great socioeconomic interest (Jha et al., 2007; Bandara, 2006; Meijerink et al., 2007). In general, remote sensors cannot directly measure water fluxes or hydrological and meteorologic variables. However, remote sensors can observe land surface characteristics such as land cover, land surface reflectance, land surface 
temperature, vegetation properties and cloud characteristics such as cloud top temperatures and thickness.

In literature, ongoing efforts are reported on development of new algorithms that rely on satellite RS data and image processing techniques to estimate hydrological variables (Su, 2002), land surface characteristics (Boegh et al., 2004) and several vegetation indices (e.g., Tucker, 1979; Xia, 1994, Borge and Leblanc, 2001; Panda et al., 2010). Examples of useful satellite based information derived for water resources management is biomass growth (Dong et al., 2003; Lobell et al., 2003; Ines et al., 2006), crop water parameters (Blaes and Defourny, 2003) and crop coefficients (Mekonnen and Bastiaanssen, 2000; Er-Raki et al., 2007), irrigation performance indicators (Bos et al., 2005; Consoli et al., 2006), and water productivity indicators (Zwart and Bastiaanssen, 2007; Teixeira, 2008; Karatas et al., 2009), is being derived.

Common satellite RS applications in hydrological modelling are deriving information on land use, elevation, meteorology, topographic and roughness information to parameterize models (Rientjes et al., 2011). Chen et al. (2005) used optical remote sensing data (Landsat TM at $30 \mathrm{~m}$ resolution) to characterize the distributions of vegetation types and the leaf area index (LAI) to parameterize a distributed hydrological model over a small catchment in Saskatchewan, Canada. Other similar applications are found in McMicheal et al. (2006) and Montzka et al. (2008). In contrast to these applications, there have been studies to estimate meteorological data such as precipitation (Haile et al., 2009) and potential evapotranspiration (Wilk et al., 2006; Stisen et al., 2008). Sánchez et al. (2010) used a series of Landsat 7 ETM+ images to estimate actual evapotranspiration over the central part of the Duero Basin in Spain. They have established a relationship between Normalized Difference Vegetation Index (NDVI) and the crop coefficient. Estimated crop coefficients along with reference evapotranspiration (ET0), based on the method described in FAO56 (Allen et al., 1998), were used to estimate actual evapotranspiration. Estimated ETa values were used as input to a HIDROMORE distributed hydrologic model.

Over the past decade, a number of algorithms have been developed for mapping actual evapotranspiration using satellite RS data (e.g., Bastiaanssen et al., 1998; Su, 2002; Tang et al., 2009). In these algorithms, the surface energy balance approach is used. Evapotranspiration is indirectly estimated as a residual in the surface energy balance. Factors that affect the surface energy balance include climatic parameters (energy availability, humidity gradient away from the leaf surface and wind speed), environmental conditions (water availability and soil characteristics) and vegetation characteristics (leaf area index, vegetation height and stomatal resistance). 
Land surface state variables, such as vegetation properties, surface temperature, surface albedo, emissivity, reflectance and land cover, are observable by remote sensing and can be related directly to the factors that affect surface energy balance.

Use of satellite RS data for hydrological model calibration and validation is not common, and only a few studies have been reported in hydrological literature. Biftu and Gan (2001) compared satellite-based net radiation and surface temperature with simulated counterparts on a daily base to spatially validate a semi-distributed hydrological model. Crow et al. (2003) used space borne radiometric surface temperature and observed streamflow data to calibrate the Variable Infiltration Capacity (VIC) model. Simulated ETa fluxes were evaluated using data from a several number of flux towers. They found that multi-variable calibration reduced the error in ETa simulation by up to $20 \%$ relative to single variable calibration. Boegh et al. (2004) used satellite image-based leaf area index (LAI) and actual evapotranspiration to spatially validate the outputs of a distributed hydrological model. However, the comparison was restricted to one satellite overpass only. Wegehenkel and Kersebaum (2005) validated the results of a semi-distributed THESEUS hydrological model (Wegehenkel, 2000) using RS data. The simulated transpiration rates by the model were compared to RS-based transpiration rates derived through a simple empirical relationship between transpiration rates and Normalized Difference Vegetation Index (NDVI). Immerzeel and Droogers (2008) have used satellite-based actual evapotranspiration estimates to calibrate the semi-distributed Soil and Water Assessment Tool (SWAT) (Arnold et al., 1998) in part of the Krishna River Basin in India. They compared monthly actual evapotranspiration simulated by the SWAT model and that derived from RS data in different sub-catchments. In Winsemius et al. (2008), satellite-estimated actual evapotranspiration (ETa) was used to constrain land surface-related parameter values of a simplified version of the one-dimensional box-model HBV in the Luangwa River Basin in Zambia. These studies show a new direction on the use of satellite-based hydrological information for model calibration and validation.

Remote sensing, may in some cases, be the only viable option to obtain the data needed for large-scale hydrological modelling studies. These data include land surface and climate data and applications are for forcing, parameterizing, calibrating and validating hydrological models. In contrast to conventional methods of data collection, the main advantages of remote sensing techniques for hydrological modelling can be summarized as: (1) spatially distributed measurements instead of point measurements; (2) high spatial and temporal resolution; (3) data available in digital form; and (4) information can be retrieved for remotely located and inaccessible areas. 
Despite the advantages of using satellite data in hydrological modelling, most hydrological models in operational use are not designed to use spatially distributed data, which is a prerequisite to the sensible use of remotely sensed data. Research into the development of generalized algorithms and the design of hydrological models, which are more suited to the routine use of remotely sensed data, is needed. Such research should lead to operational uses of hydrological modelling. The benefit of this will be an increased use of satellite data in applications other than research.

\subsection{Modelling tools}

\subsubsection{HBV hydrological model}

To simulate the streamflow, the HBV model approach by Lindström, et al. (1997) was selected. This water balance-based conceptual model has applications primarily in simulating the rainfall-runoff relation. Applications of the approach are known for lumped model domains (Seibert, 1997; Seibert and McDonnell, 2002) and semi-distributed model domains (Lindström et al., 1997; Yu and Yang, 2000). To simulate streamflow, the model requires rainfall, temperature and potential evapotranspiration as input data. According to SMHI (2006), sub-catchments can be further divided into zones based on elevation and land use classes. Lindström et al. (1997) mentioned that the structure of the model may be considered robust by the large number of successful applications under various physiographic and climatological conditions. The main reason for selecting the model is its relatively low complexity with low demand for input data whereas runoff production mechanisms follow a sound physical description. Figure 3.2 illustrates the basic diagram of the model used to simulate streamflow. 


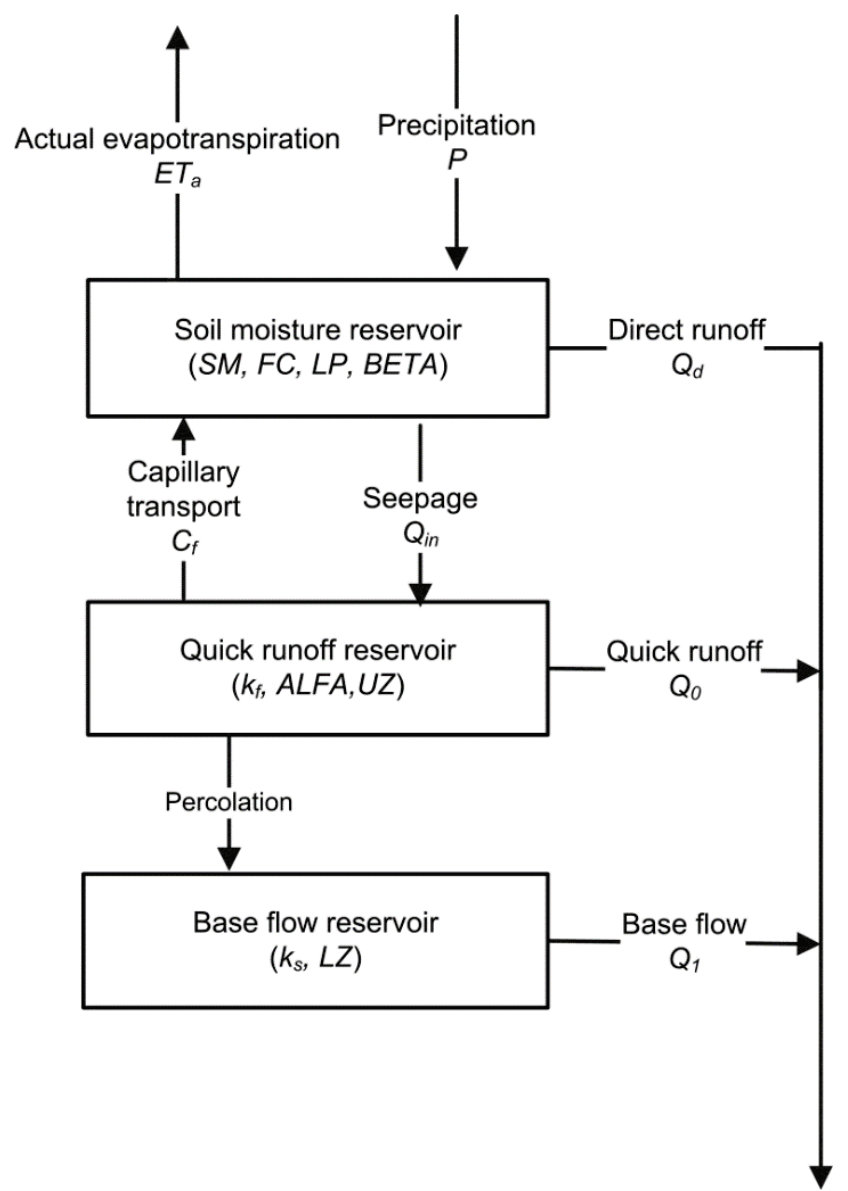

Figure 3.2: Schematization of the HBV-96 model structure (based on Lindström et al., 1997).

The soil moisture routine controls the formation of direct and indirect runoff. The runoff generation function of the HBV model covers a wide range of soil conditions with only two empirical parameters, FC and BETA. FC corresponds to the maximum water-holding capacity of the soil and BETA describes how the runoff coefficient increases as this limit is approached. Direct runoff $\left(Q_{d}\right)$ occurs if the simulated soil moisture storage that is conceptualized through the soil moisture reservoir representing the unsaturated soil exceeds parameter FC:

$$
Q_{d}=\max (P+S M-F C, 0)
$$

where: $S M(\mathrm{~mm})$ is the soil moisture depth, $F C(\mathrm{~mm})$ maximum waterholding capacity of the soil and $P(\mathrm{~mm})$ is precipitation amount. 
The remaining part of the precipitation $\left(P-Q_{d}\right)$ infiltrates to the soil moisture reservoir, seeps through the soil layer or leaves the soil moisture reservoir via evapotranspiration. The seepage through the soil layer causes indirect runoff $\left(Q_{i n}\right)$, which is determined through a power relationship with parameter BETA as shown in Equation (3.2) with the amount of infiltrating water and the soil moisture storage as:

$$
Q_{\text {in }}=\left[\frac{S M}{F C}\right]^{B E T A} \cdot\left(P-Q_{d}\right)
$$

where: $Q_{\text {in }}\left(\mathrm{mm} \mathrm{d}^{-1}\right)$ is the indirect runoff, BETA is the unit less parameter that accounts for the nonlinear relationship between seepage and the available water in the soil. Figure 3.3 illustrates the runoff response to the increment of rainfall in the HBV model.

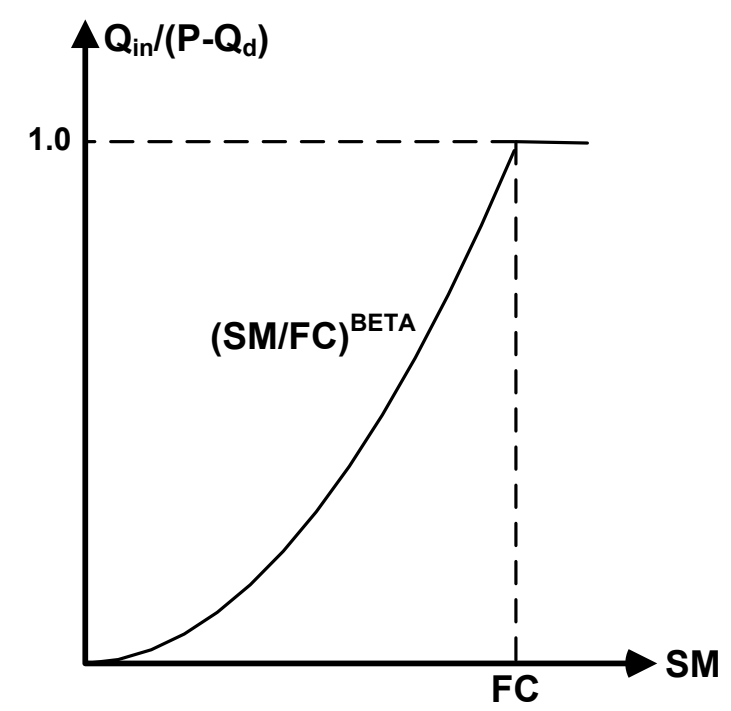

Figure 3.3: Runoff response to the increment of rainfall.

Equation 3.2 indicates that indirect runoff increases with increasing soil moisture storage, but also decreases to zero if infiltration becomes zero.

Actual evapotranspiration $\left(E T_{a}\right)$ depends on the potential evapotranspiration, the soil moisture storage in the reservoir and a parameter $L P(-)$, which is a limit above which evapotranspiration reaches its reference value. $E T_{a}$ is estimated following Equations 3.3 and 3.4.

$$
\begin{aligned}
& E T_{a}=\frac{S M}{L P . F C} \cdot E T_{0} \text { if } S M<(L P . F C) \\
& E T_{a}=E T_{0} \quad \text { if } S M \geq(L P . F C)
\end{aligned}
$$


where: $E T_{a}\left(\mathrm{~mm} \mathrm{~d}^{-1}\right)$ is the actual evapotranspiration and $E T_{0}\left(\mathrm{~mm} \mathrm{~d}^{-1}\right)$ is the potential evapotranspiration. $L P$ is a fraction between 0 and 1 .

The actual evapotranspiration is thus equal to the potential evapotranspiration when the actual soil moisture is above a specified threshold $(L P)$. Figure 3.4 illustrates the relationship between actual and potential evapotranspiration.

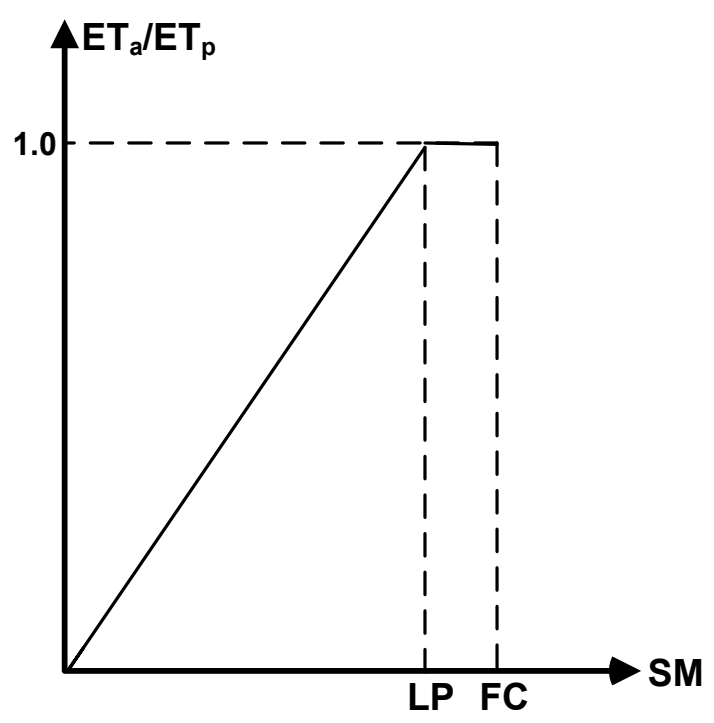

Figure 3.4: Relationship between actual and potential evapotranspiration.

In the quick runoff routine, three components are distinguished, which are percolation to the base flow reservoir, capillary transport to the soil moisture reservoir and quick runoff. Percolation is denoted through parameter PERC ( $\left.\mathrm{mm} \mathrm{d}^{-1}\right)$, which is a constant percolation rate that occurs when water is available in the quick runoff reservoir. Capillary transport is estimated following Equation 3.5.

$$
C_{f}=C F L U X\left[\frac{F C-S M}{F C}\right]
$$

where: $C_{f}\left(\mathrm{~mm} \mathrm{~d}^{-1}\right)$ is the capillary flow and $\operatorname{CFLUX}\left(\mathrm{mm} \mathrm{d}^{-1}\right)$ is the maximum value for capillary flow.

If the yield from the soil moisture routine is higher than the percolation, water becomes available for quick flow as estimated by by Equation 3.6.

$$
Q_{0}=K_{f} \cdot U Z^{(1+A L F A)}
$$


where: $Q_{0}\left(\mathrm{~mm} \mathrm{~d}^{-1}\right)$ is the quick runoff, $U Z(\mathrm{~mm})$ is the storage in the quick runoff reservoir, ALFA (-) is a measure for the nonlinearity of the flow in the quick runoff reservoir and $K_{f}\left(\mathrm{~d}^{-1}\right)$ is a recession coefficient. The delayed flow of the catchment is generated in the base flow routine through Equation 3.7.

$$
Q_{1}=K_{S} \cdot L Z
$$

where: $Q_{1}\left(\mathrm{~mm} \mathrm{~d}^{-1}\right)$ is the base flow, $L Z(\mathrm{~mm})$ is the storage in the base flow reservoir and $K_{\mathrm{s}}\left(\mathrm{d}^{-1}\right)$ is a recession coefficient.

In the routing routine the discharges are routed downstream with a modified version of Muskingum's equation (Booij, 2002). In this PhD work, the transformation function is not used.

\subsubsection{Surface Energy Balance System (SEBS)}

In this study, the satellite-based surface energy balance system (SEBS) (Su, 2002 ) is used to estimate $E T_{a}$. SEBS converts satellite radiances into surface albedo, vegetation indices and surface temperature. These land surface characteristics and routinely collected meteorological data are used to solve the energy balance equation which reads:

$$
R_{n}=G_{0}+H+\lambda E
$$

where: $R_{n}$ is the net radiation, $G_{0}$ is the soil heat flux, $H$ is the sensible flux and $\lambda E$ is the latent heat flux associated with the transfer of moisture into the atmosphere. All terms are of unit $\mathrm{Wm}^{-2}$. The flow chart in Figure 3.5 shows the main steps in the SEBS algorithm. 


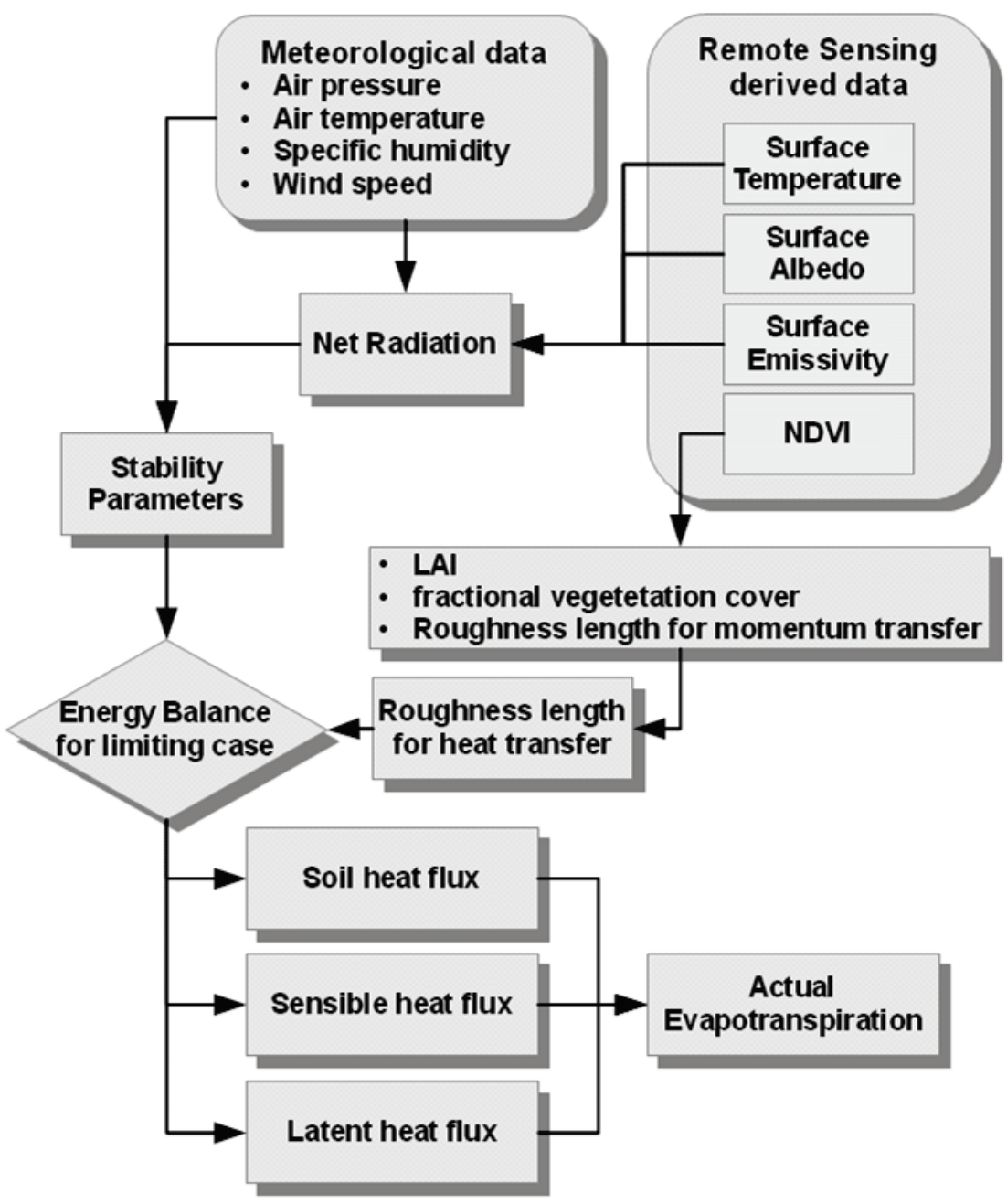

Figure 3.5: Flowchart of SEBS.

$R_{n}$ is a resultant variable by subtracting outgoing energy fluxes from the incoming energy fluxes following Equation 3.9:

$$
R_{n}=\left(1-r_{0}\right) \cdot K^{\downarrow}+\varepsilon_{s} \cdot \varepsilon_{a} \cdot T_{a}^{4}-\varepsilon_{s} \cdot \sigma \cdot T_{s}^{4}
$$

where: $r_{0}(-)$ is the broadband surface albedo, $K^{\downarrow}\left(\mathrm{Wm}^{-2}\right)$ is the downward solar radiation, $\varepsilon_{a}(-)$ is the emissivity of air, $\varepsilon_{s}(-)$ is the surface emissivity, $\sigma\left(\mathrm{Wm}^{-2} \mathrm{~K}^{-4}\right)$ is the Stefan-Bolzmann constant, $T_{a}(\mathrm{~K})$ is the air temperature and $T_{s}(\mathrm{~K})$ is the surface temperature measured by a remote sensor. A 
description on the estimation of the parameters is denied here since many such descriptions are available in literature (e.g., Iqbal, 1983). The equation to estimate the soil heat flux reads:

$$
G_{0}=R_{n} \cdot\left[\Gamma_{c}+\left(1-f_{c}\right) \cdot\left(\Gamma_{s}-\Gamma_{c}\right)\right]
$$

where: it is assumed that the ratio of soil heat flux to net radiation $\Gamma_{\mathrm{c}}=0.05$ for full vegetation canopy (Monteith, 1973) and $\Gamma_{\mathrm{s}}=0.315$ for bare soil (Kustas and Daughtry, 1989). An interpolation is performed between these limiting cases using the fractional canopy coverage, $f_{c}$, which can be determined from RS data (Choudhury et al., 1994):

$$
f_{c}=1-\left[\frac{N D V I-N D V I_{\min }}{N D V I-N D V I_{\max }}\right]^{p}
$$

The exponent $p$ is the ratio of the leaf angle distribution and is taken as a constant (0.625), NDVI is the Normalized Difference Vegetation Index, and $N D V I_{\max }$ and $N D V I_{\min }$ are the $N D V I$ for full vegetation cover and bare soil, respectively.

The evaporative fraction is used to estimate actual evapotranspiration and is defined as the ratio of latent heat flux to the net available energy. Equation (3.8) can be rewritten and expressed as latent heat flux by considering evaporative fraction $\Lambda(-)$ and net available energy $\left(R_{n}-G_{0}\right)$ :

$$
\begin{aligned}
& \lambda E=\Lambda .\left(R_{n}-G_{0}\right) \\
& \text { where: } \Lambda=\frac{\lambda E}{H+\lambda E}=\frac{\lambda E}{R_{n-G_{0}}}
\end{aligned}
$$

The net available energy may have different time scales, from instantaneous (at the time of the satellite overpass) to daily integrated values, or for periods elapsing between two consecutive satellite images. For the time scale of 1 day or longer, $G_{0}$ can be ignored and net available energy reduced to net radiation $\left(R_{n}\right)$. For the daily time scale, $E T_{a 24}$ is formulated by assuming constant evaporative fraction over the day:

$$
E T_{a 24}=\frac{86400 \cdot 10^{3}}{\lambda \rho_{w}} \cdot \Lambda \cdot R_{n 24}
$$


where: $R_{n 24}\left(\mathrm{Wm}^{-2}\right)$ is the 24 -hour average net radiation, $\lambda\left(\mathrm{J} \mathrm{kg}^{-1}\right)$ is the latent heat of vaporization and $\rho_{w}\left(\mathrm{~kg} \mathrm{~m}^{-3}\right)$ is the density of water.

Daily net radiation is calculated using the following equation (de Bruin and Stricker, 2000):

$$
R_{n 24}=\left(1-1 \cdot 1 \cdot r_{0}\right) \cdot K^{\downarrow}-\frac{110 \cdot K^{\downarrow}}{K_{\text {exo }}^{\downarrow}}
$$

where: $r_{0}(-)$ is the surface albedo, $K^{\downarrow}$ is the global radiation at the surface level and $K^{\downarrow}$ exo is the extraterrestrial solar radiation. Incoming solar radiation $\left(K^{\downarrow}\right)$ is estimated using the standard equation suggested by Allen et al. (1998).

$$
K^{\downarrow}=\left(0.25+0.5 \cdot \frac{n}{N}\right) \cdot K_{\text {exo }}^{\downarrow}
$$

where: $n(\mathrm{hr})$ is the actual sunshine hours measured in the field and $N(\mathrm{hr})$ is the theoretical maximum hours of sunshine.

For the estimation of evaporative fraction, the energy balance consideration in limiting cases is used (Su, 2002). In the dry-limit, where the entire area is assumed to be dry, soil moisture is limited and no evapotranspiration can take place. The latent heat flux is assumed to be zero and the sensible heat flux $\left(H_{d r y}\right)$ will have its maximum value. It follows from Equation 3.8 that:

$$
H_{d r y}=R_{n}-G_{0}
$$

In the wet-limit, where the soil water supply is unlimited, evapotranspiration takes place at the potential rate. The evapotranspiration is only limited by the energy available under the given surface and atmospheric conditions. In that case, sensible heat flux $\left(H_{\text {wet }}\right)$ takes its minimum value:

$$
H_{\text {wet }}=R_{n}-G_{0}-\lambda E_{\text {wet }}
$$

The ratio between the latent heat flux for the actual evapotranspiration ( $\lambda E$ ) and the wet-limit latent heat flux $\left(\lambda E_{\text {wet }}\right)$ is called the relative evaporation $\Lambda_{r}(-)$. It is calculated as:

$$
\Lambda_{r}=\frac{\lambda E}{\lambda E_{\text {wet }}}=1-\left[\frac{\lambda E_{\text {wet }}-\lambda E}{\lambda E_{\text {wet }}}\right]=1-\left[\frac{H-H_{w e t}}{H_{\text {dry }}-H_{w e t}}\right]
$$


Substituting $\Lambda_{r}$ in Equation (3.14) results in:

$$
\Lambda=\frac{\lambda E}{R_{n}-G_{0}}=\frac{\Lambda_{r} \cdot \lambda E_{\text {wet }}}{R_{n}-G_{0}}
$$

To estimate $H_{\text {wet }}$, an equation similar to the Penman-Monteith combination equation is used (Monteith, 1965). Reference is made to Su (2002) and van der Kwast (2009) for further description.

SEBS has a wide range of applications. Jia et al. (2009) report on estimation of daily to annual evapotranspiration in the Yellow River Delta wetland whereas (Jia et al., 2003) report on estimation of the sensible heat flux in the Tomelloso area in Spain. Other examples are given in Qin et al. (2008), who used SEBS to estimate $E T_{a}$ over the Heith River Basin in China, and in Jin et al. (2009), who used SEBS to estimate water availability in the Zhangye River Basin in China. In Muthuwatta et al. $(2010 ; 2013)$, the approach has been applied to the Karkheh River Basin in Iran to estimate $E T_{a}$ at daily base for assessing aspects of water availability for crop production. SEBS- $E T_{a}$ estimates from the latter work (presented in Chapter 4) are used in this chapter.

SEBS calculated $E T_{a}$ values are affected by a range of uncertainties such as (a) the gradients of land surface temperature and air temperature, (b) the choice of fractional vegetation cover formula, (c) the selected displacement height and the height at which wind speed is measured, and (d) the representation of spatial variability of various properties of the study area (Gibson et al., 2011). Applications of SEBS have been validated for various satellite sensors. In McCabe and Wood (2006), data from Landsat-ETM, ASTER and MODIS satellite sensors were used to evaluate the effects of pixel sizes for the Walnut Creek watershed in Iowa. SEBS estimates were also compared with tower-based eddy covariance observations and indicated that SEBS- $E T_{a}$ values, in general, agreed well with an average deviation of 0.2 $\mathrm{mm} \mathrm{d}^{-1}$ for Landsat and $0.6 \mathrm{~mm} \mathrm{~d}^{-1}$ for ASTER at the pixel scale. In the case of MODIS, an average deviation of about $2 \mathrm{~mm} \mathrm{~d}^{-1}$ was found, but MODISbased $E T_{a}$ deviated by only $-3.6 \%$ and $2.9 \%$ for the estimates made by Landsat and ASTER, respectively, when observations are averaged over the much larger MODIS pixels. Su (2002) describes that SEBS can provide reliable estimates of sensible heat flux, as long as the variables used are within $50 \%$ of their actual values. Jia et al. (2009) show that SEBS-based estimates using MODIS images compared well to estimates based on FAO-56 Penman-Monteith equation (Allen et al., 1998) for wet vegetated surfaces. Ma et al., (2009) compared SEBS- $E T_{a}$ with in-situ estimates in the Tibetan 
Plateau and reported that SEBS estimates deviate by a highest value of $10 \%$ compared to the in-situ measurements. 


\section{Assessment of Water Availability and Consumption*}

\subsection{Introduction}

Allocation of water is a tradeoff between total available water and demand from various users such as agricultural, industrial, domestic, and environmental (Duan and Bastiaanssen, 2013). To understand such tradeoffs, and to adequately allocate water resources between various users, it is pertinent to have a reliable knowledge of hydrological variables that control water availability. Often there is a lack of field data on such hydrological variables which hampers judicious management and planning of water resources. Two important hydrological variables that are critical in quantifying water availability are precipitation and $E T_{a}$.

In many water resources studies, $E T_{a}$ is estimated as a residual to close the water balance. For instance, Domingo et al. (2001) and Loukas et al. (2005) calibrated a catchment-scale streamflow model by changing $E T_{a}$. In these studies, estimations of $E T_{a}$ cannot be considered to be reliable, since estimated $E T_{a}$ obscures and compensates for any shortcomings and limitations of the modelling approach. More advanced field procedures to estimate $E T_{a}$ are based on eddy correlation techniques and scintillometer data (Hemakumara et al., 2003). An important limitation of these approaches, however, is that the information is obtained only for small spatial domains, and estimates of $E T_{a}$ over larger areas are not ascertained. In this respect, considering effects of spatial and temporal variations of surface characteristics on $E T_{a}$ cannot be assured (Ahmad et al., 2006).

For estimating $E T_{a}$ over large spatial domains, satellite-based methods are advocated (Bastiaanssen and Chandrapala, 2003; Bandara, 2003; Bos, 2004; Ahmad et al., 2005). Satellite-based approaches provide information over large areas whereas satellite observations can also be repeated over time. These two features allow aggregation of hydrological indicators over large spatial domains for selected time periods. These advantages have triggered the development of approaches and algorithms to estimate spatially distributed $E T_{a}$. Typical to these approaches is the solution of the energy balance at the land surface (Bastiaanssen et al., 1998; Roerink et al., 2000; Jia et al., 2003), where $E T_{a}$ is calculated as the residual term of the energy balance equation.

* Based on: Muthuwatta, L.P., Ahmad, M.D., Bos, M.G., Rientjes, T.H.M., (2010). Assessment of water availability and consumption in the Karkheh River Basin (Iran) using remote sensing and geo-statistics. Water Resources Management, 24,459-484. 
For this study, the Surface Energy Balance System (SEBS) (Su, 2002, algorithm is selected since it has wide application globally. Furthermore, multiple studies have already validated SEBS and they show that the evapotranspiration and energy flux estimates by SEBS are comparable with the field measurements (Su, 2002; Jia et al., 2003; Van der Kwast et al., 2009; Jarmain and Mengistu, 2011).

In water balance studies, it is crucial to assess patterns of spatial and temporal variability of precipitation. Accurate assessments of spatio-temporal distributions of precipitation require a dense network of meteorological stations with observation intervals of maximum one day. Since available data in the study area represent point-scale observations by weather stations, spatial interpolation techniques are required to arrive at spatial coverage. In this study, precipitation data are accumulated over selected time periods and a global geo-statistical interpolation method based on the Kriging approach is adopted. The Kriging approache is commonly considered as being favorable when compared to local approaches such as inverse distance and isohyets procedures. The Kriging approach is based on the theory of regionalized variables (Journel and Huijbregts, 1978; Goovaerts, 1999; Sen and Habib, 2000) and relies on a semi-variogram that describes spatial dependency between observations. Furthermore, estimates are not largely affected by the presence of clustered data and Kriging algorithms are hence referred to as Best Linear Unbiased Estimators (BLUE). Capitalising on these characteristics, the Kriging approach assesses spatial correlation structures between neighbouring observations to predict attribute values at un-sampled locations. Tabios and Salas (1985) and Phillips et al. (1992), among others, have shown the effectiveness of the Kriging approach in estimating precipitation in heterogeneous terrains such as the Karkheh River Basin.

In this study, estimates of the spatial and temporal distribution of precipitation and $E T_{a}$ over the Karkheh River Basin were used to investigate the water availability and consumption on a monthly time step at the subbasin scale. 


\subsection{Methods}

\subsubsection{Precipitation}

To estimate the spatial distribution of precipitation, the Simple Kriging approach was used. Simple Kriging requires precipitation data to satisfy the condition of first order stationarity, which assumes a constant mean value over the area. This, however, is questionable for the study area due to its large-scale topographic variability. For this reason, the standardization procedure based on Equation 4.1, as proposed by Sutcliffe and Carpenter (1968), was used. In this procedure, the trend component of the precipitation data with respect to elevation was removed by adjusting the data to an equivalent precipitation at a certain elevation that was termed the standard elevation. Adjustments commonly result in higher values when compared to observed precipitation below the standard elevation and lower values when compared to observed precipitation above the standard elevation. Therefore, adjustments result in lower variability of precipitation ranges and values are closer to a certain mean value that satisfies the first-order stationarity assumption.

$$
P_{i, \text { Standard }}=P_{i}+\left(H_{\text {Standard }}-H_{i}\right) \cdot \xi
$$

where: $P_{\mathrm{i}, \text { Standard }}$ is the precipitation at the standard elevation for station $\mathrm{i}, P_{\mathrm{i}}$ is the measured precipitation at station $\mathrm{i}, H_{\mathrm{i}}$ is the elevation at station $\mathrm{i}$, $H_{\text {Standard }}$ is the area-specific standard elevation and $\xi$ is the precipitation lapse rate that is the rate of change in precipitation with respect to the elevation.

The standard elevation was established through a trial and error approach with the objective to find an elevation value for which precipitation does not show a specific trend with elevation. This was accomplished through the conversion of measured precipitation values into equivalent values at the various estimated standard elevations. Hereafter, these elevations are referred to as base elevations. The first base elevation value was considered the mean elevation for all precipitation stations. Thereafter, the measured precipitation values were converted to equivalent precipitation values at elevations with $100 \mathrm{~m}$ intervals above and below the mean.

Scatter plots between equivalent precipitation at the stations and the respective station elevations were examined for each base elevation. The base elevation at which precipitation values did not show a trend was considered as the standard elevation. These equivalent precipitation values are termed standardized precipitation values and serve for spatial interpolation by means of simple Kriging. After the interpolation, the trend 
component is added to the spatially distributed precipitation values following Equation 4.2.

$$
P=P_{\text {Standard }}-\left(H_{\text {Standard }}-H\right) . \xi
$$

where: $P$ is the corrected precipitation grid value, $P_{\text {standard }}$ is the interpolated precipitation grid value at the standard height and $H$ is the average pixel height extracted from the digital elevation model.

Monthly precipitation over sub-catchments is derived by disaggregating the annual precipitation using the ratio between monthly and annual precipitation in each sub-catchment. For this, monthly percentages of annual precipitation have been calculated for the precipitation stations. In situations where there is more than one station per sub-catchment, an average value of observed precipitation is considered before defining the ratios. In sub-catchments without stations, ratios are defined for the nearest station. In this way, a monthly ratio is defined for each sub-catchment. Sub-catchment-wide monthly precipitation is estimated by multiplying the annual precipitation map with the respective ratios.

\subsubsection{Actual evapotranspiration}

In this study, the Surface Energy Balance System (SEBS) (Su, 2002) has been adopted to estimate $E T_{a}$. SEBS has been developed to solve the surface energy balance by integrating remote sensing data in the visible, near infrared and thermal infrared bands, and in-situ meteorological data (Chapter 3). For SEBS applications, a number of land surface parameters are extracted from reflectance and radiance that are estimated using satellite images. Such parameters are surface albedo, emissivity, surface temperature, fractional vegetation cover and leaf area index. Required in-situ meteorological data are air pressure, temperature, humidity and wind speed. Radiation components, such as downward solar radiation and downward longwave radiation, can either be measured directly or defined through parameterization. Daily net radiation is calculated based on surface albedo, daily atmospheric transmittance and daily incoming extraterrestrial solar radiation. The daily evapotranspiration is determined from the total daily available energy, by assuming that the evaporative fraction $(\Lambda)$ is a constant over the day. Shuttleworth et al. (1989) identified the constancy of the evaporative fraction during daylight hours. They analyzed data from four clear-sky days over relatively homogeneous grasslands, and found that the midday evaporative fraction is nearly equal to the average daylight evaporative fraction. Nichols and Cuenca (1993) used 72 days of data and showed that the midday evaporative fraction was highly correlated with the average daytime evaporative fraction. The assumption of a constant 
evaporative fraction over a day is often used to estimate actual evapotranspiration (e.g., Farah et al., 2004; McCabe and Wood, 2006; Akbari et al., 2007; Immerzeel and Droogers, 2008).

For time integration over a month, season or year, the approach by Bastiaanssen et al. (2002) (Equation 4.3) is used in this study.

$$
E T_{\text {aint }}=\frac{d t \cdot 8 \cdot 64 \cdot 10^{7}}{\lambda_{\rho w}} \cdot \Lambda \cdot R_{n 24 t}
$$

where: $R_{n 24 t}\left(\mathrm{Wm}^{-2}\right)$ is the average net radiation value for the time interval $d t$ as measured in days, $\lambda\left(\mathrm{J} \mathrm{Kg}^{-1}\right)$ is the latent heat of vaporization, $\rho_{w}(\mathrm{Kg}$ $\mathrm{m}^{-3}$ ) is the density of water and $\Lambda$ is the evaporative fraction.

\subsection{Results and discussion}

\subsubsection{Precipitation}

The scatter plot of Figure 4.1 was prepared to assess the effect of elevation on annual precipitation. For all stations, daily precipitation was observed for November 2002 to October 2003 and, when accumulated, a relationship to elevation was found with the coefficient of determination $\left(R^{2}\right)$ of 0.89 . This value can be considered high and indicates that precipitation is closely related to elevation.

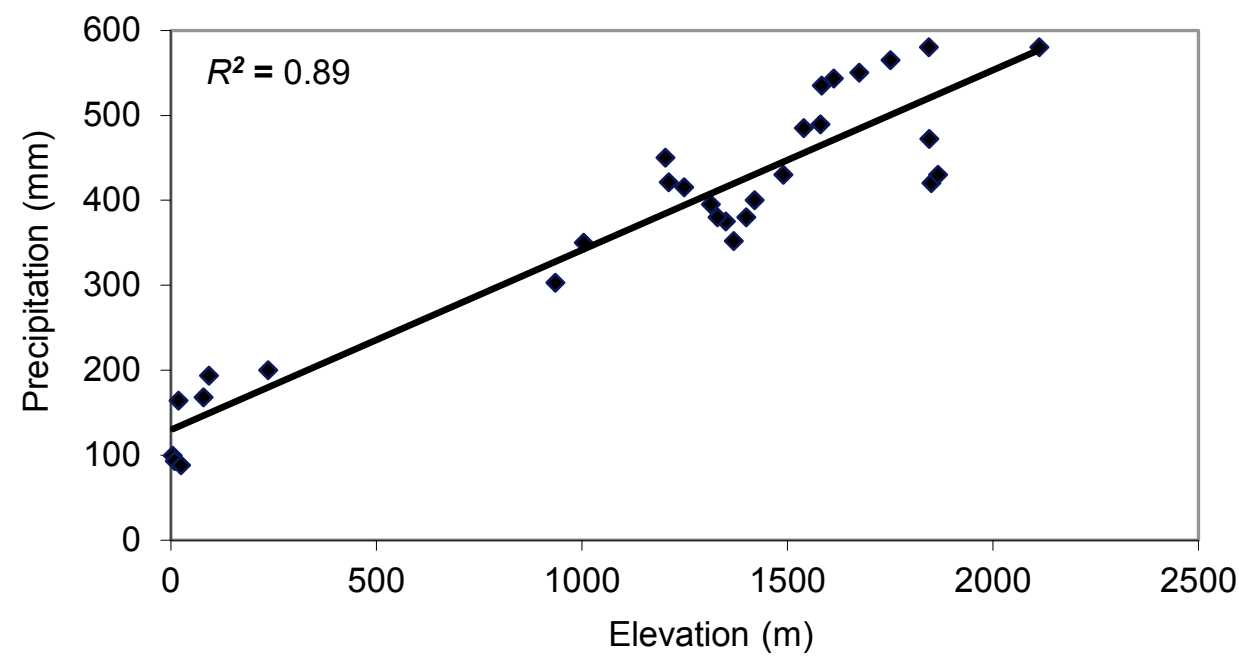

Figure 4.1: Scatter plot of annual precipitation over elevation. 
The graph shows a gradient of approximately 0.2 and indicates a precipitation lapse rate of $200 \mathrm{~mm}$ for a 1,000 $\mathrm{m}$ elevation increase. The analysis showed that the lower and upper bounds for the lapse rate were 173 $\mathrm{mm}$ for $1,000 \mathrm{~m}$ and $227 \mathrm{~mm}$ for $1,000 \mathrm{~m}$, respectively. The observed precipitation data was transformed to the equivalent values for a number of standard elevations, and it was found that the equivalent precipitation values at $1,200 \mathrm{~m}$ did not show a trend with elevation. Therefore, the 1,200 m elevation was selected as the standard elevation in this study.

Slopes facing North and West receive higher precipitation, as moisture is carried by the wind across the Northern and Western boundary of the basin. Spatial analysis on the scatter plot indicated that some points at higher elevation that are below the trend line represent precipitation stations located at the leeward side of terrain. Standardized precipitation values at 1,200 m were interpolated and the trend component was added using Equation (4.2). The result of interpolation is shown in Figure 4.2. The standard crossvalidation procedure (Daly et al., 1994) was used to verify the interpolated precipitation values at the pixels that cover the precipitation stations. Results indicated that the difference between interpolated and observed annual precipitation ranged between $2.9 \%$ and $6.7 \%$ of the observed precipitation. The same procedure was followed to interpolate precipitation data using the upper and lower boundaries of the lapse rate. Results indicate that the subcatchment-scale estimated annual precipitation using the maximum and minimum lapse rate does not differ more than $6 \%$ from precipitation estimates based on the established lapse rate. 


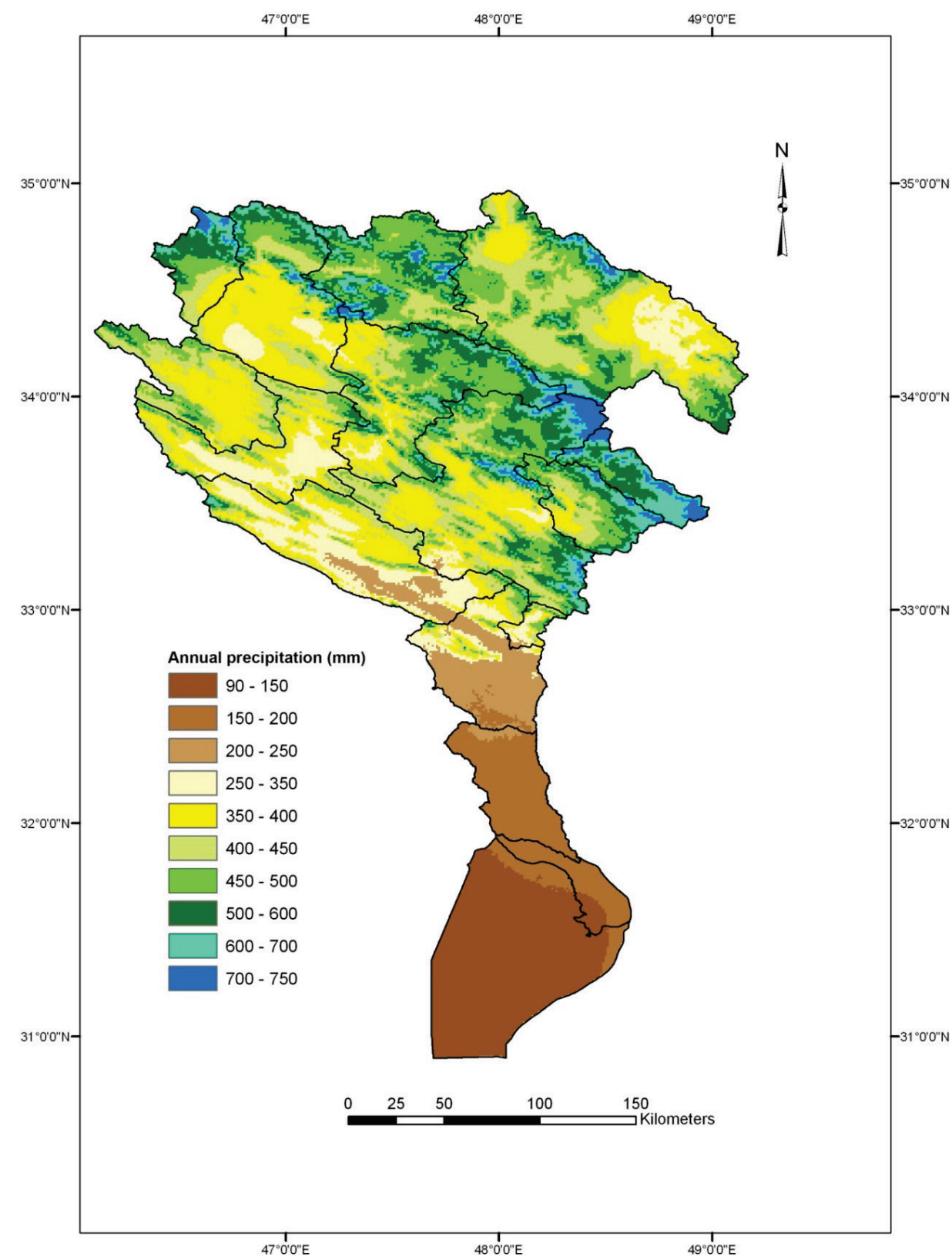

Figure 4.2: Spatial distribution of annual precipitation in the Karkheh River Basin from November 2002 to October 2003.

During the study period, the Karkheh Basin received $18,507 \times 10^{6} \mathrm{~m}^{3}$ of precipitation. Analysis of the annual precipitation data from 1994 to 2004 
showed that minimum and maximum precipitation was 14,500 and $23,500 \times$ $10^{6} \mathrm{~m}^{3} \mathrm{y}^{-1}$, respectively. Therefore, the period from November 2002 to October 2003 can be considered a moderate year in terms of precipitation volume. In the Upper Karkheh, there are 26 precipitation stations and precipitation values range from 303 to $592 \mathrm{~mm} \mathrm{y}^{-1}$. With the exception of Jelogir, Pole Zal and Paye pole, all sub-catchments located in the Upper Karkheh have at least one station which measured more than $500 \mathrm{~mm} \mathrm{y}^{-1}$ of precipitation for the study period. For instance, there are six stations distributed within the Doab sub-catchment. The minimum and maximum precipitation values for these stations were 321 and $570 \mathrm{~mm} \mathrm{y}^{-1}$, respectively. In Pole Dokhtar, precipitation values range from 396 to $567 \mathrm{~mm}$ $\mathrm{y}^{-1}$. Therefore, after interpolation, the average precipitation show values above $400 \mathrm{~mm} \mathrm{y}^{-1}$ for all sub-catchments except for Jelogir, Pole Zal and Paye pol. Results of monthly precipitation volumes at the sub-catchment scale are presented in Table 4.1.

Table 4.1: Variation of monthly precipitation volumes $\left(10^{6} \times \mathrm{m}^{3}\right)$ for respective subcatchments for the period November 2002 to October 2003

\begin{tabular}{|c|c|c|c|c|c|c|c|c|c|c|c|c|c|c|}
\hline Sub-catchment & $\begin{array}{l}\text { Area } \\
\left(\mathrm{km}^{2}\right)\end{array}$ & Nov & Dec & Jan & Feb & Mar & Apr & May & Jun & Jul & Aug & Sep & Oct & Sum \\
\hline \multicolumn{15}{|l|}{ Upper Karkheh } \\
\hline Doab & 7,767 & 480 & 411 & 343 & 754 & 617 & 548 & 103 & 0 & 0 & 0 & 0 & 137 & 3,393 \\
\hline Pole Chehr & 3,121 & 225 & 267 & 197 & 295 & 140 & 211 & 42 & 0 & 0 & 0 & 0 & 14 & 1,391 \\
\hline Doabe Merek & 1,286 & 67 & 161 & 83 & 83 & 50 & 83 & 17 & 0 & 0 & 0 & 0 & 0 & 544 \\
\hline Ghor Baghestan & 4,072 & 170 & 409 & 273 & 290 & 170 & 307 & 51 & 0 & 0 & 0 & 0 & 17 & 1,687 \\
\hline Holilan & 4,371 & 326 & 268 & 211 & 460 & 211 & 249 & 38 & 0 & 0 & 0 & 0 & 153 & 1,917 \\
\hline Dartoot & 2,613 & 152 & 265 & 207 & 219 & 161 & 127 & 12 & 0 & 0 & 0 & 0 & 12 & 1,154 \\
\hline Tang Sazin & 2,889 & 175 & 257 & 187 & 246 & 140 & 129 & 23 & 0 & 0 & 0 & 0 & 12 & 1,170 \\
\hline Kaka Reza & 1,137 & 51 & 96 & 57 & 125 & 100 & 108 & 17 & 0 & 0 & 0 & 0 & 11 & 564 \\
\hline Cham Anjir & 1,637 & 78 & 128 & 71 & 171 & 107 & 136 & 21 & 0 & 0 & 0 & 0 & 7 & 721 \\
\hline Pole Dokhtar & 6,767 & 428 & 428 & 285 & 656 & 342 & 428 & 57 & 0 & 0 & 0 & 0 & 200 & 2,823 \\
\hline Jelogir & 4,116 & 247 & 290 & 160 & 320 & 160 & 218 & 29 & 0 & 0 & 0 & 0 & 15 & 1,438 \\
\hline Pole Zal & 335 & 15 & 15 & 11 & 22 & 17 & 25 & 2 & 0 & 0 & 0 & 0 & 2 & 110 \\
\hline Paye Pol & 2,707 & 98 & 92 & 59 & 124 & 105 & 151 & 13 & 0 & 0 & 0 & 0 & 7 & 648 \\
\hline \multicolumn{15}{|l|}{ Lower Karkheh } \\
\hline Abdul Khan & 1,967 & 41 & 33 & 46 & 33 & 52 & 49 & 3 & 3 & 0 & 0 & 0 & 8 & 267 \\
\hline Hamidieh & 931 & 5 & 19 & 36 & 12 & 15 & 11 & 1 & 0 & 0 & 0 & 0 & 0 & 100 \\
\hline Susangerd & 5,963 & 23 & 104 & 232 & 58 & 93 & 64 & 6 & 0 & 0 & 0 & 0 & 0 & 579 \\
\hline Karkheh basin & 51,677 & 2,582 & 3,245 & 2,458 & 3,867 & 2,480 & 2,842 & 435 & 3 & 0 & 0 & 0 & 594 & 18,507 \\
\hline
\end{tabular}

Note: Sub-catchments are shown in Figure 2.1 


\subsubsection{Satellite based actual evapotranspiration}

Daily maps of $E T_{a}$ were estimated by the SEBS algorithm using 19 cloud-free MODIS images that were available to this study. In order to estimate monthly and annual $E T_{a}$, the evaporative fractions estimated in the days of satellite overpasses were considered to be representative for specified time intervals. These intervals were selected in such a way that the date of the selected image is in the middle or close to the middle of the interval. This selection was recommended by Bastiaanssen et al. (2002) who used a set of NOAAAVHRR images to allow for time integration in $E T_{a}$ estimations. They validated the procedure by a set of $E T_{a}$ values as estimated by the Bowen ratio method. In their study, the time between consecutive cloud-free images ranged between 2 and 35 days. In this present study, only two time intervals which are 37 and 45 days are outside that range. These intervals were found in February and April and fall in the rainy season. Farah et al. (2004) stated that the soil moisture dynamics and, thus, indirectly the rainfall events, control the long-term seasonal variations of evaporative fraction. Therefore, we hypothesize that the assumption of the representative evaporative fraction over those two intervals can be justified as well, since significant changes in soil moisture are not to be expected during the rainy season. The annual $E T_{a}$ map shown in Figure 4.3 was prepared by the procedure described in Section 3.4.2. 


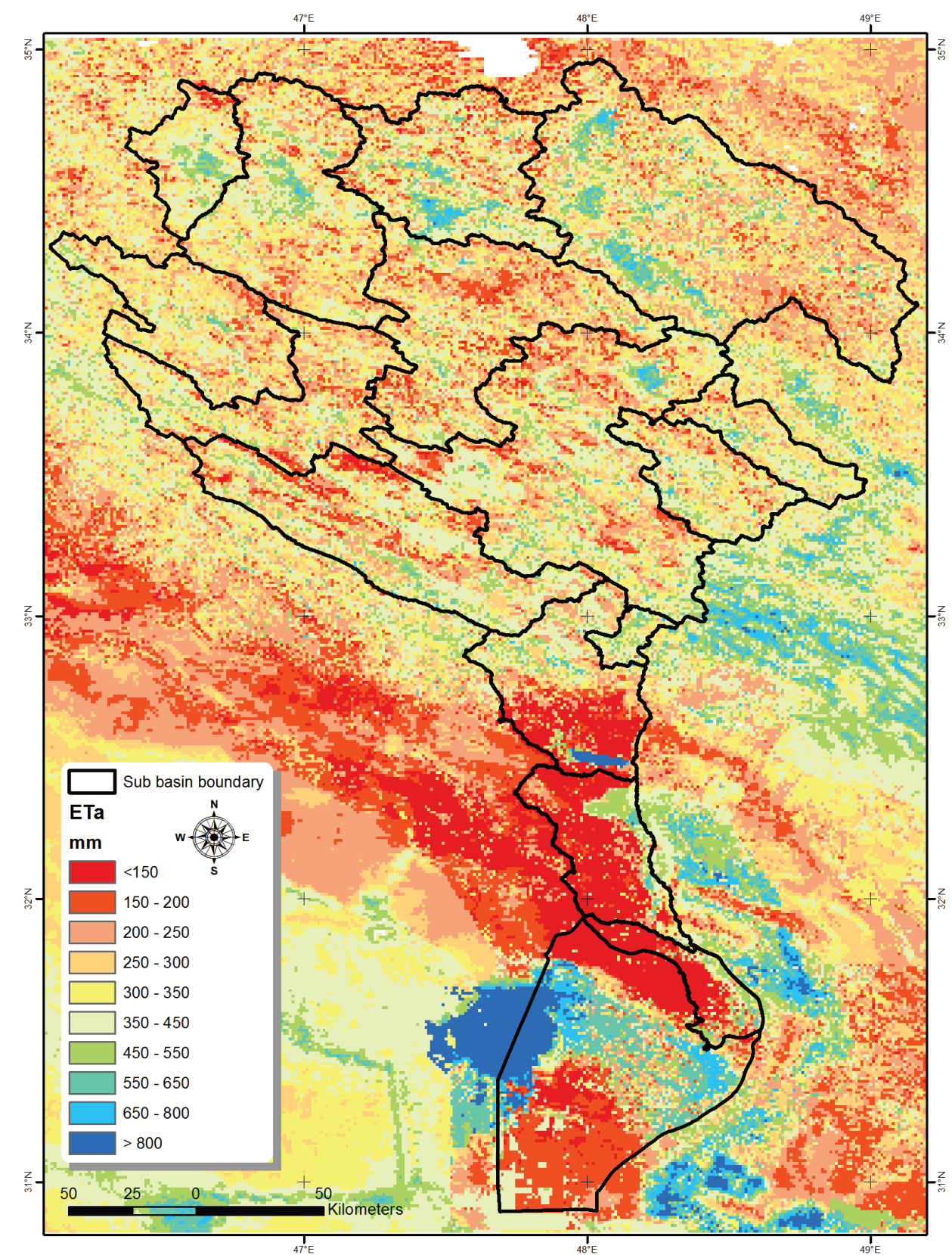

Figure 4.3: Spatial distribution of annual actual evapotranspiration $\left(E T_{a}\right)$ in the Karkheh Basin, November 2002 to October 2003.

The map indicates that the range of annual $E T_{\mathrm{a}}$ values goes up to $1,681 \mathrm{~mm}$. The highest value is found for a pixel located in the Karkheh reservoir and the lowest is in the bare land/desert areas downstream of the Karkheh dam. 
Cropped areas show large spatial variations in the annual $E T_{a}$ whereas irrigated areas in both Upper and Lower Karkheh are characterized by high $E T_{a}$ values. There are some pixels in the mountain area that show high values of $E T_{a}$. In these areas, snowfall during the winter months resulted in continuous snow cover and snowmelt in the months of May and June which caused replenishment of the soil moisture. It is noted that there are numerous small streams and seasonal lakes that fill local depressions in the areas concerned. At the beginning of the dry season, the saturated or nearsaturated soils allow for high $E T_{a}$ values. Spatial and temporal variations of monthly $E T_{a}$ at sub-catchment scale are shown in Table 4.2.

Table 4.2: Variation of actual monthly evapotranspiration $\left(10^{6} \times \mathrm{m}^{3}\right)$ in the Karkheh sub-catchments for the period November 2002-October 2003.

\begin{tabular}{|c|c|c|c|c|c|c|c|c|c|c|c|c|c|c|}
\hline Sub-catchment & $\begin{array}{c}\text { Area } \\
\left(\mathrm{km}^{2}\right)\end{array}$ & Nov & Dec & Jan & Feb & Mar & Apr & May & Jun & Jul & Aug & Sep & Oct & Sum \\
\hline \multicolumn{15}{|l|}{ Upper Karkheh } \\
\hline Doab & 7,767 & 230 & 167 & 121 & 314 & 595 & 428 & 350 & 70 & 74 & 48 & 31 & 176 & 2,604 \\
\hline Pole Chehr & 3,121 & 83 & 74 & 46 & 119 & 231 & 190 & 198 & 32 & 27 & 17 & 11 & 65 & 1,093 \\
\hline Doabe Merek & 1,286 & 32 & 16 & 22 & 44 & 83 & 91 & 112 & 16 & 13 & 7 & 6 & 14 & 456 \\
\hline Ghor Baghestan & 4,072 & 103 & 58 & 69 & 143 & 263 & 262 & 275 & 37 & 27 & 14 & 10 & 47 & 1,308 \\
\hline Holilan & 4,371 & 133 & 93 & 76 & 159 & 282 & 215 & 175 & 33 & 27 & 16 & 9 & 55 & 1,273 \\
\hline Dartoot & 2,613 & 67 & 45 & 57 & 103 & 175 & 165 & 152 & 19 & 13 & 6 & 3 & 21 & 826 \\
\hline Tang Sazin & 2,889 & 82 & 59 & 62 & 114 & 184 & 164 & 150 & 25 & 11 & 5 & 5 & 23 & 884 \\
\hline Kaka Reza & 1,137 & 36 & 27 & 19 & 41 & 74 & 67 & 48 & 12 & 20 & 10 & 5 & 31 & 390 \\
\hline Cham Anjir & 1,637 & 50 & 40 & 30 & 58 & 97 & 102 & 88 & 23 & 18 & 11 & 5 & 34 & 556 \\
\hline Pole Dokhtar & 6,767 & 206 & 157 & 129 & 228 & 381 & 395 & 362 & 98 & 72 & 40 & 26 & 103 & 2,197 \\
\hline Jelogir & 4,116 & 110 & 90 & 88 & 149 & 229 & 231 & 236 & 68 & 25 & 11 & 7 & 58 & 1302 \\
\hline Pole Zal & 335 & 10 & 7 & 7 & 12 & 19 & 90 & 26 & 14 & 5 & 1 & 1 & 6 & 198 \\
\hline Paye Pol & 2,707 & 70 & 58 & 43 & 83 & 127 & 87 & 117 & 55 & 28 & 16 & 13 & 43 & 740 \\
\hline \multicolumn{15}{|l|}{ Lower Karkheh } \\
\hline Abdul Khan & 1,967 & 48 & 43 & 14 & 36 & 50 & 46 & 38 & 14 & 12 & 6 & 2 & 17 & 326 \\
\hline Hamidieh & 931 & 26 & 23 & 11 & 27 & 35 & 21 & 14 & 6 & 7 & 5 & 2 & 10 & 187 \\
\hline Susangerd & 5,963 & 182 & 162 & 172 & 318 & 486 & 290 & 211 & 172 & 106 & 56 & 67 & 118 & 2,340 \\
\hline Karkheh basin & 51,677 & 1,468 & 1,119 & 966 & 1,948 & 3,311 & 2,844 & 2,552 & 694 & 485 & 269 & 203 & 821 & 16,680 \\
\hline
\end{tabular}

Note: sub-catchments are shown in Figure 2.1.

In general, monthly values of $E T_{a}$ are highest during March to May, which indicates the growing period for both rainfed and irrigated wheat (Table 2.2). In May, growing periods of wheat and maize crops overlap and result in high $E T_{a}$, especially in the Upper Karkheh. It is noted that, for this period, sufficient water is available by irrigation, presence of local water bodies and snowmelt. The analysis revealed that high $E T_{a}$ during the summer months is mainly from water supply by irrigation. During the hot months after May, the water demand by atmospheric forcing is high. However, soils are already largely depleted and, consequently, sub-catchment-scale $E T_{a}$ values are 
relatively low. $E T_{a}$ values during the dry summer period for three subcatchments in the Lower Karkheh are due to vegetation near the river and maize production in some parts of the harvested wheat fields in May. The Hoor-Al-Azim swamp and the irrigated areas in the Lower Karkheh cause relative high annual $E T_{a}$ in the Susangerd sub-catchment. A frequency distribution of the estimated annual $E T_{a}$ in the Upper and Lower Karkheh is presented in Figure 4.4.

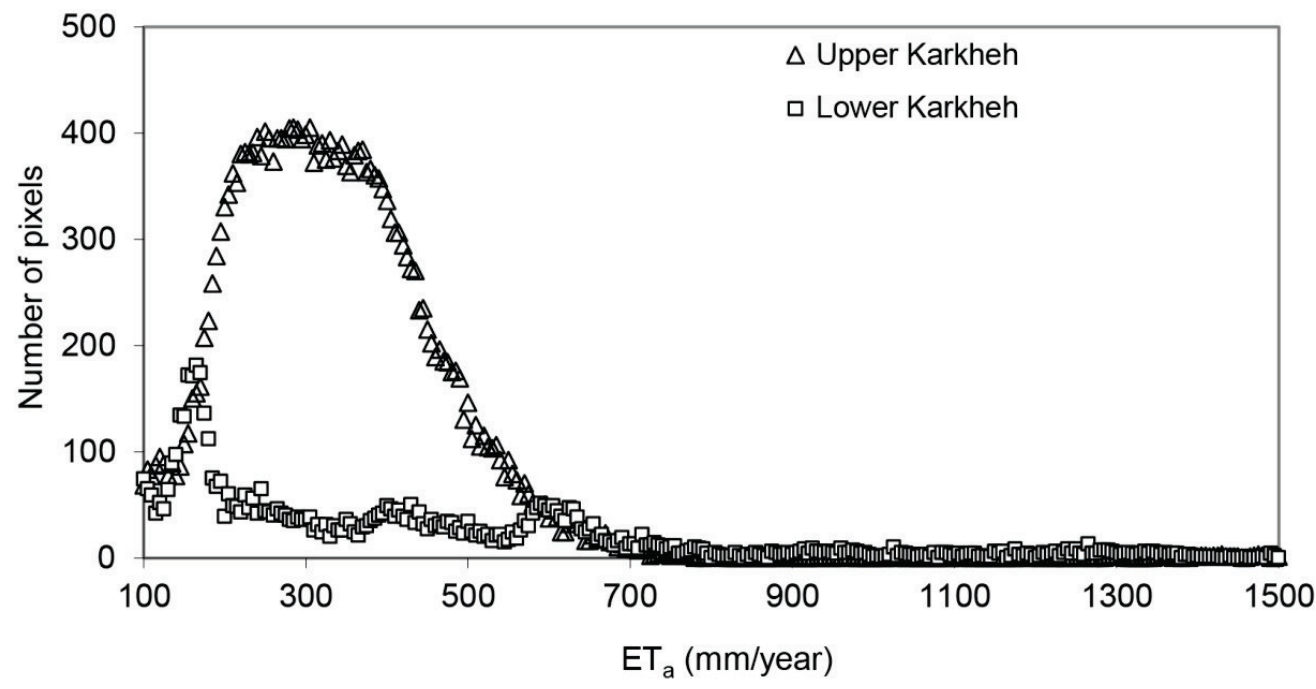

Figure 4.4: Frequency distribution of the annual actual evapotranspiration $\left(E T_{a}\right)$ for the Upper and Lower Karkheh.

The maximum $E T_{a}$ for MODIS pixels that are $1 \mathrm{~km}^{2}$ in size for the Upper and Lower Karkheh was $1,681 \mathrm{~mm} \mathrm{y}^{-1}$ and $1,618 \mathrm{~mm} \mathrm{y}^{-1}$, respectively. For both areas, however, $E T_{a}$ for the majority of pixels was below $600 \mathrm{~mm} \mathrm{y}^{-1}$. Further analysis revealed gradual variations in the $E T_{a}$ from vegetation that includes forest, agriculture and orchards in the Upper Karkheh. The Lower Karkheh consists of desert, bare lands, irrigated area and sand dunes, and $E T_{a}$ is hence characterized by relatively large changes. Highest values of $E T_{a}$ in Lower Karkheh were around $1,600 \mathrm{~mm} \mathrm{y}^{-1}$ and were found in the swamp area. In Figure 4.4, the peak that is around $170 \mathrm{~mm} \mathrm{y}^{-1}$ in the Lower Karkheh indicates desert and bare lands that are close to the irrigated areas. Values around $400 \mathrm{~mm} \mathrm{y}^{-1}$ indicate $E T_{a}$ from vegetation and agricultural areas that are close to the river and downstream of the Karkheh dam. A third peak which is around $600 \mathrm{~mm} \mathrm{y}^{-1}$ represents irrigated areas in the Lower Karkheh.

\subsubsection{Actual evapotranspiration for specific land uses}

The land use map shown in Figure 2.5 was used to extract $E T_{a}$ for different land uses. However, the problem of mixed pixels was unavoidable due to the 
spatial resolution of the MODIS data $(1 \mathrm{~km} \times 1 \mathrm{~km})$ and the fragmented nature of the land use in some parts of the basin. As such, $E T_{a}$ was calculated for mixed pixels, since it was not possible to extract $E T_{a}$ for each land use present in these pixels (McCabe and Wood, 2006). It must be noted that such factors constrain the estimation of $E T_{a}$ for specific land uses. However, the presence of large-scale crop areas, bare land and swamp areas allowed identification of homogeneous pixels. Such land uses and locations were identified through ground-truth surveys and GPS readings during field visits.

For the Lower Karkheh, the swamp has the highest $E T_{a}$ and ranges from 37 to $204 \mathrm{~mm}$ per month, whereas the bare land has lowest $E T_{a}$. Seasonal and annual average $E T_{a}$ for irrigated wheat in the Lower Karkheh was $448 \mathrm{~mm}$ and $714 \mathrm{~mm}$, respectively. For the Upper Karkheh, the reservoir has the highest $E T_{a}$ with minimum and maximum values of 61 and $225 \mathrm{~mm}$ per month, respectively. For rainfed wheat in the Upper Karkheh, seasonal $E T_{a}$ ranged from 232 to $370 \mathrm{~mm}$ whereas annual values ranged from 327 to 396 $\mathrm{mm}$. The average $E T_{a}$ for the rainfed wheat was $302 \mathrm{~mm}$ per season for the season. For irrigated wheat in the Upper Karkheh, seasonal and annual average $E T_{a}$ values are $432 \mathrm{~mm}$ and $647 \mathrm{~mm}$, respectively. Results of seasonal $E T_{a}$ values for wheat, found in this study, closely agree with values in areas with similar climatic settings (Zwart and Bastiaanssen, 2007). Also, $E T_{a}$ values for irrigated winter wheat are close to the recommended water requirements (450 to $650 \mathrm{~mm}$ per season) for regions with similar settings (Doorenbos and Kassam, 1979). Our results indicate that growing wheat under rainfed conditions is under significant water stress. Secondary statistics on irrigated and rainfed wheat production used by Ahmad et al. (2009) also indicate water stress, since irrigated areas produce 2.0 to 4.4 ton $^{h^{-1}}$ whereas rainfed production is less than 2 ton ha ${ }^{-1}$.

To assess temporal variations of $E T_{a}$, reference is made to Figure 4.5 with monthly values that are extracted for irrigated and rainfed wheat, bare soil and swamp pixels. 


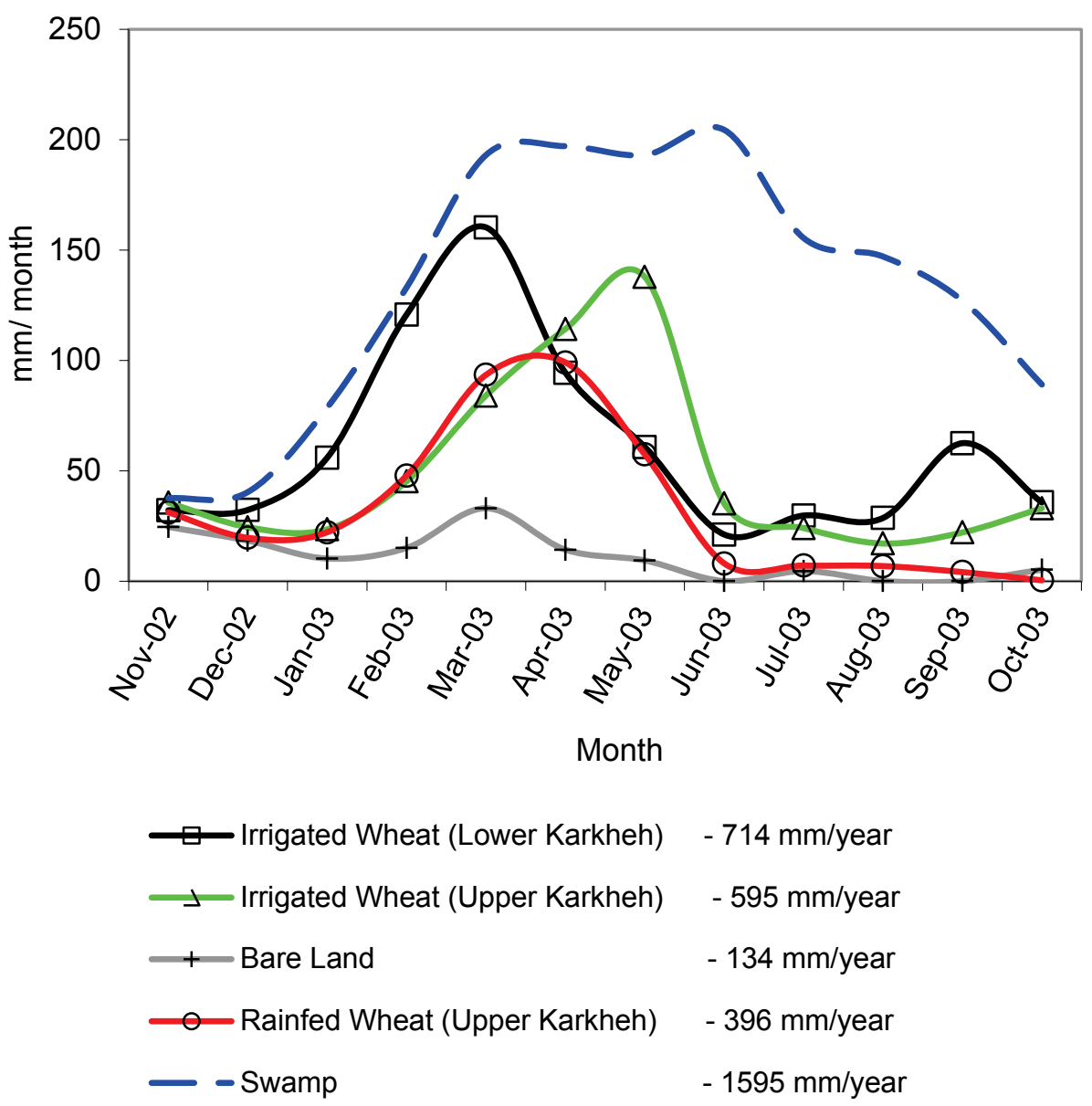

Figure 4.5: Actual evapotranspiration for specific land uses in the Karkheh River Basin.

For the months of November and December, $E T_{a}$ was relatively low for all land uses due to low atmospheric forcing across the Karkheh. During the crop development stages between January to March in the Upper Karkheh, $E T_{a}$ shows a substantial increase. In the Upper Karkheh, the $E T_{a}$ for rainfed and irrigated wheat is similar until April. Then, the $E T_{a}$ of the irrigated wheat continues to rise because of irrigation while the $E T_{a}$ of the rainfed wheat drops sharply. For the Lower Karkheh, crop development stages are between December and February and $E T_{a}$ shows a substantial increase during this period. For Lower Karkheh, $E T_{a}$ is highest in March since wheat is fully grown whereas from May onwards only small-scale agriculture from harvested wheat fields is practiced. From January to October, the swamp area has the highest $E T_{a}$ while bare soil showed lowest values. 
As shown in Figure 4.5, the total $E T_{a}$ from an irrigated wheat field (pixel) in the Upper Karkheh is $595 \mathrm{~mm} \mathrm{y}^{-1}$. In the Upper Karkheh, total $E T_{a}$ from a rainfed wheat field is $396 \mathrm{~mm} \mathrm{y}^{-1}$. This means that the yield from rainfed wheat fields can increase from less than 2 ton ha ${ }^{-1}$ to more than 4 ton ha ${ }^{-1}$ due to the additional consumption of about $200 \mathrm{~mm} \mathrm{y}^{-1}$. In August and September, the very low values of $E T_{a}$ of less than $1 \mathrm{~mm} \mathrm{~d}^{-1}$ are from the fallow lands after the harvesting. In rainfed areas, $E T_{a}$ follows the precipitation patterns. Higher $E T_{a}$ values for wheat in March and April are due to the fully grown crop stage.

\subsection{Comparison of different methods to estimate actual evapotranspiration}

In the absence of instruments such as weighing lysimeters or Bowen ratio and eddy-covariance surface energy balance measurements, the estimated $E T_{a}$ was compared to Priestley and Taylor $E T_{a}$ and potential crop evapotranspiration estimated for two irrigated crop areas. Satellite-based $E T_{a}$ of a pixel in the middle of the Hoor-Al-Azim swamp is compared to Priestley and Taylor $E T_{a}$ values of the nearby Bostan meteorological station (Figure 4.6). The comparison with Priestley and Taylor $E T_{a}$, however, can be justified, since the middle of the swamp is covered with homogeneous vegetation while availability of water is not limiting evapotranspiration.

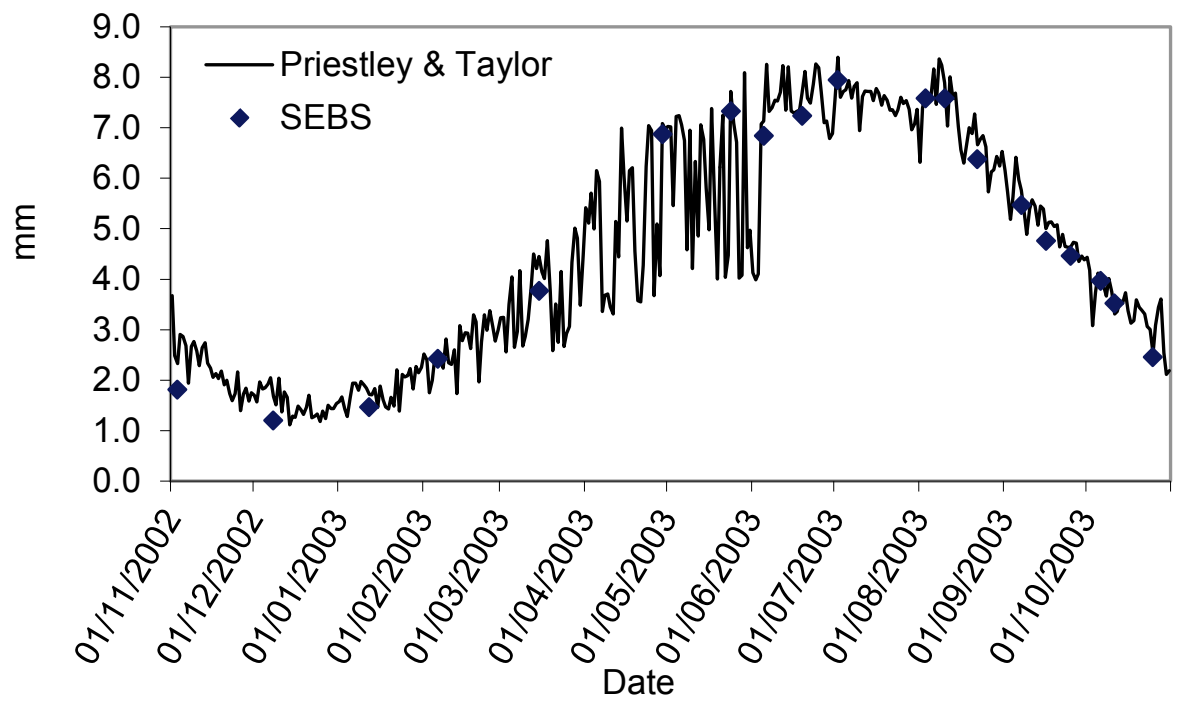

Figure 4.6: Comparison of $E T_{a}$ estimated by SEBS at the swamp with the Priestley \& Taylor $E T_{a}$ calculated from the meteorological data collected at the Bostan station (Latitude: $31^{\circ} 43^{\prime} \mathrm{N}$, Longitude: $48^{\circ} 0^{\prime} \mathrm{E}$ ) in the Lower Karkheh Basin. 
The comparison indicates that $E T_{a}$ largely agrees with the values of Priestley and Taylor $E T_{a}$. It is noted that estimations are made over different spatial scales: being the point scale for the Bostan meteorological station and the pixel scale for the SEBS estimate. In several studies, satellite-based $E T_{a}$ has been compared to point estimations of $E T_{a}$ (e.g., Kite and Droogers, 2000; Loheide II and Gorelick, 2005; Koloskov et al., 2007). In this comparison, the main idea is to verify if SEBS $E T_{a}$ values compare to Priestley and Taylor $E T_{a}$ values, and to assess temporal patterns rather than to rigorously validate the time-space distributions of estimated $E T_{a}$. Moreover, data available in this study does not allow such validation.

Further, $E T_{a}$ from large-scale irrigated wheat areas in the Upper and Lower Karkheh are compared with the respective potential crop evapotranspiration $\left(E T_{p}\right)$ values. Crop coefficients $\left(K_{c}\right)$ for wheat, as obtained from FAO56 (Allen et al., 1998, Bos et al., 2009) for similar climatic conditions and crop development stages, are used. Monthly values of $E T_{a}$ and $E T_{p}$ for the Upper and Lower Karkheh are presented in Figures 4.7 and 4.8, respectively.

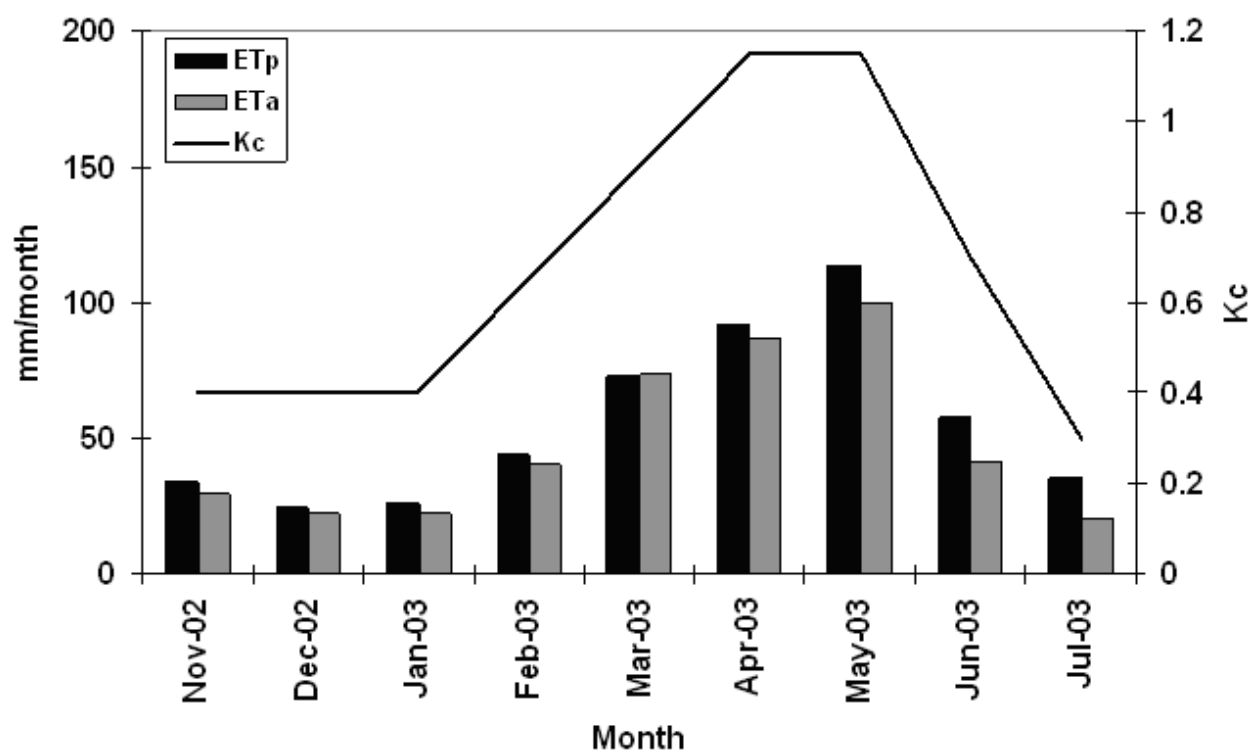

Figure 4.7: Comparison of $E T_{a}$ estimated by SEBS with $E T_{p}$ calculated from meteorological data collected at Kangavar station (Latitude: $34^{\circ} 30^{\prime} \mathrm{N}$, Longitude: $47^{\circ}$ $\left.59^{\prime} \mathrm{E}\right)$, and literature-based $K_{c}$ values for a wheat site in the Upper Karkheh Basin. 


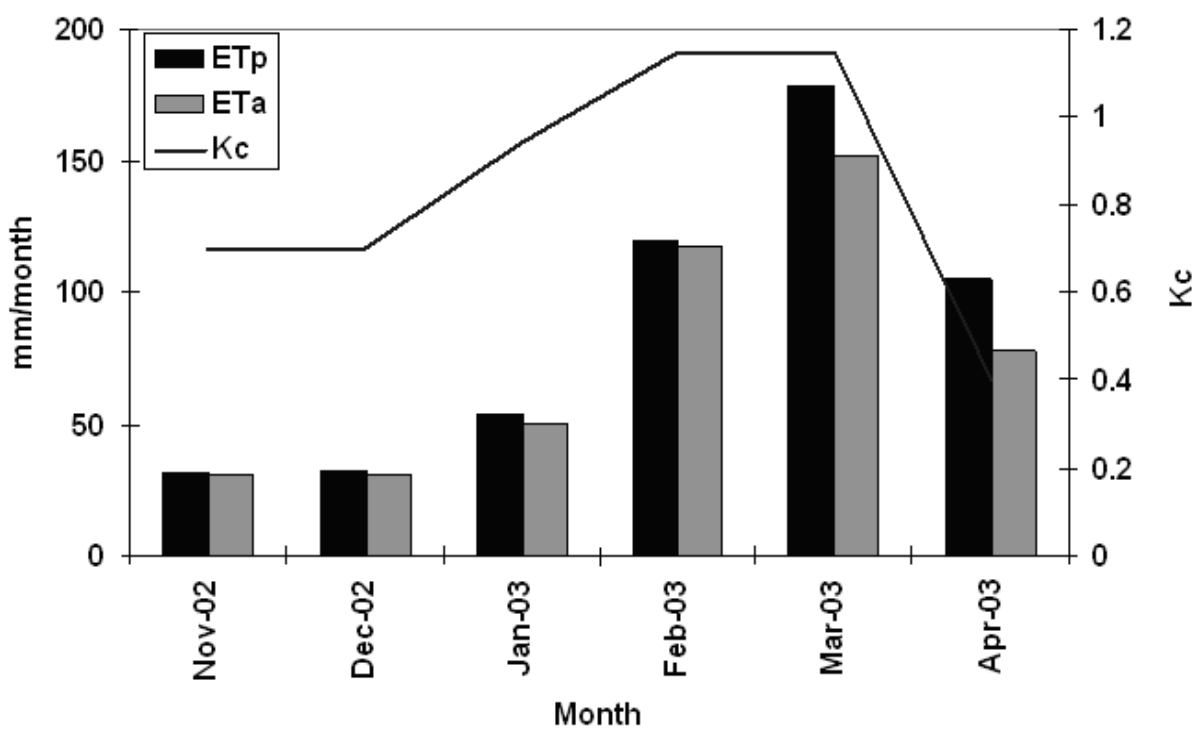

Figure 4.8: Comparison of $E T_{a}$ estimated by SEBS with $E T_{p}$ calculated from meteorological data collected at Ahvaz station (Latitude: $31^{\circ} 20^{\prime} \mathrm{N}$, Longitude: $48^{\circ} 41^{\prime}$ $\mathrm{E})$, and literature-based $\mathrm{K}_{\mathrm{c}}$ values for a wheat site in the Lower Karkheh Basin.

In the Upper Karkheh, the wheat growing season starts in November. During the first three months of the growing season, $E T_{a}$ is equal to $E T_{p}$ (about 1 $\mathrm{mm} \mathrm{d}^{-1}$ ) after which the crops develop rapidly leading to higher ET demand. During this time period, the values of both $E T_{a}$ and $E T_{p}$ are high (Figure 4.7). The crop matures in July. Due to low precipitation from May to July, crops in the Upper Karkheh depend mainly on irrigation water supplies. As noticed by the $E T_{a}$ estimates, the values of $E T_{a}$ in these months are lower than the $E T_{p}$ values, indicating insufficient irrigation. This may be due to limited water availability. In the Lower Karkheh, the growing period is smaller (i.e. from November to April). The $E T_{p}$ is higher in this region. Similar to the Upper Karkheh, initially the $E T_{a}$ and $E T_{p}$ are equal but differences emerge in March and April (Figure 4.8). This area is also predominantly supported by irrigation in the drier months. Table 4.3 shows the seasonal and annual accumulated $E T_{a}$ and $E T_{p}$ for two wheat pixels.

Table 4.3: Accumulated $E T_{a}$ and $E T_{p}$ for two wheat pixels in the Upper and Lower Karkheh.

\begin{tabular}{lcccc}
\hline & \multicolumn{2}{c}{ Upper Karkheh } & \multicolumn{2}{c}{ Lower Karkheh } \\
\cline { 2 - 5 } & $E T_{a}(\mathrm{~mm})$ & $E T_{p}(\mathrm{~mm})$ & $E T_{a}(\mathrm{~mm})$ & $E T_{p}(\mathrm{~mm})$ \\
\hline Seasonal & 437 & 499 & 459 & 520 \\
Annual & 621 & - & 693 & - \\
\hline
\end{tabular}


The accumulated $E T_{a}$ and $E T_{p}$ for the growing season is 437 and $499 \mathrm{~mm}$ per season for Upper Karkheh whereas it is 459 and $520 \mathrm{~mm}$ per season for the Lower Karkheh, respectively. This indicates a $12.5 \%$ and $11.7 \%$ difference with respect to the accumulated $E T_{p}$ during the growing season for Upper and Lower Karkheh, respectively. It is important to note that $E T_{p}$ calculations are based on $K_{c}$ values from literature (Allen et al., 1998; Bos et al., 2009), which are not specifically verified for Iranian crops. Furthermore, comparisons are made between $E T_{a}$ of a $1 \mathrm{~km} \times 1 \mathrm{~km}$ MODIS pixel and $E T_{p}$ estimates based on point data of meteorological stations. Taking these facts into consideration, the aforementioned differences in percentages are regarded as being within an acceptable range. Further, the relative evapotranspiration, which is the ratio between $E T_{a}$ and $E T_{p}\left(E T_{a} / E T_{p}\right)$, can be used to express crop water stress during the season. To facilitate crop growth, water stress should be limited, especially during the first three growth stages (Bos et al., 2009). As shown in Figures 4.7 and 4.8 , monthly relative evapotranspiration values of both wheat areas (Upper and Lower Karkheh) are above 0.85 during the first three stages. This suggests that, these two areas are supplied with adequate water during the growing period. Further, the $E T_{a}$ results were verified by a sub-catchment-scale water balance analysis.

\subsection{Water Balance}

To solve the water balance at sub-basin scale, spatial estimates of precipitation and $E T_{a}$ and secondary data on streamflow were substituted into Equation (4.4). For each sub-basin, mean values of $E T_{a}$ and precipitation are defined by dividing the sum of pixel values by the number of pixels. These values were converted into volumes by multiplication with sub-basin areas to allow volumetric assessments.

$$
P+Q_{\text {in }}+G_{\text {in }}+E T_{a}-Q_{\text {out }}-G_{\text {out }}=\Delta s
$$

In this equation, $P$ is the precipitation, $Q_{\text {in }}$ is the surface water inflow, $G_{\text {in }}$ is the groundwater inflow, $E T_{a}$ is the actual evapotranspiration, $Q_{\text {out }}$ is the surface water outflow, $\mathrm{G}_{\text {out }}$ is the groundwater outflow and $\Delta S$ is the storage change during the time interval considered. This includes the changes in storage in groundwater, surface water and soil moisture. Values of water balance components are presented in Table 4.4. Since the water balance is solved for a full hydrological year, and since estimations are at the sub-basin scale, it is assumed that the change in groundwater storage is negligible. 
Table 4.4: Water balance for the entire basin and major sub-basins $\left(10^{6} \times \mathrm{m}^{3}\right)$ from November 2002-October 2003.

\begin{tabular}{lcccccc}
\hline Sub-basin & $\mathrm{P}$ & $\mathrm{Q}_{\text {in }}$ & $E T_{a}$ & $\Delta \mathrm{S}_{\mathrm{S}}$ & $\mathrm{Q}_{\text {out }}$ & Closure (\%) $^{*}$ \\
\hline Gamasiab & 4,784 & - & 3,697 & - & 742 & 7.2 \\
Qarasou & 2,230 & - & 1,764 & - & 399 & 3.0 \\
Kashkan & 4,108 & - & 3,143 & - & 939 & 0.6 \\
Saymareh & 6,437 & 2,079 & 5,223 & 368 & 2,851 & 0.9 \\
Upper & 17,559 & - & 13,827 & 368 & 2,851 & 2.9 \\
Lower & 948 & 2,880 & 2,853 & - & Not & \\
Entire basin & 18,507 & - & 16,680 & 368 & Not & \\
\hline
\end{tabular}

${ }^{*}$ Closure $=\left(\mathrm{P}+Q_{\text {in }}-E T_{a}-\Delta \mathrm{S}_{\mathrm{S}}-Q_{\text {out }}\right) \times 100 /\left(\mathrm{P}+Q_{\text {in }}\right)$.

During the study period, the Karkheh Basin received $18,507 \times 10^{6} \mathrm{~m}^{3}$ of precipitation whereas $16,680 \times 10^{6} \mathrm{~m}^{3}$ of water evapotranspired. The difference between precipitation and $E T_{a}$ is $1,827 \times 10^{6} \mathrm{~m}^{3}$. Based on data collected from the Iranian Energy Ministry, the water volume in the reservoir has increased by some $368 \times 10^{6} \mathrm{~m}^{3}$ during the study period. The unaccountable volume of water remains as $1,459 \times 10^{6} \mathrm{~m}^{3}$, which is $7.8 \%$ of the precipitation volume and is referred to as the closure term. However, apart from the assumption on negligible storage changes, the closure term also includes the effects of error in estimation of precipitation, $E T_{a}$ and measured streamflow within the basin. For the Upper Karkheh, which includes the Karkheh reservoir, the closure term is only $2.9 \%$ in reference to the precipitation volume. This percentage is considered low and is affected by unknown groundwater recharge, changes in soil water storage in the unsaturated zone or due to errors in the precipitation and $E T_{a}$ estimates. In the Lower Karkheh, annual $E T_{a}$ is higher than the annual precipitation by irrigation water supply coming from the Karkheh reservoir. Data on river flows into the swamp is not available and closure of the water balance could not be established.

For operational water management, it is crucial to have a good knowledge on the temporal dimension of the water balance for the different areas within the basin. Therefore, monthly water balances are examined for both Holilan and Pole Dokhtar in the upper and middle areas and for the whole of the Lower Karkheh. Tables $4.5,4.6$ and 4.7 show the monthly variations in the water balance terms for these three areas. 
Table 4.5: Monthly variations of the water balance terms $\left(10^{6} \times \mathrm{m}^{3}\right)$ in Holilan subcatchment from November 2002-October 2003.

\begin{tabular}{lllllllllllllll}
\hline Month & $\mathrm{N}$ & $\mathrm{D}$ & $\mathrm{J}$ & $\mathrm{F}$ & $\mathrm{M}$ & $\mathrm{A}$ & $\mathrm{M}$ & $\mathrm{J}$ & $\mathrm{J}$ & $\mathrm{A}$ & $\mathrm{S}$ & $\mathrm{O}$ & Annual \\
\hline $\mathrm{P}$ & 326 & 268 & 211 & 460 & 211 & 249 & 38 & 0 & 0 & 0 & 0 & 153 & 1,916 \\
$E T_{a}$ & 133 & 93 & 76 & 159 & 282 & 215 & 175 & 33 & 27 & 16 & 9 & 55 & 1,273 \\
$\mathrm{Q}_{\text {in }}$ & 22 & 54 & 91 & 159 & 329 & 335 & 95 & 22 & 8 & 5 & 7 & 15 & 1,142 \\
Qout & 32 & 61 & 137 & 269 & 401 & 318 & 144 & 40 & 18 & 10 & 11 & 24 & 1,465 \\
\hline
\end{tabular}

Between November 2002 and February 2003, the precipitation is 2.7 times higher than ETa and the difference between surface inflow and outflow is $173 \times 106 \mathrm{~m} 3$. This suggests that some of the precipitation surplus contributes to river discharge whereas most of it was retained in the subcatchment as snow, soil moisture or groundwater storage. In March, precipitation is lower than ETa and the ETa demand is presumably supplied by the antecedent soil moisture storage. In April, precipitation is higher than ETa and the outflow is lower than the inflow (Table 4.5). In May, the precipitation is very low, but ETa is still high due to open water evaporation from seasonal lakes created by the melting snow. Orchards and some irrigated crops, such as maize, cause a high ETa during the dry period from June till September. The declining trend of ETa after March can be attributed to the predominant rainfed agriculture in this sub-catchment.

Table 4.6: Monthly variations of the water balance terms $\left(10^{6} \times \mathrm{m}^{3}\right)$ in Pole Dokhtar sub-catchment from November 2002-October 2003.

\begin{tabular}{llllllllllllll}
\hline Month & $\mathrm{N}$ & $\mathrm{D}$ & $\mathrm{J}$ & $\mathrm{F}$ & $\mathrm{M}$ & $\mathrm{A}$ & $\mathrm{M}$ & $\mathrm{J}$ & $\mathrm{J}$ & $\mathrm{A}$ & $\mathrm{S}$ & $\mathrm{O}$ & Annual \\
\hline $\mathrm{P}$ & 428 & 428 & 285 & 656 & 342 & 428 & 57 & 0 & 0 & 0 & 0 & 200 & 2,824 \\
$E T_{a}$ & 206 & 157 & 129 & 228 & 381 & 395 & 362 & 98 & 72 & 40 & 26 & 103 & 2,197 \\
Qin & 18 & 19 & 23 & 36 & 149 & 93 & 42 & 20 & 17 & 13 & 10 & 11 & 451 \\
Qout & 44 & 57 & 58 & 127 & 207 & 235 & 77 & 32 & 22 & 15 & 16 & 54 & 944 \\
\hline
\end{tabular}

Pole Dokhtar is located in the middle part of the basin (Figure 2.1). From November to March, the ETa trends are similar to that of Holilan. However, from March to April, the increase of ETa is larger in Pole Dokhtar. This is due to the relatively higher atmospheric demand for water. The percentage of irrigated area is only $3 \%$ and is considered small in comparison with other sub-catchments located in the upper basin area. The ETa from June to September comes mainly from the forest that covers some $39.0 \%$ of the subcatchment (Figure 2.5). In this sub-catchment, the closure term of the annual water balance is $4.1 \%$. This implies that the water balance can be explained by the above four main components (P, ETa, Qin, Qout), since there are no substantial groundwater extractions in the area. 
Table 4.7: Monthly variations of the water balance terms $(106 \times \mathrm{m} 3)$ in Lower Karkheh sub-basin (surface outflow is not measured from November 2002-October 2003.

\begin{tabular}{llcccccccccccc}
\hline Month & $\mathrm{N}$ & $\mathrm{D}$ & $\mathrm{J}$ & $\mathrm{F}$ & $\mathrm{M}$ & $\mathrm{A}$ & \multicolumn{1}{c}{$\mathrm{M}$} & $\mathrm{J}$ & \multicolumn{1}{c}{$\mathrm{J}$} & $\mathrm{A}$ & $\mathrm{S}$ & $\mathrm{O}$ & Annual \\
\hline $\mathrm{P}$ & 69 & 156 & 314 & 103 & 160 & 124 & 10 & 3 & 0 & 0 & 0 & 8 & 947 \\
$E T_{a}$ & 257 & 228 & 196 & 380 & 571 & 359 & 266 & 192 & 124 & 64 & 71 & 145 & 2,853 \\
$\mathrm{Q}_{\text {in }}$ & 244 & 223 & 266 & 201 & 193 & 200 & 183 & 158 & 344 & 410 & 255 & 203 & 2,880 \\
Qout & - & - & - & - & - & - & - & - & - & - & - & - & - \\
\hline
\end{tabular}

In Lower Karkheh, ETa is higher than precipitation throughout the year. The difference was supplemented by water released from the reservoir. The high ETa between February and June is due to the fully grown irrigated crops and the higher ETa from the swamp. From July to September, there are no crops grown and evaporation from bare soils, and vegetation near the river and the swamp area justify the ETa values.

Although the water balance closure term is low, it must be realized that estimated precipitation and ETa values may deviate from true values. For instance, by the procedure of interpolating and reconstructing precipitation patterns, only basin-wide orographic effects were considered. Effects of local topographic features, such as slope aspect and orientation, could not be quantified and also the observation network is sparse. We assume that these constraints have an effect on our results, as the terrain in the Upper Karkheh is highly heterogeneous. Cross-validation showed, however, maximum deviation of $6.7 \%$ between interpolated and recorded precipitation, but we speculate that this deviation could be higher, especially in the upper part of the river basin.

For ETa estimations, SEBS uses several relationships based on simplified assumptions to estimate energy fluxes. It must be noted that these formulations use some empirical constants that could introduce some error to the estimation of ETa. In this study, emissivity of the air, incoming longwave radiation and the temperature at the planetary boundary layer were estimated as a function of air temperature. For this, maps of air temperature were constructed based on interpolation using data recorded at the meteorological stations. This could introduce some errors to the final ETa estimation. In this study, aerodynamic roughness height values were defined for separate land use classes. Since values are somewhat arbitrarily defined, this causes uncertainty that becomes more pronounced when considering the large number of mixed pixels. 


\subsection{Summary and Conclusions}

In this chapter, an attempt has been made to quantify the spatial and seasonal patterns of water availability and consumption through evapotranspiration across the Karkheh River Basin using satellite images combined with routinely collected meteorological and river flow data. Timespace $E T_{a}$ has been estimated by the SEBS approach, and 19 MODIS-TERRA satellite images for the period of November 2002 to October 2003 have been used. For the same period, precipitation data collected from 30 stations served for spatial interpolation using the simple Kriging approach for the entire Karkheh. The analysis revealed that, for the period of study (i.e., November 2002-October 2003), the Karkheh Basin received 18,507 $\times 10^{6} \mathrm{~m}^{3}$ of water through precipitation while $16,680 \times 10^{6} \mathrm{~m}^{3}$ evapotranspired. The Karkheh Basin can be divided into the Upper and Lower Karkheh by the Karkheh dam. The Karkheh reservoir, which has a designed storage capacity of $7,500 \times 10^{6} \mathrm{~m}^{3}$ with a live storage capacity of about $4,700 \times 10^{6} \mathrm{~m}^{3}$, has been in operation since 2002 and was designed to irrigate 320,000 ha in the Lower Karkheh. The basin drains into the transboundary Hoor-Al-Azim swamp, which is a large-scale wetland between Iran and Iraq

For the Upper Karkheh, the closure term of the annual water balance is $2.9 \%$ when normalized to the precipitation. Since there is no measured flow into the swamp, closure of the water balance could not be established for the Lower Karkheh and hence also not for the entire basin. For the entire basin, however, the difference between precipitation and $E T_{a}$ was $1,827 \times 10^{6} \mathrm{~m}^{3}$ while the water storage increase in the reservoir was $368 \times 10^{6} \mathrm{~m}^{3}$ for the period of study. Therefore, the unaccountable volume of water was 1,459 $\times$ $10^{6} \mathrm{~m}^{3}$, which is $7.8 \%$ of the precipitation. By simple reasoning, this is the maximum possible discharge from the basin for the study period. Presumably, the discharge will be lower, since groundwater recharge occurs. This implies that the drainage ratio is less than 0.1 and, therefore, the basin must be considered a very water-scarce basin. In this respect, it must be noted that it is important to maintain the flow into the swamp to guarantee sustainability of the wetland ecosystem, which is a Ramsar site.

Furthermore, $E T_{a}$ from May to September is estimated at $3,490 \times 10^{6} \mathrm{~m}^{3}$ for the Upper Karkheh. The negative closure term for this period presumes that a substantial part of $E T_{a}$ was supported by capillary rise from groundwater storage. In rainfed wheat areas, the small difference between seasonal and annual $E T_{a}$ indicates that there is hardly any water consumed by summer crops. In irrigated wheat areas, this difference is larger when compared to rainfed areas, as some crops are grown during the summer months. This also indicates that possibilities to grow additional summer crops only are limited. Therefore, we conclude that, for the Karkheh Basin, the most viable option to 
increase agricultural production is to improve water productivity rather than to focus on development of additional water resources.

In this chapter, a satellite-based energy balance approach, in combination with geo-statistical techniques, has been used to show its effectiveness in estimating spatial patterns of water consumption. The spatially distributed information produced in this study, could serve in various applications in the field of water management. For example, spatially distributed $E T_{a}$, along with other variables can be used in multi-variable calibration of hydrological models (Chapter 5), help in classifying land suitability for agricultural (Chapter 6) and to develop water-stress indicators (Chapter 6). In Chapter 5 spatially distributed $E T_{a}$ and streamflow are used to calibrate the hydrological model and hence close the water balance. Such calibrated models could be very useful to serve as a baseline to assess implications under various water management scenarios. In Chapter 6, spatially distributed $E T_{a}$ is used to calculate water stress indicator (ratio of $E T_{a} / E T_{p}$ ) in the agricultural areas. The $E T_{a}$ is also used to classify the areas sutitable for the expantion of rainfed wheat. 


\section{Multi-variable Calibration of a Semi- distributed Hydrological Model Using streamflow Data and Satellite-Based Evapotranspiration*}

\subsection{Introduction}

In basin scale water management, for streamflow (Qs) assessments it is common to apply rainfall-runoff models that simulate hydrological behavior at catchment scale. The largest group of rainfall-runoff models contains the conceptual models which aim to simulate watershed responses and the catchment water balance, in general. As mentioned in Chapter 3, in conceptual models, parameters are not directly measurable and require optimization through calibration with the objective of obtaining good agreement between observed and simulated counterparts of some hydrological variables of interest. Traditionally, rainfall-runoff models are calibrated based on the Qs hydrograph, but such calibration must be questioned since it inherently involves many criteria (Gupta et al., 1998). Madsen (2000), Gupta et al. (2008) and Khu et al. (2008), among others, discussed that, for evaluation of rainfall-runoff models, a second model output variable such as groundwater levels or soil moisture should be considered.

In rainfall-runoff modelling such approaches are presented in multi-variable model calibration (Seibert, 1997; Gupta et al., 1999; Downer and Ogden 2003; Fenicia et al., 2005; Campo et al., 2006; Khu et al., 2008). These approaches use a second (state) variable, such as soil moisture storage indicators and ground temperature, which only indirectly affects the water balance. Obviously, performance assessments of such approaches are constrained, since it remains uncertain as to how well the water balance of the area of study is represented. To overcome the constraint, the use of two water balance terms for multi-variable calibration is suggested in this study. Multi-variable calibration using Qs and satellite-based evapotranspiration fluxes has not received much attention in literature and we consider this a novelty of this work. Evapotranspiration data, as used in Qs modelling, is most often from ground-based weather stations that, traditionally, only serve to estimate reference evapotranspiration.

Based on: Rientjes, T.H.M., Muthuwatta, L.P., Bos, M.G., Booij, M.J., Bhatti, H.A., (2013). Multi-variable calibration of a semi-distributed hydrological model using streamflow data and satellite-based evapotranspiration. Journal of Hydrology, 505, 276-290. 
Station data may have relatively poor spatial coverage, and the data may not necessarily be considered representative for larger areas.As such, it was hypothesized that the water balance of the model is affected when satellite data are used instead of station data. It was further hypothesized that model performance and model parameters are affected when satellite-based actual evapotranspiration estimates are used as a second calibration variable. Assessing such aspects has motivated this work, where the aim is to evaluate single and multi-variable model calibration for a water balance-based rainfallrunoff model using Qs and satellite-based actual evapotranspiration data.

$R S$ applications in hydrology commonly ignore the closure of a water balance, since applications normally aim at simulating single processes or deriving variables described in Chapter 3. RS applications in conceptual rainfall-runoff modelling, where closure of the water balance constrains calibration and validation results, are not common.

The overall objective of this work is to test multi-variable calibration for a mass conservative conceptual rainfall-runoff model using daily Qs and satellite-based $E T_{a}$. Novel to the research on multi-variable calibration in rainfall-runoff modeling is the use of satellite-based $E T_{a}$ and the use of two terms that jointly close the water balance of the model. Specific objectives of this study are to 1 ) develop a procedure to construct daily time series of satellite-based $E T_{a}, 2$ ) assess how model performance is affected by selected multi-variable calibration targets, 3) assess reproduction of the second term that closes the water balance, and 4) assess model and parameter uncertainty. In this thesis, the rainfall-runoff model, HBV, based on Lindström et al. (1997), is applied to the Upper Karkheh River Basin.

\subsection{Sub-catchments and data}

For the HBV model setup, the Upper Karkheh is divided into seven subcatchments (Figure 5.1). Table 5.1 provides details of these sub-catchments. The smallest sub-catchment is Doabe Merek and the largest Holilan. Mean annual Qs at sub-catchment outlets range from 2.2 to $87.6 \mathrm{~m} 3 \mathrm{~s}-1$ (Table 5.1). It is noted that the sub-catchments in the Upper Karkheh, such as Pole Chehr, Ghor Baghestan, Holilan and Jelogir receive surface water from upstream sub-catchments. Runoff hydrographs for such catchments are constructed by hydrograph separation, where upstream inflows are subtracted from the observed Qs at the catchment outlet. Qs routing is ignored in modelling since travel times are relatively short ( $<1$ day) and since data on channel properties are not available. 
Table 5.1: Details of the sub-catchments.

\begin{tabular}{lcccc}
\hline Sub-catchment & Area $(\mathrm{km} 2)$ & $\begin{array}{c}\text { Upstream } \\
\text { Sub-catchment }\end{array}$ & $\begin{array}{c}\text { Number of Meteo. } \\
\text { stations }\end{array}$ & $\begin{array}{c}\text { Mean daily Qs } \\
\left(\mathrm{m}^{3} \mathrm{~s}^{-1}\right)(2001- \\
2003)\end{array}$ \\
\hline Doab & $7,766.8$ & - & 4 & 8.5 \\
Pole Chehr & $3,121.5$ & Doab & 2 & 16.2 \\
Doabe Merek & $1,285.7$ & - & 1 & 2.1 \\
Ghor Baghestan & $4,071.9$ & Doabe Merek & 1 & 10.7 \\
Holilan & $9,873.3$ & $\begin{array}{c}\text { Pole Chehr } \\
\text { Ghor Baghestan }\end{array}$ & 3 & 49.7 \\
Pole Dokhtar & $9,541.5$ & - & 3 & 26.2 \\
Jelogir & $4,116.3$ & $\begin{array}{c}\text { Holilan } \\
\text { Pole Dokhtar }\end{array}$ & 2 & 87.6 \\
\hline
\end{tabular}

Table 2.7 (Chapter 2) summarizes the data used in this study. Screening of data indicated that the Qs records at the outlets of five sub-catchments are unreliable and, therefore, data from the seven gauging stations of the catchments (Figure 5.1) are used. Consistency of the daily time series of Qs data were analyzed using double mass curves, and by plotting the ratio of incremental differences of precipitation and Qs, as suggested in Rientjes et al., (2011). Outliers in rainfall or Qs were identified and corrected. 


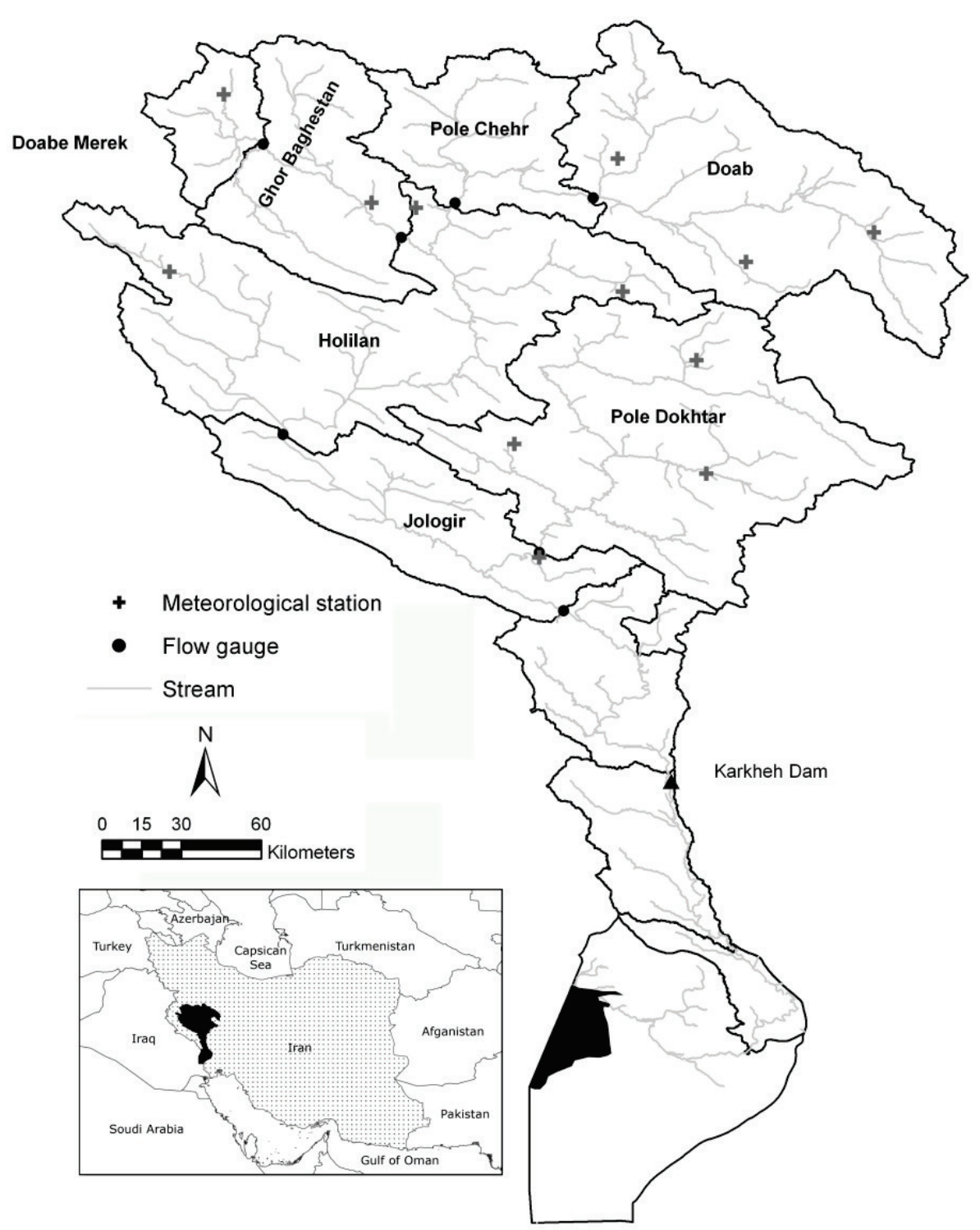

Figure 5.1: Location of sub-catchments and the streamflow gauging stations used for modeling.

For estimation of satellite-based actual evapotranspiration $\left(E T_{a}\right), 88$ cloudfree images from the Moderate Resolution Imaging Spectroradiometer on board the TERRA satellite (MODIS-TERRA) (source: http://ladsweb.nascom.nasa.gov/) are used for the period April 2000 to December 2003 (Muthuwatta et al., 2010; 2013). Meteorological data required for estimation of satellite-based $E T_{a}$ is collected at 12:00 local time 
and is close to the overpass time of the satellite, which is between 10:42 and 11:05 local time. The Penman-Monteith method served to estimate the daily reference evapotranspiration $\left(E T_{0}\right)$ required for the rainfall-runoff modelling. To estimate daily $E T_{0}$, minimum and maximum values of relative humidity and the average of the measured wind speed values at three hourly intervals are used as suggested in Allen et al. (1998).

In the sub-catchments where daily observations from more than one meteorological station are available, weighted-area averages were estimated with the use of Thiessen polygons. Table 5.2 shows the Thiessen weights for the four rain gauges in Doab sub-catchment and the estimated annual precipitation.

Table 5.2: Thiessen weights and annual precipitation for Doab sub-catchment ( 2000 to 2003).

\begin{tabular}{lccccc}
\hline Station name & Weight $\left(W_{i}\right)$ & \multicolumn{5}{c}{ Annual Precipitation $\left(P_{i}\right)(\mathrm{mm})$} \\
& & 2000 & 2001 & 2002 & 2003 \\
\hline Hamedan & 0.09 & 544.6 & 225.7 & 299.6 & 441.7 \\
Kangvar & 0.36 & 624.8 & 278.0 & 413.4 & 526.3 \\
Malayer & 0.30 & 646.9 & 319.6 & 269.7 & 332.6 \\
Nahavand & 0.25 & & & & \\
\hline Catchment average & & $\mathbf{6 6 1 . 4}$ & $\mathbf{3 0 2 . 6}$ & $\mathbf{3 3 5 . 6}$ & $\mathbf{4 3 5 . 0}$ \\
\hline
\end{tabular}

Analysis of estimating areal precipitation for the Karkheh Basin is reported in Masih (2011), who showed that areal estimates at annual base by station data are dissimilar from estimates by elevation weighted, inverse distance interpolation. Differences, however, did not notably propagate in Qs modeling for larger sized ( $>1,600 \mathrm{~km}^{2}$ ) sub-catchments. In this study, we compared the Thiessen estimates at sub-catchment scale to estimates by Kriging interpolation as shown in Muthuwatta et al., (2010), to analyze the effects of rainfall representation. Comparison at annual base showed that differences are smaller than differences shown in Masih et al. (2011), and may be due to the relative large size of the sub-catchments. Errors in point measurements and spatial representation of precipitation by Thiessen polygons may affect the averaging results. Legates and DeLiberty (1993) and Dingman (2002) show that errors of in-situ measured precipitation commonly range between +5 or -5 to $15 \%$ and we, therefore, assume that the error in the precipitation data used in this study is of similar magnitude. Prior to the application of data, consistency tests are performed and erroneous data are corrected. In 
Table 5.3, annual figures (2001 to 2003) of precipitation and $E T_{a}$ are shown. On annual scale, the difference between precipitation and $E T_{a}$ gives the Qs from the respective catchments. The ratio between the $\mathrm{Qs}$ and $E T_{a}$ volumes shows that, on average, Qs is only $18 \%$ of the $E T_{a}$ volume and that a small error in $E T_{a}$ may result in a relatively large error in Qs. Further analysis shows that the ratio between Qs and precipitation is about $15 \%$.

Table 5.3: Annual water balance of the seven sub-catchments (2001 to 2003) $\left(\mathrm{m}^{3} \times 10^{6}\right)$.

\begin{tabular}{lcccccc}
\hline & $P$ & $E T_{a}$ & $P-E T_{a}$ & $Q_{\text {in }}$ & $Q_{\text {out }}$ & $Q s / E T_{a}$ \\
\hline Doab & 3,129 & 2,911 & 218 & 0 & 267 & 0.07 \\
Pole Chehr & 1,354 & 1,144 & 210 & 267 & 512 & 0.18 \\
Doabe Merek & 541 & 491 & 50 & 0 & 67 & 0.10 \\
Ghor Baghestan & 1,648 & 1,477 & 171 & 67 & 339 & 0.12 \\
Holilan & 4,176 & 3,017 & 1159 & 851 & 1,566 & 0.38 \\
Pole Dokhtar & 4,101 & 3,428 & 673 & 0 & 827 & 0.20 \\
Jelogir & 1,347 & 1,391 & -44 & 2,393 & 2,764 & -0.03 \\
Sum & 16,296 & 13,859 & 2,437 & - & - & 0.18
\end{tabular}

Note: $\mathrm{Q}_{\text {in }}$ - Observed surface flow from upstream, Qout - Observed outflow, Qs streamflow.

\subsection{Methods}

\subsubsection{Time series of SEBS-based actual evapotranspiration}

For estimation of daily satellite-based $E T_{a}$, 88 cloud-free MODIS-TERRA images were acquired for the period April 2000-December 2004. Images have a spatial resolution of $1 \mathrm{~km} \times 1 \mathrm{~km}$ and are irregularly distributed over time because of cloud coverage (See Table 2.8). To estimate $E T_{a}$ for days that satellite images were not available, a Penman-Monteith-based approach, as proposed by Immerzeel and Droogers (2008), is expanded. In that approach, the latent heat flux is estimated by using MODIS images and a SEBS algorithm. By substitution of estimated latent heat flux $(\lambda E)$ (Equation 5.1 ) of the Penman-Monteith equation, surface resistance $\left(r_{s}\right)$ values were estimated inversely for days when satellite images were available. For days when satellite images were not available, the estimated $r_{s}$ value of the preceding image was applied to all days in between the successive images with recorded daily meteorological data. In this approach, $r_{s}$ is allowed to linearly change between consecutive images to reflect the daily growth 
stages of the vegetation. The Penman-Monteith equation (Monteith, 1965) reads:

$$
\lambda E=\frac{\Delta\left(R_{n}-G_{0}\right)+\rho_{a} \cdot c_{p} \cdot \frac{\left(e_{s}-e_{a}\right)}{r_{a}}}{\Delta+\gamma\left(1+\frac{r_{s}}{r_{a}}\right)}
$$

where: $\Delta$ is the slope of the saturated vapor pressure curve $\left(\mathrm{KPa} \mathrm{K}^{-1}\right), \rho_{a}$ is the air density $\left(\mathrm{kg} \mathrm{m}^{-3}\right), c_{p}$ is the air specific heat at constant pressure $\left(\mathrm{J} \mathrm{kg}^{-1}\right.$ $\left.\mathrm{K}^{-1}\right),\left(e_{s}-e_{a}\right)$ is the vapor pressure deficit of the air $(\mathrm{kPa}), \gamma$ is the psychometric constant $\left(\mathrm{kPa} \mathrm{K}^{-1}\right)$, and $r_{s}$ and $r_{a}$ are the surface and aerodynamic resistances $\left(\mathrm{sm}^{-1}\right)$, respectively. Daily net radiation $\left(R_{n}\right)$ can be estimated by using sunshine hours. The soil heat flux $\left(G_{0}\right)$ is assumed to be zero at a daily time step, as it is positive when the soil is warming and negative when the soil is cooling (Allen et al., 1998). Surface resistance $\left(r_{s}\right)$ controls the difference between $E T_{a}$ and $E T_{0}$, i.e., evapotranspiration falls below its reference value in case $r_{s}$ exceeds a certain minimum threshold value (e.g., Bastiaanssen and Bandara, 2001). Routinely collected daily meteorological data on air temperature, humidity, wind speed and sunshine hours can be used to estimate all terms in Equation 5.1, except for the two resistance terms. Therefore, estimating daily values of $r_{s}$ and $r_{a}$ allows for the estimation of $E T_{a}$ for days when satellite images are not available.

The transfer of heat and water vapor from the evaporating surface into the air is determined by $r_{a}$ and reads:

$$
r_{a}=\frac{\ln \left[\frac{\left(z_{m}-d\right)}{z_{o m}}-\psi_{m}\right] \cdot \ln \left[\frac{\left(z_{h}-d\right)}{z_{o h}}-\psi_{h}\right]}{k^{2} \cdot u_{z}}
$$

where: $z_{m}$ is the height of wind speed measurement $(m), z_{h}$ is the height of humidity measurements $(m), d$ is the zero displacement height $(m), z_{o m}$ is the roughness length governing momentum transfer $(m), z_{o h}$ is the roughness length governing transfer of heat and vapor $(\mathrm{m}), k$ is the Von Karman's constant $(-), u_{z}$ is the wind speed at height $z\left(\mathrm{~ms}^{-1}\right)$, and $\psi_{m}{ }^{(-)}$ and $\psi_{h}(-)$ are the stability correction functions for momentum and heat transport, respectively.

For estimation of $z_{o m}$, an empirical relation proposed by Su et al. (2001) is used: 


$$
z_{\text {om }}=0.005+0.5 \cdot\left[\frac{N D V I}{N D V I_{\max }}\right]^{2.5}
$$

where: $N D V I_{\max }$ is the $N D V I$ for full canopy. The relationship between $z_{\text {oh }}$ and $z_{o m}$ is given in Equation 5.4 using a dimensionless quantity $k B^{-1}$ :

$$
z_{o h}=\frac{z_{o m}}{\exp \left(k B^{-1}\right)}
$$

Su et al. (2001) proposed to estimate $k B^{-1}$ by combining models of $k B^{-1}$ for full canopy, partial canopy and bare soil. In this study, the above formulation was adapted, where a formulation by Gieske (2007) that is based on a revised relation for the heat transfer coefficient from bluff-rough surfaces into the atmosphere was used for bare soils. For a detailed description, reference is made to Brutsaert (1999). Spatial distributions of roughness length and stability correction factors are estimated for days when images are available which, in turn, are used to estimate $r_{a}$ (Equation 5.2). For days when satellite images are available, $\lambda E$ is estimated using the SEBS algorithm. Through Equation 5.1, $r_{s}$ is inversely estimated using $r_{a}, \lambda E$ and respective meteorological data. In the procedure $r_{s}$ and $r_{a}$ are interpolated between consecutive images. The interpolated daily values and recorded data on air temperature, humidity, wind speed and sunshine hours are used to estimate $E T_{a}$ for days when satellite images are not available. Muthuwatta et al. (2010) show that the SEBS-ET $T_{a}$ compares well to daily estimates of Priestley and Taylor $E T_{a}$ over a well-watered pixel in a swamp area. In the absence of more reliable in situ data to validate SEBS-ET $T_{a}$ estimates, we assume that estimates represent the real-world actual evapotranspiration well.

\subsubsection{Hydrological modelling}

For Qs simulation, a modified version of the HBV model by Lindström et al. (1997) has been selected. This model consists of six routines -precipitation accounting, soil moisture quick runoff and base flow, which transform excess water from the soil moisture zone to local runoff, a transformation function and a routing routine. It is noted that the transformation function that smoothens the Qs is not used since sub-catchments in this study are of a relatively large size. For estimation of $E T_{0}$, the Penman-Monteith equation is selected (Allen et al. 1998) although other approaches are known as well (Merz and Blöschl, 2004; Lindström et al., 1997). Section 3.4.1 illustrates the basic diagram of the HBV model and the equations used.

For the Upper Karkheh Basin, the model is applied in a semi-distributed fashion and for each sub-catchment a lumped model is developed with 
specific model forcing. Based on the split sample test, we selected periods for calibration and validation. The model is calibrated for the period April 2000 to March 2002 and validated for the period April 2002 to December 2003.

\subsubsection{Model performance assessment}

Model performance is assessed by the Nash-Sutcliffe coefficient (NS) (Equation 5.5) of efficiency (Nash and Sutcliffe, 1970) and the Relative Volume Error (RVE) (Equation 5.6). NS is selected to evaluate the goodnessof-fit of the simulated hydrograph. RVE is selected because it indicates the water balance error.

$$
\begin{aligned}
& N S=1-\frac{\sum_{i=1}^{i=N}\left[V_{s}(i)-V_{o}(i)\right]^{2}}{\sum_{i=1}^{i=N}\left[V_{0}(i)-\overline{V_{o}(i)}\right]^{2}} \\
& R V E=\frac{\sum_{i=1}^{i=N}\left[V_{s}(i)-V_{o}(i)\right]}{\sum_{i=1}^{1=N} V_{o}(i)}
\end{aligned}
$$

where: $\mathrm{i}=$ the time step, $\mathrm{N}=$ the total number of time steps, $V_{s}(i)$ and $V_{o}(i)=$ the simulated and observed variables (here Qs and $E T_{a}$ ) during the $\mathrm{i}^{\text {th }}$ time step, respectively, and $\overline{V_{o}(i)}=$ the mean value of the observed variables over the calibration period. In case the model estimates perfectly match with observations then NS becomes 1 and RVE becomes 0 . In the practice of modeling, models are assumed to perform well for NS values larger than 0.8. However, Gupta et al. (2008) show that interpreting NS values is not straightforward. NS values lower than 0 indicate that simulated values, on average, are a poorer predictor than the long-term mean of the observations. With respect to $R V E$, error values within a range of $+5 \%$ or $5 \%$ indicate (very) good performance whereas errors within a range of $+10 \%$ or $-10 \%$ indicate satisfactory performance (Parajka et al., 2007; Madsen, 2000). Seibert (1999) and De Vos and Rientjes (2007), for instance, show that one parameter set may indicate a good fit for the NS coefficient, but may indicate a poor fit for $R V E$ and vice versa. To assess overall performance of the model, we selected a performance measure $Y$ (Akhtar et al., 2009) that combines NS and RVE (Equation 5.7): 


$$
Y=\frac{N S}{1+|R V E|}
$$

A value of $Y$ close to 1 indicates an excellent model performance whereas values lower than 0.6 indicate poor performance.

\subsubsection{Parameter estimation}

In this work, parameter values are optimized through a Monte Carlo Simulation (MCS) procedure. MCS is selected because of its large number of successful applications (e.g., Seibert, 1999; Wagener et al., 2003; Choi and Beven, 2007; Booij and Krol, 2010; Rientjes et al., 2011). For further discussion on optimization procedures, we refer to Gupta et al. (2008), De Vos and Rientjes (2008) and Efstratiadis and Koutsoyiannis (2010).

In MCS, a large number of parameter sets are randomly generated and serve to assess the performance of the model. In this Bayesian approach, the parameter values are selected within a pre-defined parameter space and model performance is assessed through an objective function. Most important in MCS is the selection of model calibration parameters, determination of prior parameter space, selection of probability distributions for the calibration parameters, determination of the number of simulations to be executed and the selection of the objective function(s). For first applications in hydrology, we refer to Beven and Binley (1992) and Harlin and Kung (1992).

In this study, we define three model calibration cases. Case 1 represents the most common application where calibration and parameter optimization of the HBV model is on Qs. To assess how well HBV-ETa matches SEBS-ET performance measures are simply applied. In Case 2, calibration and parameter optimization is on $E T_{a}$, so that the HBV-ETa model matches best with SEBS-ETa. Model performance is also assessed for Qs by simple application of performance measures to observed and simulated counterparts.

In Case 3, both Qs and $E T_{a}$ are used simultaneously in model calibration to optimize parameter values. Model performance is evaluated through a preference-based objective function that simultaneously minimizes deviations between respective variables. This function weights $Y_{Q}$ and $Y_{E T a}$ as in Equation 5.8:

$$
Y_{T O T}=w_{Q} Y_{Q}+w_{E T_{a}} Y_{E T_{a}}
$$


where: $w_{Q}$ and $w_{E T_{a}}$ are the respective weights for Qs and $E T_{a}$. In the approach, weights are defined for each sub-catchment and reflect on statistical properties of the time series. $Y_{\text {TOT }}$ is also estimated for cases 1 and 2 following Equation (5.8). Weights are presented in Table 5.10 and the same weights are applied for all three cases.

In studies by Abbaspour et al. (2007) and Rostamian et al. (2008), weights are taken inversely proportional to the variance of the observed data. The procedure is particularly useful when variables are of the same order of magnitude. If variables are of a different magnitude then weights have a bias towards the variable that has the smallest values. However, hydrological processes that are characterized by small values do not necessarily reflect their impact to best simulate catchment responses. To overcome biases, Rode et al. (2007) take weights inversely proportional to the coefficient of variation to reflect the relative magnitude of the observations. The latter approach is adopted in this study.

Parameters are independently estimated for the three cases (Case 1 to 3 ), where time series of daily Qs and daily $E T_{a}$ are used. Since both terms are sink terms to the model, matching one term directly affects the second one. By applying the lumped HBV model to respective sub-catchments, HBV- $E T_{a}$ estimates are assumed to be representative at sub-catchment scale, as in Immerzeel and Droogers, (2008) and Winsemius et al., (2008). In the procedure, to compare the HBV- $E T_{a}$ with SEBS- $E T_{a}$, the pixel estimates are averaged over the sub-catchments to arrive at equivalent estimates. We note that $E T_{a}$ estimates also cover for water abstractions from Qs channels to support irrigation. Therefore, for Qs model calibration we use time series at the catchment outlet.

The selection of model parameters, for which the HBV model has shown to be sensitive, is based on studies by Seibert (1999), Lidén and Harlin (2000), Merz and Blöschl (2004), Wale et al. (2009) and Deckers et al. (2010). Table 5.4 shows the prior value ranges for parameters based on a simple manual sensitivity analysis and studies by Seibert (1997) and Booij (2005). In the procedure, a uniform distribution is assumed for all parameters and parameter values are randomly drawn from parameter space as defined by the parameter value ranges. For the melting factor and threshold temperature in the degree-day procedure, we followed Booij (2005) and Gotzinger and Bardossy (2005) and applied default values from SMHI (2006). 
Table 5.4: Prior parameter ranges used for MCS.

\begin{tabular}{|c|c|c|c|c|}
\hline Parameter & Unit & Description & Prior $r$ & range \\
\hline$F C$ & $\mathrm{~mm}$ & Maximum soil moisture storage & 100 & -500 \\
\hline BETA & - & $\begin{array}{l}\text { Parameter of power relationship to simulate } \\
\text { indirect runoff }\end{array}$ & 1.0 & -1.2 \\
\hline$L P$ & - & Evaporation reduction parameter & 0.1 & - $\quad 1.0$ \\
\hline$A L F A$ & - & Measure of non-linearity for fast flow & 0.1 & -2.0 \\
\hline$K_{f}$ & $d^{-1}$ & Recession coefficient for fast flow & 0.01 & 0.1 \\
\hline$K_{s}$ & $d^{-1}$ & Recession coefficient for slow flow & $0.01-$ & 0.05 \\
\hline PERC & $\mathrm{mm} \mathrm{d}^{-1}$ & Maximum percolation rate & 0.1 & - 1.1 \\
\hline
\end{tabular}

Principle to the validity of MCS is that the entire parameter space is examined to allow statistical evaluation of the results. To determine the minimum run number, the evolution of $Y$ was assessed by systematically increasing the run number from 500 to 60,000. Figure 5.2 shows graphs of $Y_{Q}$ and $Y_{E T a}$ as a function of the number of runs for Doab sub-catchment.
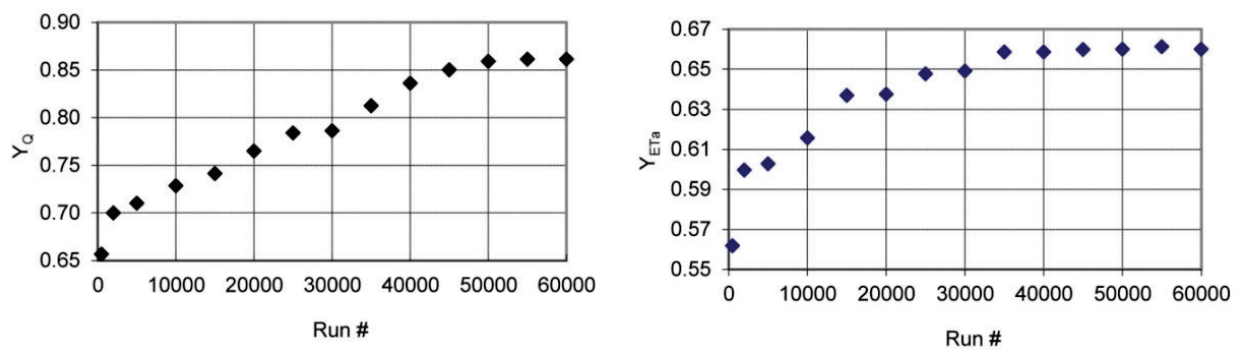

Figure 5.2: Evolution of $Y$ against run number for $Q s$ and $E T_{a}$ (Doab sub-catchment).

For Qs, $Y_{Q}$ levels off after 50,000 runs whereas for $E T_{a}, Y_{E T a}$ levels off after 35,000 runs. From these results, we assume that the parameter space is sufficiently examined for both Qs and $E T_{a}$ when the run number is set to 50,000 . Out of these, the 1,000 best simulations (i.e., that have the highest $Y_{Q}$ and $Y_{E T a}$ values) are selected to narrow parameter space. Parameter sets are examined, and minimum and maximum values for each parameter are determined. The MCS procedure of 50,000 runs is then repeated for the narrowed parameter space after which, for the respective cases, parameter values for the 25 parameter sets that produced the highest $Y_{Q}$ and $Y_{E T a}$ values are averaged. The sample size of 25 is chosen arbitrarily, but is assumed to be sufficiently large to yield representative values. The averaged 
parameter values and parameter sets are used for further analysis and for comparison purposes for cases 1,2 and 3 .

\subsection{Results and Discussion}

\subsubsection{Time series of actual evapotranspiration}

The constructed time series of SEBS-ETa at daily base for Doab subcatchment is shown in Figure 5.3. The highest values are observed after the end of the wet season (i.e., May) when rainwater has replenished the soil and crops are grown. During the second half of the dry season (July to September), $E T_{a}$ values are lowest and characterized by low daily fluctuations due to depletion of the upper part of the unsaturated zone. Constructed time series are validated by eight images which were not used for development. Images are selected to cover for periods with low and high $E T_{a}$ during the annual cycle. Estimates for validation are indicated by the $\Delta$-symbol.

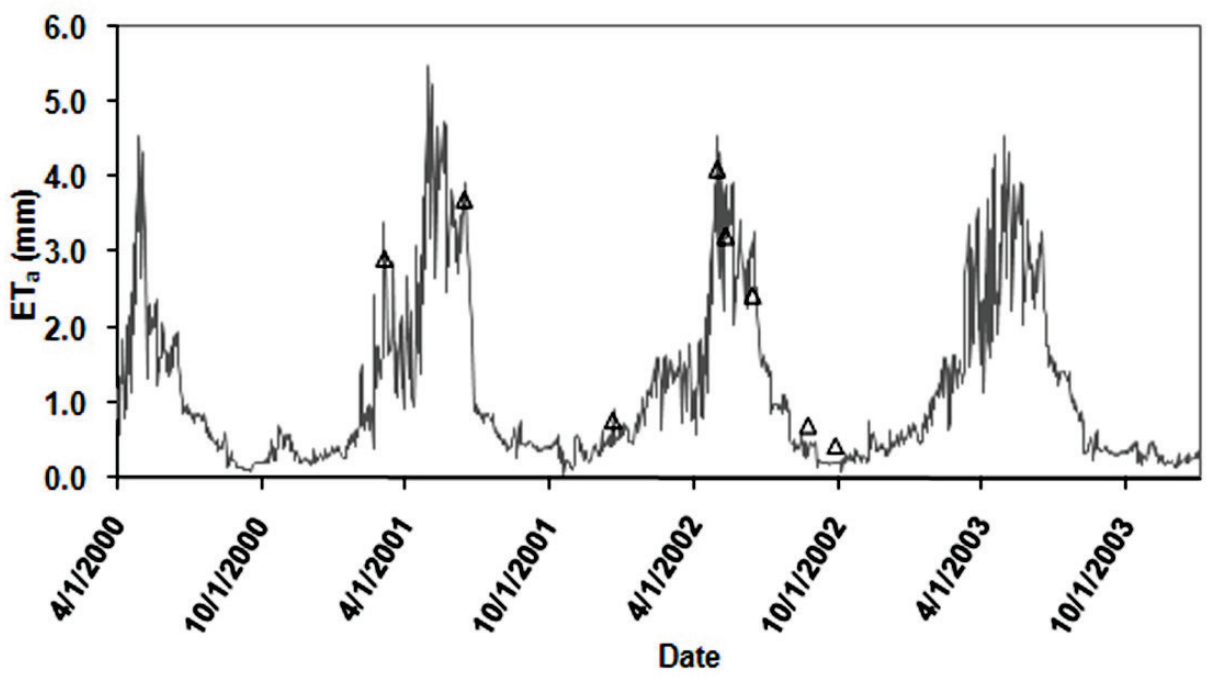

Figure 5.3: Constructed time series of SEBS-ETa for Doab sub-catchment. Estimates used for validation are indicated by the $\Delta$-symbol.

To evaluate accuracy, we selected measures of the Coefficient of Determination (R2) and the root mean square error (RMSE). For the subcatchments, R2 values ranged from 0.81 to 0.92 whereas for RMSE values ranged from 0.31 to $0.53 \mathrm{~mm} \mathrm{d-1}$ (Table 5.5). Figure 5.3 shows that validation estimates compared well to counterparts in the reconstructed time series, and suggest effectiveness of the procedure. 
Multi-variable calibration of a semi-distributed hydrological model

Table 5.5: Statistics of SEBS_daily estimates versus SEBS estimates (RMSE in $\mathrm{mm}$

\begin{tabular}{lccccccc}
$\left.\mathrm{d}^{1}\right)$. & Doab & Pole & Doabe & Ghor & Holilan & Pole & Jelogir \\
\hline$R^{2}$ & 0.92 & 0.88 & 0.81 & 0.87 & 0.91 & 0.90 & 0.87 \\
$R M S E$ & 0.37 & 0.40 & 0.53 & 0.43 & 0.37 & 0.31 & 0.33 \\
\hline
\end{tabular}

Results in Figure 5.3 indicate that daily fluctuations are well represented when compared to the reconstructed time series and suggest effectiveness of the procedure to reconstruct time series of daily ETa. Values of R2 and RMSE for the seven sub-catchments suggest that the performance of the approach is comparable. Further, the accumulated ETa by SEBS and SEBS_daily for the one year period from November 2002 to October 2003 were compared for all sub-catchments. The differences between annual ETa by the two methods were less than $10 \%$.

\subsubsection{Calibration on Qs (Case 1)}

The average model efficiency values of NS, RVE and YQ of the best performing 25 parameter sets are presented in Table 5.6 and indicate a good performance for five sub-catchments. For Holilan and Jelogir, NS and RVE values indicate poor performance, suggesting that simulated and observed hydrographs do not match well. It is noted that Qs generated in these catchments is determined by hydrograph separation, as discussed in Section 5.2, and is presumably the main cause for the observed Qs hydrographs being unreliable. The water balance terms presented in Table 5.3 for Jelogir show that the catchment outflow is larger than the total of Qs from upstream connected sub-catchments and precipitation. Therefore, the observed Qs measurements at the outlet of Jelogir are considered as not being reliable. For all catchments, except for Ghor Baghestan and Pole Dokhtar, model validation results slightly deteriorate, but NS, RVE and $Y$ values indicate a satisfactory to good performance.

Table 5.6: Model efficiency for Qs for respective periods when calibration and validation are on $Q s$ (Case 1 ).

\begin{tabular}{|c|c|c|c|c|c|c|c|}
\hline \multirow{2}{*}{ Sub-catchment } & \multirow{2}{*}{$\begin{array}{l}\text { Area } \\
\mathrm{km}^{2}\end{array}$} & \multicolumn{3}{|c|}{$\begin{array}{c}\text { Calibration } \\
\text { April 2000-March } 2002\end{array}$} & \multicolumn{3}{|c|}{$\begin{array}{c}\text { Validation } \\
\text { April 2002-December } 2003\end{array}$} \\
\hline & & NS & RVE & $Y$ & NS & RVE & $Y$ \\
\hline Doab & $7,766.8$ & 0.88 & -2.52 & 0.86 & 0.78 & -6.31 & 0.73 \\
\hline Pole Chehr & $3,121.5$ & 0.79 & -0.94 & 0.78 & 0.77 & -6.20 & 0.73 \\
\hline Doabe Merek & $1,285.7$ & 0.83 & -3.60 & 0.80 & 0.76 & -2.80 & 0.74 \\
\hline Ghor Baghestan & $4,071.9$ & 0.66 & -1.92 & 0.65 & 0.72 & -8.20 & 0.67 \\
\hline Holilan & $9,873.3$ & 0.50 & -9.70 & 0.46 & 0.49 & -24.10 & 0.39 \\
\hline Pole Dokhtar & $9,541.5$ & 0.74 & -6.71 & 0.69 & 0.72 & -4.90 & 0.69 \\
\hline Jelogir & $4,116.3$ & 0.11 & -12.20 & 0.10 & 0.21 & -10.40 & 0.19 \\
\hline
\end{tabular}


Figure 5.4 shows the calibration results for Qs for the Doab sub-catchment. Results for Case 1 indicate a good match except for a very high peak flow in the month of May. Possible causes for this mismatch are a poor spatial representation of the observed rainfall that is characterized by very high intensities or the Monte Carlo procedure which is not able to identify a parameter set that, for the time series available, allow simulation of the highest flows.

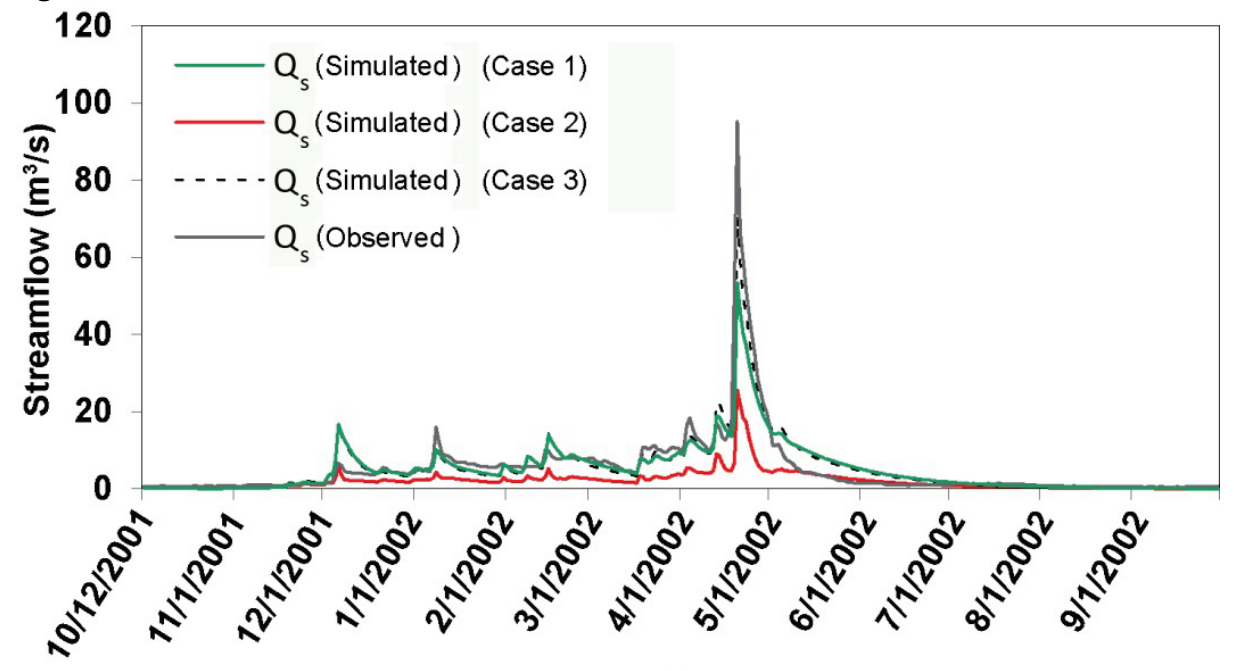

Date

Figure 5.4: Comparison of observed and simulated daily Qs for Doab sub-catchment for all three cases.

Efficiency values are also calculated for ETa, where HBV-ETa is compared to SEBS-ETa averaged over the sub-catchments. Results presented in Figure 5.5 show that HBV-ETa for case 1 deviate substantially from the SEBS-ETa. Differences are relatively large for the wet season and also for the first months of the dry season. HBV-ETa shows much higher fluxes during the wet season and also much quicker depletion of the catchment after the rainy season, with consistently lower ETa. This indicates that SEBS-ETa is not well represented by the HBV-ETa, with model efficiency values that indicate relatively poor performance (Table 5.7). Values are, notably, below the minimum acceptable level of 0.6 except for Pole Dokhtar. 
Table 5.7: Model efficiency for ETa for respective periods when calibration and validation are on Qs (Case 1).

\begin{tabular}{lcccccc}
\hline \multirow{2}{*}{ Sub-catchment } & \multicolumn{3}{c}{ Calibration } & \multicolumn{3}{c}{ Validation } \\
\cline { 2 - 7 } & $N S$ & $R V E$ & $Y$ & $N S$ & $R V E$ & $Y$ \\
\hline Doab & 0.55 & -15.20 & 0.48 & 0.61 & -6.20 & 0.57 \\
Pole Chehr & 0.43 & -10.10 & 0.39 & 0.55 & -13.40 & 0.49 \\
Doabe Merek & 0.57 & -9.40 & 0.52 & 0.53 & -7.40 & 0.49 \\
Ghor Baghestan & 0.51 & -18.40 & 0.43 & 0.63 & -10.53 & 0.57 \\
Holilan & 0.63 & -19.30 & 0.53 & 0.69 & -17.90 & 0.58 \\
Pole Dokhtar & 0.71 & -8.40 & 0.65 & 0.69 & -16.40 & 0.59 \\
Jelogir & 0.22 & -26.30 & 0.17 & 0.18 & -8.10 & 0.15 \\
\hline
\end{tabular}

Except for Pole Dokhtar, all YETa efficiency values are below 0.6, suggesting that HBV-ETa does not match well with SEBS-ETa, presumably because of poor representation. NS for Holilan sub-catchment is 0.63 and indicates a fair performance, but RVE is out of the acceptable range. Results suggest that the HBV model solves the water balance in such a way that emphasis is on matching Qs. Therefore, ETa can be interpreted as the process that closes the water balance. The closure causes HBV-ETa to deviate from SEBS-ETa with poor representation, particularly during both dry and wet seasons.

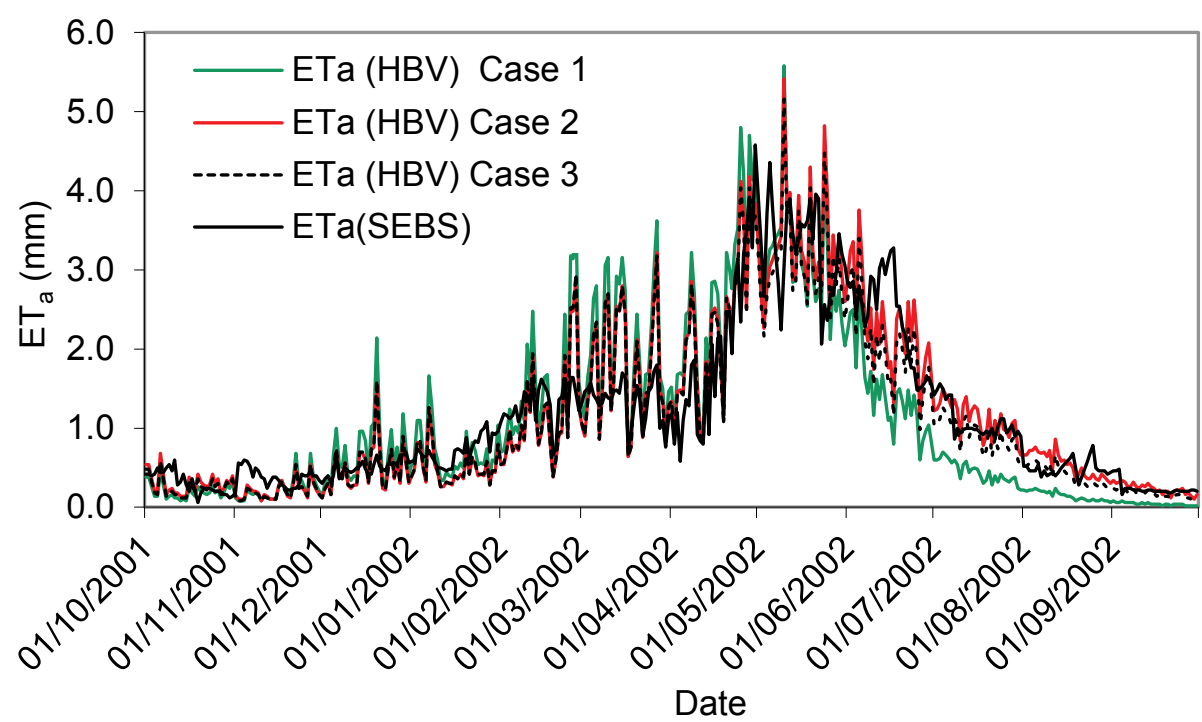

Figure 5.5: Comparison of HBV-ETa to satellite-based ETa for Doab sub-catchment for all three cases.

\subsubsection{Calibration on actual evapotranspiration (Case 2)}

In Case 2, calibration is aimed at matching HBV-ETa to SEBS-ETa, which is considered to be the real-world ETa. Results are presented in Figure 5.5 and 
show that seasonal patterns match well with good representation of ETa after the end of the wet season, but also with good ETa estimates for periods of high ETa during the wet season. As such, the accumulated deviation between HBV-ETa and SEBS-ETa is smaller than in Case 1. Performance indicators of ETa for Case 2 (Table 5.8) show much higher values for ETa than in Case 1 for all sub-catchments. This suggests much better HBV model performance to represent SEBS-ETa.

Table 5.8: Model efficiency for ETa when calibration and validation are on ETa (Case 2).

\begin{tabular}{lcccccc}
\hline \multirow{2}{*}{ Sub-catchment } & \multicolumn{3}{c}{ Calibration } & \multicolumn{3}{c}{ Validation } \\
\cline { 2 - 7 } & $N S$ & $R V E$ & $Y$ & $N S$ & $R V E$ & $Y$ \\
\hline Doab & 0.71 & -7.31 & 0.66 & 0.75 & -6.0 & 0.71 \\
Pole Chehr & 0.72 & -0.39 & 0.72 & 0.69 & -2.40 & 0.68 \\
Doabe Merek & 0.76 & -2.60 & 0.74 & 0.75 & -3.60 & 0.72 \\
Ghor Baghestan & 0.79 & -1.50 & 0.78 & 0.68 & -7.00 & 0.63 \\
Holilan & 0.80 & -7.61 & 0.74 & 0.89 & -4.60 & 0.86 \\
Pole Dokhtar & 0.84 & -1.42 & 0.83 & 0.72 & -5.10 & 0.68 \\
Jelogir & 0.68 & -9.60 & 0.62 & 0.74 & -4.80 & 0.71 \\
\hline
\end{tabular}

Table 5.9 shows YQ efficiency of the model when optimized parameters from YETa are applied to Qs (Case 2). For all seven sub-catchments, model performance of Qs is quite low and, compared to case 1, indicate significant deterioration. Qs volumes are much smaller than ETa volumes (Table 5.3) and, therefore, a relatively small error in ETa causes a relatively large error in Qs and vice versa. Such effects are shown in Figure 5.4, where the observed and simulated Qs are compared for all three cases. The simulated hydrograph for Case 2 shows a very low base flow for the entire simulation period, but peak flows are also underestimated. The poor Qs simulation result suggests that the water balance of the catchment is not well represented. However, when ETa is used as a calibration target, results suggest that the water balance is reproduced with good accuracy. In this case, ETa is well estimated by the HBV model, but causes significant deterioration of Qs as partly affected by the relatively small Qs volume. 
Table 5.9: Model efficiency for Qs when calibration and validation are on ETa (Case 2).

\begin{tabular}{lcccccc}
\hline \multirow{2}{*}{ Sub-catchment } & \multicolumn{3}{c}{ Calibration } & \multicolumn{3}{c}{ Validation } \\
\cline { 2 - 7 } & $N S$ & $R V E$ & $Y$ & $N S$ & $R V E$ & $Y$ \\
\hline Doab & 0.34 & -7.10 & 0.32 & 0.49 & -9.20 & 0.45 \\
Pole Chehr & 0.45 & -9.20 & 0.41 & 0.28 & -13.40 & 0.25 \\
Doabe Merek & 0.59 & -12.20 & 0.52 & 0.52 & -9.10 & 0.48 \\
Ghor Baghestan & 0.34 & -8.80 & 0.31 & 0.33 & -6.60 & 0.31 \\
Holilan & 0.49 & -7.90 & 0.45 & 0.54 & -10.20 & 0.49 \\
Pole Dokhtar & 0.50 & -11.45 & 0.45 & 0.46 & -12.40 & 0.41 \\
Jelogir & 0.20 & -15.90 & 0.17 & 0.18 & -18.70 & 0.15 \\
\hline
\end{tabular}

\subsubsection{Calibration on streamflow and actual evapotranspiration (Case 3)}

In this case, multi-variable calibration is carried out on Qs and ETa. Objective functions for both variables are simultaneously optimized and resultant performance indicators represent weighted sums for YTOT (Section 5.3.4). Table 5.10 shows that the normalized weights for Qs, in general, are slightly larger than weights for ETa.

Table 5.10: Weights used in multi-variable calibration (Case 3).

\begin{tabular}{lcc}
\hline Sub-Catchment & $w_{Q}$ & $w_{E T_{a}}$ \\
\hline Doab & 0.52 & 0.48 \\
Pole Chehr & 0.51 & 0.49 \\
Doabe Merek & 0.50 & 0.50 \\
Ghor Baghestan & 0.54 & 0.46 \\
Holilan & 0.53 & 0.47 \\
Pole Dokhtar & 0.55 & 0.45 \\
Jelogir & 0.51 & 0.49 \\
\hline
\end{tabular}

In Figures 5.4 and 5.5, simulated Qs and ETa for Case 3 are compared to results in cases 1 and 2. Qs shows a solution with a good match for most parts of the simulated hydrograph of Case 1. Peak flows are even closer to observed counterparts than in Case 1. Low-flows match those in Case 1 rather well. Moreover, simulated low flows in Case 3 are close to the observed low flows. Similar to Case 1, the lower part of the recession limb is slightly higher compared to the observed data. Results for ETa are much better than those for Case 1 and are closer to the calibration results for Case 2. Results match well, particularly during the wet season, but fluxes are slightly lower during the first months after the start of the dry season. ETa is well represented in Case 3 and suggests the effectiveness of the use of 
SEBS-ETa in multi-variable model calibration with, generally, highest values. Both Qs and ETa are well represented with fair fits for low flows, peak flows and wet-season recession, and also for ETa estimates during the wet season, inter-event periods and the wet-season recession period. Simulation results also match well to observed time series of Qs and SEBS-ETa. Overall, hydrological behavior of the catchment is well represented in Case 3, and constrains of single variable calibration in cases 1 and 2 are considerably weakened. Effects of the large different volumes of Qs and ETa, as shown in Case 2, do not cause a distinct deterioration of simulation results in Case 3 and, moreover, suggest the effectiveness of the use of two water balance terms in mass conservative rainfall-runoff model calibration.

Performance indicators for all three cases are shown in Table 5.11. A comparison of $Y Q$ for all three cases shows the highest value for Case 1, lowest value for Case 2 and values for Case 3 that are slightly lower than that of Case 1. Values for Case 3 are relatively high for most sub-catchments, except for Holilan and Jelogir, for which results are rejected in Case 1 due to unreliable Qs records. Results for YETa indicate a similar pattern, with slightly poorer results for Case 3 compared to Case 2, where ETa was the calibration target. For Case 3, YETa values are higher than 0.6 for all sub-catchments. 
Table 5.11: Model efficiency for all three cases. Hatched values indicate values for optimized parameters by calibration. All other values result from simple application of the objective functions.

\begin{tabular}{|c|c|c|c|c|c|c|c|}
\hline \multirow[t]{2}{*}{ Sub-catchment } & \multirow[t]{2}{*}{ Case } & \multicolumn{3}{|c|}{$\begin{array}{l}\text { April } 2000 \text { - March } 2002 \\
\text { (calibration period) }\end{array}$} & \multicolumn{3}{|c|}{$\begin{array}{c}\text { April } 2002 \text { - December } 2003 \\
\text { (validation period) }\end{array}$} \\
\hline & & $Y_{Q}$ & $Y_{E T a}$ & $Y_{\text {TOT }}$ & $Y_{Q}$ & $Y_{E T a}$ & $Y_{\text {TOT }}$ \\
\hline \multirow[t]{3}{*}{ Doab } & 1 & 0.86 & 0.48 & 0.68 & 0.73 & 0.57 & 0.65 \\
\hline & 2 & 0.32 & 0.66 & 0.48 & 0.45 & 0.71 & 0.57 \\
\hline & 3 & 0.85 & 0.63 & 0.74 & 0.71 & 0.70 & 0.71 \\
\hline \multirow[t]{3}{*}{ Pole Chehr } & 1 & 0.78 & 0.39 & 0.59 & 0.73 & 0.49 & 0.61 \\
\hline & 2 & 0.41 & 0.72 & 0.56 & 0.25 & 0.68 & 0.46 \\
\hline & 3 & 0.73 & 0.71 & 072 & 0.69 & 0.64 & 0.66 \\
\hline \multirow[t]{3}{*}{ Doabe Merek } & 1 & 0.80 & 0.52 & 0.66 & 0.74 & 0.49 & 0.61 \\
\hline & 2 & 0.52 & 0.74 & 0.63 & 0.48 & 0.72 & 0.60 \\
\hline & 3 & 0.74 & 0.73 & 0.73 & 0.71 & 0.70 & 0.70 \\
\hline \multirow[t]{3}{*}{ Ghor Baghestan } & 1 & 0.65 & 0.43 & 0.54 & 0.67 & 0.57 & 0.62 \\
\hline & 2 & 0.31 & 0.78 & 0.53 & 0.31 & 0.63 & 0.45 \\
\hline & 3 & 0.62 & 0.72 & 0.66 & 0.64 & 0.62 & 0.63 \\
\hline \multirow[t]{3}{*}{ Holilan } & 1 & 0.46 & 0.53 & 0.49 & 0.39 & 0.58 & 0.47 \\
\hline & 2 & 0.45 & 0.74 & 0.59 & 0.49 & 0.86 & 0.66 \\
\hline & 3 & 0.43 & 0.68 & 0.54 & 0.32 & 0.73 & 0.51 \\
\hline \multirow[t]{3}{*}{ Pole Dokhtar } & 1 & 0.69 & 0.65 & 0.67 & 0.69 & 0.59 & 0.64 \\
\hline & 2 & 0.45 & 0.83 & 0.62 & 0.41 & 0.68 & 0.53 \\
\hline & 3 & 0.67 & 0.81 & 0.73 & 0.67 & 0.67 & 0.67 \\
\hline \multirow[t]{3}{*}{ Jelogir } & 1 & 0.10 & 0.17 & 0.13 & 0.19 & 0.15 & 0.17 \\
\hline & 2 & 0.17 & 0.62 & 0.39 & 0.15 & 0.71 & 0.42 \\
\hline & 3 & 0.11 & 0.61 & 0.35 & 0.10 & 0.60 & 0.34 \\
\hline
\end{tabular}

Results in cases 1 and 2 suggest that the model performs well when Qs (Case 1) or SEBS-ETa (Case 2) are used in single variable calibration. For both cases, the second term (i.e., ETa for case 1 and Qs for case 2) closes the water balance and is not well represented. Causes for the poor results in cases 1 and 2, however, are somewhat different. The fact that volumes of ETa are much larger than that for Qs, affected the simulation and calibration 
results with particular poor fit of Qs in Case 2. Effects on ETa are much less pronounced when calibration is on Qs in Case 1, which is partly caused by the relatively small Qs volume. However, in this case, HBV-ETa and SEBS-ETa show principally different characteristics during the dry and wet seasons. This suggests that HBV-ETa does not represent SEBS-ETa well during the dry season and inter-rainfall event periods in the wet season. In Case 3, the multi-variable calibration, however, a solution has been found with relatively good fit for both Qs and ETa. Calibration resulted in YQ and YETa values that are higher than 0.61 in all sub-catchments, with the highest values of 0.85 for YQ and 0.81 for YETa. For the remaining sub-catchments, YTOT ranges between 0.66 and 0.74 and indicate satisfactory performance.

To further assess how the selected calibration target affects the water balance of the model, for all three cases, daily ETa and Qs are accumulated and shown in Figures 5.6 and 5.7. The accumulated distribution functions indicate that deviations between observed and simulated counterparts consistently increase over certain periods whereas the deviations decrease over other periods. In Figure 5.6, accumulated ETa, for all three cases, is compared to SEBS-ETa, and show that deviations increase during the dry season and decrease during the wet season. Comparing ETa of cases 1 and 2 to ETa of multi-variable calibration for Case 3, shows that differences are smallest for Case 2 and largest for Case 1. At the end of the simulation period, the difference of ETa between Cases 1 and 3 is much smaller than the difference between Cases 2 and 3 .

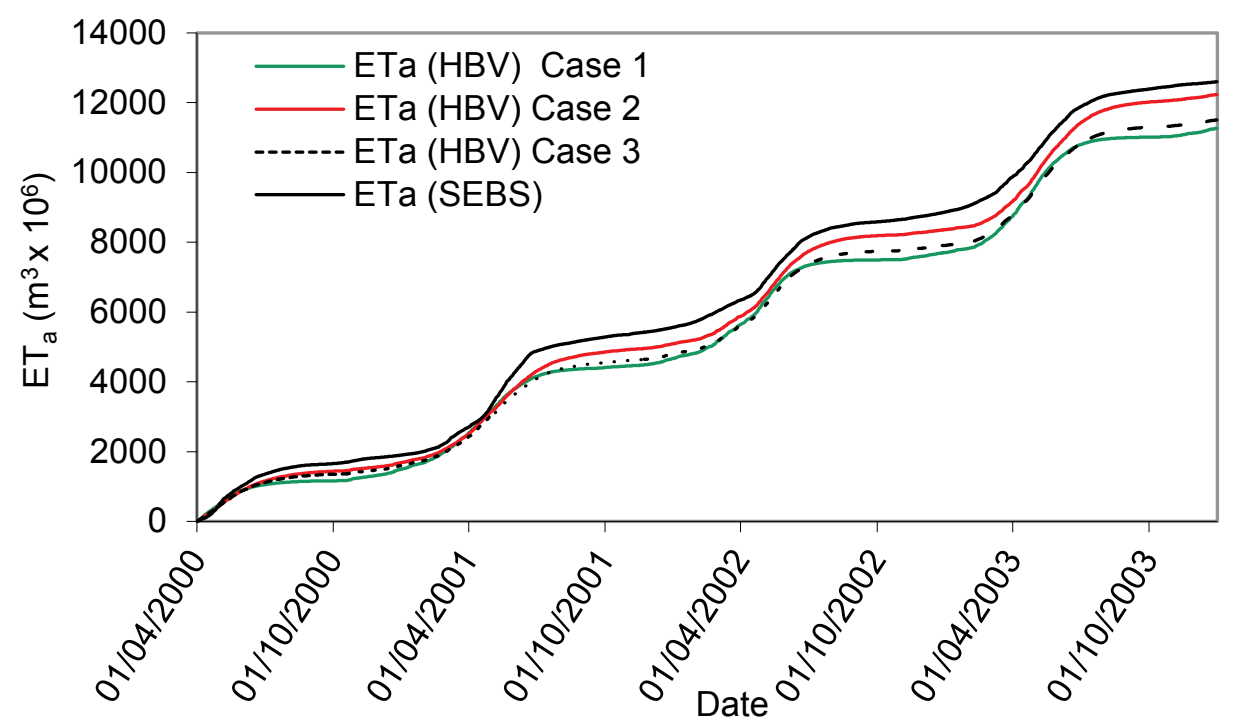

Figure 5.6: Cumulative distribution of HBV-based ETa and SEBS-based ETa from for Doab sub-catchment for all three cases. 


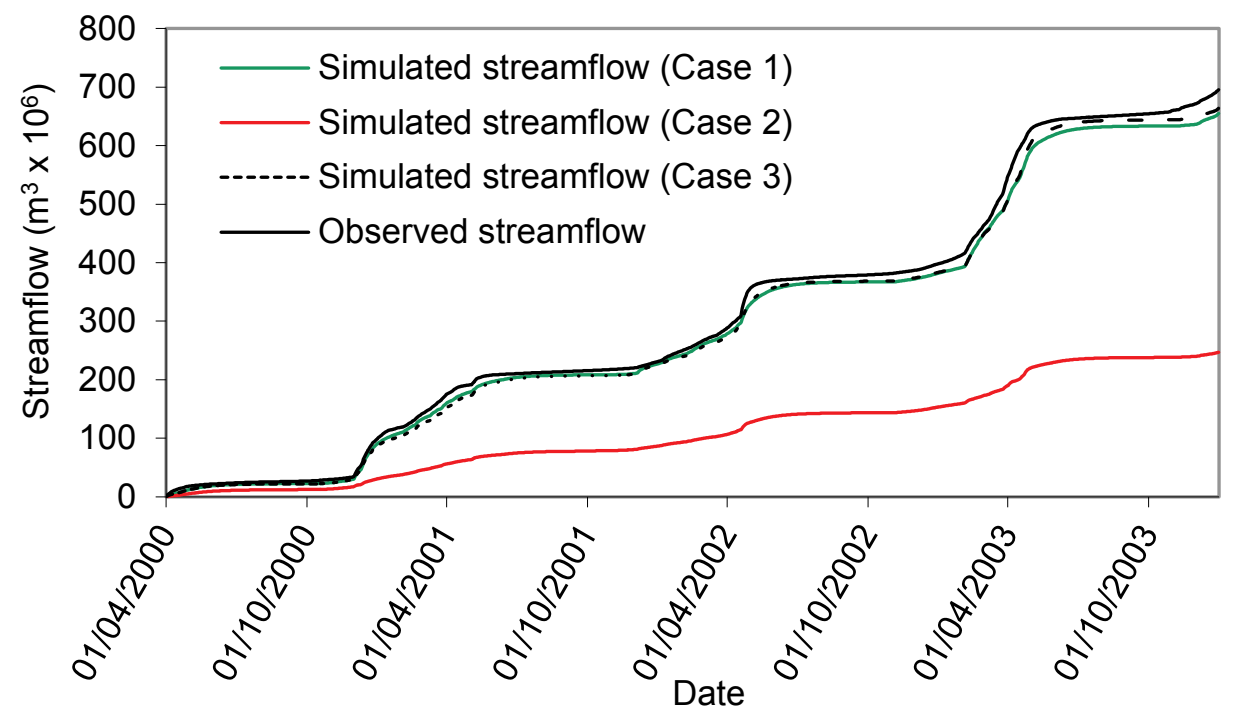

Figure 5.7: Cumulative distribution of Qs for Doab sub-catchment for all three cases.

A comparison of accumulated Qs is shown in Figure 5.7. Hydrographs of observed and simulated Qs show large differences for Case 2. Over the simulation period, Qs of Case 2 only equals about one-third of the observed Qs, and suggests that flows during both the dry and wet seasons are very poorly simulated. Also, the effect of the low ratio between ETa and Qs (Table 5.3) has propagated in the simulation results. Differences between the observed and simulated Qs of Cases 1 and 3 over the simulation period are relatively small and, at the end of the simulation period, accumulated Qs in Case 1 is only slightly lower than in Case 3 . It appears that during the wet season more water is lost from the model for Case 2 compared to Case 3 . During the dry season the difference remains approximately constant or decreases slightly. Since the simulation period only covers three years, the described dry season-wet season pattern does not allow generalization. The cumulative distribution functions of the sum of ETa and Qs are shown in Figure 5.8. For all cases, the loss of water from the model is smaller than the observed volume by Qs and ETa from the Doab catchment. The loss is largest for Case 2 and smallest for Case 1. It appears that ETa calibration results in Case 2, to a large extent, affect the model behavior and, therefore, the water balance of the model. ETa graphs also show that, for all three cases, deviations develop at the start of the dry season that becomes smaller during the wet season. During the second half of the wet season, distribution functions largely overlap for three consecutive years. This suggests that selected single and multi-variable calibration targets only have little effect on the total volume of water that is lost from the model. For all three years, differences start to increase at the beginning of the dry period when soils are 
replenished and crops have the highest demand for water. Further, accumulated differences increase over the consecutive years.

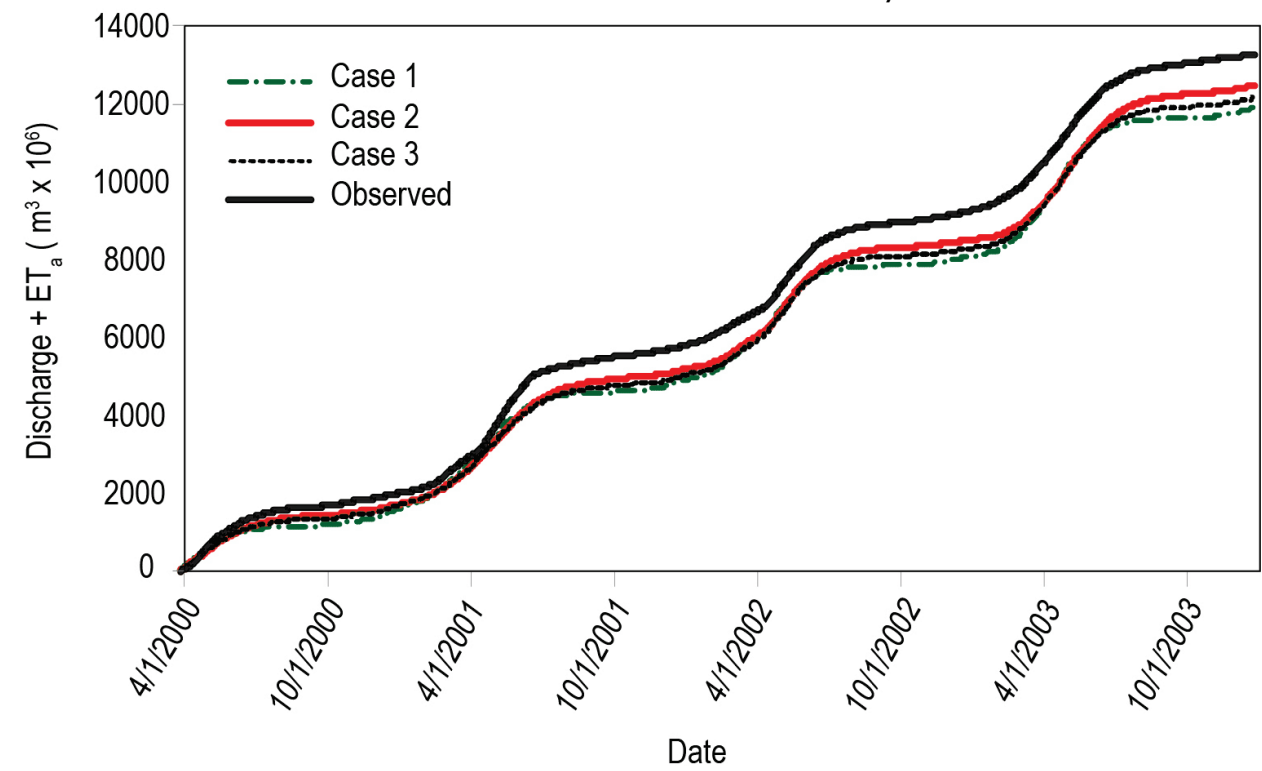

Figure 5.8: Cumulative distributions of daily Qs and ETa for Doab sub-catchment for all three cases.

\subsubsection{Parameter estimation}

In the HBV model, ALFA, Kf, Ks and PERC directly affect simulation of Qs. Parameters FC and BETA only indirectly affect Qs and ETa whereas LP directly affects ETa. For all parameters, box-whisker plots are shown in Figure 5.9 with value ranges of the optimized parameters for Doab sub-catchment, for the 25 best performing sets in the MCS procedure. For these sets, parameter values are standardized to their prior parameter range as used for the MCS procedure. The minimum value of the prior range of the calibration parameters was subtracted from the optimized values and then normalized by the prior range. The 7 calibration parameters for the three cases are shown in 21 columns, and box plots show the posterior distributions of the calibration parameter. Boxes depict the median, upper and lower quartiles whereas the whiskers show the most extreme values within 1.5 times the interquartile range from the ends of the box.

The differences in the three cases indicate that parameters have specific optimum values depending on the selected calibration variable(s). Case 2 produced relatively high values for the lower and upper quartiles for FC and LP. Interquartile value ranges for both parameters are smaller for Case 2 compared to the other two cases and suggest a stable region in parameter space. For Case 1, the median values of FC and LP are lowest with relatively 
large whisker ranges. This indicates that calibration on ETa reduces the uncertainty of the parameters that affect ETa.

For Case 2, PERC has the lowest median with a small interquartile range. For Case 1 , it has the highest median and largest interquartile range. Therefore, single variable calibration on Qs results in more uncertain estimates for PERC compared to calibration on ETa. We can only speculate for the large interquartile range, but it appears that the amount of water that is lost from the soil moisture reservoir by ETa, in general, causes lower percolation that is characterized by lower fluctuation. A low PERC value constrains the flow of water to the base flow reservoir and thus directly affects the low base flows in Case 2. However, Case 3 produces parameter values that are in between the values of cases 1 and 2, which indicate some trade-off effect of multivariable calibration. For $\mathrm{Ks}$, Case 2 produces a larger parameter range compared to the other two cases and indicates relatively large parameter uncertainty, whereas there is no clear difference between Case 1 and Case 2. The box value ranges for $\mathrm{Kf}$ are of similar magnitude and suggest that uncertainty of the parameter estimates are not affected by the selected calibration target. Box values for ALFA suggest that single variable calibration on ETa results in more uncertain estimates compared to calibration on Qs. The box value ranges for BETA are smallest for Case 2, but similar values are shown for Cases 1 and 3 .

Results, therefore, suggest that calibration of the model by both Qs and ETa (Case 3) decreases the uncertainty of the parameters related to the ETa process and PERC compared to traditional model calibration based on Qs (Case 1). For the other parameters, notable increases or decreases of uncertainty are not found between Case 1 and Case 2. Averaged parameter values of the best performing 25 parameter sets for three cases for the Doab sub-catchments are presented in Table 5.12 . 


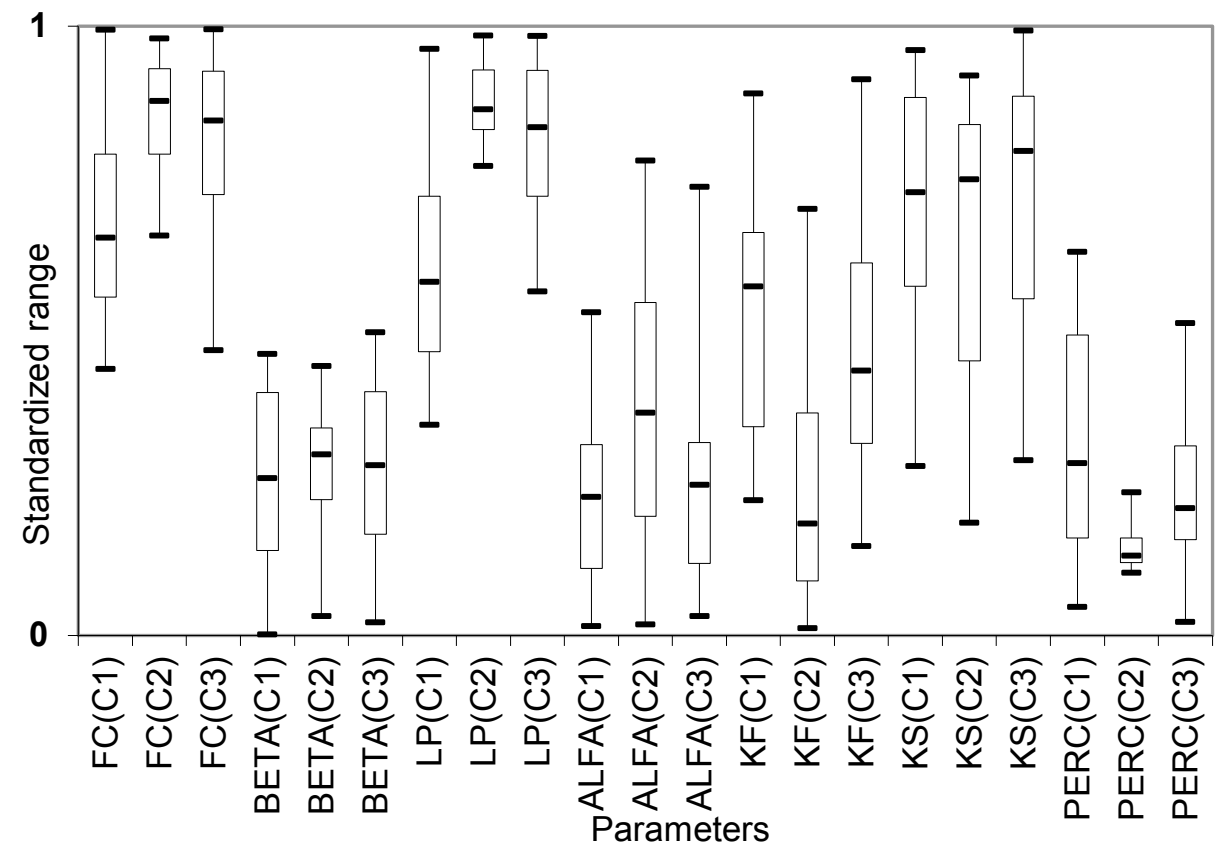

Figure 5.9: Box-whisker plots of parameters standardized by the prior range used for Monte Carlo Simulations (Doab sub-catchment).

Table 5.12: Averaged parameter values of the best performing 25 parameter sets for all three cases for Doab sub-catchment.

\begin{tabular}{l|ccccccc}
\hline & $\begin{array}{c}F C \\
(m m)\end{array}$ & $\begin{array}{c}B E T A \\
(-)\end{array}$ & $\begin{array}{c}L P \\
(-)\end{array}$ & $\begin{array}{c}A L F A \\
(-)\end{array}$ & $\begin{array}{c}K_{f} \\
\left(d^{-1}\right)\end{array}$ & $\begin{array}{c}K_{s} \\
\left(d^{-1}\right)\end{array}$ & $\begin{array}{c}P E R C \\
\left(m m d^{-1}\right)\end{array}$ \\
\hline Case 1 & 363.2 & 1.042 & 0.66 & 0.69 & 0.04 & 0.03 & 0.48 \\
Case 2 & 448.1 & 1.046 & 0.86 & 0.63 & 0.02 & 0.01 & 0.39 \\
Case 3 & 430.5 & 1.044 & 0.81 & 0.72 & 0.04 & 0.04 & 0.40 \\
\hline
\end{tabular}

\subsubsection{Impact of weights on model performance}

To examine how the weight values $W Q$ and $w E T a$ affect the performance of the model and, subsequently, the optimized model parameter values, a simple sensitivity analysis was carried out using different weight combinations. Graphs in Figure 5.10 show the relationship between $Y$ values and combinations of $\mathrm{WQ}$ and $\mathrm{WETa}$ values for Doab sub-catchment. Combinations where $\mathrm{wQ}=0$ and $\mathrm{wETa}=1$ and $\mathrm{wQ}=1$ and $\mathrm{wETa}=0$ represent single variable calibration by ETa and Qs, respectively. The graphs suggest that model performance results are only affected when one of the weights has a relatively low value $(<0.3)$. Consequently, the second weight has a higher value $(>0.7)$ and simulation results for the low-weight value quickly deteriorate. For weights between 0.3 and 0.7 , model performance for 
both ETa and Qs gives satisfactory results. Also, sensitivity of the model to changes of the weight values in this range is relatively low, since changes up to a maximum of $10 \%$ are indicated between the lowest and highest $Y$ values for the respective variables (ETa or Qs).

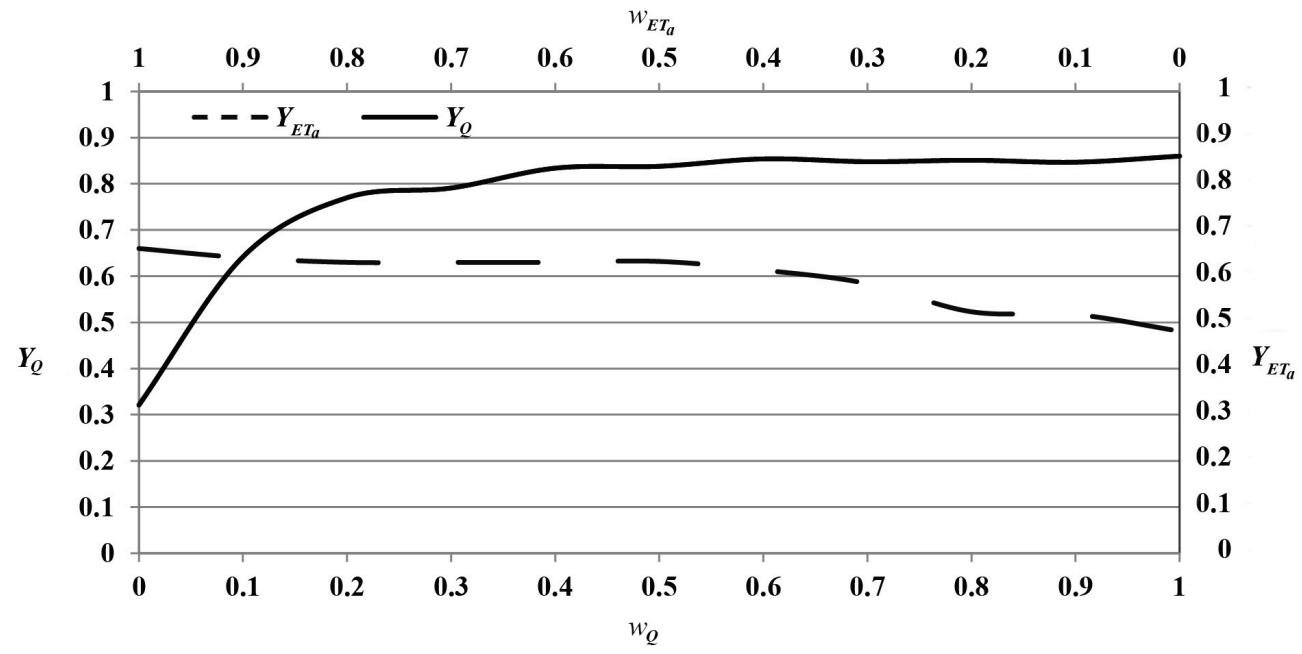

Figure 5.10: Variation of model performances (YTOT) for different weights in Doab sub-catchment.

\subsubsection{Uncertainty of measurement data}

Uncertainty of modeling results in this study is partly caused by observation errors of the time series of precipitation, ETa and Qs. For representing space variability of the precipitation, only a relatively small number of gauges were available and could affect the precipitation estimates. Moreover, gauges are not well distributed over space, so we presume that precipitation estimates have bias.Also, effects of elevation and topography could influence the accuracy of precipitation representation (e.g., Masih et al. 2011).

Michaud and Sorooshian (1994) and Xu et al. (2006) showed that errors in precipitation measurements are an important source of uncertainty in hydrological modeling in semi-arid and arid catchments. Also, $\mathrm{Xu}$ et al. (2006) showed that errors in rainfall input have a larger effect on runoff simulation in catchments with small runoff coefficient than in catchments with large coefficient. Since runoff coefficients in Karkheh are small, it is expected that small errors in the Thiessen estimation procedure may have some notable effect on model performance. Errors in the estimation of precipitation are often in the range of 5 to $15 \%$ as indicated in Section 5.2.

With respect to Qs, Harmel et al. (2006) state that errors to Qs measurements can range from plus or minus $6 \%$ to $19 \%$ depending on 
channel types, channel conditions and the measurement technique. Error estimates in WMO (1994) and Butts et al., (2004) are of similar order.

To rationalize how potential errors of the three water balance terms may affect simulation results, we applied a sensitivity analysis with arbitrary changes of $5 \%$ introduced to all three terms with maximum increase and decrease of $20 \%$ and $-20 \%$, respectively. The sensitivity test is applied to the multi-variable model calibration Case 3 following the procedure in Section 5.3.4. For instance, in the case of precipitation, MCS was applied for every $5 \%$ change in precipitation, where the precipitation used for calibration served as reference. The average of the best 25 parameter sets for each run was compared with the optimized parameter set found in Case 3 that serves as a reference case. Table 5.12 presents the sensitivity of model parameters to the percentage change in precipitation in Doab sub-catchment. Simulation results for precipitation showed highest sensitivity, and results of ETa and Qs are only briefly discussed.

Table 5.13: Change of parameter values and the model performance with respect to the change of precipitation.

\begin{tabular}{lcccccccc}
\hline & \multicolumn{7}{c}{ Change of precipitation } \\
\cline { 2 - 9 } Parameter & $-20 \%$ & $-15 \%$ & $-10 \%$ & $-5 \%$ & $5 \%$ & $10 \%$ & $15 \%$ & $20 \%$ \\
\hline FC & -31.6 & -24.3 & -8.3 & 2.2 & 1.2 & 4.2 & 6.1 & 9.6 \\
BETA & -8.3 & -5.8 & -3.1 & -0.3 & 1.5 & 4.7 & 4.8 & 6.9 \\
LP & 9.4 & 7.4 & 5.2 & 3.9 & 1.7 & 2.3 & 2.8 & 3.1 \\
ALFA & -6.2 & -4.4 & -3.7 & -2.9 & 4.1 & 9.1 & 12.6 & 13.9 \\
$K_{f}$ & 12.6 & 5.8 & 4.3 & 1.9 & 3.9 & 10.7 & 24.6 & 37.1 \\
$K_{S}$ & 3.4 & 3.1 & 2.8 & 0.8 & 2.7 & 7.4 & 11.1 & 12.5 \\
PERC & 57.5 & 32.1 & 21.4 & 11.2 & -4.9 & -6.7 & -14.6 & -13.1 \\
$Y_{\text {TOT }}$ & -48.1 & -37 & -21.2 & -9.3 & -16.1 & -21.7 & -29.1 & -36.3 \\
\hline
\end{tabular}

Changes of parameter values are largest when precipitation is reduced by $20 \%$. For instance, a reduction of precipitation by $20 \%$ causes FC to decrease by $32 \%$ and PERC increases by $57 \%$ compared to the optimized parameter values in Case 3. Changes in other parameters are smaller than $+10 \%$ or $-10 \%$ of the reference value, except for $\mathrm{Kf}$. There are no substantial changes identified in the parameters when precipitation is changed by $+5 \%$ or $-5 \%$. When precipitation is increased by $20 \%$, changes in FC, LP and BETA are minimal whereas $\mathrm{Kf}$ increased by $37 \%$. Deterioration of the model performance (YTOT) is $48 \%$ and $36 \%$ when the precipitation is changed by $+20 \%$ and $-20 \%$, respectively. Although the changes in parameter values are less than $10 \%$ when the precipitation change is within $+5 \%$ or $-5 \%$, deterioration of YTOT was in the range of $9 \%$ to $16 \%$. 
Similar changes $(+20 \%$ or $-20 \%$ in steps of $5 \%$ ) have been introduced to observed Qs and satellite-based ETa. When the Qs was changed by $+20 \%$ or $-20 \%$, parameters other than FC and PERC showed changes of $+5 \%$ to $-5 \%$ of the optimized parameter values in Case 3. Changes in FC and PERC are $9 \%$ and $-63 \%$, respectively, when observed Qs is increased by $20 \%$. When observed flows are reduced by $20 \%$, poorest model performance is indicated with a decrease of $24 \%$ for YTOT. When the change in Qs is within the $+5 \%$ or $-5 \%$ range, deterioration of performances (YTOT) is less than $6 \%$ compared to Case 3. Changes of $-20 \%$ to $+20 \%$ for SEBS-ETa showed that changes in parameter values are less than $4 \%$ for all parameters whereas YTOT reduced by less than $5 \%$. This indicates that uncertainties in precipitation can affect the MCS results substantially whereas the effects of uncertainties in Qs and ETa are relatively low.

\subsection{Conclusions}

The mass conservative HBV model was selected and was calibrated based on a MCS procedure and an objective function $Y$ that combines the NashSutcliffe efficiency and the Relative Volume Error performance measures. We conclude that multi-variable calibration is most effective in reproducing the catchment water balance and to close the water balance. Effectiveness of the use of satellite-based ETa for model calibration is proven, but ETa estimates should be used in combination with Qs data to reproduce the catchment water balance.

\section{Time series completion}

Constructed satellite-based ETa time series at daily base were validated by eight images not used. Validation results showed good matches at daily base during both dry and wet seasons. The procedure to linearly interpolate daily surface resistance to estimate SEBS-ETa between the days when images are available proved to be effective. To further improve the procedure, we recommend testing an interpolation procedure that considers changes in land surface characteristics and weather parameters for days when satellite images are not available.

\section{Model performance assessment}

Two water balance terms are selected for model calibration and thus closure of the water balance by the HBV model could be evaluated. Best calibration results in terms of $Y$ are obtained when calibration is on Qs (Case 1 ) or on SEBS-ETa (Case 2). In the latter case, Penman-Monteith-based ETa by the HBV model was matched to satellite-based ETa and indicated YETa values higher than 0.62 with a highest value of 0.83 . For both cases, simulation of the second variable resulted in low performance values. A first cause of such a mismatch relates to the volumes of Qs and ETa that largely differ were a 
small error in ETa results in a relatively large error in Qs. A second cause relates to the use of satellite-based ETa that indicates that HBV-ETa during inter-rainfall event periods in the wet season is too high and that ETa after the wet season is relatively low when catchments deplete. Both these aspects suggest that HBV-ETa only poorly represents the SEBS-ETa, which we assume to represent the real-world ETa.

We consider the use of satellite-based ETa in multi-variable model calibration in mass conservative, conceptual rainfall-runoff modeling a novelty of this work. Through the use of a preference-based multi-variable objective function, it is shown that the HBV model is able to produce simulation results that show satisfactory to good performance for both Qs and ETa. Characteristics of both processes are well represented and, contrary to single variable calibration, indicate robustness of the applied HBV model structure. The multi-variable calibration approach also indicated that effects of the large differences in the Qs and ETa volumes weaken. As such, the preferencebased multi-variable calibration approach provided a satisfactory solution to the reproduction and closure of the water balance.

A sensitivity analysis on weight values for Qs and ETa in Case 3 showed that the model results are most sensitive to low weights $(<0.3)$. When the weight for a variable is below 0.3 , considerable deterioration of model performance in terms of $Y$ is shown. When weights are between 0.3 and 0.7 , the maximum change between the lowest and highest $Y$ values for a single variable (ETa or Qs) is about $10 \%$

In literature, very few efforts report on the use of satellite-based Eta in multivariable calibration for conceptual rainfall-runoff modeling. We stress that our results on calibration on two water balance terms are only first results and hence do not allow generalization. We recommend further tests where analysis should focus on Pareto optimization to better assess trade-offs between the selected objectives and to further assess the uncertainty issue. Analysis could also focus on updating the model structure to better represent periods where the model consistently fails to close the water balance (Choi and Beven, 2007; de Vos et al., 2010). In this thesis, however, the issue of time variance is ignored and it is assumed that model parameters and model structure do not require updating. First, a better understanding is needed on multi-variable model calibration by use of Eta. We advocate exploring the applicability of satellite-based Eta and Qs in runoff hydrology in ungauged catchments and regionalization studies, with the aim of reproducing the catchment water balance, in particular. For such studies, results by this work suggest that availability of Qs records for a number of catchments remain a prerequisite to indicate the possible error in the Qs hydrographs from the gauged and ungauged systems. 


\section{Parameter estimation}

Optimized parameter values in multi-variable calibration by Qs and SEBS-Eta (Case 3 ) resulted in parameter values that, in general, are in between the best performing values for calibration Cases 1 and 2 . Uncertainty of parameter estimates, in general, is highest for those parameters that have a relatively small effect on the selected calibration variable. 


\section{Strategies to increase wheat production in the water-scarce Karkheh River Basin, Iran*}

\subsection{Introduction}

In the Karkheh River Basin, the wet season is from October to May, and rainfed and irrigated agriculture are practiced to produce wheat which is the main crop. Not all rainwater in the northern part of the basin is used for local agriculture, and excess rainwater is stored in reservoirs or discharged downstream to support agriculture in areas where rainfall is insufficient.

The population in Iran has grown from 54 million in 1990 to 74 million in 2010, and a population of 87 million is anticipated by 2025 . The Karkheh Basin produces approximately $11 \%$ of the country's demand for wheat (Marjanizadeh, 2008) and it is the government's policy to maintain this percentage up to 2025 to remain self-sufficient. In 2003, approximately $1,800 \times 10^{6} \mathrm{~kg}$ of wheat was produced, which implies that production should increase to about $2,300 \times 10^{6} \mathrm{~kg}$ by 2025 . Clear strategies to increase production by $500 \times 10^{6} \mathrm{~kg}$ are not available. Proposing such a strategy is the main focus of this study.

Increasing agricultural production often leads to changes in land use. Examples of such changes are deforestation and the conversion of nature into agricultural land. In areas where water is limited, such as the Karkheh River Basin, the premise for imposed changes is that water evapotranspired by the replaced vegetation could be used to increase wheat production whereas not increasing the total consumption of water in the basin.

Besides changes in land use, agricultural production can be increased by agricultural practices such as land preparation, tillage, fertilization management, seed rates and quality seeds. Among these practices, fertilization management commonly has the greatest impact on crop yields when water is not a limiting factor. The impact of fertilizer applications on wheat yield has been reported in a number of studies in different areas of the world (Rahman et al. 1995; Mazid et al., 2003; Oweis and Hachum 2003;

\footnotetext{
* Based on: Muthuwatta, L.P., Rientjes, T.H.M., Bos, M.G (2013) Water productivity assessment and strategies to increase wheat production in the Karkheh River BasinIran. Agricultural Water Management, 124, 1-10.
} 
FAO, 2006). According to these studies, optimized fertilizer applications could increase yields by $23 \%$ to $60 \%$ compared to the existing yields. In this respect, Wichelns (2003) describe that optimal yields are achieved when optimal levels of both water and fertilizer are applied.

Another factor that affects wheat yield is the seed rate. Nauman et al. (2011) reported the highest wheat yield when the seed rate is between 125 to 150 $\mathrm{kg} \mathrm{ha}^{-1}$ in Faisalabad, Pakistan. Smid and Jenkinson (1979), based on the data from Ontario, Canada, showed that the highest wheat yields can be obtained when the seed rates are close to $170 \mathrm{~kg} \mathrm{ha}^{-1}$. Based on the field experiment carried out at Kabootarabad agricultural station in central Iran, Hemmat and Taki (2001) showed maximum wheat crop yields when the seed rate is between 130 to $160 \mathrm{~kg} \mathrm{ha}^{-1}$. As such, by managing these non-water inputs, yields can be increased without demand for additional water resources. This leads to more productive use of water in terms of yield per cubic meter of water consumed (Molden et al. 2010). This particularly applies to areas where available water resources are limited or scarce, such as in the Karkheh River Basin.

The objective of this study is to explore strategies to meet food production targets by the year 2025 by a) increasing yields in the current wheat production areas, and b) increasing rainfed wheat production by land conversion. For both strategies, only the currently available water resources can be used whereas all aspects and factors that relate to agricultural practices and land suitability are not constraining.

This study only aimed to assess whether wheat production can be increased to meet the targets by the year 2025 using available water resources. Large investments are necessary for the expansion of production areas, but discussing this aspect is outside the scope of this work.

\subsection{Land use soils and water consumption of the Karkheh River Basin}

\subsubsection{Land use and soils}

Figure 2.5 presents the map indicating major land use classes in the Karkheh River Basin. Both rainfed and irrigated agriculture are practiced in the Upper Basin whereas only irrigated agriculture is practiced in the Lower Basin. Table 6.1 shows the extent of the main land uses in each sub-basin. 
Table 6.1: Land use (in hectares) in the sub-basins of the Karkheh River Basin.

\begin{tabular}{lcccc}
\hline Sub-basin & Irrigatedagriculture & Rainfedagriculture & Rangelands & Other \\
\hline Gamasiab & 125,200 & 238,500 & 378,700 & 342,100 \\
Qarasou & 74,100 & 309,700 & 63,500 & 85,900 \\
Kashkan & 29,800 & 259,800 & 188,700 & 471,400 \\
Saymareh & 60,400 & 533,900 & 168,600 & 931,700 \\
Lower Karkheh & 220,200 & 47,100 & 54,200 & 559,900 \\
\hline Total & 509,700 & $1,389,000$ & 853,700 & $2,391,000$ \\
\hline
\end{tabular}

Irrigation covers approximately 510,000 ha whereas rainfed agriculture covers approximately $1,390,000$ ha (Table 6.1 ) in the basin. Table 6.2 shows the average yield and the standard deviations for irrigated and rainfed wheat of the different sub-basins in the Karkheh River Basin. Irrigated and rainfed wheat yields ( $\mathrm{kg}$ ha-1) show large differences. To estimate averages and standard deviations of wheat yield for sub-basins, data from a field survey carried out by Ahmad et al. (2009) is used.

Table 6.2: Average yield $\left(\mathrm{kg} \mathrm{ha}^{-1}\right)$ for irrigated and rainfed wheat for sub-basins of the Karkheh River Basin (adapted from Ahmad et al. 2009).

\begin{tabular}{lclll}
\hline Sub-basin & \multicolumn{3}{c}{ Irrigated } & \multicolumn{2}{c}{ Rainfed wheat } \\
\hline Gamasiab & $4,860 \pm 1,300$ & $(0.27 *)$ & $1,820 \pm 570$ & $(0.31)$ \\
Qarasou & $4,030 \pm 970$ & $(0.24)$ & $1,730 \pm 550$ & $(0.32)$ \\
Kashkan & $3,420 \pm 1,020$ & $(0.30)$ & $1,410 \pm 580$ & $(0.41)$ \\
Saymareh & $2,680 \pm 1,070$ & $(0.40)$ & $1,290 \pm 480$ & $(0.37)$ \\
Lower Karkheh & $2,490 \pm 1,200$ & $(0.48)$ & $1,220 \pm 620$ & $(0.51)$ \\
\hline
\end{tabular}

${ }^{*}$ Coefficient of variation. \pm indicated one standard deviation.

Table 6.2 indicates that the coefficient of variation (CV) of yield for both rainfed and irrigated wheat areas in each sub-basin is in same order of magnitude. The variation in yield indicates that there are opportunities to increase yield in low-yielding areas, by improving water management and non-water inputs.

A digitized soil classification map was available from the Department of Soil and Water Research Institute (SWRI), Iran. This soil map indicates fine (chromic calcixererts) to medium (fluventic calcixerepts) textured soils and soils including rock outcrops (lithic xerorthents) as being the dominant soils in the study area. The valley soils are mainly fine-to-medium in texture (ustic to aquic torrifluvents). 


\subsubsection{Water consumption}

For calculating ETa, the Surface Energy Balance System (SEBS) (Su, 2002) algorithm is used. The estimation procedure of $E T_{a}$ described in Muthuwatta et al. (2010) (Chapter 4) was used to estimate $E T_{a}$ from November 2002 to October 2003, a complete cropping year. For this, 19 Moderate Resolution Imaging Spectroradiometer (MODIS) images were used which have a spatial resolution of $1 \mathrm{~km} \times 1 \mathrm{~km}$. $E T_{a}$ for wheat areas were estimated for the cropping season and for the annual period from November 2002 to October 2003. A full description on the estimation is in Section 3.4.2. Figure 6.1 presents the monthly variation of $E T_{a}$ for two pixels, where one pixel exclusively covers irrigated wheat and the second pixel exclusively covers rainfed wheat in the Upper Karkheh.

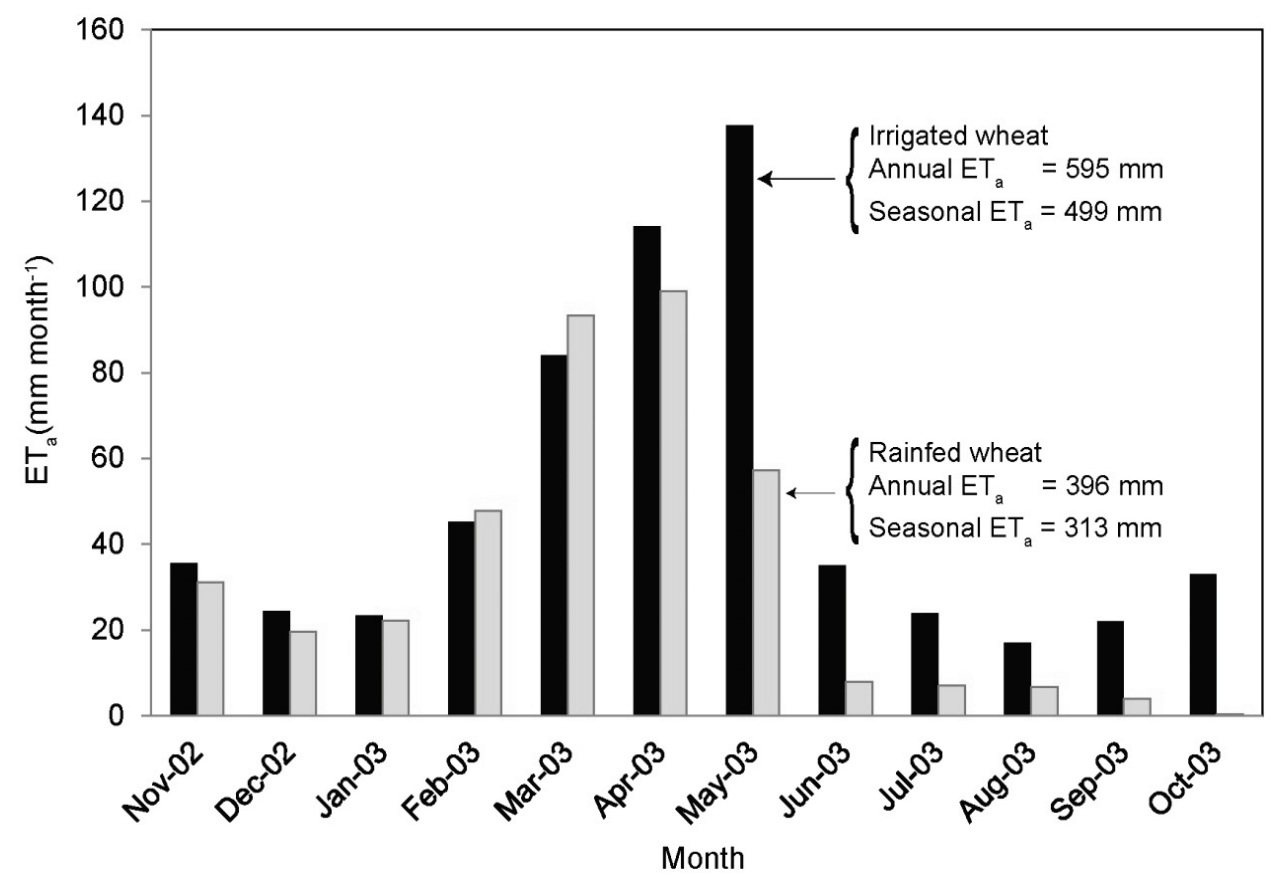

Figure 6.1: Monthly variation of $E T_{a}$ for two pixels, where single pixels exclusively represent production areas of irrigated or rainfed wheat (adapted from Muthuwatta et al., 2010).

On an annual basis, irrigated wheat consumed about $199 \mathrm{~mm}$ more water than rainfed wheat. Seasonal ETa from irrigated wheat was about $499 \mathrm{~mm}$ whereas rainfed wheat consumed about $313 \mathrm{~mm}$. Therefore, to convert one hectare of rainfed wheat to irrigated wheat, approximately $186 \mathrm{~mm}$ of additional water will be consumed during the cropping season (equal to 1,860 m3 ha-1). The overall efficiency of irrigation water use remains at $30 \%$ for Iran (Bos and Nugteren, 1974, 1990; Qureshi et al., 2009). Thus, about 
three times more water needs to be available to actually irrigate one hectare. Since Karkheh is a water-scarce river basin (Muthuwatte et al, 2010), options to develop additional water resources to supplement rainfed wheat areas are limited.

\subsection{Crop water productivity and relative evapotranspiration}

Two indicators that measure the performance of an agricultural system are the crop water productivity (CWP) (Molden et al., 2003) and the relative evapotranspiration (ETa/ETp) (Bos et al., 2005). The concept of CWP was proposed as an indicator to evaluate the relationship between crop yield $(\mathrm{kg})$ and the amount of water (m3) consumed by the crop. Increasing CWP is often advocated as a strategy to increase food production in water-scarce areas (Kijne et al., 2003; Bos et al., 2005; Sadras and Angus, 2006; Molden et al., 2007; Amarasinghe et al., 2010). Higher CWP may result from improved water management and improved agricultural practices (Breman et al., 2001; Nangia et al., 2008; Ahmad and Giordano, 2010). Recent studies (Qureshi et al. 2009; Ahmad et al. 2009) analyzed the CWP of irrigated wheat in the Karkheh River Basin found significant variations. They have concluded that there is considerable scope for increase in productivity at plot level and sub-basin scale.

The relative evapotranspiration (ETa/ETp) is the ratio of actual evapotranspiration (ETa) over potential evapotranspiration (ETp) and is used to indicate whether water is sufficiently available to support agricultural production throughout the growing season (Bos et al., 2007). A crop is not water-stressed if ETa is equal to ETp during each growth stage and the yield of the crop can be maximized in terms of $\mathrm{kg}$ ha-1 (Bos, 2004). Based on wheat yield data from the Central Great Plains, USA, Bos et al. (2007) showed that ETa/ETp can be reduced considerably whereas keeping crop yields high. In this study, ETp is estimated by multiplying Penman-Monteith reference evapotranspiration by specific crop coefficients $(\mathrm{Kc})$ for wheat in FAO56 (Allen et al. 1998; Bos et al. 2009). Selected coefficients are for similar climatic conditions and respective crop development stages. Meteorological data for estimating ETO were collected from Islamic Republic of Iran Meteorological Organization (IRIMO). Assessments on CWP and the development of strategies to increase production require information on current and potential crop yields, water consumption patterns by actual evapotranspiration, the relationship between yield and ETa/ETp, and land suitability for agricultural expansion. A major constraint is the lack of field data on land use and land cover, and water consumed by croplands, particularly when areas are remote and of a relatively large size, such as in the Karkheh Basin. Therefore, we advocate the use of satellite remote 
sensing to observe land cover and related properties in a spatially coherent manner.

\subsection{Methodology}

The methodology applied considers assessments on: a) ETa/ETp and CWP of current wheat production areas, b) land suitability to convert certain land cover to wheat production areas, and c) two strategies to increase wheat production using improved agricultural practices, and through land conversion to expand the production area. For the last scenario, calculations are performed.

\subsubsection{Assessment of wheat production}

Data on irrigated and rainfed wheat yields ( $\mathrm{kg} \mathrm{ha-1)}$ at plot scale at 298 farms for the cropping years 2002 and 2003 were collected. To account for differences in agro-climatic conditions, the Karkheh Basin was divided into Upper Karkheh (North part) and Lower Karkheh (South part). The Upper Karkheh has four major sub-basins and the Lower Karkheh is considered as one sub-basin. To represent the distribution of rainfed and irrigated farming systems, we selected 110 villages. From these villages, 298 farms were selected (about three farms per village) with farm sizes ranging from 4 to 33 ha. For the Upper Karkheh, 63, 31, 54 and 81 farms were selected for Gamasiab, Qarasou, Kashkan and Seyamreh sub-basins, respectively, whereas 69 farms were selected for the Lower Karkheh. Farming information on crop yield, fertilizer application and seed rate were collected through a questionnaire survey. Satellite-based ETa in Muthuwatta et al. (2010) was used to estimate water consumption by wheat fields. Crop yields were related to ETa ( $\mathrm{mm}$ per season) for the cropping season. The relationship between yield and CWP, and yield and ETa/ETp were established for all sub-basins. Based on these relationships, the target value for the ETa/ETp for irrigated wheat is identified. The target value is defined as the value above which further increase of ETa/ ETp has no substantial effect on the crop yield and, therefore, CWP can be maximized at a lower value of ETa.

The crop production function analysis, the results of which are discussed later, was carried out to quantify the effects of water, nitrogen fertilizer (hereafter referred to as fertilizer) and seed rates on yields of both irrigated and rainfed wheat areas. The outcome of this analysis was used to estimate the possible increase of production in existing wheat areas by managing fertilizer and seed rates. 


\subsubsection{Land suitability}

The land suitability analysis identified areas with topographic slopes that would allow wheat production. In the procedure, a land cover map (Figure 2.5) based on classification of satellite images (Ahmad et al. 2009) was used to identify the locations with specific land cover. The distribution of slopes across the Karkheh Basin is based on processing a Shuttle Radar Topography Mission (SRTM) Digital Elevation Model (DEM) of $90 \mathrm{~m} \times 90 \mathrm{~m}$ resolution. In a number of land suitability assessment studies on crop production (Bandyopadhyay et al. 2009), a slope less than $5 \%$ is classified as being suitable, a slope between $5 \%$ and $7 \%$ is classified as being moderately suitable and a slope between $7 \%$ and $10 \%$ is classified as being marginally suitable. In this study, we only consider the first two classes as being suitable for rainfed wheat production, which is further discussed in Section 6.5.5.

To find areas where water is available to grow wheat, we evaluated areas where agriculture is not practiced and water consumption by the respectivevegetation cover was higher or close to the average value of ETa/ETp of rainfed wheat. This allowed identifying areas that are potentially suitable for land conversion based on the premise that the amount of water that is consumed by the present land cover (other than agriculture) can be used to grow wheat. For the study area, some rangelands have an ETa/ETp that is in the same order of magnitude as rainfed wheat and, therefore, sufficient water is available to support wheat production.

\subsection{Results and discussion}

\subsubsection{Production of irrigated wheat}

Actual evapotranspiration for pixels for wheat areas was grouped in a number of ETa classes from low to high (Table 6.3). To demonstrate the variation in yield across the farms for the various ETa classes, we calculated average yield and highest yield, and indicated fertilizer and seed rates, based on the data from the field survey. Furthermore, for each ETa class the ETa/ETp and the CWP are calculated to identify ETa classes where water is used most optimally. For this, CWP is estimated by dividing the yield with the mid-point value of the respective ETa class. Table 6.3 shows the results for the Gamasiab sub-basin.

Among our surveyed samples, only 11 farms are located in the areas where ETa is less than $200 \mathrm{~mm}$ per season. Therefore, we do not have a representative sample for these areas. Also, the ETa map and the land use map revealed that only about $2 \%$ of the wheat area (both rainfed and irrigated) has ETa lower than $200 \mathrm{~mm}$ per season. Therefore, analyses in this 
study are restricted to the wheat areas with ETa higher than $200 \mathrm{~mm}$ per season.

Table 6.3: Water consumption $\left(E T_{a}\right)$, actual evapotranspiration/potential evapotranspiration $\left(E T_{a} / E T_{p}\right)$, average and highest irrigated wheat yield, crop water productivity $(C W P)$, fertilizer application and seed rate for the $E T_{a}$ classes in Gamasiab sub-basin.

\begin{tabular}{|c|c|c|c|c|c|c|c|}
\hline \multirow{2}{*}{$\begin{array}{l}E T_{a} \\
\text { (mm per }\end{array}$} & \multirow[t]{2}{*}{$E T_{a} / E T_{p}$} & \multicolumn{2}{|c|}{ Average yield } & \multirow{2}{*}{$\begin{array}{l}\text { Highest } \\
\text { Yield } \\
\text { (kg ha- }\end{array}$} & \multirow{2}{*}{$\begin{array}{l}\text { Fertilizer } \\
\left(\mathrm{kg} \mathrm{ha}^{-}\right.\end{array}$} & \multirow{2}{*}{$\begin{array}{c}\text { Seed } \\
(\mathrm{kg}\end{array}$} & \multirow{2}{*}{$\begin{array}{l}\text { No. of } \\
\text { farms }\end{array}$} \\
\hline & & $\begin{array}{c}\text { Yield } \\
\text { (kg }\end{array}$ & $\begin{array}{c}C W P \\
(\mathrm{~kg}\end{array}$ & & & & \\
\hline$<200$ & - & 1,100 & - & 2,700 & 237 & - & - \\
\hline $200-250$ & 0.41 & 2,700 & 1.20 & 3,500 & 250 & 80 & 3 \\
\hline $250-300$ & 0.50 & 3,700 & 1.35 & 4,500 & 250 & 140 & 6 \\
\hline $300-350$ & 0.61 & 5,300 & 1.63 & 6,000 & 200 & 200 & 5 \\
\hline $350-400$ & 0.67 & 5,400 & 1.44 & 6,000 & 212 & 170 & 5 \\
\hline $400-450$ & 0.76 & 5,500 & 1.29 & 6,000 & 225 & 230 & 6 \\
\hline $450-500$ & 0.85 & 5,500 & 1.16 & 5,800 & 220 & 200 & 4 \\
\hline $500-550$ & 0.94 & 5,400 & 1.03 & 6,000 & 200 & 160 & 5 \\
\hline $550-600$ & 0.96 & 5,500 & 0.96 & 6,000 & 250 & 140 & 4 \\
\hline
\end{tabular}

In the Gamasiab sub-basin, the average wheat yields for respective ETa classes range from 1,100 to $5,500 \mathrm{~kg}$ ha- 1 . Average CWP for the different ETa classes ranges from 0.96 to $1.63 \mathrm{~kg} \mathrm{~m}-3$ whereas ETa/ETp ranges from 0.41 to 0.96 . For CWP, the highest $(1.63 \mathrm{~kg} \mathrm{~m}-3)$ and lowest $(0.96 \mathrm{~kg} \mathrm{~m}-3)$ values are found for ETa/ETp values of 0.61 and 0.96 , respectively. When CWP is lowest (0.96), ETa/ETp is highest (0.96) with a high average yield of $5,500 \mathrm{~kg}$ ha-1. For the Gamasiab sub-basin, relationships between yield and ETa/ETp for all the farms are shown in Figure 6.2. 


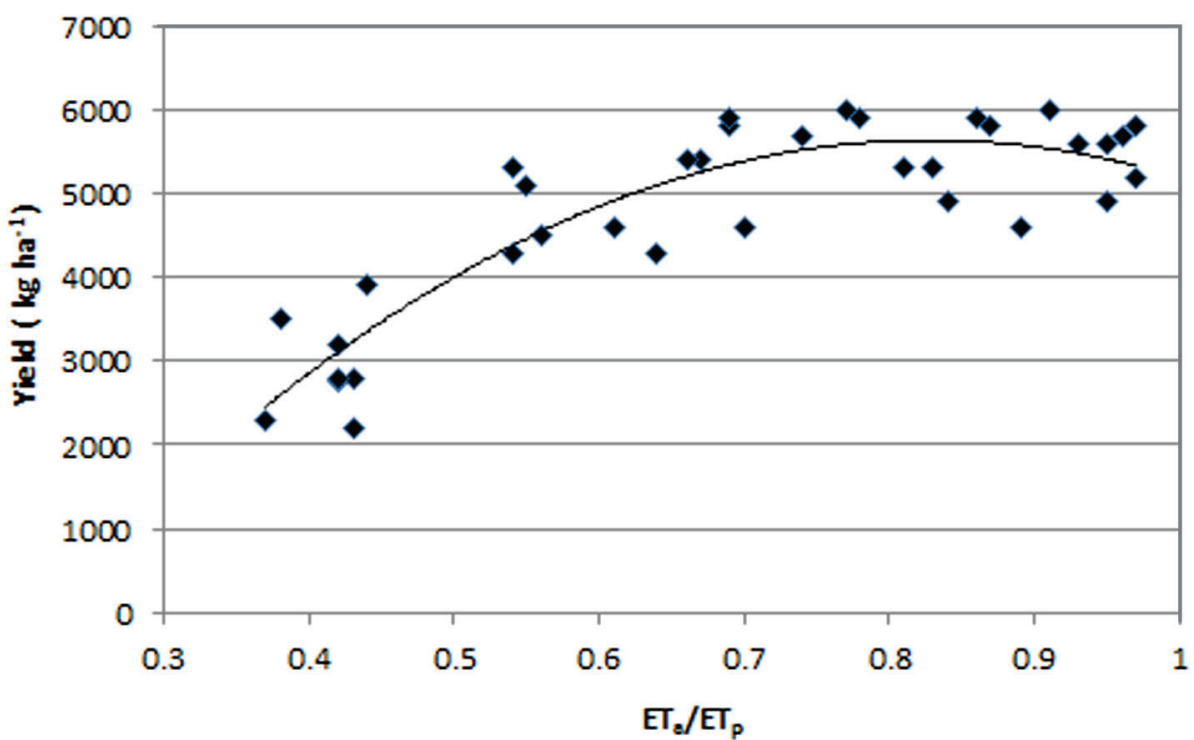

Figure 6.2: Relationships between yield and actual evapotranspiration/potential evapotranspiration $\left(E T_{a} / E T_{p}\right)$ for irrigated wheat in the Gamasiab sub-basin.

As shown in Figure 6.2, when ETa/ETp is at 0.67 , yield reaches to $5,400 \mathrm{~kg}$ ha-1. At this point, the yield reduction compared to the maximum yield $(6,000 \mathrm{~kg} \mathrm{ha}-1)$ is $10 \%$ whereas water consumption is only at $67 \%$ of its potential (highest) value. Above this value, the effect of water stress on yield is only minor and thus can be accepted. Therefore, in terms of water availability, the areas with ETa/ETp above $0.67(0.67-1.0)$ are suitable to grow irrigated wheat without significant loss of yield.

Considering that the objective of this study is to explore strategies to increase wheat production by only using available water resources, the operational target for the ETa/ETp should be 0.67 and, accordingly, the intended value of ETa/ ETp should be greater than 0.67. Bos et al. (2009) showed that the operational target of ETa/ETp for wheat is about 0.67 for the Central Great Plains, USA, and resembles results of this study. Figure 6.3 shows the relationship between CWP and ETa/ETp. 


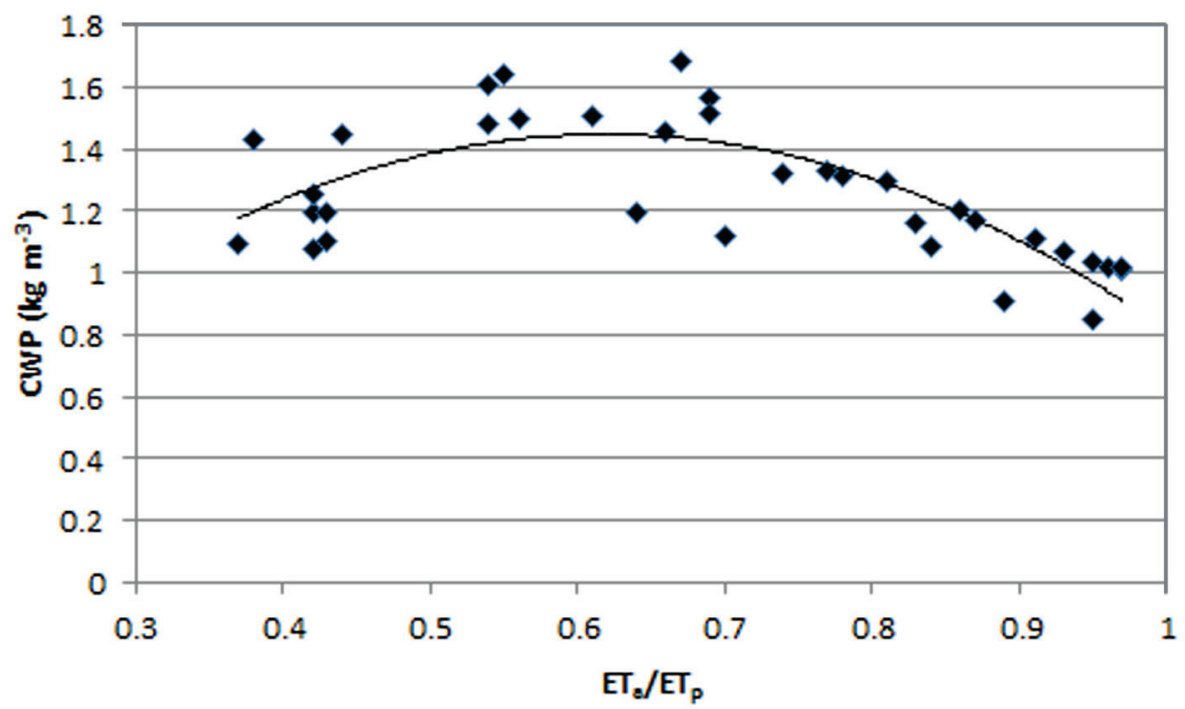

Figure 6.3: Relationship between crop water productivity (CWP) and actual crop evapotranspiration/potential evapotranspiration (ETa/ETp) for irrigated wheat in the Gamasiab sub-basin.

CWP increases when ETa/ETp is 0.67 and starts to decrease when ETa/ETp is higher than 0.67 . Therefore, if the cumulative ETa becomes as low as $67 \%$ of its potential value, the maximum wheat yield is found in terms of optimal water consumption. In some farms, CWP values are as high as $1.4 \mathrm{~kg} \mathrm{~m}-3$ and yields are about $3,500 \mathrm{~kg}$ ha-1. In some other farms, CWP is as low as 0.95 and yields are about 5,500 kg ha-1. This difference in CWP values is due to the higher water consumption by the farms with higher yields. We note that yields and thus CWP are also affected by soils and agricultural practices such as cropping patterns and field preparation, but these aspects are not evaluated in this work. This would require further investigation, but is outside the scope of this work.

Analysis on average irrigated wheat yields in Qarasou, Kashkan, Seymareh and Lower Karkheh sub-basins show a range from $500 \mathrm{~kg}$ ha-1 to 4,500 kg ha-1 whereas CWP values range from 0.5 to $1.23 \mathrm{~kg} \mathrm{~m}-3$. Average fertilizer rates in Qarasou, Kashkan, Seymareh and Lower Karkheh are 233, 123, 120 and $132 \mathrm{~kg}$ ha-1, respectively. This indicates that fertilizer rates for Kashkan, Seymareh and Lower Karkheh are significantly lower than application rates recommended by FAO (2005), explained further in Section 6.5.3. Data on seed rates for five sub-basins showed that Gamasiab has the highest rate, which is more than the rates reported in other studies (e.g., Nauman et al. 2011; Smid and Jenkinson 1979; Hemmat and Taki 2001). Seed rates for the irrigated wheat areas in the other four sub-basins are significantly lower 
compared to the rates presented in the above-mentioned studies. This indicates that there is considerable scope for increasing crop yield through better management of fertilizer and seeds, which will eventually lead to an increase in CWP.

Further analysis revealed that the target values of Eta/Etp for irrigated wheat in the different sub-basins range from 0.64 to 0.67 . In this study, the target value of 0.67 is assumed for all sub-basins, and based on this value suitable areas for irrigated wheat are identified. We note that the idea of an intended range of Eta/Etp is not applicable to rainfed wheat areas with dry periods, since cumulative Eta can be significantly lower than cumulative Etp. As such, the possibility for Eta/Etp to reach its maximum value (i.e., 1.0) is very low.

\subsubsection{Production of rainfed wheat}

Yields for different Eta classes were analyzed for rainfed wheat in the Upper Karkheh. Results for the Gamasiab sub-basins in the Upper Karkheh are presented in Table 6.4.

Table 6.4: Water consumption $\left(E T_{a}\right)$, average and highest rainfed wheat yield, crop water productivity $(C W P)$, fertilizer application rate and seed rate in different $E T_{a}$ classes in Gamasiab sub-basin.

\begin{tabular}{|c|c|c|c|c|c|c|}
\hline \multirow{2}{*}{$\begin{array}{l}E T_{a} \\
\text { (mm per }\end{array}$} & \multicolumn{2}{|c|}{ Average } & \multirow{2}{*}{$\begin{array}{l}\text { Highest } \\
\text { Yield } \\
\left(\mathrm{kg} \mathrm{ha}^{-1}\right)\end{array}$} & \multirow{2}{*}{$\begin{array}{l}\text { Fertilizer } \\
\left(\mathrm{kg} \mathrm{ha}^{-1}\right)\end{array}$} & \multirow{2}{*}{$\begin{array}{c}\text { Seed } \\
\text { (kg ha- }\end{array}$} & \multirow{2}{*}{$\begin{array}{l}\text { No. of } \\
\text { farms }\end{array}$} \\
\hline & $\begin{array}{c}\text { Yield } \\
\text { (kg ha- }\end{array}$ & $\begin{array}{c}C W P \\
\left(\mathrm{~kg} \mathrm{~m}^{-}\right.\end{array}$ & & & & \\
\hline$<200$ & 1,000 & - & 1,300 & 85 & - & - \\
\hline $200-250$ & 1,500 & 0.49 & 2,000 & 160 & 80 & 6 \\
\hline $250-300$ & 1,700 & 0.62 & 2,500 & 140 & 90 & 8 \\
\hline $300-350$ & 1,900 & 0.58 & 3,200 & 150 & 90 & 8 \\
\hline $350-400$ & 2,800 & 0.61 & 4,000 & 170 & 110 & 7 \\
\hline
\end{tabular}

The rainfed wheat yield for all Eta classes is significantly lower compared to yields for irrigated wheat areas. For instance, in the Gamasiab sub-basin, the average irrigated wheat yield is $5,400 \mathrm{~kg}$ ha- 1 for Eta class 350 to $400 \mathrm{~mm}$ per season (Table 6.3) whereas it is only $2,800 \mathrm{~kg}$ ha-1 for rainfed wheat (Table 6.4). The average yields and the difference between the average and highest observed yields increase when Eta increases.

Average rainfed wheat yields in different Eta classes for the other three subbasins in the Upper Karkheh range from 500 to $2,100 \mathrm{~kg} \mathrm{ha-1.Average}$ fertilizer application rates are below $132 \mathrm{~kg}$ ha- 1 whereas the average seed rates for the sub-basins are below $90 \mathrm{~kg}$ ha-1. These values are significantly lower compared to the recommended fertilizer rates (FAO, 2005) and the seed rates reported in other studies. 


\subsubsection{Fertilizer application \& seed rates for irrigated wheat areas in different sub-basins}

As presented in Section 6.1, the highest fertilizer application is found in the Gamasiab sub-basin whereas the lowest is in Seymareh sub-basin. The recommended Nitrogen fertilizer application for wheat in Iran is about $180 \mathrm{~kg}$ ha-1 (FAO, 2005). However, fertilizer application data for the different subbasins indicated that the highest yields were achieved when the application rate was about $200 \mathrm{~kg}$ ha-1 and when water was not a limiting factor. Therefore, in this study, we assume a fertilizer application rate of $200 \mathrm{~kg}$ ha1 as maximum recommended rate.

As presented in Section 6.1, the recommended seed rates to obtain the highest yield are between 125 to $170 \mathrm{~kg}$ ha-1. Hence, we assumed $170 \mathrm{~kg}$ ha-1 as the maximum recommended rate seed rate for the Karkheh River Basin. Seed rates presented in Section 6.1 show that the Gamsiab sub-basin has the highest application rate, which is above the optimum value. However, the seed rates in the other four sub-basins are significantly lower than the optimum value.

\subsubsection{Crop production function}

The crop production function estimates the effect of various factors on yields (Hussain et al., 2003; Amarasinghe et al., 2010). In this study, a multiple regression analysis was carried out to estimate the crop production function that explains the effects of fertilizer, water availability and seed rate on wheat yields. A set of functional forms that include linear, log-linear and quadratic forms were tested and the function most suited for the data sets is selected based on the coefficient of determinants (R2). The form of the crop production function is given in Equation 6.1 and the related coefficients for three different areas are given in Table 6.5.

$$
\text { Yield }=\mathrm{a}_{0}+\mathrm{a}_{1} E T_{a}+\mathrm{a}_{2} F+\mathrm{a}_{3} S R
$$

where: Yield is wheat yield in $\mathrm{kg} \mathrm{ha}^{-1}, E T_{a}$ is actual evapotranspiration in $\mathrm{mm}$ per season, $F$ is the fertilizer application rate in $\mathrm{kg} \mathrm{ha}^{-1}$ and $S R$ is the seed rate in $\mathrm{kg} \mathrm{ha}^{-1}$.

Table 6.5: Coefficients of the crop production functions.

\begin{tabular}{lcccccc}
\hline & $\mathrm{a}_{0}$ & $\mathrm{a}_{1}$ & $\mathrm{a}_{2}$ & $\mathrm{a}_{3}$ & $R^{2}$ & No. of points \\
\hline Irrigated wheat - Upper Karkheh & -352.60 & 5.1 & 6.60 & 6.90 & 0.78 & 127 \\
Irrigated wheat - Lower Karkheh & -97.30 & 1.1 & 12.20 & 4.81 & 0.76 & 41 \\
Rainfed wheat - Upper Karkheh & -551.20 & 2.9 & 7.80 & 2.22 & 0.71 & 91 \\
\hline
\end{tabular}


In Table 6.5, R2 values for all three production functions are higher than 0.7 which implies that the selected three variables explain more than $70 \%$ of the variation in yields.

Each coefficient presented in Table 6.5 indicates the change in wheat yield per unit change in one variable, whereas the other variables remain constant. For instance, in irrigated wheat areas in the Upper Karkheh, an increase in ETa by one unit ( $1 \mathrm{~mm}$ per season) increases the yield by $5.1 \mathrm{~kg}$ ha-1 whereas a unit increase of fertilizer increases the yield by $6.6 \mathrm{~kg}$ ha-1. In the Lower Karkheh, a unit increase in fertilizer increases the yield by $12.2 \mathrm{~kg}$ ha1. This is understandable as wheat areas in the Lower Karkheh receive irrigated water from the Karkheh Dam, and the fertilizer applications are about 50\% lower compared to the Gamasiab sub-basin. Also, in rainfed wheat areas, the main variable affecting yield is fertilizer. Seed rates have a high impact on yield in irrigated areas in the Upper Karkheh, and an increase in the seed rates of $1 \mathrm{~kg}$ ha- 1 increases the yield by $6.9 \mathrm{~kg}$ ha-1. For rainfed wheat areas, the increase in yield per unit increase in seed rate is about 2.2 $\mathrm{kg}$ ha-1.

\subsubsection{Land suitability}

On the basis of the slope map created using DEM, areas with a slope less than $5 \%$ and 5 to $7 \%$ are identified. For further identification of areas suitable for land conversion, the slope classes are combined with the land cover map and the Eta/Etp map. For the rainfed wheat areas in the Upper Karkheh, Eta/Etp ranges from 0.37 to 0.52 . As such, for the two slope classes, rangeland areas that have Eta/Etp greater than 0.5 were selected as suitable areas to expand rainfed wheat. Figure 6.4 shows the areas selected for expansion of rainfed wheat in Gamasiab sub-basin. Since precipitation in the Lower Karkheh is too low to support rainfed agriculture, land suitability has not been analyzed. 


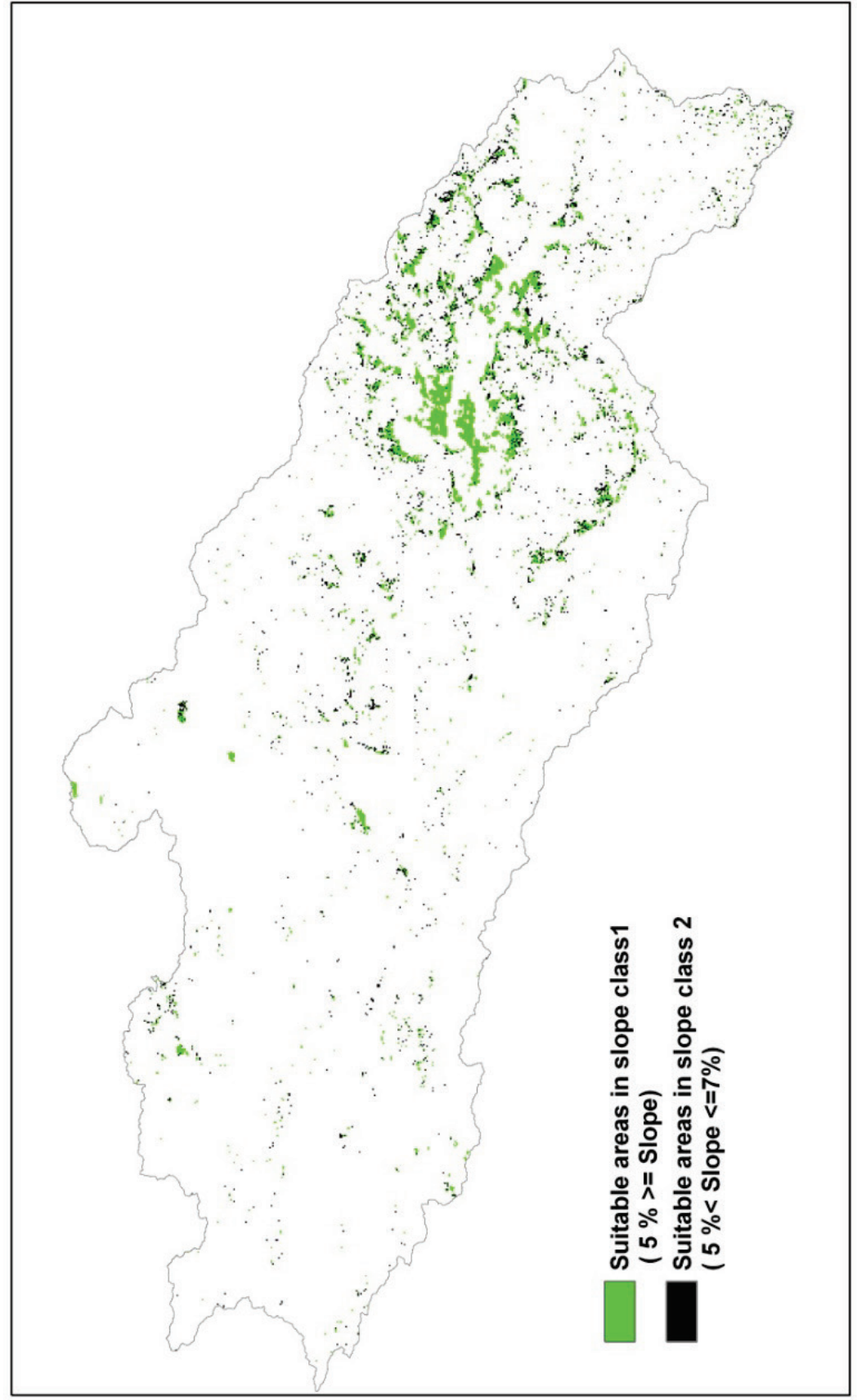

Figure 6.4: Rangeland area with $E T_{a} / E T_{p}$ greater than 0.5 for respective slope classes.

The total extent of rangelands and the suitable areas in two different slope classes in different sub-basins are presented in Table 6.6. 
Table 6.6: Size of the area for the respective slope classes having $E T_{a} / E T_{p}>0.5$.

\begin{tabular}{lccc}
\hline Sub-basin & Total rangelands & \multicolumn{2}{c}{ Rangeland areas (ha) under slope } \\
\cline { 3 - 4 } & $(\mathrm{ha})$ & 25,110 & $5-7 \%$ \\
\hline Gamasiab & 378,700 & 4,050 & 12,650 \\
Qarasou & 63,500 & 6,635 & 2,450 \\
Kashkan & 188,700 & 9,840 & 3,910 \\
Saymareh & 168,600 & 45,635 & 6,360 \\
\hline Total & $799,500^{*}$ & 25,370
\end{tabular}

Note: ${ }^{*}$ Rangelands in the Lower Karkheh Basin are not considered.

Table 6.6 shows that land availability for the expansion of rainfed wheat is highest in the Gamasiab sub-basin. It is noted that, in the Qarasou subbasin, the land availability is relatively low because of the highly heterogeneous terrain (Ghaffari et al. 2008) and also due to the small size of the sub-basin. Results show that, the production area for rainfed wheat can be expanded by approximately 45,600 ha for slope class 0 to $5 \%$ (highly suitable) and by 25,370 ha for slope class 5 to $7 \%$ (moderately suitable), making the total additional land area suitable for the expansion of rainfed wheat to 71,000 ha. Water consumption for the suitable areas in slope classes 0 to $5 \%$ and 5 to $7 \%$ is estimated at $149 \times 106 \mathrm{~m} 3$ and $74 \times 106$ $\mathrm{m} 3$, respectively, totaling $223 \times 106 \mathrm{~m} 3$. The expansion of the rainfed wheat to 71,005 ha of rangelands in highly and moderately suitable areas will not have an impact on the water balance of sub-basins, as new wheat areas will consume the same amount of water by the rangelands before land conversion.

\subsubsection{Production strategies}

\section{Strategy A: Increase yield in the current wheat production areas}

\section{Irrigated wheat production}

As shown in Section 6.5.1, water stress has a minimal effect on yield in the wheat areas that have ETa/ETp higher than 0.67. In these areas, water is not a limiting factor for wheat production and the chances are higher for increasing yield by managing non-water inputs such as fertilizer and seeds. In areas where ETa/ETp is lower than 0.67, water is the limiting factor and increasing yield by managing non-water inputs is minimal.

As shown in Table 6.3, fertilizer application rates and seed rates are already at high levels in the irrigated wheat areas of the Gamasiab sub-basin. The gap between average yield and the maximum observed yield in the respective ETa classes could possibly be due to the differences in other factors such as soils and land preparation. Therefore, the Gamasiab subbasin is not considered when we estimate projected production values in 
existing irrigated areas. In the irrigated wheat areas in Kashkan, Saymareh and Lower Karkheh, both fertilizer application rates and seed rates are below the maximum threshold. For instance, fertilizer application rates for about $35 \%$ of irrigated wheat areas are below the threshold value, and in some areas the application rates are less than $50 \%$ of the threshold value. The average seed rates indicate that the seed rates for about $75 \%$ of the wheat areas are at lower values compared to the recommended maximum rates reported in literature. This indicates that the yields in areas, where ETa/ETp is higher than the target value, can be increased by more than $25 \%$ of the yield gap by only optimizing either fertilizer or seed rates or both. Yield gap in this study is defined as the gap between highest observed yield and the average yield for ETa classes. For instance, in the Kashkan sub-basin, in the ETa interval 400 to $450 \mathrm{~mm}$ per season, the current average yield and the highest observed yield are 3,700 kg ha-1 and 5,500 kg ha-1, respectively. Twenty-five percent of the yield gap is about $450 \mathrm{~kg}$ ha- 1 . This can be achieved by using about $60 \mathrm{~kg}$ ha-1 of additional fertilizer, as the current application rate is $120 \mathrm{~kg}$ ha- 1 . Furthermore, in the Lower Karkheh, the extent of the wheat areas having ETa/ETp of 0.67 is about 37,100 ha and the average yield is $2,300 \mathrm{~kg}$ ha- 1 . The highest yield observed is $5,000 \mathrm{~kg} \mathrm{ha}-1$, and increasing the average yield by $25 \%$ of the yield gap would increase it by $675 \mathrm{~kg} \mathrm{ha}-1$. This requires an additional application of $50 \mathrm{~kg}$ ha- 1 of fertilizer. The possible increase in yield in each sub-basin is estimated and presented in Table 6.7.

Table 6.7: Projected production values in existing irrigated wheat areas when yield is increased by $25 \%$ of the yield gap

\begin{tabular}{lcc}
\hline Sub-basin & $\begin{array}{c}\text { Current irrigated area within } \\
\text { the intended range of } E T_{a} / E T_{p}(\mathrm{ha})\end{array}$ & $\begin{array}{c}\text { Additional production } \\
\left(\mathrm{kg} \times 10^{6}\right)\end{array}$ \\
\hline Gamasiab & 37,800 & - \\
Qarasou & 21,900 & 5.5 \\
Kashkan & 11,700 & 5.3 \\
Saymareh & 32,900 & 11.8 \\
Lower Karkheh & 50,157 & 32.3 \\
\hline Total & 154,457 & 54.9 \\
\hline
\end{tabular}

Note: Intended range: $E T_{a} / E T_{p}$ higher than 0.67 .

For these estimations only the wheat areas having ETa/ETp in the optimum range are considered. Results suggest that about $10 \%$ of the wheat production targets by 2025 can be met by better input management in the existing irrigated wheat areas. 


\section{Rainfed wheat production}

Since the rainfed wheat yields are significantly lower than the irrigated yields, we presume that the yield gap for rainfed wheat can be minimized in all ETa classes by managing fertilizer and seeds. For instance, in the Gamasiab subbasin, the average yield in the rainfed wheat areas having ETa between 200 and $250 \mathrm{~mm}$ per season is about $1,500 \mathrm{~kg} \mathrm{ha}-1$, and the maximum observed yield is about $2,000 \mathrm{~kg}$ ha- 1 . To increase yield by $50 \%$ of the yield gap, yield should increase by $250 \mathrm{~kg}$ ha- 1 . This could be achieved by increasing the fertilizer application by about $32 \mathrm{~kg}$ ha-1. In Table 6.8, the increase in rainfed wheat production as a result of improved agricultural practices is shown, where average production figures have increased by $25 \%$ and $50 \%$ of the yield gap. The current average and highest yields were estimated based on the data collected in a field survey.

Table 6.8: Projected production values in existing rainfed wheat areas.

\begin{tabular}{lcccc}
\hline Sub-basin & $\begin{array}{c}\text { Current yield } \\
\left(\mathrm{kg} \mathrm{ha}^{-1}\right)\end{array}$ & $\begin{array}{c}\text { Highest yield } \\
\left(\mathrm{kg} \mathrm{ha}^{-1}\right)\end{array}$ & $\begin{array}{c}\text { Increase in production }\left(10^{6} \mathrm{~kg}\right) \\
25 \%{ }^{*} \text { of yield } \\
\text { gap }\end{array}$ & $\begin{array}{c}50 \% \text { of yield } \\
\text { gap }\end{array}$ \\
\hline Gamasiab & 1,850 & 2,755 & 18 & 36 \\
Qarasou & 1,770 & 2,850 & 46 & 92 \\
Kashkan & 1,412 & 1,875 & 14 & 27 \\
Saymareh & 1,296 & 1,631 & 21 & 43 \\
Lower & - & - & - & - \\
Karkheh & - & - & 99 & 198 \\
\hline Total & & & 9 & \\
\hline
\end{tabular}

* $25 \%$ - yield increase by $25 \%$ of the yield gap. Lower Karkheh is not included because precipitation in this region is insufficient to support rainfed agriculture.

There is about 80,600 ha of existing rainfed wheat in the Gamasiab sub-basin and the average yield gap is $905 \mathrm{~kg}$ ha-1, of which $25 \%$ is $226 \mathrm{~kg}$ ha- 1 . In this sub-basin, increasing the yield by $25 \%$ of the yield gap would produce an additional $18 \times 106 \mathrm{~kg}$ of wheat. Therefore, for the entire basin, increasing yields at plot level by $25 \%$ and $50 \%$ of the yield gap would result in an increase in rainfed wheat production by $99 \times 106 \mathrm{~kg}$ and $199 \times 106 \mathrm{~kg}$, respectively. The yield gap is higher in the rainfed wheat areas in the Qarasou sub-basin compared to the other three sub-basins. In this sub-basin, the rainfed wheat area covers about 170,000 ha. Therefore, the highest increment in estimated wheat production is shown for the Qarasou sub-basin. Among the four sub-basins, Saymareh has the largest area of rainfed wheat. However, an increase in production in this sub-basin, after increasing the yield by $25 \%$ and $50 \%$ of the yield gap, is low compared to the Qarasou subbasin and due to lower yields compared to other three sub-basins. 


\section{Strategy B: Land conversion to expand the rainfed wheat area}

As presented in Section 6.5.5, an analysis was carried out to find suitable rangeland that can be converted into rainfed wheat. The potential areas for two slope classes are shown in Table 6.6 and the location of these areas is shown in Figure 6.4. The results of increased production for the two slope classes are shown in Table 6.9. For each slope class in the four sub-basins in the Upper Karkheh, average yields and an increase in yield by $25 \%$ and $50 \%$ of the yield gap are used to project the increase in wheat production. The highest production increase is in the Gamasiab sub-basin when compared to other sub-basins. This is because more land is available in this sub-basin to expand the rainfed wheat area. Despite having a similar level of yield as in the Gamasiab sub-basin, the production increase is comparatively low in the Qarasou sub-basin, as land availability of expanded rainfed wheat areas in two slope classes is only 6,500 ha.

Table 6.9: Projected increase in rainfed wheat production as a result of expanding the land area.

\begin{tabular}{lcccc|cccc}
\hline Sub-basin & \multicolumn{5}{c}{ Increase in production $\left(10^{6} \mathrm{~kg}\right)$ for different slope classes } \\
& \multicolumn{5}{c}{ Slope < $5 \%$} & \multicolumn{4}{c}{ Slope 5-7\% } \\
\cline { 2 - 10 } & $\begin{array}{c}\text { Area } \\
\text { (ha) }\end{array}$ & Average & $25 \% *$ & $50 \%$ & $\begin{array}{c}\text { Area } \\
\text { (ha) }\end{array}$ & Average & $25 \% *$ & $50 \%$ \\
\hline Gamasiab & 25,110 & 54 & 62 & 70 & 12,650 & 27 & 31 & 35 \\
Qarasou & 4,050 & 8 & 10 & 11 & 2,450 & 5 & 6 & 7 \\
Kashkan & 6,635 & 11 & 12 & 12 & 3,910 & 7 & 7 & 7 \\
Saymareh & 9,840 & 13 & 15 & 16 & 6,360 & 9 & 9 & 10 \\
\hline Total & 45,635 & 86 & 99 & 109 & 25,370 & 48 & 53 & 59 \\
\hline
\end{tabular}

$* 25 \%$ - yield increase by $25 \%$ of the yield gap, Average - current average yield.

In the most suitable areas, where the slope is less than $5 \%$, the increase in production can be $86 \times 106 \mathrm{~kg}$ if the current average rainfed yields are maintained. Increasing yields at plot level by $25 \%$ and $50 \%$ of the yield gap implies an increase of $99 \times 106 \mathrm{~kg}$ and $109 \times 106 \mathrm{~kg}$, respectively. When considering the moderately suitable land with a land slope class of 5 to $7 \%$, wheat production could be increased by an additional $48 \times 106 \mathrm{~kg}$ when current yields are taken into consideration. An additional $53 \times 106 \mathrm{~kg}$ and 59 $\times 106 \mathrm{~kg}$ of wheat can be produced if the yield increase is $25 \%$ and $50 \%$ of the yield gap, respectively.

In Table 6.10, the increases in wheat production for the two strategies are shown. Results indicate that a combined strategy is needed to meet the wheat production targets by 2025 . 
Table 6.10: Projected wheat production $(\mathrm{kg} \times 106)$ values for the two strategies.

\begin{tabular}{lcccc|cccccc}
\hline & \multicolumn{3}{c|}{ Strategy A } & \multicolumn{5}{c}{ Strategy B } \\
\hline & $\begin{array}{l}\text { Irrigated } \\
25 \%\end{array}$ & $50 \%$ & $25 \%$ & $50 \%$ & Rainfed & \multicolumn{3}{c}{ Slope $<5^{\circ}$} & \multicolumn{4}{c}{ Slope $5^{\circ}-7^{\circ}$} \\
& 55 & - & 99 & 198 & 86 & 99 & 109 & 48 & 53 & 59 \\
\hline Total & 11 & - & 20 & 40 & 17 & 20 & 22 & 9 & 11 & 12 \\
\hline$\%$ of the target
\end{tabular}

Note: Strategy A: Improving yield in the existing irrigated and rainfed wheat areas, Strategy B: Expanding the area under rainfed wheat.

For Strategy $A$, it is shown that a yield increase by $25 \%$ of the yield gap in both irrigated and rainfed areas is only $11 \%$ and $20 \%$ of the required target, respectively. However, $40 \%$ of the required production target can be met when the yield increased by $50 \%$ of the yield gap in existing rainfed areas. Therefore, increasing the yield by $25 \%$ of the existing irrigated wheat areas and $50 \%$ of the existing rainfed areas, $51 \%$ of the wheat production targets for 2025 can be achieved. For Strategy B, an increase in production is only $34 \%$ of the 2025 target after increasing the yield by $50 \%$ of the yield gaps in both highly suitable and moderately suitable areas. This indicates that by using the two proposed strategies, only $85 \%$ of the required wheat production target for 2025 can be achieved.

\subsection{Conclusions}

Wheat production in the Karkheh River Basin in Iran is assessed using measures of Relative Evapotranspiration (ETa/ETp), Crop Water Productivity (CWP) and the crop production function analysis. Based on these assessments, two strategies are explored to increase wheat production: a) increase yield in the current production areas, and b) land conversion to expand the rainfed wheat area.

Water-stressed conditions in irrigated wheat areas in different sub-basins were assessed using ETa/ETp. The ratio ranged from 0.31 to 0.96 . Based on this analysis, the minimum threshold value for ETa/ETp was established as 0.67 , and it was found that the effect of water stress on irrigated wheat yield is minimal at a higher value. Further, we found that about 154,500 ha of irrigated wheat in the basin have ETa/ETp higher than 0.67, thus having opportunities to increase yield by managing non-water inputs.

Crop production function analysis shows that more than $70 \%$ of the variation of yields in both rainfed and irrigated wheat areas can be explained by water use, fertilizer application rate and seed rate. This analysis further showed that an increase in yield by $25 \%$ in irrigated wheat areas (where ETa/ETp is above 0.67 ) and $50 \%$ in rainfed wheat areas are possible by managing fertilizer and seeds. 
Land suitability according to the topographic slope analysis and the current level of water consumption revealed that, 45,600 ha of rangelands in the slope class less than $5 \%$ and 25,300 ha in the slope class 5 to $7 \%$ consume similar amounts of water as in current rainfed wheat areas. This indicates that the area of rainfed wheat can be expanded to 71,000 ha of the rangelands without additional water requirements. In Strategy $B$, we assumed that these areas are converted to rainfed wheat areas.

Assessment of CWP indicates that, in irrigated wheat areas, CWP ranges from 0.50 to $1.63 \mathrm{~kg} \mathrm{~m}-3$ whereas in rainfed wheat areas, it is significantly lower and ranges from 0.37 to $0.62 \mathrm{~kg} \mathrm{~m}-3$. Further, increasing yield by $25 \%$ of the yield gap increases CWP in some irrigated areas by more than $20 \%$ compared to the current values. In rainfed areas, the yield increase by $25 \%$ and $50 \%$ of the yield gap would increase CWP by more than $35 \%$ and $55 \%$, respectively, in some areas. However, total projected wheat production shows that only $85 \%$ of the required wheat target by 2025 can be achieved by implementing the two strategies proposed in this study.

The spatial variations in ETa/ETp and CWP are possible only with the estimation of pixel-based ETa values. Therefore, this thesis provides a case study on using freely available satellite data, such as MODIS, to quantify and understand the variations of water-stress conditions and CWP. Finally, we evaluated wheat production and a possible production increase by only using available water resources based on advanced scientific estimations. Results and approaches might form the base for practical implementation to increase crop water productivity for wheat farming in the Karkheh River Basin. 


\section{Conclusions}

Water resources management is often hampered due to the lack of groundbased data. For instance, information on streamflow data is not always available in river basins around the world since gauging stations are not available or since station malfunction or degraded. Lack of data often leads to a high uncertainty in water resource assessment and a low confidence in decision making. This study shows that satellite remote sensing and hydrological modelling provide an alternative data source to fill the data gaps. Satellite images can be converted into hydrological information by using algorithms, whereas hydrological models serve to simulate time series of hydrological data.

The main objective of this study is to quantify the spatial and temporal distribution of water availability for agriculture in the Karkheh River Basin in Iran by integrating satellite remote sensing and hydrological modeling. The study also evaluated the possible increase of wheat production in the basin to meet wheat production demands by 2025 within the constraints of existing water resources.

\subsection{Estimation of Actual Evapotranspiration}

The estimation of ETa using satellite data is presented in Chapter 4. The Surface Energy Balance System (SEBS) algorithm, along with MODIS-TERRA images, was used. The study period was from November 2002 to October 2003 and covers a complete cropping year. Estimation of ETa is carried out using 19 MODIS-TERRA satellite images. The water balance computed using SEBS-based ETa, and the network-based and spatially interpolated precipitation, suggests that the water balance is sufficiently understood. For instance, the sub-catchment-scale water balance closure term, which is defined as the percentage difference between observed and estimated outflows compared to the incoming water in a sub-basin, ranges from $7.2 \%$ to $0.6 \%$. This implies that the satellite-based energy balance approach and geo-statistical techniques have shown to be effective in estimating spatial patterns of water consumption and water availability. Further, this study shows the effectiveness of using freely available satellite images to estimate spatial patterns of water consumption over large river basins.

A novel approach (presented in Chapter 5) to estimate the ETa for the days that MODIS satellite data are not available, due to cloud cover, proved to be effective. The validation results presented in Figure 5.3 showed good matches on a daily basis during both dry and wet seasons. Estimates ETa by the SEBS_daily method compared well to estimates produced by the original 
SEBS algorithm with RMSE ranging from $0.31 \mathrm{~mm} \mathrm{~d}-1$ to $0.53 \mathrm{~mm} \mathrm{~d}-1$. Further, the comparison of total actual evapotranspiration by the two methods (SEBS and SEBS_daily) for the one-year period from November 2002 to October 2003 showed less than 10\% differences for all subcatchments. This suggests the consistency of the proposed methodology in generating daily ETa. This approach could be applied anywhere in the world, since the estimation of ETa relies on MODIS images that have coverage across the world on a daily basis. Also, images are freely available.

\subsection{Quantification of water availability}

Annual streamflow for all sub-catchments defined in this study was calculated by subtracting SEBS ETa from the interpolated precipitation. For the Karkheh basin the volume of water drained from an area by steam flow over the volume of water that enters the area by precipitation is the drainage ratio is less than $10 \%$. This indicates that the basin is water-scarce (Chapter 4 ) and the opportunities for developing additional water resources are limited in the basin.

Future water allocation plans, as presented in Chapter 2, indicate a significant increase $(80 \%)$ in water allocations for irrigated agriculture by 2025 (as compared to 2002) due to increase in food demand. As presented in Chapter 4, opportunities to develop more water resources in the Karkheh River Basin are minimal, thus making it impractical to increase water availability by $80 \%$ for anticipated growth in food production. As such, the expected rise in agricultural production could only be achieved by increasing the crop water productivity in existing areas and expanding the rainfed agricultural areas. These two measures would help to conserve the water allocation to agriculture by 2025. As shown in this study, increasing the rainfed agricultural areas has the best potential.

\subsection{Calibration and parameterization of a hydrological model}

This study evaluated multi-variable model calibration using daily SEBS ETa and streamflow data. The mass conservative HBV model described in Chapter 3 was used, and the model was calibrated based on the Monte Carlo Simulation (MCS) procedure. The model performances were assessed by an objective function $(Y)$ that combines the Nash-Sutcliffe Efficiency and the Relative Volume Error performance measures.

It was shown that, although single variable calibration (i.e. using either streamflow or ETa ) produced a high model performance, the overall performance of the model (as measured by validating the second variable) 
was low. For instance, in Doab sub-catchment, YQ and YETa values were 0.86 and 0.48 , respectively, when calibrated for streamflow, which results in a YTOT of 0.68 . When both streamflow and ETa were used for calibration YQ, YETa and YTOT were $0.85,0.63$ and 0.74 , respectively (Table 5.11). This shows a significant improvement in the performance of the hydrological model for simulating ETa, by marginally affecting the model's performance in simulating streamflow. Using multi-variable calibration also reduces the uncertainty of the parameters as show in Figure 5.9.

\subsection{Increasing wheat production and ensuring downstream water availability}

A common perception about water-scarce river basins is that there are little opportunities to increase agricultural production. However, findings of this study show that for the water-scarce Karkheh River Basin agricultural production, in particular wheat, can be increased through increasing Crop Water Productivity and improved management of consumptive water use within constraints of available water resources.

As presented in Chapter 6, classification of wheat production areas based on ETa/ETp provided a basis for identifying water-deficit and -surplus areas for irrigated wheat. This approach allowed identifying the areas in each subbasin which fall within the optimum ETa/ETp range between 0.67 and 1.0, where water is not the limiting factor for increasing wheat yield. Classifying wheat areas based on ETa/ETp and the results of the production function analysis showed that, in some areas, yield gaps are not due to the limitation of water. Further, this analysis showed that an increase in yield by $25 \%$ in irrigated wheat areas, where water is not a limiting factor, and $50 \%$ in rainfed wheat areas are possible by improved management of fertilizer and seeds.

Land suitability analysis (presented in Chapter 6) conducted using the topographic slope and current level of water consumption revealed that the rainfed wheat can be expanded to an additional 71,000 ha of the rangelands without additional water requirements. This is about $8 \%$ of the total extent of rangelands in the basin and does not jeopardize the ecosystem services related to grazing. Thus, about $223 \times 106 \mathrm{~m} 3$ of water evaporated by rangelands can be used for wheat production without disturbing the overall water balance of the basin. This also guarantees the water availability for downstream uses, including minimal flow requirements for the Hoor-Al-Azim samp. 


\subsection{Implications for Iran's agriculture policy}

Important findings of this study are the following:

1) The approach to estimate SEBS based $E T_{a}$ for cloudy days to complete daily time series by cloud free satellite images was proven effective thus allowing identification of water stresses areas.

2) Classification of rangelands in the basin based on water consumption showed suitable areas for expanding the rainfed wheat areas without impacting the overall water budget in the basin.

3) Development of strategies to increase wheat production in the study area by combining analysis of $E T_{a} / E T_{p}$ and land suitability have proven to be effective to partially meet wheat production targets by 2025 .

Though the estimation of satellite-based $E T_{a}$ and analyzing spatial variation of precipitation are common approaches at present, assessment of water resource availability (Chapter 4 ) using these approaches will shed new light on the water balance in the study area.

Results from this study indicate that it is possible to achieve part of the required wheat production targets by 2025 through expansion of rainfed agriculture. However, this requires investments in improved water management and production technologies, and land use policy changes. However, the current policy focus is on higher investment in irrigated agriculture.

The findings of this research study reveal that there are substantial gains to be made through improvements in crop water productivity. The wide variation in water application for irrigated wheat in the basin is based on farmers' perception that increasing irrigation and fertilizer application would increase crop yields.

\subsection{Recommendations and future directions}

Although simulation models and satellite images substantially improve the data availability for water resources management, the value of in-situ measured data sets is imperative. Field-observed data, such as that collected from flux towers, scintillometers and Bowen ratio towers, help to validate the outcomes of satellite RS analysis and simulation models, thus allowing for more rigorous validation of water fluxes. Furthermore, other field measurements, such as streamflow rates, crop types and crop yields, are also important for the validation of hydrological model simulations and satellite-based products. 
Since an increasing number of satellite-based data products are becoming available in the public domain, further research directed towards developing hydrological models to seamlessly incorporate such data is required. Such models should also handle multi-variable calibration. In this study, Monte Carlo Simulation is combined with a preference-based multi-objective function, but more advanced optimization search algorithms and use of alternative objective functions could further improve model performance. 


\section{References}

Abbaspour, K.C., Yang, J., Maximov, I., Saber, R., Bogner, K., Mieleitner, J., Zobrist, J., Srinivasan, R., 2007. Modelling hydrology and water quality in the pre-alpine/alpine Thur watershed using SWAT. Journal of Hydrology, 333, 413-430.

Abbott, M.B., Bathurst, J.C., Cunge, J.A., O'Connell, P.E., Rasmussen, J., 1986. An introduction to the European Hydrological System Systeme Hydrologique Europeen, "SHE", 1: History and philosophy of a physically-based, distributed modelling system. Journal of Hydrology, 87, 45-59.

Ahmad, M.D., Bastiaanssen, W.G.M., Feddes, R.A., 2005. A new technique to estimate net groundwater use across large Irrigated areas by combining remote sensing and water balance approaches, Rechna Doab, Pakistan. Hydrogeology Journal, 13, 653-664.

Ahmad, M.D., Biggs, T., Turral. H., Scott, C.A., 2006. Application of SEBAL approach and MODIS time-series to map vegetation water use patterns in the data scarce Krishna river basin of India. IWA Journal of Water Science and Technology 53(10): 83-90.

Ahmad, M.D., Islam, A., Mashi, I., Muthuwatta, L.P., Karimi P., Turral H.M., 2009. Mapping basin-level water productivity using remote sensing and secondary data in the Karkheh River Basin, Iran. Water International, 34:1,119-133.

Ahmad, M.D., Giordano, M., 2010.The Karkheh River Basin: the food basket of Iran under pressure. Water international, 35, 5:522-544.

Akbari, M., Toomanian, N., Droogers, P., Bastiaanssen, W., Gieske. A., 2007. Monitoring irrigation performance in Esfahan, Iran, using NOAA satellite imagery. Agricultural Water Management, 88, 99 - 109.

Akhtar, M., Ahmad, N., Booij, M.J., 2009. Use of regional climate model simulations as input for hydrological models for the HindukushKarakorum- Himalaya region. Hydrology and Earth System Science, 13, 1075-1089.

Ako, A.A., Eyong, G.E.T., Nkeng, G.E., 2010. Water Resources Management and Integrated Water Resources Management (IWRM) in Cameroon. Water Resource Management, 24:871-888.

Albek, M., Ogutveren, U.B., Albek, E., 2004. Hydrological modelling of Seydi Suyu watershed (Turkey) with HSPF. Journal of Hydrology $285260-$ 271.

Allen, R.G., Pereira, L.S., Raes, D., Smith, M. 1998. Crop evapotranspiration: guidelines for computing crop water requirements. FAO irrigation and drainage paper, 56. FAO, $300 \mathrm{pp}$.

Amarasinghe, U.A., Malik, R.P.S., Sharma B.R., 2010. Overcoming growing water scarcity: Exploring potential improvements in water productivity in India. Natural Resources Forum, 34: 188-199. 
Andersson, L., Moody, D., 2004. Foreword. International Journal of Water Resources Development, 20,267-274.

Arnold J.G., Srinivasan P., Muttiah R.S., Williams J.R., 1998. Large area hydrologic modelling and assessment. Part I. Model development. Journal of American Water Resources Association. 34, 73-89.

Ashrafi, S., Qureshi, A.S. Gichuki, F. 2004. Karkheh Basin profile: Strategic research for enhancing agricultural water productivity. Draft Report. Challenge Program on Water and Food.

Awad, M., Khawlie, M., Darwich, T., 2009. Web based meta-database and its role in improving water resources management in the Mediterranean Basin. Water Resources Management, 23:2669-2680.

Balonishnikova, J., Heal, K., Guobin, F., Karambiri, H., Oki, T., 2006. World water resources, water use and management. Chapter 2, Hydrology 2020: An integrating science to meet world water challenges, ed. Oki, T.; Valeo, C.; Heal, K. IAHS Publication 300. Wallingford, UK: IAHS Press.

Bandara, K.M.P.S., 2003. Monitoring irrigation performance in Sri Lanka with high-frequency satellite measurements during the dry season. Agricultural Water Management, 58(2):159-170.

Bandara, K.M.P.S., 2006. Assessing irrigation performance by using remote sensing. Doctoral thesis, Wageningen University, Wageningen, The Netherlands.

Bandyopadhyay, S., Jaiswal, R.K., Hedge, V.S., Jayaraman, V., 2009. Assessment of land suitability potentials for agriculture using a remote sensing and GIS based approach. International Journal of Remote Sensing. 30, 4, 20, 879-895.

Bansouleh, B.F., 2009. Development of a spatial planning support system for agricultural policy formulation related to land and water resources in Borkhar \& Meymeh district, Iran. Doctoral thesis, Wageningen University, The Netherlands.

Bastiaanssen, W.G.M., Menenti , M., Feddes, R.A., Holtslag, A.A.M., 1998. A remote sensing surface energy balance algorithm for land (SEBAL):1. Formulation. Journal of Hydrology, 212-213:198-212.

Bastiaanssen, W.G.M., Bandara, K.M.P.S., 2001. Evaporative depletion assessments for irrigated watersheds in Sri Lanka. Irrigation Science, $21,1-15$.

Bastiaanssen, W.G.M., Ahmad, M.D., Chemin, Y., 2002. Satellite surveillance of evaporative depletion across the Indus Basin. Water resources research, 38(12).

Bastiaanssen, W.G.M., Chandrapala, L., 2003. Water balance variability across Sri Lanka for assessing agricultural and environmental water use. Agricultural Water Management, 58(2):171-192.

Bergström, S., 1976. Development and application of a conceptual runoff model for Scandinavian catchments. SMHI RH07, Norrköping. 
Bergström, S., 1991. Principles and confidence in hydrological modelling. Nordic Hydrology, 22: 123-136.

Bergström, S., Lindström, G., Pettersson, A., 2002. Multi-variable parameter estimation to increase confidence in hydrological modelling. Hydrological Processes, 16, 413-421.

Beven, K., 1989. Changing ideas in hydrology- The case of physically based models. Journal of hydrology, 105, 157-172.

Beven, K., Binley, A., 1992. The future of distributed models: model calibration and uncertainty prediction. Hydrological Processes. 6, 279-298.

Biftu, G.F., Gan, T.Y., 2001. Semi-distributed, physically based, hydrological modelling of the Paddle River Basin, Alberta, using remotely sensed data. Journal of Hydrology, 244, 137-156.

Blaes, X., Defourny, P., 2003. Retrieving crop parameters based on tandem ERS $1 / 2$ interferometryc coherence images. Remote Sensing of Environment, 88, 374-385.

Boegh, E., Thorsen, M., Butts, M.B., Hansen, S., Christiansen, J.S., Abrahamsen, P., Hasager, C.B., Jensen, N.O., van der Keur, P., Refsgaard, J.C., Schelde, K., Soegaard, H., Thomsen, A., 2004. Incorporating remote sensing data in physically based distributed agro-hydrological modelling. Journal of Hydrology, 287, 279-299.

Booij, M.J., 2002. Appropriate modelling of climate change impacts on river flooding. Doctoral thesis, Wageningen University, The Netherlands.

Booij, M.J., 2005. Impact of climate change on river flooding assessed with different spatial model resolutions. Journal of Hydrology, 303, 176198.

Booij, M.J., Krol, M.S., 2010. Balance between calibration objectives in a conceptual hydrological model. Hydrological science journal, 55, 1017-1032.

Borge, N.H., Leblanc, E., 2001. Comparing prediction power and stability of broadband and hyper spectral vegetation indices for estimation of green leaf area index and canopy chlorophyll density. Remote Sensing of Environment, 76, 156-172.

Bos, M.G., Nugteren, J., 1974. On Irrigation Efficiencies. Publication 19. 1st Edition 1974; 2nd Edition 1978; 3rd Revised Edition 1982; 4th Edition 1990. International Institute for Land Reclamation and Improvement/ILRI, Wageningen. pp. 117. 4th edition also published in Farsi with IRANCID, Tehran.

Bos, M.G., 2004. Using the depleted fraction to manage the groundwater table in irrigated areas. Irrigation and drainage systems, 18(3): 201209.

Bos, M.G., 2005. Is there enough fresh water?, International Institute for Geo-Information Science and Earth Observation, Enschede, Netherlands, $16 \mathrm{pp}$. 
Bos, M.G., Burton, M.A., Molden, D.J., 2005. Irrigation and Drainage Performance Assessment; Practical Guidelines, CABI Publishing, Wallingford, UK, $156 \mathrm{pp}$.

Bos, M.G., van den Bosch, H., Diemont, H., van Keulen, H., Lahr, J., Meijerink, G., Verhagen, A., 2007. Quantifying the sustainability of agriculture. Irrig Drainage Systems, 21:1-15.

Bos, M.G., Kselik, R.A.L., Allen, R.G., Molden, D., 2009. Water requirements for irrigation and the environment. Springer Science + Business Media B.V.

Breman, H., Groot, J.J.R., Van Keulen, H., 2001. Resource limitations in Sahelian agriculture. Global Environmental Change, 11:59-68.

Brutsaert, W., 1999. Aspects of bulk atmospheric boundary layer similarity under free convective conditions. Reviews of Geophysics, 37(4): 439451.

Burnash, R. J. C., 1995: The NWS River Forecast System-Catchment modelling. Computer Models of Watershed Hydrology, V.P. Singh, Ed., Water Resources Publications, 311-366.

Butts, M.B, Payne, J.T., Kristensenb, M., Madsen, H., 2004. An evaluation of the impact of model structure on hydrological modelling uncertainty for streamflow simulation. Journal of hydrology, 298, 242-266.

Cai, X., Rosegrant, M., 2003. World water productivity: Current situation and future options. In: Kijne, J.W., Barker, R. and Molden, D. (eds.), Water Productivity in Agriculture: Limits and Opportunities for Improvements, Comprehensive Assessment of Water Management in Agriculture Series 1. UK: CABI International.

Campo, L., Caparrini, F., Castelli, F., 2006. Use of multi-platform, multitemporal remote-sensing data for calibration of a distributed hydrological model: an application in the Arno basin, Italy. Hydrological Processes, 20, 2693-2712.

Cao, W., Bowden, W.B., Davie, T., Fenemor, A., 2006. Multi-variable and multi-site calibration and validation of SWAT in a large mountainous catchment with high spatial variability. Hydrological Processes, 20, 1057-1073.

Carrera, J., Neuman, S.P., 1986. Estimation of aquifer parameters under transient and steady state conditions: 1 . Maximum likelihood method incorporating prior information. Water Resources Research, 22(2), 199-210.

Casa, R., Rossi, M., Sappa, G., Trotta, A., 2009. Assessing Crop Water Demand by Remote Sensing and GIS for the Pontina Plain, Central Italy. Water Resources Management, 23, 1685-1712.

Charters C., Sood, A., 2013. The water for food paradox.Aquatic Procedia,1,3 $-19$. 
Chen, J.M., Chen, X., Ju, W., Geng, X., 2005. Distributed hydrological model for mapping evapotranspiration using remote sensing inputs. Journal of Hydrology, 305, 15-39.

Choi, H.T.B., Beven, K.J., 2007. Multi-period and multi-criteria model conditioning to reduce prediction uncertainty in an application of TOPMODEL within the GLUE framework. Journal of Hydrology, 332, 316-336.

Choudhury, B.J., Ahmed, N.U., Idso S.B., Reginato R.J., Daughtry C.S.T., 1994. Relations between Evaporation Coefficients and Vegetation Indexes Studied by Model Simulations. Remote Sensing of Environment, 50, 1-17.

Chowdary, V.M., Ramakrishnan, D., Srivastava, Y.K., Chandran, V., Jeyaram, A., 2009. Integrated Water Resource Development Plan for Sustainable Management of Mayurakshi Watershed, India using Remote Sensing and GIS. Water Resources Management, 23:15811602.

Consoli, S., D'Urso, G., Toscano, A., 2006. Remote sensing to estimate ETfluxes and the performance of an irrigation district in southern Italy. Agricultural Water Management, 81, 295-314.

Croke, B.F.W., Letcher, R.A., Jakeman, A.J., 2006. Development of a distributed flow model for underpinning assessment of water allocation options in the Namoi River Basin, Australia. Journal of Hydrology, 319: 51-71.

Crow, W.T., Wood, E.F., M. Pan, M., 2003. Multiobjective calibration of land surface model evapotranspiration predictions using streamflow observations and spaceborne surface radiometric temperature retrievals. Journal of Geophysical Research - Atmospheres, 108(D23).

Daly C, Neilson, R.P., Phillips, D.L. 1994. A statistical - topographic model for mapping climatological precipitation over mountainous terrain. Journal of Applied Meteorology, 33.

De Bruin, H.A.R., Stricker, J.N.M, 2000. Evaporation of grass under nonrestricted soil moisture conditions. Hydrological Science Journal, 45, 3, 391- 406

de Fraiture, C., Wichelns, D., 2010. Satisfying future water demands for agriculture Agricultural Water Management, 97, 4, 502-51.1.

De Vos, N.J., Rientjes,T.H.M., 2007. Multi-objective performance comparison of an artificial neural network and a conceptual rainfall-runoff model. Hydrological Science Journal, 52, 397-413.

De Vos, N.J., Rientjes,T.H.M., 2008. Multi-objective training of artificial neural networks for rainfall-runoff modelling. Water Resources Research, 44, W08434.

De Vos, N.J., Rientjes, T.H.M., Gupta ,H.V., 2010. Diagnostic Evaluation of Conceptual Rainfall-Runoff Models Using Temporal Clustering. Hydrological Processes, 24, 2840-2850. 
Deckers, D.L.E.H., Booij, M.J., Rientjes, T.H.M., Krol, M.S., 2010. Catchment variability and parameter estimation in multi-objective regionalisation of a rainfall-runoff model. Water Resources Management, 24, 39613985.

Dehghanisanij, H., Oweis, T., Qureshi, A.S. 2006. Agricultural Water Use and Management in Arid and Semiarid areas: Current Situation and Measures for Improvement. Annals of Arid Zone, 45, 1-24, 2006.

Dingman, S.L., 2002. Physical Hydrology (Second Edition). Prentice Hall, New Jersey.

Domingo, F., Villagarcy, L., Boer, M.M., Alados-Arboledas. L., Puigdefa'bregas, J., 2001 . Evaluating the long-term water balance of arid zone stream bed vegetation using evapotranspiration modelling and hill slope runoff measurements. Journal of Hydrology, 243: $17-30$.

Dong, J., Kaufmann, R.K., Mynenia, R.B., Tuckerb, C.J., Kauppic, P.E., Liskid, J., Buermanna, W., Alexeyevf, V., Hughesg, M.K., 2003. Remote sensing estimates of boreal and temperate forest woody biomass: Carbon pools, sources, and sinks. Remote Sensing of Environment, 84, 393- 410.

Doorenbos, J., Kassam, A.H., 1979. Yield response to water, Irrigation and drainage paper 33, FAO Roame, Italy.

Downer, C.W., Ogden, F.L., 2003. Prediction of runoff and soil moistures at the watershed scale: Effects of model complexity and parameter assignment. Water Resources Research, 39, (3), 1045.

Duan, Z., Bastiaanssen, W.G.M., 2013. Estimating water volume variations in lakes and reservoirs from four operational satellite altimetry databases and satellite imagery data. Remote Sensing of Environment, 134,403-416.

Efstratiadis, A., Koutsoyiannis, D., 2010. One decade of multi-objective calibration approaches in hydrological modelling: a review. Hydrological Science Journal, 55(1). 58-78.

Er-Raki, S., Chehbouni, A., Guemouria, N., Duchemin, B., Ezzahar, J., Hadria, R., 2007. Combining FAO-56 model and ground-based remote sensing to estimate water consumptions of wheat crops in a semi-arid region. Agricultural Water Management, 8 7, 41 - 54 .

Falkenmark, F., Rockström, J., Karlberg, L., 2009. Present and future water requirements for feeding humanity. Food science, 1, 59- 69.

FAO, 2003. Review of World Water Resources by Country, Water Reports 23, Food and Agriculture Organization of the United Nations. Rome.

FAO, 2005. Fertilizer use by crop in the Islamic Republic of Iran. Food and Agriculture Organization of the United Nations, Rome.

FAO, 2006. Fertilizer use by crops. FAO fertilizer and plant nutrition bulletin 17. Food and Agriculture Organization of the United Nations, Rome. 
FAO. 2009. AQUASTAT-FAO's information system on water and agriculture. Rome, Italy: FAO. http://www.fao.org/.

Farah O.H., Bastiaanssen, W.G.M., Feddes, R.A., 2004. Evaluation of the temporal variability of the evaporative fraction in a tropical watershed. International Journal of Applied Earth Observation and Geoinformation, 5, 129-140.

Fenicia, F., Zhang, G.P., Rientjes, T., Hoffmann, L., Pifster, L., Savenije, H.H.G., 2005. Numerical simulations of runoff generation with surface water-groundwater interactions in the Alzette river alluvial plain (Luxembourg). Physics and Chemistry of the Earth, 30, 277-284.

Fenicia, F., Savenije, H.H.G., Matgen, P., Pfister, L., 2007. A comparison of alternative multiobjective calibration strategies for hydrological modelling. Water Resources Research, 43.

Gallego, F.J., 2004. Remote sensing and land cover area estimation. International of Remote Sensing, 25, 15, 3019-3047.

Garizábal, I.G., Causapé, J., 2010. Influence of irrigation water management on the quantity and quality of irrigation return flows. Journal of Hydrology, 385, 36-43.

Ghaffari, A., De Pauw, E., Mirghasemi, S.A., 2008. Assessing land suitability for crop production in the Karkheh River Basin, Iran. In: Proceedings of the 2nd International forum on water and food, 10-14 November, 2008, Addis Ababa. ISBN 978-92-990053-0-9 Vol. I.

Gibson, L.A., Münch, Z., Engelbrecht, J., 2011. Particular uncertainties encountered in using a pre-packaged SEBS model to derive evapotranspiration in a heterogeneous study area in South Africa. Hydrology and Earth System Science, 15, 295-310.

Gieske, A.S.M., 2007. Numerical Modelling of Heat and Water Vapour Transport through the Interfacial Boundary Layer into a Turbulent Atmosphere. In: Particle - laden flow, from geophysical to Kolmogorov scales, in: Geurts, B.J., Clercx, H., Uijttewaal.W. Dordrecht, Springer, (ERCOFTAC Series; 11).

Gleick, P., 2003. Global freshwater resources: Soft path solutions for the $21^{\text {st }}$ century. Science, 302: 1524-1528.

Goovaerts, P., 1999. Geo-statistics in soil science: state-of-the-art and perspectives. Geoderma, 89, 1-46.

Gotzinger, J.G., Bardossy, A. 2005. Integration and calibration of a conceptual rainfall-runoff model in the framework of a decision support system for river basin management. Advances in Geosciences, 5, 31-35.

Guo, X., Wang, J., Xie, J., He, T., Lian, G. and Chunyan, L.V., 2005. Land degradation analysis based on the land use changes and land degradation evaluation in the Huan Beijing area. In Remote Sensing for Environmental Monitoring, GIS Applications, and Geology V, 
Proceedings of SPIE, M. Ehlers and U. Michel (Eds), 5983, pp. 598319.

Gupta, H.V., Sorooshian, S., Yapo, P.O., 1998. Toward improved calibration of hydrologic models: Multiple and non-commensurable measures of information. Water Resources Research, 34, 4, 751-763.

Gupta, H.V., Bastidas, L.A., Sorooshian, S., Schuttleworth, W.J., Yang, Z.L., 1999. Parameter estimation of a land surface scheme using multicriteria methods, Journal of Geophysical Research, 104, 1949119503.

Gupta, H.V., Wagener, T., Y. Liu, Y., 2008. Reconciling theory with observations: Elements of a diagnostic approach to model evaluation. Hydrological Processes, 22, 3802-3813.

Haile, A.T., Rientjes, T.H.M., Gieske, A.S.M., Gebremichale, M., 2009. Rainfall variability over mountainous and adjacent lake areas: the case of Lake Tana basin at the source of the Blue Nile river. Journal of Applied Meteorology and Climatology, 48, 1696-1717.

Harlin, J., Kung, C., 1992. Parameter uncertainty and simulation of design floods in Sweden. Journal of Hydrology, 137, 209-230.

Harmel, R.D., Cooper, R.J., Slade, R.M., Haney, R.L., Arnold, J.G., 2006. Cumulative uncertainty in measured streamflow and water quality data for small watersheds. Transactions of the American Society of Agricultural and Biological Engineers, 49, 3, 689-701.

Heilman, J.L., Heilman, W.E., Moore, D.G., 1982. Evaluating the crop coefficient using spectral reflectance. Agronomy Journal, 74:967971.

Hemakumara, M., Chandrapala, L., Moene, A.F., 2003. Evapotranspiration fluxes over mixed vegetation areas measured from large aperture scintillometer. Agricultural Water Management, 88:109-122.

Hemmat, A., Taki, O., 2001. Grain yield of irrigated winter wheat as affected by stubble-tillage management and seeding rates in central Iran. Soil and Tillage Research 63(1-2): 57-64.

Hussain, I., Sakthivadivel, R., Amarasinghe, U., 2003. Land and water productivity of wheat in the western Indo-Gangetic plains of India and Pakisthan: a comparative analysis. In: Kijne, J.W., Barker, R. and Molden, D. (eds.), Water Productivity in Agriculture: Limits and Opportunities for Improvements, Comprehensive Assessment of Water Management in Agriculture Series 1. UK: CABI International.

Immerzeel, W.W., Droogers, P., 2008. Calibration of a distributed hydrological model based on satellite evapotranspiration. Journal of Hydrology, 349,411-424.

Ines, A.V.M., Honda, K., Das Gupta, A., Droogers, P., Clemente, R.S., 2006. Combining remote sensing-simulation modelling and genetic algorithm optimization to explore water management options in irrigated agriculture. Agricultural Water Management, 8 3, 221-232. 
Iqbal, M., 1983. An introduction to solar radiation, Academic press, Canada.

Jarmain C., Mengistu, M.G., 2011. Validating energy fluxes estimated using the surface energy balance system (SEBS) model for a small catchment. WRC Report No. KV290/11, Water Research Commission, Pretoria. ISBN 978-1-4312-0184-6.

Jha, M.K., Chowdhury, A., Chowdary, V.M., Peiffer, S. 2007. Groundwater management and development by integrated remote sensing and geographic information systems: prospects and constraints. Water Resources Management, 21, 2, 427-467.

Jia, L., Su, Z., van den Hurk, B., Menenti, M., Moene, A., De Bruin. H.A.R., Yrisarry, J.J.B., Ibanez, M., Cuesta, A., 2003. Estimation of sensible heat flux using the Surface Energy Balance System (SEBS) and ATSR measurements. Physics and Chemistry of the Earth, Parts $A / B / C$, 28(1-3), 75-88.

Jia, L., Xi, G., Liu, S., Huang, C., Yan, Y., Liu, G., 2009.Regional estimation of daily to annual regional evapotranspiration with MODIS data in the Yellow River Delta wetland. Hydrology and Earth System Science, 13, 1775-1787.

Jin, X., Schaepman, M.E., Clevers, J.G.P.W., Su, Z., 2009. Impact and consequences of evapotranspiration changes on water resources availability in the arid Zhangye Basin, China. International Journal of Remote Sensing, 30, 12.

Journel, A.G., Huijbregts, C.J., 1978. Mining Geostatistics. Academic Press, New York.

Karatas, B.S., Akkuzu, E., Unal, H.B., Asik, S., Avci, M., 2009. Using satellite remote sensing to assess irrigation performance in Water User Associations in the Lower Gediz Basin, Turkey. Agricultural Water Management, 96, 982-990.

Khan, S., Hafeez, M.M., Rana, T., Mushtaq, S., 2008. Enhancing water productivity at the irrigation system level: A geospatial hydrology application in the Yellow River Basin. Journal of Arid Environments, 72, 1046-1063.

Khu, S.T., Madsen, H., di Pierro, F., 2008. Incorporating multiple observations for distributed hydrologic model calibration: an approach using a multi-objective evolutionary algorithm and clustering. Advances in Water Resources, 31, 1387-1398.

Kijne, J.W., Barker, R., Molden, D. 2003. Water productivity in agriculture: limits and opportunities for improvement (Comprehensive Assessment of Water Management in Agriculture Series 1). CABI, Wallingford.

Kite, G.W., Droogers, P., 2000. Comparing evapotranspiration estimates from satellites, hydrological models and field data. Journal of hydrology, 229(1-2), 3-18. 
Koloskov, G., Mukhamejanov, K.H., Tanton, T.W. 2007. Monin-Obukhov length as a cornerstone of the SEBAL calculations of evapotranspiration. Journal of hydrology, 335: 170-179.

Kustas, W.P., Daughtry, C.S.T., 1989. Estimation of the soil heat flux/net radiation ratio from spectral data. Agriculture and forest Meteorology, 49, 205-223.

Lannerstad, M., 2009. Water realities and development trajectories, Global and local agricultural production dynamics. Doctoral thesis, Linköping Universirt, Department of environmental studies, Sweden.

Legates, D. R., DeLiberty, T.L., 1993. Precipitation measurement biases in the United States. Water Resources Bulletin. 29, 855-861.

Lidén, R., Harlin, J., 2000. Analysis of conceptual rainfall-runoff modelling performance in different climates. Journal of Hydrology, 238, 231247.

Lindström, G., Johansson, B., Persson, M., Gardelin, M., Bergström, S., 1997. Development and test of the distributed HBV-96 hydrological model. Journal of Hydrology, 201, 272-288.

Lobell, D.B., Asner, G.P., Monasterio, I.O., Benning, T.L., 2003. Remote sensing of regional crop production in the Yaqui Valley, Mexico: estimates and uncertainties. Agriculture, Ecosystems and Environment, 94, 05-220.

Loheide II, S.P., Gorelick, S.M., 2005. A local scale high-resolution evapotranspiration mapping algorithm (ETMA) with hydrological applications at riparian meadow restoration sites. Remote sensing of environment, 98, 182-200.

Loukas, A., Vasiliades, L., Domenikiotis, C., Dalezios, N.R., 2005. Basin-wide actual evapotranspiration estimation using NOAA/AVHRR satellite data. Physics and Chemistry of the Earth, 30, 69-79.

Ma, W., Ma, Y., Li, M., Hu1, Z., Zhong, L., Su, Z., Ishikawa, H., Wang, J., 2009. Estimating surface fluxes over the north Tibetan Plateau area with ASTER imagery. Hydrology and Earth System Science, 13, 5767.

Madsen, H., 2000. Automatic calibration of a conceptual rainfall-runoff model using multiple objectives. Journal of Hydrology, 235, 276-288.

Madsen, H., 2003. Parameter estimation in distributed hydrological catchment modelling using automatic calibration with multi objectives. Advances in water resources, 26, 205-216.

Marjanizadeh, S., 2008. Developing a "best case scenario" for Karkheh River Basin management (2025 horizon); a case study from Karkheh River Basin, Iran. Doctoral thesis, University of Natural Resources and Applied Life Sciences, Vienna.

Masih, I, Ahmad, M.D., Uhlenbrook, S., Turral, H., Karimi, P., 2009. Analyzing streamflow variability and water allocation for sustainable 
management of water resources in the semi-arid Karkheh River Basin, Iran Physics and Chemistry of the Earth, 34, 329-340.

Masih, I., 2011. Understanding hydrological variability for improved water management in the semi-arid Karkheh basin, Iran. Doctoral thesis, Delft University of Technology, The Netherlands.

Masih, I., Maskey, S., Uhlenbrook, S., Smakhtin, V., 2011. Assessing the impact of areal precipitation input on streamflow simulations using the SWAT model. Journal of the American Water Resources Association. (JAWRA) 47(1):179-195.

Mazid, A., Tutwiler, R.N., Al-Ahmed, H., Abdelali-Martini, M., Maya, F., 2003. Impact of Modern Agricultural Technologies on Durum Wheat Production in Syria, Integrated Natural Resource Management Research Report Series, No. 3, ICARDA, Aleppo, Syria.

McCabe, M.F., Wood, E.F., 2006. Scale influences on the remote estimation of evapotranspiration using multiple satellite sensors. Remote Sensing of Environment 106, 271-285.

McMichael, C.E., Hope, A.S., Loaiciga, H.A., 2006. Distributed hydrological modelling in California semi-arid shrublands: MIKE SHE model calibration and uncertainty estimation. Journal of Hydrology, 317, 307-324.

Meijerink, A. M. J., Gieske, A. S. M., Vekerdy, D., 2005. Surface energy balance using satellite data for the water balance of a traditional irrigation-wetland system in SW Iran. Irrigation and Drainage Systems, 19, 89-105.

Meijerink, A.M.J., Bannert, D., Batelaan, O., Lubczynski, M.W., Pointet, T., 2007. Remote sensing applications to groundwater. IHP-VI, Series on Groundwater (16) UNESCO, France.

Mekonnen, G., Bastiaanssen, W.G.M., 2000. A new simple method to determine crop coefficients for water allocation planning from satellites: results from Kenya, Irrigation and Drainage Systems, 14: 237-256.

Merz, R., Blöschl, G., 2004. Regionalization of catchment model parameters. Journal of Hydrology, 287, 95-123.

Michaud, J.D., Sorooshian, S., 1994. Effect of rainfall-sampling errors on simulations of desert flash floods. Water Resources Research, 30, 10, 2765- 2775.

Milliman, J.D., Farnsworth, K.L., 2011. River Discharge to the coastal ocean: A global synthesis. Cambridge University Press.

Mohammadian, A., Zehtabian, G., 2006. The investigation of the upper-most function of restoration and maintenance of Qanats in Iran, a case study: Jan and Riz Watershed, Bohshehr Province. First International Conference on Water, Ecosystems and Sustainable Development in Arid and Semi-Arid Zones, Urumqi, China, October 19-25, 2006. 
Molden, D.J., Murray-Rust, H., Sakthivadivel, R., Makin, I., 2003. A waterproductivity framework for understanding and action. In: Kijne, J.W., Barker, R. and Molden, D. (eds.), Water Productivity in Agriculture: Limits and Opportunities for Improvements, Comprehensive Assessment of Water Management in Agriculture Series 1. UK: CABI International.

Molden, D., Oweis, T., Steduto, P., Kijne, J.W., Hanjra, M.A., Bindraban, P.S., 2007. Pathways for increasing agricultural water productivity. In: Water for food, water for life: a comprehensive assessment of water management in agriculture, chapter 7. Earthscan. http://www.iwmi.cgiar.org/ assessment/Publications/books.htm.

Molden, D., Oweis, T., Steduto, P., Bindraban, P., Hanjra, M.A., Kijne, J., 2010. Improving agricultural water productivity: Between optimism and caution. Agricultural Water Management, 97, 4: 528-535.

Monteith, J.L., 1965. Evaporation and environment. Symposia of the Society for Experimental Biology, 19, 205-234.

Monteith, J.L., 1973. Principles of Environmental Physics. Edward Arnold Press, London.

Montzka, C., Canty, M., Kumkel, R., Menz, G., Vereecken, H., Wendland, F., 2008. Modelling the water balance of a mesoscale catchment basin using remotely sensed land cover data, Journal of Hydrology, 353, 322-334.

Moran, M.S., Inoue, Y., Barnes, E.M., 1997. Opportunities and limitations for image-based remote sensing in precision crop management. Remote Sensing of Environment, 61,319-346.

Mroczkowski, M., Raper, G.P., Kuczera, G., 1997. The quest for more powerful validation of conceptual catchment Models. Water Resources Research, 33, 10, 2325-2335.

Muthuwatta, L.P., Ahmad, M.D., Bos, M.G., Rientjes, T.H.M., 2010. Assessment of water availability and consumption in the Karkheh River Basin (Iran) using remote sensing and geo-statistics. Water Resources. Management, 24, 459-484.

Muthuwatta, L.P., Rientjes, T.H.M. and Bos, M.G., 2013.Strategies to increase wheat production in the water scarce Karkheh River Basin, Iran. Agricultural water management, 124, 1-10.

Nangia, V., Turral, H., Molden, D., 2008. Increasing water productivity with improved $\mathrm{N}$ fertilizer Management. Irrigation and Drainage Systems, 22:193-207.

Nash, J.E., Sutcliffe, J.V., 1970. River flow forecasting through conceptual models. Part I: a discussion of principles. Journal of. Hydrology, 10, 282-290.

Nauman, M.T., Muhammad, M., Muhammad, W., Asghar, A.M.T., Iqbal, M.A.N.A., Mohsin, A.U. 2011. Nutrient and seed rate effect on yield and yieldcontributing characters of wheat at agro-climatic 
(subtropical) condition of Faisalabad. Agricultural Science Research Journal, 2, 44 - 49.

Nichols, W.E., Cuenca, R.H., 1993. Evaluation of the evaporative fraction for the parameterization of the surface energy balance. Water Resources Research, 29, 11, 3681-3690.

Olsson, J.A., Andersson, L., 2007. Possibilities and problems with the use of models as a communication tool in water resource management. Water Resources Management, 21, 97-110.

Oweis, T.Y., Hachum, A.Y., 2003. Improving water productivity in the dry areas of west Asia and north Africa. In: Kijne, J.W., Barker, R. and Molden, D. (eds.), Water Productivity in Agriculture: Limits and Opportunities for Improvements, Comprehensive Assessment of Water Management in Agriculture Series 1. UK: CABI International.

Oyebande, L., 2001. Water problems in Africa-how can sciences help? Hydrological Sciences Journal, 46, 6, 947-961.

Panda, S.S., Ames, D.P., Panigrahi, S., 2010. Application of Vegetation Indices for Agricultural Crop Yield Prediction Using Neural Network Techniques. Remote Sensing, 2010, 2, 673-696

Parajka, J., Blöschl. G., Merz, R., 2007. Regional calibration of catchment models: Potential for ungauged catchments. Water Resources Research, 43, w06406.

Parajka, J., Blöschl, G., 2008. Spatio-temporal combination of MODIS images - potential for snow cover mapping, Water Resources Research, 44, W03406.

Perrin, C., Michel, C., Andréassian, V., 2003. Improvement of a parsimonious model for streamflow simulation. Journal of Hydrology, 279, 275289.

Phillips, D.L., Dolph, J., Marks, D., 1992. A comparison of geostatistical procedures for spatial analysis of precipitations in mountainous terrain. Agricultural and Forest Meteorology 58: 119-141.

Pimentel, D, Burgess, M., 2013. Soil erosion threatens food production. Agriculture, 3, $443-463$.

Qin, C., Jia, Y, Su, Z., Zhou, Z., Qiu, Y., Suhi, S., 2008. Integrating remote sensing information into a distributed hydrological model for improving water budget predictions in large-scale basins through data assimilation. Sensors, 8, 4441-4465.

Qureshi, A.S., Oweis, O., Karimi, P., Porehemmat, J., 2009.Water productivity of irrigated wheat and maize in the Karkheh River Basin of Iran. Irrigation and Drainage, 59, 3, 264-276.

Refsgaard, J.C., 1997. Parameterisation, calibration and validation of distributed hydrological model. Journal of Hydrology, 198, 69-97.

Reggiani, P., Rientjes, T.H.M., 2005. Flux parameterization in the representative elementary watershed approach: application to a natural basin. Water Resources Research. 41, 4, W04013. 
Rahman, S.M., Khalil, M.I., Ahmed, M.F. 1995. Yield-water relations and nitrogen utilization by wheat in salt-affected soils of Bangladesh. Agricultural Water Management. 28 (1), 49-56.

Rientjes, T.H.M., 2004. Inverse modelling of the rainfall-runoff relation: $A$ multi objective model calibration approach. Doctoral thesis, Technical University of Delft, The Netherlands.

Rientjes, T.H.M., Perera, B.U.J., Haile, A.T., Reggiani, P. and L. P. Muthuwatta, L.P., 2011. Regionalisation for lake level simulation - the case of Lake Tana in the Upper Blue Nile, Ethiopia, Hydrology and Earth System Science, 15, 1167-1183.

Rockström, J., Axberg, G.N., Falkenmar, M., Lannerstad, M., Rosemarin, A., Caldwell, I., Arvidson, A., Norström, M., 2005. Sustainable Pathways to Attain the Millennium Development Goals: Assessing the Key Role of Water, Energy and Sanitation. Stockholm Environmental Institute, $103 \mathrm{pp}$.

Rockström, J., Lannerstad, M., Falkenmark, M., 2007. Assessing the water challenge of a new green revolution in developing countries, PNAS, $104,15,6253-6260$.

Rockström J., Falkenmark, M., Karlberg, L., Hoff, H., Rost, S., Gerten, D., 2009. Future water availability for global food production: The potential of green water for increasing resilience to global change. Water Resources Research, 45.

Rode, M., Suhr, U., Wriedt, G., 2007. Multi-objective calibration of a river water quality model - Information content of calibration data. Ecological Modelling, 204, 129-142.

Roerink, G.J., Su, Z., Menenti, M., 2000. S-SEBI: A simple remote sensing algorithm to estimate the surface energy balance. Physics and Chemistry of the Earth. Part B: Hydrology, Oceans and Atmosphere, 25, 2, 147-157.

Rostamian, R., Jaleh, A., Afyuni, M., Mousavi, S.F., Heidarpour, M. Jalalian, A., Abbaspour, K.C., 2008. Application of a SWAT model for estimating runoff and sediment in two mountainous basins in central Iran. Hydrological Science Journal, 53, 5.

Sadras, V.O., Angus, J.F., 2006. Benchmarking water-use efficiency of rainfed wheat in dry environments. Australian Journal of Agricultural Research, 57, 847-856.

Sakthivadivel, R., de Fraiture, C., Molden, D., Perry, C., Kloezen, W., 1999. Indicators of land and water productivity in irrigated agriculture. International Journal of Water Resources Development 15(1/2):161179.

Sánchez, N., Martínez-Fernández, J., Calera, A., Torres, E., Pérez-Gutiérrez, C., 2010. Combining remote sensing and in situ soil moisture data for the application and validation of a distributed water balance model (HIDROMORE). Agricultural Water Management, 98, 69-78. 
Schmugge, T.J., Kustas, W.P., Ritchie, J.C., Jackson, T.J., Rango, A., 2002. Remote sensing in hydrology, Advances in Water Resources, 25, 1367-1385.

Seckler, D., Amarasinghe, U., Molden, D., de Silva, R. Barker, R., 1998. World Water Demand and Supply, 1990 to 2025: Scenarios and Issues. IWMI Research Report 19, International Water Management Institute, Colombo.

Seibert, J., 1997. Estimation of Parameter Uncertainty in the HBV Model. Nordic Hydrol. 28 (4/5), 247-262.

Seibert, J., 1999. Regionalization of parameters for a conceptual rainfallrunoff model. Agricultural and Forest Meteorology, 98-99, 279-293.

Seibert, J., McDonnell, J.J., 2002. On the dialog between experimentalist and modeler in catchment hydrology: Use of soft data for multi-criteria model calibration. Water Resources Research, 38, 11, 1241.

Sen, Z., Habib, Z., 2000. Spatial precipitation assessment with elevation by using point cumulative semivariogram technique. Water resources management, 14: 311-325.

Shiklomanov, I.A. 2000. "Appraisal and Assessment of World Water Resources." Water International 25 (1): 11-32. SIWI (Stockholm International Water Institute) and IWMI (International Water Management Institute). 2004. Water-More Nutrition Per Drop: Towards Sustainable Food Production and Consumption Patterns in a Rapidly Changing World. Stockholm: Stockholm International Water Institute.

Shiklomanov, I.A., 1999. World Water Resources and Water Use: Present Assessment and Outlook for 2025. State Hydrological Institute, St Petersburg, Russia.

Shuttleworth, W.J., Gurney, R.J., Hsu, A.Y., Ormsby, J.P., 1989. FIFE: the variation in energy partition at surface flux sites. IAHS Publication, 186: 67-74.

SMHI (2006), Integrated Hydrologic Modelling System (IHMS). Manual version 5.1 .

Smid, A.E., Jenkinson, R.C., 1979. Effect of rate and date of seeding on yield and yieldcomponents of two winter wheat cultivers grown in Ontario. Candian Journal of Plant Science. 59: 939-943.

Stisen, S., Jensen, K.H., Sandholt, I., Grimes, D.I.F., 2008. A remote sensing driven distributed hydrological model of the Senegal River basin. Journal of Hydrology, 354, 131-14.

Su, Z., Schmugge, T., Kustas, W.P., Massman, W.J, 2001. An evaluation of two models for estimation of the roughness height for heat transfer between the land surface and the atmosphere. Journal of Applied Meteorology, 40, 1933-1951. 
Su, Z., 2002. The Surface energy balance system (SEBS) for estimation of turbulent heat flux. Hydrology and Earth System Sciences, 6, 1, 8589.

Sutcliffe, J.V., Carpenter, T.G., 1968. The assessment of runoff from the mountainous and semi -arid areas in western Iran. Hydrological aspects of the utilization of water (IAHS General Assembly of Bern), 383-394. IAHS publication, 76, IAHS press, Wallingford, UK.

Tabios, G.Q., Salas, J.D., 1985. A comparative analysis of techniques for spatial interpolation of precipitation. Water Resources Bulletin. 21, 3, 365-380.

Tang, Q., Peterson, S., Cuenca, R.H., Hagimoto, Y., Lettenmaier, D.P., 2009. Satellite based near-real-time estimation of irrigated crop water consumption. Journal of Geophysical Research, 114, D05114.

Teixeira, A.H. de C., 2008. Measurements and modelling of evapotranspiration to access agricultural water productivity in basins with changing land use patterns: A case study in the Sao Francisco river basin, Brazil. Doctoral thesis, Wageningen University, The Netherlands.

Tucker, C. J., 1979: Red and photographic infrared linear combinations for monitoring vegetation. Remote Sensing of Environment, 8, 127-150.

Tuong, T.P., Bouman, B.A.M., 2003. Rice production in water-scarce environments. In: Kijne JW, Barker R, Molden D (eds) Water productivity in agriculture: Limits and opportunities for improvement. CAB International Publishing.

UN, 2011. World Population Prospects, the 2010 Revision. United Nations, Department of Economic and social affairs, Population Division.

UNESCO, 2009. The United Nations World Water Development Report: Water in a changing world. The United Nations Educational, Scientific and Cultural Organization.

Van der Kwast, J., 2009. Quantification of top soil moisture patterns. Doctoral thesis, Utrecht University, The Netherlands.

Vrugt, J.A., Gupta, H.V., Bastidas, L.A., Bouten, W., Sorooshian, S., 2003. Effective and efficient algorithm for multiobjective optimization of hydrologic models. Water Resources Research, 39, 8, 1214.

Wagener, T., McIntyre, N., Lees, M.J., Wheater, H.S., Gupta, H.V., 2003. Towards reduced uncertainty in conceptual rainfall-runoff modelling: Dynamic identifiability analysis. Hydrological Processes, 17, 455-476.

Wale, A., Rientjes, T.H.M., Gieske, A.S.M., Getachew. H.A., 2009. Ungauged catchment contributions to Lake Tana's water balance. Hydrological Processes, 23, 3682-3693.

Wallace, J.S., 2000. Increasing agricultural water use efficiency to meet future food production. Agriculture Ecosystems and Environment, 82, 105-119. 
Wegehenkel, M., 2000. Test of a modelling system for simulating water balances and plant growth using various different complex approaches. Ecological Modelling, 129 1, 39-64.

Wegehenkel, M., Kersebaum, K.C., 2005. The validation of a modelling system for calculating water balance and catchment discharge using simple techniques based on field data and remote sensing data. Physics and Chemistry of the Earth, 30, 171-179.

Wilk, J., Kniveton, D., Andersson, L., Layberry, R., Todd, M.C., Hughes, D., Ringrose, S., Vanderpos, C., 2006. Estimating rainfall and water balance over the Okavango River Basin for hydrological applications. Journal of Hydrology, 331, 18- 29.

Winsemius, H.C., Savenije, H.H.G., Bastiaansen, W.G.M., 2008. Constraining model parameters on remote sensed evaporation: justification for distribution in ungauged basins? Hydrology and Earth System Science, 12, 1403-1413.

Wichelns, D., 2003.Enhancing water policy discussions by including analysis of non-water inputs and farm-level constraints. Agricultural Water Management, 62, 93-102.

Wolski, P., 1999. Application of reservoir modelling to hydrotopes identified by remote sensing. Doctoral thesis, International Institute for Aerospace Survey and Earth Science, Enschede, The Netherlands.

World Meteorological Organisation (WMO), 1994. Fifth edition, Guide to Hydrological Practices: Data Acquisition, and Processing, Analysis, Forecasting and Other Applications, WMO Publ. No.168.

Xia, L., 1994. A two-axis adjusted vegetation index (TWVI). International Journal of Remote Sensing, 15, 7, 1447-1458.

Xie, H., Tian, Y.Q., Granillo, J.A., Keller, G.R., 2007. Suitable remote sensing methods and data for mapping and measuring active crop fields. International Journal of Remote Sensing, 28(1-2), 395-411.

Xu, C., Tunemar, L., Chen, Y.D., Singh, V.P., 2006. Evaluation of seasonal and spatial variations of lumped water balance model sensitivity to precipitation data errors. Journal of Hydrology, 324, 80-93.

Young, A.R., 2006. Streamflow simulation within UK un-gauged catchments using a daily rainfall-runoff model. Journal of Hydrology, 320, 155172.

Yu, P.S., Yang, T.C., 2000. Fuzzy multi-objective function for rainfall-runoff model calibration. Journal of Hydrology. 238, 1-14.

Zehtabian, G., Khosravi, H., Ghodsi, M., 2010. High Demand in a Land of Water

Scarcity: Iran. Schneier, G., Madanes, M. Courel, F. (eds.), Water and Sustainability in Arid Regions, Springer Science+Business Media B.V. 2010. 
Zwart, S.J, Bastiaanssen, W.G.M., 2004. Review of measured crop water productivity values for irrigated wheat, rice, cotton and maize. Agricultural Water Management, 69, 115-133.

Zwart, S.J., Bastiaanssen, W.G.M., 2007. SEBAL for detecting spatial variation of water productivity and scope for improvement in eight irrigated wheat systems. Agricultural water management, 89, 287296.

Zwart, S.J., Bastiaanssen,W.G.M., de Fraiture, C., Molden, D.J. 2010.A global benchmark map of water productivity for rainfed and irrigated wheat. Agricultural Water Management, 97 10, 1617-1627. 


\section{Summary}

Lack of hydrological information is one of the main limitations for adequate water resources management. To fill gaps in information by in situ measured data, hydrological models and satellite remote sensing can be used. In modelling, satellite remote sensing is increasingly being used. Applications serve to estimate time-variant hydro-meteorological information or to provide time-invariant system characteristics such as elevation and land cover.

The main objective of this study is to quantify the spatial and temporal distribution of water availability for agriculture in the Karkheh River Basin in Iran by integrating satellite remote sensing and hydrological modeling. Findings served to evaluate possibility to increase wheat production in the basin within the constraints of existing water resources.

Satellite images from the Moderate Resolution Imaging Spectroradiometer (MODIS) along with the Surface Energy Balance System (SEBS) algorithm were used to estimate daily values of the_E $E T_{a}$ in the basin (Chapter 4). Gaps in $E T_{a}$ time series due to cloud cover were filled in using an approach which is based on the Penman-Monteith equation and linearly interpolated surface resistance values based on satellite data (Chapter 5). Assessments on crop water consumption for the one-year period from November 2002 to October 2003 show that over $90 \%$ of the water received by the basin as precipitation is evapotranspired. Estimated outflow from the basin for the same period was $7.8 \%$ of the precipitation and indicates that the basin is water-scarce.

For hydrological modelling, the HBV-96 model was used (Chapter 3). Performance of the model was tested in a multi-variable calibration approach (Chapter 5). For model calibration, satellite based SEBS $E T_{a}$ and streamflow data were used to assess water balance closure when different calibration variables were used. The results of the multi-variable model calibration are presented in Table 5.11 and show significant water balance closure error for the variable which closes the water balance. Calibration of the HBV-96 model on SEBS based ETa yielded very poor simulation results for stream flow with large water balance closure error. Comparing time series of HBV-96 simulated ETa and SEBS based ETa_shows large deviations during the first months of the dry season and for ETa estimates at rainy days. It is concluded that water balance of the Karkheh basin is best represented by the HBV-96 model when both streamflow and SEBS based ETa_serve as target for model calibration.

SEBS based $E T_{a}$ _was used to assess two strategies to increase wheat production in the basin to meet 2025 targets. Strategies were to (1) increase yields in the current irrigated and rainfed wheat areas, and (2) increase the 
area under rainfed wheat through land conversion. By combining topographic catchment characteristics and $E T_{a} / E T_{p}$ as a water stress indicator, areas with water deficits and surpluses for irrigated wheat and areas suitable for expanding rainfed wheat were identified. Analysis showed that for about 154,500 ha of irrigated wheat, yields can be improved by managing nonwater inputs, such as fertilizer and seeds. In irrigated areas, when water is not a limiting factor, crop water productivity can be increased by about $20 \%$ compared to the current values (cropping years 2002 and 2003) and closes the 2025 yield gap by $25 \%$. Similarly, in rainfed areas, crop water productivity can be increased by $35 \%$ and $55 \%$ and closes the 2025 yield gap by $25 \%$ and $50 \%$, respectively.

In the basin, analysis of water consumption for different land cover types show that 853,700 ha of rangelands consume about $3,360 \times 10^{6} \mathrm{~m}^{3}$ of water annually (i.e., $390 \mathrm{~mm} / \mathrm{yr}$ ), whereas $1,389,000$ ha of rainfed areas $(60 \%$ larger than the rangeland area) consume only $3,720 \times 10^{6} \mathrm{~m}^{3}$ annually, (i.e., $270 \mathrm{~mm} / \mathrm{yr}$ ), which is $10 \%$ more than that consumed by rangelands. Land suitability analysis (Chapter 6 ) showed that about 71,000 ha of rangelands can be used to expand the rainfed wheat areas. This is about $8 \%$ of the total extent of rangelands in the basin and does not jeopardize ecosystem services. About $223 \times 10^{6} \mathrm{~m}^{3}$ of water presently evaporated by rangelands which, after land conversion, becomes available for wheat production without disturbing the overall water balance of the basin. Water availability to serve downstream areas including minimal flows for the Hoor-Al-Azim swamp is not affected.

The study shows that wheat production targets for 2025 can be met partly by reducing the yield gap of irrigated wheat and partly by expanding the rainfed wheat area. This implies that policy to increase wheat production should focus on land conversion and on improving water management and production technologies. As shown in Chapter 6, the wide variation in water application for irrigated wheat in the basin illustrates the farmers' perception on increasing crop yield through excessive irrigation and fertilizer application.

This study has not looked at the adverse impact of converting rangelands to rainfed wheat areas. In the basin, rangelands are important grazing areas for livestock which plays a critical role in the regional economy. Thus, it is necessary to include the management of livestock in future land-use and agricultural planning in the basin.

Further research is recommended on development and performance of water balance based hydrological models which integrate satellite data. To assess effectiveness of satellite data to represent catchment water balance, multivariable model calibration is recommended. In this study, simple Monte Carlo 
Simulation is combined with a preference-based multi-objective function, but more advanced optimization algorithms and the use of alternative objective functions is advocated.

This study has focused on satellite remote sensing and hydrological model simulations but the value of in situ measured data cannot be ignored. Field observed meteorological data such as that collected from flux towers, scintillometers and Bowen ratio towers, is prerequisite to validate satellite remote sensing. Furthermore, field data on crop types, crop yields and gauge data on stream flow discharges are necessary for the validation of hydrological model simulations and satellite products.

In this study, the analysis was for wheat production. Extending the analysis to other crops could result in opportunities for increasing food production and for improving water resources management at basin scale. Finally, findings could be linked to a decision support system to provide water resource managers with a robust tool to understand the effects of different water and agricultural management practices and water allocation scenarios in the basin. 


\section{Samenvatting}

Gebrek aan hydrologische informatie is één van de voornaamste belemmeringen voor een adequaat beheer van het water. Om gaten in de informatie op te vullen kunnen hydrologische modellen en satellietbeelden worden gebruikt. Als alternatief voor het gebruik van in het veld gemeten gegevens wordt aardobservatie met satellieten bij het modelleren steeds vaker ingezet. Toepassingen dienen dan om met de tijd variërende hydrometeorologische informatie te schatten of om systeemkenmerken zoals hoogte en landgebruik te bepalen.

Het hoofddoel van deze studie is het kwantificeren van de ruimtelijke en temporele verdeling van de waterbeschikbaarheid voor de landbouw in het Karkheh stroomgebied in Iran door het integreren van satelliet aardobservatie bij het hydrologisch modelleren. De uitkomsten kunnen dienen om de mogelijkheden te evalueren om de tarweproductie in het stroomgebied te verhogen binnen de beperkingen van de waterbeschikbaarheid.

Satellietbeelden van de sensor MODIS (Moderate Resolution Imaging Spectroradiometer) zijn samen met het SEBS (Surface Energy Balance System) algoritme gebruikt om $E T_{a}$ (evapotranspiratie actueel) op dagelijkse basis te schatten in het stroomgebied (Hoofdstuk 4). Gaten in tijdreeksen van $E T_{a}$ vanwege bewolking zijn opgevuld via een benadering die is gebaseerd op de Penman-Monteith vergelijking en op lineair geïnterpoleerde waarden van de oppervlakteweerstand gebaseerd op satellietgegevens (Hoofdstuk 5). Schattingen van de waterconsumptie door gewassen voor de éénjarige periode van november 2002 tot oktober 2003 tonen aan dat meer dan $90 \%$ van het door neerslag in het stroomgebied ontvangen water via evapotranspiratie weer verloren gaat. De geschatte uitstroom vanuit het stroomgebied in dezelfde periode was $7,8 \%$ van de neerslag, en dit wijst erop dat het stroomgebied waterarm is.

Voor het hydrologisch modelleren is het HBV-96 model gebruikt (Hoofdstuk 3). De prestaties van het model zijn getest met een multivariabele kalibratie benadering. Voor de modelkalibratie zijn op satellieten gebaseerde SEBS $E T_{a}$ data en rivierafvoer gegevens gebruikt om de mate van sluiting van de waterbalans te bepalen bij gebruik van de verschillende kalibratievariabelen. De resultaten van deze multivariabele modelkalibratie worden gepresenteerd in Tabel 5.11, en deze tonen een significante waterbalans sluitingsfout aan voor de modelvariabele die niet is gebuikt voor kalibratie maar de waterbalans sluit. Kalibratie van het HBV-96 model op SEBS $E T_{a}$ gaf zeer gebrekkige simulatieresultaten voor de rivierafvoer met een grote sluitingsfout in de waterbalans. Vergelijking van tijdreeksen van met HBV-96 
gesimuleerde $E T_{a}$ en van SEBS $E T_{a}$ laat grote afwijkingen zien gedurende de eerste maanden van het droge seizoen en voor de schattingen van $E T_{a}$ op regenachtige dagen. Geconcludeerd wordt dat de waterbalans in het Karkheh stroomgebied het best wordt gerepresenteerd door het HBV-96 model wanneer zowel SEBS $E T_{a}$ als de rivierafvoer voor modelkalibratie dienen.

De SEBS $E T_{a}$ is gebruikt om twee strategieën te testen voor het verhogen van de tarweproductie in het stroomgebied tot streefwaarden in 2025. De strategieën bestonden uit (1) het verhogen van de opbrengsten in de huidige geïrrigeerde en regenafhankelijke tarwegebieden, en (2) het vergroten van het regenafhankelijke tarwegebied via conversie van het landgebruik. Door het combineren van de topografische karakteristieken van het stroomgebied met $E T_{a} / E T_{p}$ als indicator voor droogtestress, zijn gebieden geïdentificeerd met watergebrek en -overschot voor geïrrigeerde tarwe en voor gebieden geschikt voor het uitbreiden tot regenafhankelijke tarwe. De analyse toonde aan dat voor ongeveer 154.000 ha geïrrigeerde tarwe de opbrengst kan worden vergroot door verbeterd beheer van kunstmest en zaden die niet afhangen van waterbeschikbaarheid. In geïrrigeerde gebieden, waar water geen beperkende factor is, kan de gewasproductie met ongeveer $20 \%$ worden verhoogd vergeleken met de huidige waarden (de groeiseizoenen van 2002 en 2003) en wordt het tekort in 2025 tot $25 \%$ gereduceerd. Evenzo, in regenafhankelijke gebieden kan de water gerelateerde opbrengst worden verhoogd met 35\% en 55\% en wordt het tekort in 2025 met 25\% resp. 50\% gereduceerd.

In het stroomgebied laat een analyse van de waterconsumptie voor verschillende typen landgebruik zien dat de 853.700 ha aan begrazingsgebieden jaarlijks ongeveer $3.360 \times 10^{6} \mathrm{~m}^{3}$ water gebruiken (d.w.z. $390 \mathrm{~mm} /$ jaar), terwijl 1.389 .000 ha regenafhankelijke gebieden (60\% meer dan het begrazingsgebied) slechts $3.730 \times 10^{6} \mathrm{~m}^{3} /$ jaar gebruiken, hetgeen $10 \%$ meer is dan wat gebruikt wordt door begrazingsgebieden. Een landgeschiktheidsanalyse (Hoofdstuk 6) laat zien dat ongeveer 71.000 ha aan begrazingsgebieden kan worden gebruikt voor uitbreiding van het regenafhankelijke tarwegebied. Dit is ongeveer $8 \%$ van de totale omvang van het begrazingsgebied in het stroomgebied en dit bedreigt het functioneren van het ecosysteem niet. Ongeveer $223 \times 10^{6} \mathrm{~m}^{3}$ water wordt door begrazingsgebieden verdampt, wat na landconversie beschikbaar is voor tarweproductie, zonder de waterbalans van het stroomgebied te verstoren. De waterbeschikbaarheid voor benedenstroomse gebieden, inclusief minimale rivierafvoeren voor het Hoor-Al-Azim moerasgebied, wordt niet beïnvloed.

Deze studie laat zien dat de tarweproductiedoelstellingen voor 2025 gedeeltelijk kunnen worden gehaald door het reduceren van het opbrengsttekort van geïrrigeerde tarwe en gedeeltelijk door het regenafhankelijke tarwegebied uit te breiden. Dit betekent dat een beleid voor het verhogen van de tarweproductie zich zou moeten richten op 
landconversie en op het verbeteren van het waterbeheer en de productietechnologieën. Zoals getoond in Hoofdstuk 6, illustreert de grote variatie in het gebruik van water voor geïrrigeerde tarwe de perceptie van boeren dat de gewasopbrengst verhoogd kan worden door excessieve irrigatie en toepassing van kunstmest.

In deze studie is niet gekeken naar de nadelige gevolgen van het converteren van begrazingsgebieden naar tarwegebieden. In het stroomgebied zijn de begrazingsgebieden belangrijk voor vee, dat een essentiële rol vervult in de regionale economie. Aldus is het noodzakelijk om de veehouderij mee te nemen in het toekomstig landgebruik en bij de planning van de landbouw in het stroomgebied.

Verder onderzoek wordt aanbevolen naar de ontwikkeling en het functioneren van hydrologische modellen die zijn gebaseerd op de waterbalans en die satellietdata kunnen integreren. Om de effectiviteit van satellietdata te bepalen voor het representeren van de waterbalans in een stroomgebied wordt multivariabele modelkalibratie aanbevolen. In deze studie wordt een eenvoudige Monte Carlo simulatie gecombineerd met een op voorkeuren gebaseerde meervoudige doelfunctie, maar meer geavanceerde optimalisatie algoritmen en het gebruik van alternatieve doelfuncties worden aangeraden.

Deze studie is gericht op satelliet aardobservatie en hydrologische modelsimulaties, maar de waarde van in situ gemeten gegevens kan niet worden genegeerd. In het veld waargenomen meteorologische gegevens zoals verzameld met fluxmasten, scintillometers en door Bowen-ratio masten zijn een voorwaarde voor het valideren van satelliet aardobservatie methoden. Bovendien zijn veldgegevens over gewassoorten, gewasopbrengsten en meetgegevens over rivierafvoeren noodzakelijk voor het valideren van hydrologische modelsimulaties en satellietproducten.

In deze studie is een analyse verricht voor de tarweproductie. Het uitbreiden van de analyse naar andere gewassen zou kunnen resulteren in mogelijkheden voor het verhogen van de voedselproductie en het verbeteren van het waterbeheer op de schaal van een stroomgebied. Ten slotte zouden de bevindingen kunnen worden gekoppeld aan een beslissingsondersteunend system dat waterbeheerders kan voorzien van degelijk gereedschap om hen de effecten te laten inzien van verschillende praktijken van landbouwbeheer en van scenario's voor waterallocatie. 


\section{Appendix \\ Data requirements for a water balance study at river basin level, using remote sensing, in order to test strategies to improve crop (wheat) production}

\section{Contents}

1 Assessment of water availability and consumption.

1a Estimation of actual evapotranspiration $\left(E T_{a}\right)$ using satellite data.

$1 \mathrm{~b} \quad$ Interpolation of precipitation using observed rainfall data.

1c Computation of water balance for various sub-basins.

$2 \quad$ Hydrological modeling.

2a Estimation of daily time series of $E T_{a}$ data.

2b Hydrological modeling using multi variable calibration.

3 Strategies to increase (crop) wheat production.

3a Development of crop production functions

3b Assessment of wheat production.

3c Land suitability analysis

3d Development of strategies to increase wheat production. 


\section{Assessment of Water Availability and Consumption.}

1a Estimation of actual evapotranspiration ( $\left.E T_{a}\right)$ using satellite data.

Surface Energy Balance System (SEBS) was used to estimate $E T_{a}$. This required four sets of data derived from Remote Sensing images (RS). At river basin the MODIS level 1B products can be used. They can be downloaded from http:/ladsweb.nascom.nasa.gov/. The following spatial data was derived from these remote sensing images:

\section{Albedo}

To estimate albedo, pixel scale reflectance data based on MODIS band 1,2 , $3,4,5,7$ were used. Normalized Difference Vegetation Index (NDVI) using band1 and 2. NDVI was used to derive Leaf Area Index (LAI) and Fractional vegetation cover.

\section{Emissivity}

Surface emissivity has been calculated using fractional vegetation cover, which is a function of NDVI. Emissivity of air calculation is based on air temperature.

\section{Surface temperature}

Surface temperature was estimated by using the MODIS bands 31 and 32 and corrected for the elevation by Digital Elevation Model (DEM). In addition to RS data, the following daily meteorological data were collected from the Iranian Meteorological Organization.

Temperature

Relative humidity

Wind speed

The data sets were collected from 16 meteorological stations. These point data were converted to grid data using IDW interpolation techniques. This was done to match the meteorological data to the pixel size of satellite images.

\section{Radiation data}

Net short wave radiation was estimated using albedo and extra-terrestrial incoming solar radiation. Net incoming long wave radiation was estimated using the standard equations based on surface and air emissivity, air temperature and estimated surface temperature.

\section{Land Use (Spatial data)}

Land Use data sets were used to extract land use specific $E T_{a}$. For this, a land use map was prepared by classifying the time series of MODIS images with bands in the visible and near infrared areas of the electromagnetic spectrum. To validate the classified map, ground truth data at 198 locations were used. 
This validation is only feasible in areas where ground truth data can be collected.

\section{$1 b$ Interpolation of precipitation using observed rainfall data.}

For the interpolation of precipitation data, the geo-statistical approach, detrended Kriging, was used. This technique allows for accounting for the trend of the precipitation data with respect to the elevation. Monthly precipitation data was collected at 30 meteorological stations. The precipitation station density was 1 station per $1700 \mathrm{~km} 2$.

\section{1c Computing water balance for various sub-basins.}

For the water balance within the sub-basins of the study area, spatially interpolated precipitation, satellite based ETa, and observed stream flow data were used. In this water balance, the following components were quantified:

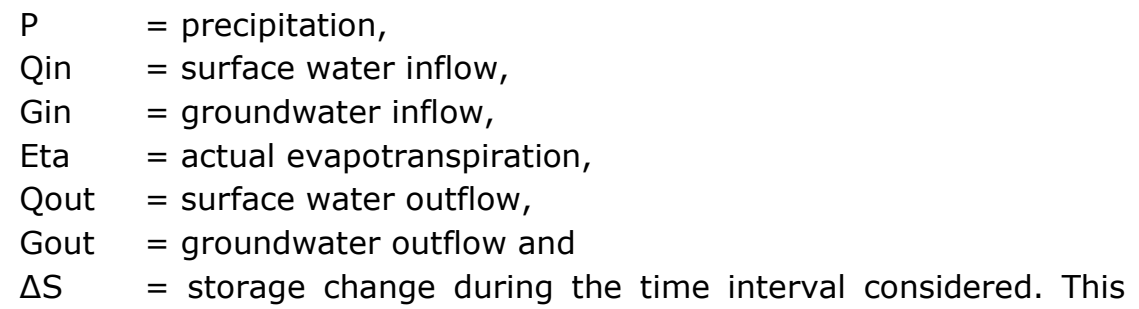
includes the changes in storage in groundwater, surface water and soil moisture.

The details for the estimation procedures for ETa, precipitation and water balance is describe in: Muthuwatta, L.P., Ahmad, M.D., Bos, M.G., Rientjes, T.H.M., (2010). Assessment of water availability and consumption in the Karkheh River Basin (Iran) using remote sensing and geo-statistics. Water Resources Management. 24,459-484.

\section{Hydrological Modeling.}

\section{2a Estimation of daily time series of ETa data.}

To estimate ETa for days when satellite images were not available, a Penman-Monteith based approach was used. In this approach, pixel based surface resistance values were estimated inversely using the PenmanMonteith equation for the days when satellite images were available. To estimate the pixel based ETa for the days without satellite images, linearly interpolated values of surface resistance values between successive days with satellite images together with meteorological data were used.

$2 b \quad$ Hydrological modeling and data.

To simulate the stream flow at the sub-basin outlets, semi-distributed version 
of the HBV conceptual model was used. Inputs for the HBV model are meteorological data such as precipitation, temperature and reference evapotranspiration. Stream flow data was also collected Daily time series of estimated actual evapotranspiration calculated based on SEBS at sub-basin level and observed stream flow were used for the multi-variable calibration of the hydrological model. The following data sets were used in this exercise:

\section{Meteorological data (measured point data)}

Data from 16 stations with longer time series of daily data were used for the hydrological modeling. The density of the meteorological stations which has daily data is about 1 station per $2500 \mathrm{~km} 2$. Reference evapotranspiration (ETO) was estimated using meteorological data with the Penman-Monteith equation. Fraction of forest, which is an input to the model, was estimated using the land use map derived from the satellite data.

\section{Measured Stream flow data (point data)}

Daily Stream flow data at 7 locations were used for calibration of the model.

\section{Digital Elevation Model (DEM)}

Shuttle Radar Topography Mission (SRTM) digital elevation model (DEM) (acquired from http://srtm.csi.cgiar.org/), was used to estimate the upstream contributing area for each river gauging station.

\section{Model calibration}

To calibrate the model, daily time series of stream flow and satellite-based ETa were used in a multi-variable calibration framework. Three calibration cases were used - in case one stream flow is used as the calibration target; in case two, satellite-based ETa is used as calibration target; and in case three, a preference-based multi-variable objective function is applied, which is weighted for stream flow and ETa. Monte Carlo Simulations were used to estimate parameter values.

The details of the model used, daily ETa estimation procedure and the model calibration procedure are described in: Rientjes, T.H.M., Muthuwatta, L.P., Bos, M.G., Booij, M.J., Bhatti, H.A., 2013. Multi-variable calibration of a semidistributed hydrological model using streamflow data and satellite-based evapotranspiration, Journal of Hydrology, doi: http://dx.doi.org/10.1016/j.jhydrol.2013.10.006 


\section{Strategies to Increase Wheat Production}

Two strategies are assessed to increase wheat production in the Karkheh River Basin in Iran to meet targets by the year 2025. Following steps were followed:

\section{3a Development of Crop production functions.}

A multiple regression analysis was carried out to estimate the crop production function that explains the effects of fertilizer, water availability and seed rate on wheat yields for both, rain-fed and irrigated wheat. For this, yield in rainfed and irrigated wheat farms, plot scale fertilizer application rates and seed rates were collected.

\section{Wheat yields}

Irrigated and rain-fed wheat yields $(\mathrm{kg} / \mathrm{ha})$ at 298 farms for at least two cropping years 2002 and 2003 were collected. These farms were selected from 110 villages to represent both rain-fed and irrigated wheat with the farm sizes ranging from 4 to 33 ha

\section{Fertilizer and seed rates}

The fertilizer application rates $(\mathrm{kg} / \mathrm{ha})$ and seed rates $(\mathrm{kg} / \mathrm{ha})$ were collected for the 298 farms selected through a field survey. Using production functions the change in wheat yield per unit change in one variable, while keeping the other variables constant, were estimated. This was used to estimate the possible increase of wheat production by non-water inputs (fertilizer and seeds) for both, rain-fed and irrigated wheat.

\section{3b Assessment of wheat production.}

Satellite-based ETa was used to estimate water consumption by wheat fields. The relationship between yield and crop water productivity (CWP), and yield and actual evapotranspiration/ potential evapotranspiration (ETa/ETp) were established for all sub-basins. Based on these relationships, the target value for the ETa/ETp for irrigated wheat was identified. The target value is defined as the value above which further increase of ETa/ETp has no substantial effect on the crop yield. Based on these information irrigated wheat areas with sufficient water availability were identified. For these areas, yield gap (which is the different between current yield and the maximum possible yield) was calculated. Different wheat production estimates were made for different percentage of yield gap closing, e.g. how much production can be increased by closing $25 \%$ of yield gap in existing irrigated wheat areas. Yield gaps were also estimated for the rain-fed wheat areas and the possible increase in production of wheat by closing the yield gap (by certain percentage) were estimated. 


\section{3c Land suitability analysis.}

Land slopes, current land use and water availability were used to conduct the land suitability analysis so as to expand the rain-fed wheat areas. Land slope was derived from DEM. Current range land areas (to be converted to rain-fed wheat) located in the suitable slope classes were identified. Pixel scale water availability for rain-fed wheat was assessed based on ETa/ETp (actual evapotranspiration/ potential evapotranspiration). Possible increase of production was estimated for the additional rain fed wheat areas.

3d Development of strategies to increase wheat production.

Two strategies are assessed to increase wheat production:

(a) to increase yields in the current irrigated and rain-fed wheat areas

(b) to increase the area under rain-fed wheat through land conversion.

This part of the study is described in: Muthuwatta, L.P., Rientjes, T.H.M. and Bos, M.G., 2013. Strategies to increase wheat production in the water scarce Karkheh River Basin, Iran. Agricultural water management, 124, 1-10. 


\section{Curriculum Vitae}

Lal Perakum Muthuwatta was born on March 18, 1965, in Kandy, Sri Lanka. After secondary school, he joined the University of Peradeniya, Sri Lanka, where he obtained a B.Sc. degree in mathematics and chemistry in December 1991. He completed the Master of Philosophy degree on mathematical modelling at the Open University of Sri Lanka in 1988. In 2004, he obtained the Master of Science degree on environmental systems analysis from the International Institute for Geo-Information Science and Earth Observation (ITC) in Enschede, the Netherlands. In April 1997, he joined the headquarters of the International Water Management Institute (IWMI) in Colombo, Sri Lanka. At IWMI, he joined a group of researchers working on remote sensing (RS) and geographic information system (GIS) applications for water resources management. His work at IWMI includes land use classifications, actual evapotranspiration estimations, spatial analysis and hydrological model applications. He has worked in international research teams and has extensive experience with the use of different GIS and image processing software, and modelling tools. In December 2005, he started his PhD studies at the University of Twente, Faculty of Geo-Information Science and Earth Observation (ITC), the Netherlands, as a sandwich program between ITC and IWMI. Presently, Lal is working as a hydrologist at IWMI.

\section{List of Publications}

Peer reviewed journal articles:

Muthuwatta, L.P., Rientjes, T.H.M. and Bos, M.G., 2013. Strategies to increase wheat production in the water scarce Karkheh River Basin, Iran. Agricultural water management, 124, 1-10.

Rientjes, T.H.M., Muthuwatta, L.P., Bos, M.G., Booij, M.J., Bhatti, H.A., 2013. Multi-variable calibration of a semi-distributed hydrological model using streamflow data and satellite-based evapotranspiration, Journal of Hydrology , doi: http://dx.doi.org/10.1016/j.jhydrol.2013.10.006

Muthuwatta, L.P., Ahmad, M.D., Bos, M.G., Rientjes, T.H.M., (2010). Assessment of water availability and consumption in the Karkheh River Basin (Iran) using remote sensing and geo-statistics. Water Resources Management. 24,459-484.

Muthuwatta, L.P., Ahmad, M.D., Rientjes, T.H.M., Bos, M.G. (2010). Estimating the spatial variability of water consumption in the Karkheh River Basin, Iran - using MODIS data. AQUA mundi, Am02015: 115 - 122, DOI 10.4409/Am-016-10-0015.

Ahmad, M.D., Islam, A., Mashi, I., Muthuwatta, L.P., Karimi P., Turral H.M., 2009. Mapping basin-level water productivity using remote sensing and secondary data in the Karkheh River Basin, Iran. Water International, $34: 1,119-133$. 


\section{Conference contributions:}

Muthuwatta L.P, Booij M.J., Rientjes T.H.M., Bos M.G., Gieske A.S.M., Ahmad M.D. (2009). Calibration of a semi-distributed hydrological model using discharge and remote sensing data. Symposium HS.2 at $8^{\text {th }}$ IAHS Scientific Assembly, 6-12 September 2009, Hyderabad, India.

Muthuwatta, L.P., Mobin-ud-Din Ahmad, Bos, M.G. and Rientjes, T.H.M. (2008) Surface energy balance modeling to track water consumption by heterogeneous land uses in Karkheh river. In: Proceedings of the 2nd International forum on water and food, 10-14 November, 2008, Addis Ababa. Colombo: CGIAR, 2008. ISBN 978-92-990053-0-9 Vol. I. pp. 101-104.

Muthuwatta, L.P., Ahmad, M.D., Bos, M.G. and Rientjes, T.H.M. (2008) Estimating the spatial variability of water consumption in the Karkheh River Basin, Iran using MODIS data. In: ACRS 2008 : proceedings of the 29th Asian Conference on Remote Sensing, 10-14 November 2008, Colombo, Sri Lanka. Colombo: Survey Department of Sri Lanka, Asian Association on Remote sensing, 2008. 6 p.

Ahmad, M.D., Islam, A., Mashi, I., Muthuwatta, L.P., Karimi P., Turral H.M., (2008). Water productivity mapping to identify opportunities to improve agricultural water management in the Karkheh River Basin, Iran. In: 2nd International Forum on Water and Food, 10-14 November, 2008, Addis Ababa. Colombo: CGIAR, 2008. ISBN 978-92-990053-0-9 Vol. I. pp. pp.119122. 


\section{ITC Dissertation List}

http://www.itc.nl/research/phd/phd_graduates.aspx 